A DIGIThL WIRE

FOR FOSTERING

MATHEMATICAL MEDICATION LEARNING

IN UOCATIONAL EDUCATION 

A Digital Wire for Fostering Mathematical Medication Learning in Vocational Education

\section{Diana Petra Zwart}


(C) 2021 Diana P. Zwart

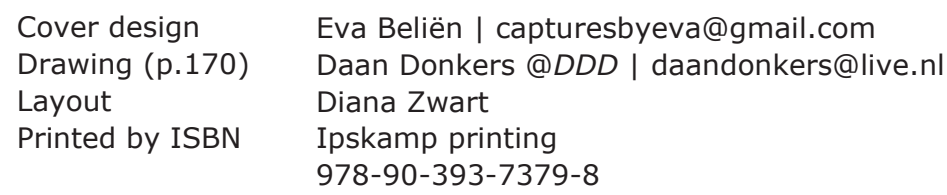

This research was supported by the Netherlands Organization for Scientific Research (NWO) under grant number: 023.006.049.

All rights reserved. No part of this publication may be reproduced or transmitted in any form or by any means, electronic or mechanical, including photocopy, recording, or any information storage or retrieval system, without permission in writing form the author. The copyright of the articles that have been accepted for publication or that have already been published, has been transferred to the respective journals. 


\title{
A Digital Wire for Fostering Mathematical Medication Learning in Vocational Education
}

\author{
Effecten van digitaal leermateriaal op het verpleegkundig rekenen \\ van studenten in het beroepsonderwijs \\ (met een samenvatting in het Nederlands)
}

\section{Proefschrift}

\author{
ter verkrijging van de graad van doctor aan de \\ Universiteit Utrecht \\ op gezag van de \\ rector magnificus, prof.dr. H.R.B.M. Kummeling, \\ ingevolge het besluit van het college voor promoties \\ in het openbaar te verdedigen op \\ vrijdag 18 juni 2021 des middags te 2.15 uur
}

door

\section{Diana Petra Zwart}

geboren op 15 april 1970

te Harderwijk 
Promotor:

Prof. dr. J.E.H. van Luit

Copromotoren: Dr. S.L. Goei

Dr. O. Noroozi 


\section{CONTENTS}

Chapter 1 General introduction

Chapter 2 The effects of Digital Learning Materials on students'

mathematics learning in vocational education

Chapter 3 Effects of Digital Learning Materials on nursing students mathematics learning, self-efficacy and task value in vocational education

Chapter 4 The effects of Computer-Based Virtual Learning Environments on nursing students' mathematical learning in medication processes

Chapter 5 The effects of a Computer-Based Virtual Learning Environment on students' mathematical learning, self-efficacy, and intrinsic motivation

Chapter 6 Nursing students' satisfaction with the instructional design of a 115 Computer-Based Virtual Learning Environment for mathematical medication learning 

Chapter 1

GENERAL INTRODUCTION

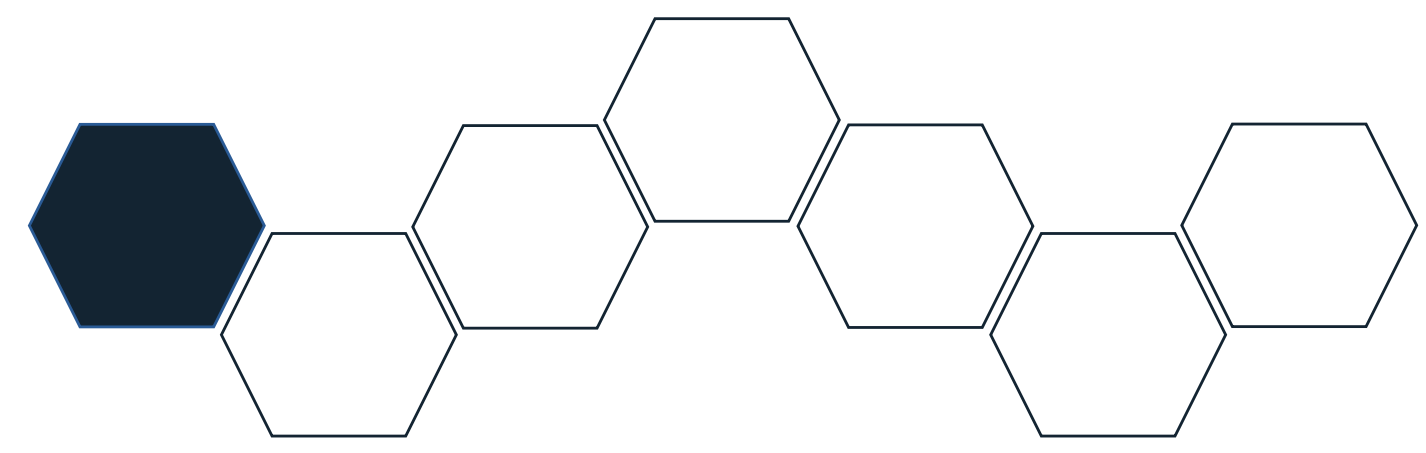




\section{Scope of the thesis}

When I started this dissertation, mathematics in vocational education was government policy: there was a great deal of money spent on implementing policies, but little attention paid to the goal of mathematics in vocational education. Visions from mathematics in primary education were used vocational education, and teachers were given training to become mathematics teachers. They practised hard with their students, but it was hard to find motivation for mathematics among the students, and it was a tough job to lift students to a standard level. Many students needed more time to reach this standard. However, the school system does not give them that time. I therefore started to design digital environments with instructional clips, and collaborated with ICT professionals in vocational education to implement these clips in school learning platforms. To me, technology was the solution for those students who needed more time to reach the standard required to succeed in vocational education. Technology enabled the students to follow mathematics lessons independently of time and place, so that they could upgrade their mathematics knowledge and skills. This entailed a great deal of work, but it felt like a democratic protest against the system: all students should have the opportunity to succeed. That is where this dissertation begins: its start is the further development of mathematics in vocational education using digital learning material, and its destination is training in the concept of mathematics for students' tasks in the future. A digital wire of digital learning materials (DLMs) with structured content, goals, assignments, procedural knowledge clips, instructional knowledge clips, and a discussion board, moves on to a computer-based virtual learning environment (CBVLE) with learning tasks and instructional activities that support information for cognitive schemas, information for procedures, transfer tasks for automation, and cognitive feedback such as reflection on learning.

\section{Introduction}

Vocational education prepares students for an occupation and provides them with an education-based vocational qualification. Vocational qualifications are developed by education and industry and meet the job-entry requirements that pertain to each sector (Ministerie van Onderwijs, Cultuur en Wetenschap, 2015). For a long time, the cognitive developmental function has placed a great emphasis on education: education should contribute to the development of students' knowledge and skills at all levels (Van de Werfhorst, Elffers, \& Karsten, 2015). However, education is changing rapidly: it essentially used to be the transfer of knowledge but is now the active application of knowledge and the development of skills for the twenty-first century, enabling students to manage the world they encounter. Nevertheless, outputs of education differ from the expertise required in the real environments for which students are supposed to be prepared (Tynjälä, 1999). Although there is a renewed focus on whether the knowledge and skills of students are 
appropriate for the main characteristics of the current and future labour market (Van de Werfhorst et al., 2015), education that is theoretical gives students inert knowledge that can be used in instructional settings but cannot be transferred in practice into complex problems (Mandl, Gruber, \& Renkl, 1996). Using knowledge in practical contexts involves executing, applying, and prioritizing it, whereas using knowledge in educational settings still entails labelling, differentiating, elaborating, and justifying it (Tynjälä, 1999). Although workplace learning is a frequent theme in vocational and higher education programmes, its accidental appearance is the usual dilemma that is faced. Incidental workplace learning is not always enough, and more formal and intentional learning with guidance and evaluation is needed (Tynjälä, 2013). Technology can provide sustainable solutions for these complex issues.

Technology offers a wide range of educational opportunities that cannot be achieved in traditional face-to-face forms of learning and instruction (Kalyuga \& Liu, 2015). Moreover, with the arrival of Artificial Intelligence and data platforms, technology is controlling education and society more quickly than we thought. This reality has consequences for educational settings that affect not only the content but also the form of education (Fresco, 2019). Education will come increasingly close to the labour market. In addition, learning is increasingly enabling us to cope throughout our lives with new knowledge and technology. Well-designed digital educational settings have the potential to provide students with these skills and with the necessary professional knowledge base for their future professions. Students can therefore become professionals who can analyse, conceptualize, synthesize, and cope with complex and authentic problems (Noroozi, 2013). However, this assumption represents a challenge for everyone in education who is involved with technology-enhanced learning environments: the transfer of knowledge is still traditional and fragmented, with a focus on learning reproducible skills. An example is the transfer of mathematical knowledge and skills in secondary and higher vocational training programmes. Being numerate in the twenty-first century means coping with the techno-mathematical aspects of students' future workplaces and society (Tout, Coben, Geiger, Ginsburg, \& Hoogland, 2017).

\section{Mathematical knowledge and skills in vocational education}

Vocational education prepares students for professional practice or higher vocational education. Mathematics is a compulsory part of the programme. A national mathematics test is a standard procedure for assessment in Dutch secondary vocational education. This national mathematics test was meant to be a booster for mathematics in vocational education, so that students would learn mathematical activities in the context of their professions. The inclusion of mathematics as a vocational course presents challenges. The test results were disappointing, which is not surprising: after all, vocational education 
supports learning through work practice (Billett, 2013), and at the moment mathematics is taught following an objective-based approach and as a collection of separate elements. A focus on the national assessment does not promote the efficiency of the learning process. The approach is mainly a result of the way in which the mathematical content of vocational education is divided: different domain-specific mathematical knowledge is taught in each semester. This becomes problematical when students do not thoroughly understand the underlying (prior) mathematical knowledge and skills from one domain, but have to move to the new domain since a new school semester has started. As a consequence, students are unable to encode and retrieve the information they need to solve problems (Peng, Namkung, Barnes, \& Sun, 2016). They need more time and instruction to understand the concepts of each domain, so that they are able to make connections with the new domainspecific knowledge. Another point is that too little attention is paid to teaching students how to integrate, evaluate, and combine knowledge elements in order to apply their mathematics knowledge and skills in the professional context. As a result, students lose track of the interconnections between these elements (Van Merriënboer \& Kirschner, 2018). Further, their mathematical academic achievement deteriorates. Since academic achievement affects a student's level of self-efficacy, students lose confidence in completing a task successfully (Bandura, 1986). Students feel less competent, and they undervalue mathematical tasks (Denissen, Zarrett, \& Eccles, 2007; Reichwein Zientek, Fong, \& Phelps, 2019). Therefore, it will be no surprise that students in vocational education are not very motivated towards mathematics (Dalby \& Noyes, 2015), even when it comes to important skills for their future professional tasks, such as health professionals' skills in administering medication.

\section{Mathematical knowledge and skills in vocational education for health professionals}

To facilitate optimal medication safety, it is necessary for health professionals to be equipped with sufficient knowledge and skills. Mathematical knowledge and medication knowledge are necessary for this, but there also needs to be increased awareness of how to act in providing medication. Although much attention has been paid to measures and training for medication safety, mistakes regularly occur in that regard (Erasmus MC, 2017). Research by the Dutch Inspectorate of Healthcare (IGZ, 2017) showed that 1,060 emergency notifications about medication in the Netherlands came from care homes and home care organizations. These emergency events were mostly caused by human error: health professionals did not read the medicine label, there was a misunderstanding with a colleague, or they made mistakes in the quantities. This points to the importance of teaching mathematical knowledge for medication. Additionally, the importance of the underlying (prior) domain-specific mathematical knowledge and skills should not be underestimated. For example, a study by the Dutch Board of Exams (CVE, 2015) showed 
that most students in vocational education encountered problems with fractions and calculating percentage amounts. When students do not thoroughly understand the underlying (prior) knowledge and skills, it is difficult for them to make connections with new domain-specific knowledge. This applies to nursing students, who need to understand the clinical sources of, and the relationship between, the elements of dosage and rate formulae and equations when solving calculation problems (Weeks et al., 2013). For this reason, the mathematical procedures must be identifiable: nursing students should learn cognitive and appropriate rules for developing the competences necessary for complex care situations in their future jobs. Therefore, teaching the concepts of mathematics required for medication processes is of great importance. Students have to be actively trained in the language and symbols of the mathematics for the medication tasks they will carry out in the future, so that they are able to see the meaning of the medication dosage calculations.

The instructional design of DLMs can assist with the concept of mathematical medication tasks for the future. DLMs can increase the effectiveness of instruction, specifically for learning mathematics for medication in vocational education (e.g., Xinhao \& Fengfeng, 2016).

\section{DLMs for learning mathematics for medication in vocational education}

DLMs consist of technology-enhanced learning environments that support students with information through learning material, such as instructional clips, online guidance, and collaboration tools. The instruction in a DLM technology-enhanced learning environment can support students with identifying useful information, understanding how materials fit together and seeing how the materials relate to their prior knowledge (Mayer, 2001). DLMs have no constraints of time and space (Chen, 2011; Lee \& Hung, 2015; Noroozi, Biemans, Weinberger, Mulder, \& Chizari, 2013). In DLM environments, instruction shifts from a traditional teacher- or system-controlled environment to on-demand education (Van Merriënboer \& Kirschner, 2018). DLMs offer educational opportunities that cannot be obtained through traditional face-to-face forms of learning and instruction (Kalyuga \& Liu, 2015).

\section{Instructional design of DLMs}

Instruction with DLMs can be delivered by an online teacher and the use of instructional clips. Instructional clips are clips that present the instructional message to the learner using audio and visual elements. They can take the form of instructional knowledge clips or procedural knowledge clips. Each clip involves a concise statement of a crucial step in the mathematical process. The sound of the clips verbalizes and gives reasons for the connections between the different elements of the domain-specific knowledge. By clearly 
arranging the steps and verbalizing and giving reasons for the thought models, using standardized information, the instructional messages can prime appropriate organizational processing by the viewer. Using this process of verbalizing and mathematical reasoning, the modelling examples do not explicitly provide the schemata for solving a particular problem, but they model the actions and strategies used to find a solution (Kollar et al., 2014). The modelling examples consist of sequences of steps that need to be followed by learners as key decision steps. These steps are: (1) provide a rational structure, (2) reduce complexity, (3) give verbal help and (4) provide modelling. The modelling examples may revolve around students' future professional tasks that involve mathematical knowledge and skills. When students have the opportunity to learn tasks based on their interests, it positively emphasises their perception of their capabilities (Lent, Brown, \& Hackett, 2002). However, modelling examples in clips do not result in a high degree of realism (Lee, Wong, \& Fung, 2010). By contrast, in a virtual learning environment, students are provided with opportunities to be trained for future professional learning tasks in realistic scenarios by making the right decisions, in ways that are not possible in real-life situations (Makransky, Borre-Gude, \& Mayer, 2019). A computer-based virtual learning environment (CBVLE) can illuminate learning experiences and make situations more authentic by including learning tasks that students need to master for their future professions. A CBVLE offers unique possibilities of building 3-D objects to teach abstract concepts (Merchant, Goetz, Cifuentes, Keeney-Kennicutt, \& Davis, 2014).

\section{CBVLEs for learning mathematics for medication in vocational education}

CBVLEs are simulated environments that can be programmed with scenarios involving professional learning tasks; their focus is on making the tacit aspects of learning tasks and related knowledge visible and accessible to students (Wang, Kirschner, Spector, \& Ge, 2018). CBVLEs enable students to work on their future professional tasks, such as everyday mathematical medication-related tasks for nursing students, which include mathematical medication problems, procedural skills, and the development of basic computational skills. When various scenarios involving students' professional learning tasks are embedded, CBVLEs have the potential to offer situated learning possibilities, allowing students to obtain the professional knowledge and skills they will need in the future. Using CBVLEs, students can interact with their peers via a keyboard, a mouse, a joystick, or a touch screen (Lee \& Wong, 2014; Lee et al., 2010; Noroozi et al., 2013).

The design of a CBVLE includes features such as interactive stories, and requires practical and clear objectives, to ensure that students have immersive experiences in a virtual world and to create a 'state of flow' in which students can succeed only through effort (Csikszentmihalyi, 1990; Shute, Ventura, Bauer, \& Zapata-Rivera, 2009). A CBVLE makes it possible to concretize abstract ideas and concepts by reorganising integrated facts, 
procedures, and ideas so that they are retrievable and easy to practise (Pollock, Chandler, \& Sweller, 2002; Xinhao \& Fengfeng, 2016). As in traditional classroom settings, the instructional activities within CBVLEs need to be effective. Virtual reality design features affect the quality of the virtual reality technology for learning and are essential in engaging students and facilitating learning (Makransky \& Petersen, 2019; Merchant et al., 2014). The graphical design of a CBVLE allows for realistic representations. This high degree of realism enables students to be cognitively engaged and motivated to learn (Csikszentmihalyi, 1990; Lee et al., 2010; Shute et al., 2009). However, encouragement for learning in a CBVLE is not just about the virtual reality features, but also about the instructional design for learning in the CBVLE.

\section{Instructional design principles of a CBVLE}

Designing teaching in virtual reality technology means amending instructional strategies and adapting them to the new technology. Many approaches are appropriate for training in tasks where there is little relationship between the objectives, but are not appropriate for complex learning that requires the integration of knowledge, skills, and attitudes (Frerejean et al., 2019). For that, Van Merriënboer and Kirschner (2018) developed a taskcentred design approach that starts the design of instruction from whole real-life tasks. The Four Components Instructional Design for complex learning (4C/ID, 2018) shows the advantage of using a holistic approach to design a learning environment. It consists of four basic components, namely (i) learning tasks, (ii) supportive information to help students to build cognitive schemas and construct schema, (iii) procedural information, and (iv) part-task practice to stimulate the automation of schemas and the development of automatic, task-specific procedures that can be applied without much demand on cognitive processing resources (Frerejean et al., 2019). It overcomes the compartmentalization and fragmentation of traditional design approaches, and for this reason is a particularly interesting design model for teaching academic concepts such as mathematics for medication for nursing students via CBVLE.

The learning tasks component (i) should offer whole-task practice as the backbone of the learning programme (Van Merriënboer \& Kirschner, 2007, p. 7): 'The learning task confronts the learner with all or almost all of the constituent skills important for real-life task performance, together with their associated knowledge and attitudes. The learning tasks are meaningful, authentic, and representative for the tasks that a professional might encounter in the real world.' A CBVLE with relevant learning tasks such as students' future professional tasks could serve to encourage learning (Merchant et al., 2014). Practising many different learning task activities, such as domain-specific types of problem, permits students to grasp the procedures and to make connections between the various subjects (Dunlosky, Rawson, Marsh, Nathan, \& Willingham, 2013; Rohrer, Dedrick, \& Stershic, 
2015). This learning technique allows students to study the concepts and mathematical content of medication, and has a positive effect on future retention (Roediger \& Karpicke, 2006).

The supportive information component (ii) explains to students how the learning domain is organized, and how to approach problems in that domain. It is the information needed to develop students' cognitive models and strategies to complete learning tasks (Frerejean et al., 2019). A CBVLE enables the relevant elements in a domain, as well as the relationships between those elements, to be specified. Setting clear goals enhances performance and addresses students' attention towards the activity of learning more than towards outcomes (Anderson \& Krathwohl, 2001; Csikszentmihalyi, 1990).

The procedural information component (iii) specifies how the recurrent aspects of the learning tasks should be performed (Van Merriënboer \& Kirschner, 2018). Procedural information involves corrective feedback, demonstrations of rules, procedures, and prerequisite knowledge. Moreover, it should be displayed 'just in time'. Instructional activities that can show students how to apply procedures to specific problems are worked examples (Chen, Kalyuga, \& Sweller, 2016; Kirschner, Sweller, Kirschner, \& Zambrano, 2018; Van Gog, Kester, \& Paas, 2011). They may take the form of domain-specific scaffolds for solving problems (Sweller, 2010). Whereas an unguided problem does not indicate which elements should be addressed, a worked example does; this reduces the number of elements that must be processed in working memory (Chen et al., 2016; Eiriksdottir \& Catrambone, 2011; Margulieux \& Catrambone, 2016). Worked examples can help lowachieving students to acquire domain-specific knowledge (Kalyuga, Chandler, \& Sweller, 2001; Kalyuga, Chandler, Tuovinen, \& Sweller, 2001; Tricot \& Sweller, 2014; Van Gog et al., 2011). However, they can also have adverse effects: once levels of expertise have increased, they become redundant, particularly for high-achieving students. Students can activate the worked examples and are then provided with step-to-step instruction in the CBVLE while they are solving problems. When their answers are not correct, students gain standardized, corrective, verification feedback (Maier, Wolf, \& Randler, 2016). Feedback can support reflection and improvement and is crucial for learning and achievement (Yuang et al., 2020).

For students who cannot master certain aspects of a learning task, the fourth component, part-task practice (iv), should be embedded to give training in one or more selected recurrent aspects. The design component of reflection on learning does not just include feedback on the quality of students' learning. In the CBVLE, reflection on learning is a tool for students' self-assessment regarding their learning, as an experience of the whole learning task. Therefore, we choose to describe this step separately as the reflection on learning component in the CBVLE. Ideally, feedback contains cognitive features and 
affective features (Nelson \& Schunn, 2009). Cognitive features influence students' performance and understanding, since the students know what to improve, and affective features affect whether students agree with the feedback. The CBVLE should strive to move students from an initial state of mind to a desired state of mind (Mor, Ferguson, \& Wasson, 2015). Since a CBVLE is a structured environment in which support and reward systems are an integral part, it should boost nursing students' intrinsic motivation for learning, and enhance their self-efficacy (Merchant et al., 2014; Pekrun, 2006).

\section{Motivational aspects}

The literature on motivation covers many constructs (e.g., perceived competence, selfefficacy, and control beliefs) (Pintrich \& De Groot, 1990). Generally, motivation involves students answering the following questions: 1) Can I do this task, 2) Why am I doing this task, and 3) How do I feel about this task? The basic construct involves a student's beliefs about performing a task and their responsibility for their performance.

\section{Self-efficacy}

Self-efficacy refers to a student's belief or expectation that they can successfully complete learning tasks (Bandura, 1988; Pajares \& Schunk, 2001). Self-efficacy influences the choices that students make. Pintrich (1988) states that students with high levels of selfefficacy will set their sights higher than those who do not believe that they can be successful. In addition, Pintrich mentions that students' efforts to learn can be driven by the relevance of the learning tasks. Wu, Tennyson, and Hsia (2010, p. 157) designate selfefficacy in e-learning environments as 'computer self-efficacy'. They state that computer self-efficacy influences performance expectations, which may, in turn, influence behaviour. This implies that students will be more motivated to learn, and will benefit and learn more, with DLMs when they become more confident and capable of learning with DLMs and more accustomed to doing so. These beliefs boost students' intrinsic motivation (Liu, Hau, \& Zheng, 2019). In addition, Passey, Goodison, Machell, and McHugh (2004) also found that DLMs had a motivational impact on engagement.

\section{Intrinsic motivation}

Intrinsic motivation is the satisfaction that is consequent on the performance of a learning task (Ryan \& Deci, 2000). It is students' urge constantly to respond to challenges, to extend their capacities, to examine and study, and to learn. If activities have intrinsic value, this means that no matter what the relevant outcomes are, students still appreciate the activity. This is in contrast to extrinsic value, where the outcomes produced are a jumping-off point (Pekrun \& Stephens, 2010). Intrinsic value and enjoyment are important affective factors for the process of learning and for students' expectation of success in classroom instruction (Lee \& Seo, 2021; Pekrun, 2006), and the same applies for computer-based instruction. Whereas high-achieving students show goal-directed 
behaviour and engage in an activity for its own sake (Liu et al., 2019), struggling students might be motivated by being presented with a learning task that they identify with the process or product (Csikszentmihalyi, 1990). The appreciation of a task, or task value, also influences learning behaviour and academic results (Joo, Lim, \& Kim, 2013; Wigfield \& Eccles, 2000).

\section{Task value}

Task value is a concept that indicates the importance, usefulness, or interest that a student ascribes to a certain task (Wigfield \& Eccles, 2000). Andrews and Aikens (2019) reported that students who gave a high utility task value to mathematics in a particular context were more interested in using mathematics to understand the content. Van der Veen and Peetsma (2009) showed that students who ascribed a high task value to a task were more motivated than students who gave the task a low task value. Joo et al. (2013) stated that task value is a predictor of student satisfaction with the task. Denissen et al. (2007) found that task value is positively related to perceived competence.

Affective aspects, such as motivation and emotion, have largely been neglected in research on online environments such as DLMs (Leutner, 2014; Mayer, 2014). In the studies described in this dissertation, a digital wire for the maintenance of mathematical knowledge and skills in vocational education and two learning environments, with digital and virtual learning material, have been developed. The aim of these environments is to use DLMs to align the teaching of the concepts of mathematical medication for all nursing students in vocational education, both high- and low-performing students, and to provide these students with the information they need to solve mathematical medication problems.

\section{Aims and outline of this dissertation}

The studies in this dissertation contribute to an instructional design for teaching mathematics for medication with DLMs in vocational education. Since the educational mathematical medication programmes in secondary and higher vocational nursing education are the same, the general term 'vocational education' is used. The aim of the study is twofold. The first aim is to use DLMs to teach mathematical concepts in the context of students' future professions, and the second is to teach students mathematics in a selfsupported and motivated DLM learning environment, using exercises for maintaining their mathematical knowledge and skills during their vocational education programme. These two aims are addressed in five research articles. Figure 1 displays an overview of the outline of this dissertation. The dark hexagons demonstrate the studies described in the chapters. The white hexagons show the most important aims of these studies. The two empty hexagons refer to the research into the subsequent prototyping and testing phases of the DLM learning environment in a technology-enhanced educational assessment system 
for mathematics in vocational nursing education, which will be carried out after the dissertation.

Chapter 2 reports on the first study of the thesis, which set out to obtain a deeper understanding of mathematical learning with DLMs in vocational education. The study examined the impact of an instructional design approach with DLMs including instructional clips, online guidance, content structuring and collaboration tools to facilitate the learning of mathematics by students in vocational education. In this chapter, the results of two pretest post-test design studies are reported. In these studies, students from the technology, economics and nursing departments were enrolled in an 8-week course that addressed domain-specific mathematical knowledge. The analysis showed that nursing students achieved the best learning outcomes, since they were involved in the assignments and collaborated as group. Their teacher was notified when they encountered technical or organizational problems. These results set the stage for a more specific articulation of the problem of mathematical learning in vocational education, and for the redesign of a prototype environment with DLMs that is related to the two aims of this dissertation: teaching concepts of mathematics in a self-supported and motivated DLMs environment and relating this to students' future professions. Therefore, for the following studies we chose nursing students' learning of mathematics for medication as the scope for the mathematical learning content in vocational education.

Chapter 3 reports on the second study. This examined the effectiveness of mathematics training with DLMs for nursing students' mathematics learning, task value and self-efficacy, comparing DLM training with a traditional face-to-face method. Furthermore, students' appreciation of the various features of DLMs was investigated. The design of instructional clips using problems from the students' future professional tasks, to show the domainspecific and procedural knowledge and to focus on the relationships that concretize the concept of mathematical medication, was part of the structure of the DLM design. A pretest post-test control group design study showed that nursing students' self-efficacy for learning mathematics for medication decreased with DLMs. Students with low learning abilities found it more difficult to engage when they were interacting with the learning materials. It was found that the online competence of the teacher, and students' dependence on this competence, formed a great barrier. Students find it difficult to break through their own learning and studying patterns. The teacher's online role should not only cover giving encouragement and feedback for finishing assignments; the teacher should also support students socially for their sense of efficacy.

The DLMs were therefore moved forward to a new digital tool consisting of a CBVLE that supports nursing students' self-directed learning towards assignments. The CBVLE enabled nursing students' tasks for learning mathematics for medication to be structured, and 
navigated the students in the digital environment around the different phases of the concept of learning mathematics for medication. Additionally, the design of the virtual learning tool gave the students the opportunity to learn mathematics in a self-directed way within the context of their future professional tasks.

Chapter 4 reports on the third study, which compared the effect of four different training conditions in a CBVLE on nursing students' learning of mathematics for medication. The students were randomly assigned to one of four conditions in the CBVLE: learning mathematics for medication without worked examples (condition 1), learning mathematics for medication with worked examples involving domain-specific knowledge (condition 2), learning mathematics for medication with worked examples involving regular thinking strategies (condition 3), and learning mathematics for medication with a combination of the two types of worked example (condition 4). Since struggling students might have lower general learning capacities, differences in nursing students' general learning capacities were investigated, as demonstrated in their non-verbal intelligence outcomes. The outcomes confirmed the expectations that learning via a CBVLE fosters nursing students' learning of mathematics for medication, but no differences were found between the four conditions (i.e., with or without worked examples). When controlling for nursing students' non-verbal intelligence, significant differences were found between the four conditions related to the outcomes of learning mathematics for medication. More specifically, no support from worked examples (condition 1) showed significantly higher learning outcomes than support from regular thinking strategies (condition 3) when non-verbal intelligence scores were considered. Moreover, the structure of the learning environment in the CBVLE outlined the nursing students' learning tasks in mathematics for medication and controlled many of the information elements and their interactions, which were pre-programmed for the learners. Worked examples may therefore have been redundant. This applied not only to high-achieving students (see Kalyuga, Chandler, \& Sweller, 2001; Kalyuga, Chandler, Tuovinen, \& Sweller, 2001; Kirschner et al., 2018; Van Merriënboer \& Sweller, 2010), but also to the low-achieving nursing students. From a cognitive load theory (CLT) perspective, this means that technology took over some of the working memory capacity, which accounts for the benefits to the low-achieving learners.

Chapter 5 refers to the fourth study, in which the effect of the four different training conditions in a CBVLE on nursing students' self-efficacy and intrinsic motivation in learning mathematics for medication via the CBVLE was compared. The study showed that the CBVLE facilitated the nursing students' learning of mathematics for medication and their self-efficacy outcomes for learning mathematics for medication, and also encouraged their intrinsic motivation for learning mathematics for medication. This study also found that the four training conditions in the CBVLE did not discriminate between nursing students' mathematical medication outcomes and their intrinsic motivation for learning mathematics 
for medication using the CBVLE. However, their self-efficacy in successfully completing mathematical learning tasks for medication via the CBVLE was positively influenced by the extra support of worked examples involving domain-specific knowledge and regular thinking strategies.

Chapter 6 reports on the fifth study, in which nursing students' satisfaction with the instructional design components of the CBVLE was investigated, together with the extent to which nursing students' satisfaction outcomes accounted for their learning of mathematics for medication, self-efficacy, and intrinsic motivation. Nursing students' satisfaction was above average in regard to the design components of the learning tasks, supportive information, part-task practice, and procedural information, although the cognitive feedback needed to be more closely customized to the nursing students' own efforts in the CBVLE. In combination, nursing students' satisfaction with the design components accounted for a medium effect on their learning of mathematics for medication, and for a large effect on their self-efficacy and intrinsic motivation. The design component of cognitive feedback for reflection on learning had to be more specifically customized to their personal performances in learning mathematics for medication via the CBVLE.

In chapter 7, which consists of a general discussion, the results of the five studies are summarized and discussed, and conclusions regarding mathematical learning with digital learning material in vocational education are drawn. Implications for educational practice are embedded, including an ethical reflection on learning with digital material in education. 


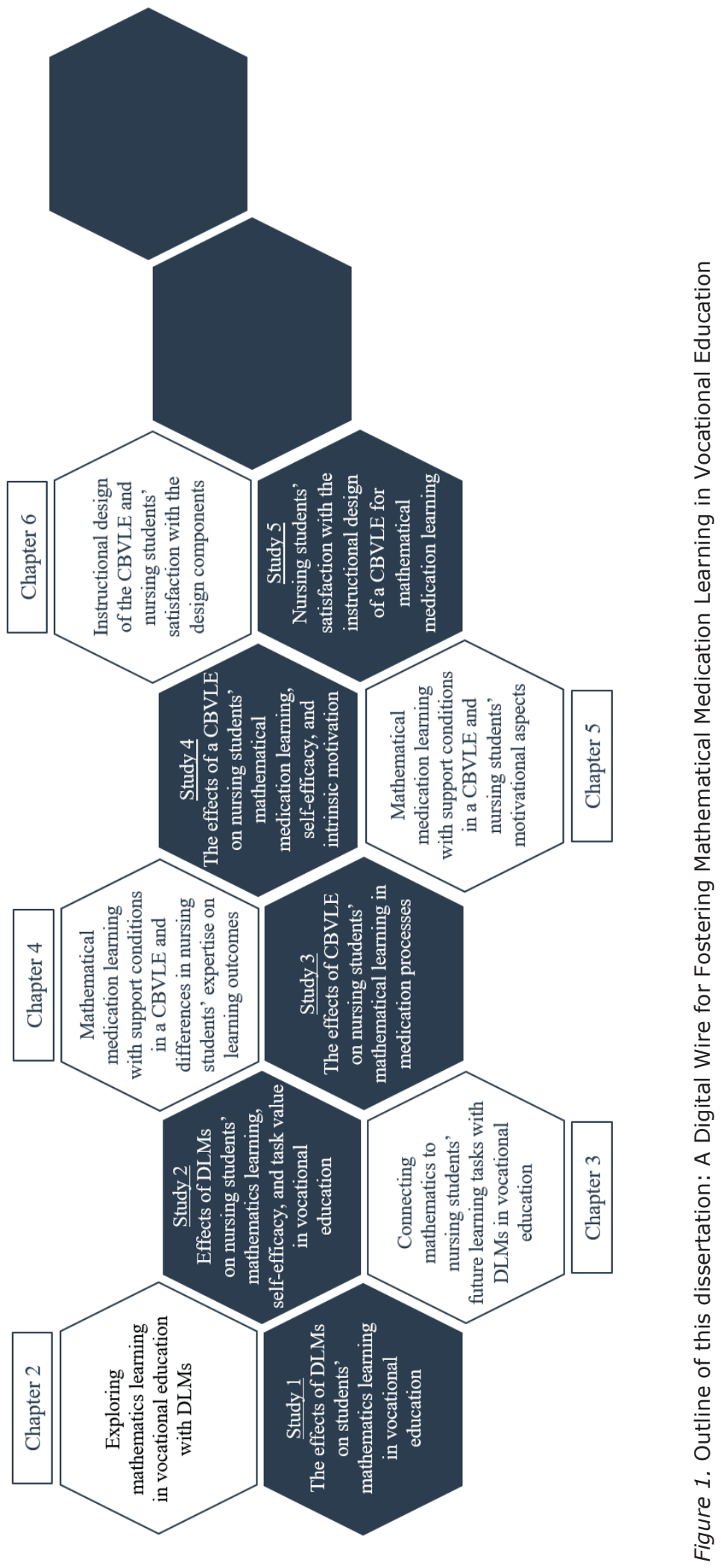




\section{References}

Anderson, L. W., \& Krathwohl, D. R. (2001). A taxonomy for learning, teaching, and assessing: A revision of Bloom's taxonomy of educational objectives. New York, NY: Longman.

Andrews, S. E., \& Aikens, M. L. (2019). Life science majors' math-biology task values relate to student characteristics and predict the likelihood of taking quantitative biology courses. Journal Microbiology and Biology Education, 19(2), 1-10. doi:10.1128/jmbe.v19i2.1589

Bandura, A. (1986). Social foundations of thought and action: A social cognitive theory. Prentice-Hall, NJ: Englewood Cliffs.

Bandura, A. (1988). Self-efficacy conception of anxiety, Anxiety Research, 1, 77-98. doi: $10.1080 / 10615808808248222$

Billett, S. (2013). Learning through practice: Beyond informal and towards a framework for learning through practice. Queensland, Australia: Griffith University. Retrieved from

http://www.unevoc.unesco.org/fileadmin/up/2013_epub_revisiting_global_trends _in_tvet_chapter4.pdf

Chen, J.-L. (2011). The effects of education compatibility and technological expectancy on e-learning acceptance. Computers \& Education, 57, 1501-1511. doi: $10.1016 /$ j.compedu.2011.02.009

Chen, O., Kalyuga, S., \& Sweller, J. (2016). Relations between the worked example and generation effects on immediate and delayed tests. Learning and Instruction, 45, 20-30. doi:10.1016/j.learninstruc.2016.06.007

Csikszentmihalyi, M. (1990). Flow: The psychology of optimal experience. New York, NY: Harper-Collins. Retrieved from https://mktgsensei.com/AMAE/Consumer\%20Behavior/flow_the_psychology_of_o ptimal_experience.pdf

CVE. (2015). College voor Examens. Handreiking rekenen $3 F$ mbo [Board of Exams. Guideline mathematics level 3F vocational education]. Utrecht, The Netherlands: Author.

Dalby, D., \& Noyes, A. (2015). Connecting mathematics teaching with vocational learning. Adults Learning Mathematics: An International Journal, 10(1), 40-49. Retrieved from https://files.eric.ed.gov/fulltext/EJ1077715.pdf

Denissen, J. J. A., Zarrett, N. R., \& Eccles, J. S. (2007). I like to do it, I'm able, and I know I am: Longitudinal couplings between domain-specific achievement, self- 
concept, and interest. Child Development, 78, 430-437. doi:10.1111/j.14678624.2007.01007.x

Dunlosky, J., Rawson, K. A., Marsh, E. J., Nathan, M. J., \& Willingham, D. T. (2013). Improving students' learning with effective learning techniques: Promising directions from cognitive and educational psychology. Psychological Science in the Public Interest, 14, 4-58. doi:10.1177/1529100612453266

Eiriksdottir, E., \& Catrambone, R. (2011). Procedural instructions, principles, and examples: How to structure instructions for procedural tasks to enhance performance, learning, and transfer. Human Factors, 53, 749-770. doi: $10.1177 / 0018720811419154$

Erasmus MC. (2017). Vervolgonderzoek medicatieveiligheid [Follow-up research medication safety]. Retrieved from https://www.nivel.nl/nl/publicatie/vervolgonderzoek-medicatieveiligheideindrapport

Frerejean, J., Van Merriënboer, J. J. G., Kirschner, P. A., Roex, A., Aertgeerts, B., \& Marcellis, M. (2019). Designing instruction for complex learning: 4C/ID in higher education. European Journal of Education, 54, 1-12. doi:10.1111/ejed.12363

Fresco, L. O. (2019). Maar welk onderwijs willen we? [But what education do we want?]. Nieuw Rotterdamse Courant, 18 November 2019. Retrieved from https:// www.nrc.nl/nieuws/2019/11/18/maar-welk-onderwijs-willen-we-a3980648

IGZ. (2017). In openheid leren van meldingen [In openness learn from notifications]. Den Haag, The Netherlands: Inspectie Gezondheidszorg en Jeugd. Retrieved from https://www.igj.nl/documenten/rapporten/2018/01/25/in-openheid-lerenvan-meldingen-2016-2017.

Joo, Y. J., Lim, K. Y., \& Kim, J. (2013). Locus of control, self-efficacy, and task value as predictors of learning outcome in an online university context. Computers \& Education, 62, 149-158. doi:10.1016/j.compedu.2012.10.027

Kalyuga, S., Chandler, P., \& Sweller, J. (2001). Learner experience and efficiency of instructional guidance. Educational Psychology, 21, 5-23. doi: $10.1080 / 01443410124681$

Kalyuga, S., Chandler, P., Tuovinen, J., \& Sweller, J. (2001). When problem solving is superior to studying worked examples. Journal of Educational Psychology, 93, 579588. doi: 10.1037/0022-0663.93.3.579

Kalyuga, S., \& Liu, T. C. (2015). Guest editorial: Managing cognitive load in technologybased learning environments. Educational Technology \& Society, 18(4), 1-8. 
Retrieved from

https://www.epc.ntnu.edu.tw/uploads/asset/data/5cc904741d41c8362f00001c/15 50_a76a3058.pdf

Kirschner, P. A., Sweller, J., Kirschner, F., \& Zambrano, R. J. (2018). From cognitive load theory to collaborative load theory. International Journal of Computer-Supported Collaborative Learning, 13, 213-233. doi:10.1007/s11412-018-9277-y

Kollar, I., Ufer, S., Reichersdorfer, E., Vogel, F., Fischer, F., \& Reiss, K. (2014). Effects of collaboration scripts and heuristic worked examples on the acquisition of mathematical argumentation skills of teacher students with different levels of prior achievement. Learning and Instruction, 32, 22-36. doi: 10.1016/j.learninstruc.2014.01.003

Lee E. A.-L., \& Wong, K. W. (2014). Learning with desktop virtual reality: Low spatial ability learners are more positively affected. Computers and Education, 79, 49-58. doi: $10.1016 /$ j.compedu.2014.07.010

Lee, E. A.-L., Wong, K. W., \& Fung, C. C. (2010). How does desktop virtual reality enhance learning outcomes? A structural equation modeling approach. Computers \& Education, 55, 1424-1442. doi:10.1016/j.compedu.2010.06.006

Lee, L.-T., \& Hung, J. C. (2015). Effects of blended e-learning: A case-study in higher education tax learning setting. Humancentric Computing and Information Sciences, 5, 1-15. doi:10.1186/s13673-015-0024-3

Lee, Y., \& Seo, E. (2021). Longitudinal relations between South Korean adolescents' academic self-efficacy and values in mathematics and English. British Journal of Educational Psychology, 91, 217-236. doi:10.1111/bjep.12357

Lent, R. W., Brown, S. D., \& Hackett, G. (2002). Social cognitive career theory. In J. Greenhaus \& G. Callanan (Eds.), Encyclopedia of career development (pp. 750754). Thousand Oaks, CA: Sage. Retrieved from https://researchgate.net/publication/303257953_/Social_cognitive_career_theor

Leutner, D. (2014). Motivation and emotion as mediators in multimedia learning. Learning and Instruction, 29, 174-175. doi:10.1016/j.learninstruc.2013.05.004

Liu, Y., Hau, K-T., \& Zheng, X. (2019). Do both intrinsic and identified motivations have long-term effects? The Journal of Psychology, 153, 288-306. doi: 10.1080/00223980.2018.1516611

Maier, U., Wolf, N., \& Randler, C. (2016). Effects of a computer-assisted formative assessment intervention based on multiple-tier diagnostic items and different 
feedback types. Computers \& Education, 95, 85-98. doi: $10.1016 /$ j.compedu.2015.12.002

Makransky, G., Borre-Gude, S., \& Mayer, R. E. (2019). Motivational and cognitive benefits of training in immersive virtual reality based on multiple assessments. Journal of Computers Assisted Learning, 35, 691-707. doi:10.1111/jcal.12375

Makransky, G., \& Petersen, G. B. (2019). Investigating the process of learning with desktop virtual reality: A structural equation modeling approach. Computers \& Education, 134, 15-30. doi:10.1016/j.compedu.2019.02.002

Mandl, H., Gruber, H., \& Renkl, A. (1996). Learning to apply: From "school garden function" to technology-based learning environments. In S. Vosniadou, E. De Corte, R. Glaser, \& H. Mandl (Eds.), International perspectives on the design of technologySupported learning environments (pp. 307-321). Mahwah, NJ: Lawrence Erlbaum Associates. Retrieved from

https://www.researchgate.net/publication/303824070_Learning_to_Apply_From_ School_Garden_Instruction_to_Technology-Based_Learning_Environments

Margulieux, L., \& Catrambone, R. (2016). Improving problem solving with subgoal labels in expository text and worked examples. Learning and Instruction, 42, 58-71. doi:10.1016/j.learninstruc.2015.12.002

Mayer, R. E. (2001). Multimedia learning. New York, NY: Cambridge University Press. doi: $10.1017 /$ CBO9781139164603

Mayer, R. E. (2014). Incorporating motivational learning into multimedia learning. Learning and Instruction, 29, 171-173. doi:10.1016/j.learninstruc.2013.04.003

Merchant, Z., Goetz, E. T., Cifuentes, L., Keeney-Kennicutt, W., \& Davis, T. J. (2014). Effectiveness of virtual reality-based instruction on students' learning outcomes in K-12 and higher education: A meta-analysis. Computers \& Education, 70, 29-40. doi:10.1016/j. compedu.2013.07.033

Ministerie van Onderwijs, Cultuur en Wetenschap (2015). Invoering referentieniveaus taal en rekenen [Implementation framework language and mathematics]. Den Haag, The Netherlands: Ministerie van Onderwijs, Cultuur en Wetenschap. Retrieved from http://mboinbedrijf.nl/images/Stand_van_zaken_invoering_referentieniveaus_taal _en_rekenen_2016.pdf

Mor, Y., Ferguson, R., \& Wasson, B. (2015). Learning design, teacher inquiry into student learning, and learning analytics: A call for action. British Journal of Educational Technology, 46(2), 221-229. doi:10.1111/bjet.12273 
Nelson, M. M., \& Schunn, C. D. (2009). The nature of feedback: How different types of peer feedback affect writing performance. Instructional Science, 37, 375-401. doi:10.1007/s11251-008-9053-x

Noroozi, O. (2013). Fostering argumentation-based computer-supported collaborative learning in higher education (Doctoral dissertation). Wageningen, The Netherlands: Wageningen University. Retrieved from https://edepot.wur.nl/242736

Noroozi, O., Biemans, H. J. A., Weinberger, A., Mulder, M., \& Chizari, M. (2013). Scripting for construction of a transactive memory system in multidisciplinary CSCL environments. Learning and Instruction, 25, 1-12. doi:10.1016/j.learninstruc.2012.10.002

Pajares, F., \& Schunk, D. H. (2001). Self-beliefs and school success: Self-efficacy, selfconcept, and school achievement, In R. Riding \& S. Rayner (Eds.), Perception (pp. 239-266). London, UK: Ablex Publishing. Retrieved from https://www.uky.edu/ eushe2/Pajares/PajaresSchunk2001.html

Passey, D., Goodison, R., Machell, J., \& McHugh, G. (2004). The motivational effect of ICT on pupils. Lancaster, UK: Lancaster University, Department of Educational Research.

http://downloads01.smarttech.com/media/research/international_research/uk/lan caster_report.pdf.

Pekrun, R. (2006). The control-value theory of achievement emotions: Assumptions, corollaries, and implications for educational research and practice. Educational Psychology Review, 18, 315-341. doi:10.1007/s10648-006

Pekrun, R., \& Stephens, S. J. (2010). Achievement emotions in higher education. In J. C. Smart (Ed.), Higher education: Handbook of theory and research (Vol. 25, pp 257306). New York, NY: Springer. doi:10.1007/978-90-481-8598-6_7

Peng, P., Namkung, J., Barnes, M., \& Sun, C. (2016). A meta-analysis of mathematics and working memory: Moderating effects of working memory domain, type of mathematics skill, and sample characteristics. Journal of Educational Psychology, 108, 455-473. doi:10.1037/edu0000079

Pintrich, P. R. (1988). A process-oriented view of student motivation and cognition. In J. S. Stark \& L. Mets (Eds.), Improving teaching and learning through research. New directions for institutional research (pp. 55-70). San Francisco, CA: Jossey-Bass. doi:10.1002/ir.37019885707 
Pintrich, P. R., \& De Groot, E. V. (1990). Motivational and self-regulated learning components of classroom academic performance. Journal of Educational Psychology, 82, 33-40. doi:10.1037/0022-0663.82.1.33

Pollock, E., Chandler, P., \& Sweller, J. (2002). Assimilating complex information. Learning and Instruction, 12, 61-86. doi:10.1016/S0959-4752(01)00016-0

Reichwein Zientek, L., Fong, C. J., \& Phelps, J. M. (2019). Sources of self-efficacy of community college students enrolled in developmental mathematics. Journal of Further and Higher Education, 43, 183-200. doi:10.1080/0309877X.2017.1357071

Roediger, H. L., \& Karpicke, J. D. (2006). The power of testing memory: Basic research and implications for educational practice. Perspectives on Psychological Science, 1 , 181-210. doi:10.1111/j.1745-6916.2006.00012.x

Rohrer, D., Dedrick, R. F., \& Stershic, S. (2015). Interleaved practice improves mathematics learning. Journal of Educational Psychology, 107, 900-908. doi: $10.1037 /$ edu0000001

Ryan, R. M., \& Deci, E. L. (2000). Self-determination theory and the facilitation of intrinsic motivation, social development, and well-being. American Psychologist, 55, 68-78. doi: 10.1037/0003-066X.55.1.68

Shute, V., Ventura, M., Bauer, M., \& Zapata-Rivera, D. (2009). Melding the power of serious games and embedded assessment to monitor and foster learning. In $U$. Ritterfeld, M. Cody, \& P. Vorderer (Eds.), Serious games: Mechanisms and effects (pp. 295-321). New York, NY: Routledge.

Sweller, J. (2010). Element interactivity and intrinsic, extraneous, and germane cognitive load. Educational Psychology Review, 22, 123-138. doi:10.1007/s10648-010-91285

Tout, D., Coben, D., Geiger, V., Ginsburg, L., \& Hoogland, K. (2017). Review of the PIAAC numeracy assessment framework: Final report. Camberwell, Australia: Australia Counsil of Education Research. Retrieved from https://www.oecd.org/skills/piaac/review of the piaac numeracy assessment framework_2017_acer.pdf

Tricot, A., \& Sweller, J. (2014). Domain-specific knowledge and why teaching generic skills does not work. Educational Psychology Review, 26, 265-283. doi: $10.1007 /$ s10648013-9243-1

Tynjälä, P. (1999). Towards, expert knowledge? A comparison between a constructivist and a traditional learning environment in the university. International Journal of Educational Research, 31, 357-442. doi:10.1016/S0883-0355(99)00012-9 
Tynjälä, P. (2013). Toward a 3-P model of workplace learning: A literature review. Vocations and Learning, 6, 11-36. doi:10.1007/s12186-012-9091-z

Van Gog, T., Kester, L., \& Paas, F. (2011). Effects of worked examples, example-problem, and problem-example pairs on novices' learning. Contemporary Educational Psychology, 36, 212-218. doi:10.1016/j.cedpsych.2010.10.004

Van Merriënboer, J. J. G., \& Kirschner, P. A. (2007). Ten steps to complex learning. A systematic approach to four-component instructional design. Mahwah, NJ: Lawrence Erlbaum Associates.

Van Merriënboer, J. J. G., \& Kirschner, P. A. (2018). Ten steps to complex learning (3rd ed.). New York, NY: Taylor \& Francis.

Van Merriënboer J. J. G., \& Sweller, J. (2010). Cognitive load theory in health professional education: design principles and strategies. Medical Education, 44, 85-93. doi:10.1111/j.1365-2923.2009.03498.x

Van der Veen, I., \& Peetsma, T. (2009). The development in self-regulated learning behavior of first-year students in the lowest level of secondary school in the Netherlands. Learning and Individual Differences, 19, 34-46. doi: $10.1016 / j$.lindif.2008.03.001

Van de Werfhorst, H., Elffers, L., \& Karsten, S. (2015). Onderwijsstelsels vergeleken: Leren, werken en burgerschap [Educational systems compared: Learning, working and citizenship]. Amsterdam, The Netherlands: University of Amsterdam, Research Institute of Child Development and Education. Retrieved from https://www.nro.nl/sites/nro/files/migrate/Onderwijsstelsels-vergeleken-2015Van-de-Werfhorst-Elffers-en-Karstens.pdf

Wang, M., Kirschner, P. A., Spector, J. M., \& Ge, X. (2018). Computer-based learning environments for deeper learning in problem-solving contexts. Computers in Human Behavior, 87, 403-405. doi:10.1016/j.chb.2018.06.026

Weeks, K. W., Hutton, B. M., Young, S., Coben, D., Clochesy, J. M., \& Pontin, D. (2013). Safety in numbers 2: Competency modelling and diagnostic error assessment in medication dosage calculation problem-solving. Nurse Education in Practice, 13, e23-e32. doi:10.1016/j.nepr.2012.10.013

Wigfield, A., \& Eccles, J. S. (2000). Expectancy-value theory of achievement motivation. Contemporary Educational Psychology, 25, 68-81. doi:10.1006/ceps.1999.1015

Wu, J.-H., Tennyson, R. D., \& Hsia, T.-L. (2010). A study of student satisfaction in a blended learning system environment. Computers \& Education, 55, 155-164. doi: $10.1016 /$ j.compedu.2009.12.012 
Xinhao, X., \& Fengfeng, K. (2016). Designing a virtual-reality-based, gamelike math learning environment. American Journal of Distance Education, 30, 27-38. doi: $10.1080 / 08923647.2016 .1119621$

Yuang, B., Wang, M., Van Merriënboer, J., Tao, X., Kushniruk, A., \& Peng, J. (2020). Investigating the role of cognitive feedback in practice-oriented learning for clinical diagnostics. Vocations and Learning, 13, 159-177. doi:10.1007/s12186-01909234-z 


\section{Chapter 2}

\section{The Effects of Digital Learning Material on Students' Mathematics Learning in Vocational Education}

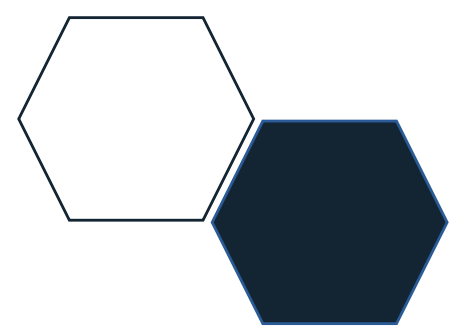

This chapter is published as: Zwart, D. P., Van Luit, J. E. H., Noroozi, O., \& Goei, S. L. (2017). Cogent Education, 4: 13581. doi:10.1080/2331186X.2017.1313581

Authors contributions: J.E.H.V.L., O.N., S.L.G. and D.P.Z. conceptualized the research. D.P.Z. collected and analyzed the data; D.P.Z. wrote the original draft, visualized the results, and edited the paper; J.E.H.V.L., O.N., and S.L.G. critically reviewed the paper. 


\section{Abstract}

This study investigates the effects of Digital Learning Material (DLM) including instructional clips, online guidance, structuring of content, and a collaboration tool on students' mathematics learning in Dutch vocational education. A pretest-posttest design was used. Apprenticeship students were asked to complete assignments and to discuss them with their peers and the online teacher. The results showed that DLM can enhance students' mathematics learning in vocational education. The learning enhancement was mostly due to the use of instructional clips and structuring of the content of the mathematics tasks. Elaborations of these results, implications, limitations, and recommendations for further research are provided. 


\section{Introduction}

Dutch vocational education prepares students, from 16 years of age to over 40 , for an occupation and provides them with requisite education-based vocational qualifications. These qualifications are developed by education and industry and meet job-entry requirements that pertain to each sector: Health and Welfare (H\&W), Economics and Services (E\&S) and Technology (T) (Ministry of Education, Culture and Science, 2015). This is how the Dutch Government ascertains that students learn the knowledge required to perform productively at their future job. This knowledge comprises of an occupation's domain-specific conceptual, procedural, and dispositional knowledge (Billett, 2013). Since the national mathematics- and language tests are also part of the curriculum as a standard procedure for assessment in vocational education, there is also a lot of attention focused on students' mathematics and language knowledge. Within that, mathematics is generally the biggest headache for students.

The national mathematics test was meant to support student's vocational education learning of mathematics in the context of their profession. Results on national mathematics test still raise cause for concern (see Examenblad, n.d.; Ministry of Education, Culture and Science, 2015). The disappointing results come as no surprise: vocational education supports learning through work practice (Billett, 2013) and mathematics in non-vocational education settings is now taught as a collection of separate elements instead of teaching them in an integrated fashion (Van Merriënboer \& Kirschner, 2007). As a result, students lose track of the interconnections between these elements. Students therefore produce flawed algorithms, which might explain their disappointing examination results.

Students' characteristics in vocational education are quite different from each other in terms of their age level, prior education, and differences in general cognitive abilities, specifically, Working Memory (WM) (Alloway, Bibile, \& Lau, 2013). And since WM is a key predictor for mathematical achievement (Wei, Yuan, Chen, \& Zhou, 2012), it is difficult for a vocational mathematics teacher to support students in a 'one size fits all' manner. An alternative to facilitating mathematics teaching and learning in vocational education is to use instructional design with Digital Learning Material (DLM).

DLM offer a wide range of educational opportunities that could not be achieved in traditional face-to-face forms of learning and instruction (Kalyuga \& Liu, 2015). DLM enhance efficiency of teaching and offer more diversified learning experiences without limitations of time, space and place (Lee \& Hung, 2015; Noroozi, Busstra et al., 2012). Despite the advantages of DLM, the use of technology by itself may not guarantee sufficient benefits for learning to warrant investigation into the development of such applications: mixed findings have been produced by empirical research on the use of DLM (see Kalyuga \& Liu, 2015; Noroozi, Busstra et al., 2012; Payne et al., 2009). Therefore, scientific literature 
suggests that DLM should be accompanied with appropriate instructional approaches (see Noroozi, Busstra et al., 2012). DLM such as instructional clips, online guidance, content structuring and collaboration tools in technology-based environments can be used to create learning environments in which students can interact meaningfully with the learning materials and their peers (Noroozi, Busstra et al., 2012). It can also facilitate the students' selection, organization and integration of new information and knowledge. Using such instructional approaches for learning mathematical concepts and solving mathematical problems for students in vocational education is rather sparse. Furthermore, it is not clear how DLM can foster the integration and acquisition of domain-specific knowledge to students in vocational education. Therefore, this study examined the impact of an instructional design approach with DLM including instructional clips, online guidance, content structuring and collaboration tools to facilitate mathematics learning of students in vocational education. And since WM is a key predictor for mathematical achievement (Wei et al., 2012), this study is also concerned with the extent to which WM influences students' mathematics learning outcomes.

\section{Mathematics in Dutch vocational education}

In vocational education, mathematics starts with the instruction of the underlying unifying principles of domain-specific knowledge within the domain of 'numbers' (e.g., notation, naming and meaning of both positive and negative (large) whole numbers, decimals, and fractions, as well as connecting, organizing, and calculating numbers, with or without calculator). After eight weeks, students are tested and regardless the scores of the test, students start with the next domain 'proportions', in which, for example, fractions and percentages take an important role. Most students encounter problems with fractions and calculating the amount of $100 \%$. They also find it difficult to count backwards from a given percentage of $100 \%$. The instruction of this new domain-specific knowledge is highly significant to encode and retrieve information from the understanding of the part-whole relation, measurement interpretation of fractions, and fractional quantities (CVE, 2015). After the domain 'proportions' students start with geometry, again regardless their scores on previous domains. Geometry has a stronger relation with performance on mathematics tasks with a strong visuospatial component (Peng, Namkung, Barnes, \& Sun, 2016). In the domain 'geometry', students have difficulty with converting and they often have insufficient understanding of compound (ratio) sizes (CVE, 2015). The importance of the underlying (prior) domain-specific knowledge and skills should not be underestimated. Since prior achievement tends to go along with the level of prior knowledge a student has accumulated (Kollar et al., 2014), this is particularly problematical when students do not understand the underlying (prior) knowledge and skills thoroughly. When students are knowledgeable in this particular domain, they can encode and retrieve information specific to it more efficiently than they can encode and retrieve information from a domain in which they are 
less knowledgeable (Peng et al., 2016). It should thus be recognized that there are students who need more time and more instruction than the standardized 8 weeks to understand the concepts of the domains, because when this particular domain is less knowledgeable to the student, it is difficult to make connections with the new domainspecific knowledge. In addition, it should also be mentioned that if a student is already able to perform a certain task, the information provided becomes redundant (Sweller, 2010) and extra instruction is not needed.

The individual differences in mathematics success might be a result of the educational design, but the success can also be the result of students' different WM capacities, which could determine how vocational education schools should shape their mathematics education. Investigating the strength of the relation between WM and different types of mathematics performance among students may be important for instructional design (Peng et al., 2016). Because WM can be seen as an important facilitating or inhibiting factor for mathematical achievement, it will be discussed more thoroughly.

\section{Working Memory and Mathematics}

Working Memory (WM) is an important cognitive skill; capacity differences between the highest and lowest scoring individuals correspond to five years of normal development (Alloway et al., 2013). It is considered important for mathematical performance (Alloway et al., 2013; Wei et al., 2012). Burgess and Hitch (2005) point out that a higher WM capacity can help students to better encode items. WM is a factor that has proven critical for general individual differences between the efficiency of filtering irrelevant information (Jost, Bryck, Vogel, \& Mayr, 2010), and it integrates domain-specific skills, knowledge, and procedures to meet the particular demands of learning tasks within a particular domain (Peng et al., 2016). Too many new elements can overburden WM, causing cognitive overload (Kalyuga, Chandler, Tuovinen, \& Sweller, 2001). In particular, WM load caused by elements of the learning environment that are necessary neither to solve the task nor for schema acquisition is called extraneous load (Sweller 2010; Van Merriënboer \& Kirschner 2007). This is another reason why WM limitations must be borne in mind in the instructional design of DLM, so that these materials effectively support students to be able to succeed.

\section{Digital Learning Material (DLM)}

The instruction in DLM environments can be designed to help students identify useful information, understand how materials fit together and see how materials relate to prior knowledge (Mayer, 2001). In DLM environments, instruction shifts from a traditional teacher- or system-controlled environment, to on-demand education (Van Merriënboer \& Kirschner, 2007). The instruction by the online teacher should encourage students to be as cognitively active as possible and discuss their ideas and conceptions from different 
perspectives (Noroozi, Weinberger, Biemans, Mulder, \& Chizari, 2012), as in face-to face settings. The instruction in DLM can also be delivered by the use of instructional clips, which present the instructional message to the learner auditorily and visually. Each clip involves a concise statement of a crucial step in the mathematical process. The sounds of the clips verbalize and reason the connections between the different elements of the domain-specific knowledge. For example, in the domain of 'proportions', the clips repeatedly show the relationships between ratio, percentages, and fractures before the instruction on domain-specific knowledge and skills starts. By clearly arranging the steps and providing, verbalizing and reasoning thought models, the instructional messages may prime appropriate organizational processing by the viewer. Using this process of verbalizing and math reasoning the modelling examples do not explicitly provide the schemata for solving a particular problem, but models the actions and strategies used to find a solution (Kollar et al., 2014). The modelling examples consist of sequences of steps the learners need to follow as key decision steps, which are 1) provide a rational structure, 2) reduce complexity, 3) give verbal help, and 4) provide modeling. Chunking information in short clips may prevent loss of information from WM (Driscoll, 2005), but this has the consequence that multiple instructional clips are needed to connect domain-specific mathematics knowledge to richer networks of knowledge and to interconnect different elements. Students should be able to solve abstract problems through mathematical manipulation (Canobi, 2009).

To answer the question of how to support students in vocational education with mathematics, the first step is to answer the question of how to work with the 'one size fits all' approach. This study aims to investigate whether and how a DLM environment enriched with instructional clips, online guidance, content structuring, and a collaboration tool, as a combination, can be designed to enhance student mathematics' competence in vocational education. The ultimate goal is to reframe instructional design in the mathematics curriculum in vocational education, through direct application and testing. Therefore, the following research questions are formulated to test the effects of DLM including instructional clips, online guidance, structuring of content, and a collaboration tool on students' mathematics learning in vocational education:

1. What are the effects of DLM on vocational education students' mathematics learning outcomes for the separate and combined domains of numbers and proportions in the sectors Health and Welfare (H\&W) and Economics and Services (E\&S) (study 1 ) and the domain of geometry in the sector Technology (study 2)?

2. What is the influence of WM capacity on mathematics learning outcomes for study 1 and study 2? 
Because students are able to watch clips that repeatedly show the relationship between ratio, percentages and fractures and clearly arrange the steps visualizing and reasoning thought models, it is expected that students' pretest mathematics learning outcomes will be improved in the posttest measurements after the DLM intervention. We expect that such positive differences are reflected in the posttest results for all programmes of the $\mathrm{H} \& \mathrm{~W}$ and E\&S and Technology sectors. Although gains are expected in the sectors, no difference in gains is expected between the sectors because all sectors have the same opportunities for disposal for the materials. The final expectation is that higher WM has a positive influence on both mathematics learning outcomes and students' satisfaction (Alloway et al., 2013; Wei et al., 2012).

\section{Method}

Context and participants

This study focuses on students in Dutch vocational education who obtain their qualification by apprenticeship training. That is, they learn in school for one day per week, and work and learn the other four days in the workplace (Baartman \& De Bruijn, 2011). Students in Dutch vocational education must attain a sufficient mathematics level. The level of the program in vocational education determines the complexity and height of the mathematics level that students need to achieve for their final degree. The difference in complexity and height depends on the single steps a student has to make to solve the problem. For example, reading tables with different types of data require calculating with time for problems with high complexity, in contrast to problems with low complexity that only demand students to map the tables.

The first study took place at 'Drenthe College' in Assen (the Netherlands), a school for vocational education. The participants were 18 students from the sectors $\mathrm{H} \& \mathrm{~W}(N=12)$ and E\&S $(N=6)$, selected because they were in the mathematics group taught by the two teachers who participated in this study. The mean age of the participants was 29.5 years $(S D=10.3$ years). The minimum age was 20 years, and the maximum age was 52 years. Three students were male and 15 were female.

The second study took place at 'Deltion College' in Zwolle (the Netherlands), a school for vocational education. The participants were 12 students from the sector Technology $(T)$, selected because these students were in the mathematics group taught by the teacher who participated in this study. The mean age of the participants was 18.2 years $(S D=1.9$ years). The minimum age was 16 years, and the maximum was 23 years. All students were male. A mathematics course was a required part of the curriculum for all students. The goal was to gain insight and practice tasks to qualify for the national mathematics test. Each sector had a teacher who guided the course online. 


\section{E-learning environment}

Students used online learning environments (see Figure 1 and Figure 2). The DLM in the course was designed, recoded, and implemented in the learning platforms for the online learning environment. Students were able to complete assignments online and interact within the DLM environment. They could watch instructional clips if they were not able to solve the problems from the book or from the online mathematics assignments. If students were still not able to solve the problems after watching the instructional clips, they could ask questions by using the collaboration tool. Teachers guided the students online by answering questions or re-explaining problems in a different way in the collaboration tool. Students were also allowed to answer or discuss their peers' questions. Each week had the same structure.

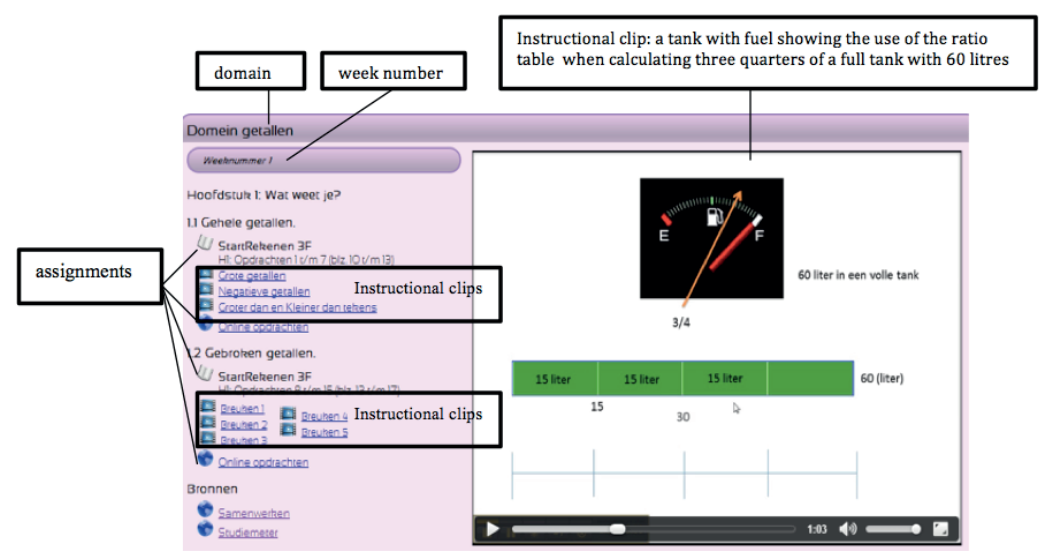

Figure 1. Screenshot e-mathematics, 'numbers' domain, week 1. 


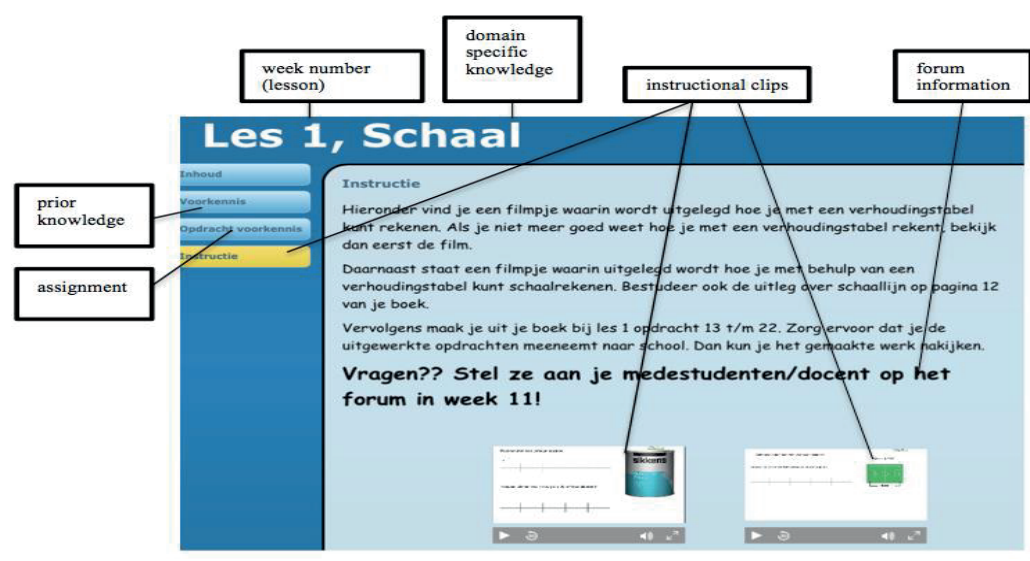

Figure 2. Screenshot e-mathematics, 'geometry' domain, week 1.

\section{Instructional clips in E-learning environment}

The instructional clips were built with modelling examples and recorded with audio. The design principles in the instructional clips consisted of sequences of steps that helped the students to solve math problems by key decision steps: 1) offer a rational structure, 2) reduce complexity, 3) give verbal help, and 4) provide modelling (Kollar et al., 2014). The instructional clips for domain-specific knowledge related to numbers, proportions, and geometry were constructed to range from easy to complex and linked to the content of the mathematics assignments for the week that were used by the school's mathematics programme. The programme's mathematics content was shifted at times, because of need for interconnection between the different elements of the domain-specific knowledge in the instructional clips. Recorded audio in the instructional clips also referred students to earlier clips for prior knowledge, so they were able to choose an earlier clip needed for solving the problem in a more complex task. For problem solving support, modelling examples were used in the clips (visual and audio).

Online guiding in E-learning environment

The teachers guided the students online, twice a week over 8 weeks for each domain. Their role was to give assistance when students had questions about assignments or to reexplain problems in a different way in the collaboration tool. Teachers had a two-day training on online guiding.

Collaboration tool

In study 1 the online (free) collaboration tool, 'Titanpad', was implemented in the learning environment. It is a user-friendly webbased application to work online synchronously on a document and chat with other students at the same time. Each student is assigned to a 
colour that makes awareness for others in terms of who contributes. In study 2, the online collaboration tool was a forum in the learning environment. It is also an online discussion space, but students communicate a-synchronously with each other. In both studies, students could interact and ask questions within the learning environment, and teachers and peers could respond to the questions. Each question and response was visible for all users.

Structuring of content

The content was designed to have the same structure every week, so that students could identify useful information, understand how the material fit together and see how the material relates to prior knowledge (Mayer, 2001). On the left side of the screen were the content of the week's assignments (either online or the book) including instructional clips, answers to the assignments, and the collaboration tool. The instructional clips, available on demand, were displayed on the right side of the screen, next to the list of assignments (see Figures 1 and 2).

Procedure

Prior to working with the DLM, students of each department were given information on the DLM environment and the online course with DLM during a live class session, which took an hour. Researcher and teacher explained the goal of the experiment and introduced the DLM environment. In study 1 , students were enrolled in an 8-week course addressing the domain-specific knowledge of numbers and in an 8-week course addressing the domainspecific knowledge of proportions. In study 2, students were enrolled in an 8-week course addressing the domain-specific knowledge of geometry. After the information session, students were tested online for their WM with a speed-math test (IDAA, Bekebrede et al., 2010). Students needed to mentally calculate the answers for 30 problems, where the answer was selected from five possibilities. The items varied in difficulty and students had a maximum of five minutes to complete the test. Since higher WM capacity can help students to better encode and manipulate items, as well as critical efficiency of filtering irrelevant information, the test scores show that the coding and interpretation of information is facilitated by WM. The reliability coefficient of this test is .89. In both studies students also took a mathematics equivalent pretest and posttest specific to the mathematics programme at the vocational education school (Lagendijk et al., 2010): 20 tasks about domain-specific knowledge of numbers and proportions each (study 1), and 20 tasks about domain-specific knowledge of geometry (study 2).

Statistical Tests

A one-way analysis of variance (ANOVA) test was used instead of a t-test to ascertain whether the means of more than two groups significantly differ. We analyzed if mean 
scores students' mathematics grades are significantly different for the separate and combined domains of numbers and proportions in study 1 and the domain of geometry in study 2 Furthermore, an ANOVA test was conducted to compare mean differences between students from the H\&W and E\&S sectors on their separate and combined mathematics gains for numbers and proportions in study 1 . For both studies, regression analysis was calculated to determine the relation between WM score and students' mathematics learning outcomes.

\section{Results}

Table 1 shows an overview of descriptive analysis of the data for both studies in terms of gender, mean age, level of study, sector, mathematics scores for the pretest and posttest on domain-specific knowledge, and WM score.

Table 1

Descriptive Statistics of the Data

Study $1(\mathrm{H} \& W) \quad$ Study $1(\mathrm{E} \& \mathrm{~S}) \quad$ Study $2(\mathrm{~T})$

\begin{tabular}{|c|c|c|c|c|c|c|c|c|c|}
\hline Total & $\mathrm{N}$ & M & SD & $\mathrm{N}$ & M & SD & $\mathrm{N}$ & M & SD \\
\hline Gender & \multicolumn{3}{|c|}{2 male 10 female } & \multicolumn{3}{|c|}{1 male 5 female } & \multicolumn{3}{|c|}{12 male } \\
\hline Age (years) & 12 & 33.08 & 10.84 & 6 & 22.33 & 2.73 & 12 & 18.17 & 1.85 \\
\hline WM & 12 & 82.60 & 10.31 & 6 & 78.00 & 14.45 & 11 & 75.90 & .16 .39 \\
\hline Pretest Numb. & 11 & 3.93 & 1.91 & 5 & 3.20 & 1.10 & . & . & . \\
\hline Posttest Numb. & 12 & $5.23 * *$ & 2.70 & 5 & 4.08 & .72 & . & . & . \\
\hline Pretest Prop. & 12 & 2.20 & 1.06 & 6 & 4.82 & 2.54 & . & . & . \\
\hline Posttest Prop. & 10 & $6.96 * * *$ & 2.85 & 6 & 5.80 & 3.03 & . & . & . \\
\hline Pretest Geom. & . & . & . & . & . & . & 12 & 3.33 & 1.13 \\
\hline Posttest Geom. & . & . & . & . & . & . & 10 & 3.73 & .76 \\
\hline
\end{tabular}

$* * \mathrm{p}<.01 * * * \mathrm{p}<.001$

Results for Research Question 1

With regard to study 1 , students scored significantly higher on the posttest than the pretest for numbers $\left(F(1,15)=8.43, p<.01, \eta^{2}=.36\right)$, proportions $(F(1,15)=21.51, p<.001$, $\left.\eta^{2}=.59\right)$, and their combination $\left(F(1,13)=28.22, p<.001, \eta^{2}=.69\right)$. With regard to study 2 , no significant difference was found between the results on the pre and posttest for geometry $(F(1,9)=2.16, p=.18)$.

Students in the H\&W sector scored significantly higher on the posttest than the pretest for numbers $(F(1,10)=5.01, p<.05, \eta 2=.33)$, for proportions $(F(1,9)=30.31, p<.001$, $\left.\eta^{2}=.77\right)$ and for their combination $\left(F(1,8)=35.68, p<.001, \eta^{2}=.82\right)$. In contrast, no 
significant differences were found between the pretest and posttest scores for students in the E\&S sector for numbers $(F(1,4)=4.25, p=.11)$, and proportions $(F(1,5)=5.55, p$ $=.07)$. However, their results for the combined domains were significantly higher in the posttest than the pretest $\left(F(1,4)=12.53, p<.03, \eta^{2}=.76\right)$. The differences between sectors H\&W and E\&S were significant for the combined domains $(F(1,12)=8.23, p<$ $\left..01, \eta^{2}=.41\right)$ and for proportions $\left(F(1,14)=10.14, p<.01, \eta^{2}=.42\right)$. No effect of sector was found for learning outcomes related to numbers $(F(1,14)=.07, p=.79)$.

Results for Research Question 2

There was no significant correlation between Working Memory (WM) scores and the differences between the pretest and posttest mathematics results in the first study for numbers $(r=.30, p=.30)$, proportions $(r=.10, p=.74)$ and their combination $(r=.34$, $p=.26)$. Similar to the first study, no significant correlation between WM and geometry learning outcomes was seen for the second study $(r=.04, p=.91)$.

\section{Conclusion and Discussion}

The present studies were designed to determine the effect of the DLM on the mathematics learning outcomes of apprenticeship students in vocational education. Furthermore, the relationship between WM scores and mathematics results was investigated. It was hypothesised that learning gains were expected for both studies. Moreover, it was expected that students with high WM would achieve higher mathematics results. Based on these two studies, the general conclusion can be drawn that DLM can foster positive learning outcomes and knowledge construction (e.g., Noroozi, Busstra et al., 2012). Furthermore, the DLM environment including instructional clips, online guidance, structuring of content and a collaboration tool helped students improve their mathematics scores, especially those in study 1 . The implementation of DLM improved students' domain-specific mathematics knowledge for both numbers and proportion domains except for the geometry topic. It appeared that in contrast to the hypothesis, differences in mathematics results could not be accounted for by WM scores.

With regard to the second research question, it was hypothesised that no differences would be found between the two sectors. On the contrary, students in the H\&W sector demonstrated significantly higher learning gains for proportions and for numbers and proportions combined than students in the E\&S sector. The students of H\&W were involved in the assignments and collaborated as a group, and if they found technical and organizational problems the teacher was immediately notified. This had an effect on their results because these students showed greater learning gains than the students of E\&S. Best, Miller, and Naglieri (2011) argue that mathematical problem-solving depends on involvement of students in the learning tasks. The students of E\&S were not interested in collaborating and working with DLM. They did not see the added value of general 
mathematics in their future profession. Students in the second study from the Technical sector also failed to see the added value of mathematics in education. These students worked with the DLM because their teacher asked them to do so. Furthermore, they argued that time was a big issue. These students work four days (sometimes even more) a week, and they only had one day a week for their study. Students need that time to finish their workplace assignments. Though the students had the possibility to practice online mathematics during seven days of the week, the DLM environment did not motivate them that much to practice more because it did not support their workplace learning. At this point, we might have overestimated the teachers' expertise in giving students guidance on technology use (Knezek \& Christensen, 2008). The teachers' role to close the gap between the innovation of the DLM environment and classroom curricula did not sufficiently emerge during and after sessions. We ignored key system factors that cannot be manipulated by the innovation such as assessments, technology policies and infrastructure (McKenney, 2013). In a productive DLM environment, in order to construct knowledge, students need to work together instead of on their own (Kanselaar, De Jong, Andriessen, \& Goodyear, 2000). However, collaborative learning needs to be structured and guided appropriately (e.g., Gillies, 2004; Kollar, Fischer, \& Slotta, 2007), otherwise students often engage in low-level learning processes because of low-level argumentation (Kollar et al., 2007; Noroozi, Kirschner, Biemans, \& Mulder, 2017; Noroozi et al., 2012). We envisage a central role for the online teacher here, in giving impetus to this collaboration. For this to occur successfully, the teacher needs to be able to scaffold student participation.

This study had a small sample of participants for making claims that are not based on coincidence. However, it was a first effort to research the development of the educational concept of DLM in Dutch vocational education. Questions arise as to whether difficulty in attending to key task dimensions and the passive approach to task completion are variables that should be taken into account, instead of using only a working memory test. The present study did not analyse the different assignments on the students' pre-tests and post-tests. Furthermore, replication of this study in vocational, secondary, or higher education with more students, a control group and under more controlled conditions would be needed to confirm the results of this study.

Author's note

The authors want to express their gratitude for the support of the students, teachers and the boards of Drenthe College and Deltion College. Special thanks also for the support of Muiswerk Educatief (2007). 


\section{References}

Alloway, T. P., Bibile, V., \& Lau, G. (2013). Computerized working memory training: Can it lead to gains in cognitive skills in students? Computers in Human Behavior, 29, 632-638. doi:10.1016/j.jecp.2009.11.003

Baartman, L. K. J., \& De Bruijn, E. (2011). Integrating knowledge, skills and attitudes: Conceptualising learning processes towards vocational competence. Educational Research Review, 6, 125-134. doi:10.1016/j.edurev.2011.03.001

Bekebrede, J. I., Garst, H., Van der Leij, A., Schijf, T., Willems, H., \& Schijf, T. (2010). $I D A A-m b o$ [Speed mathematics test for vocational education]. Retrieved from http://www.muiswerk.nl/roc/mbo/testsuite-2-screening-rekenen-wiskunde.

Best, J. R., Miller, P. H., \& Naglieri, J. A. (2011). Relations between executive function and academic achievement from ages 5 to 17 in a large, representative national sample. Learning and Individual Differences, 21, 327-336. doi:10.1016/j.lindif.2011.01.007

Billett, S. (2013). Learning through practice: Beyond informal and towards a framework for learning through practice. Retrieved from http://www.unevoc.unesco.org/fileadmin/up/2013_epub_revisiting_global_trends _in_tvet_chapter4.pdf.

Burgess, N., \& Hitch, G. J. (2005). Computational models of working memory: Putting long-term memory into context. Trends in Cognitive Sciences, 9, 535-541. doi:10.1016/j.tics.2005.09.011

Canobi, K. H. (2009). Concept-procedure interactions in children's addition and subtraction. Journal of Experimental Child Psychology, 102, 131-149. doi: $10.1016 /$ j.jecp.2008.07.008

CVE. (2015). College voor Examens. Handreiking rekenen $3 F$ mbo [Board of Exams. Guideline mathematics level 3F vocational education]. Utrecht, The Netherlands: CVE.

Driscoll, M. P. (2005). Psychology of learning for instruction. Boston, MA: Pearson Education.

Examenblad. (n.d.). Examenblad MBO. Centrale examens 2015-2016 [Examsheets: Results of the national mathematics test]. Retrieved from https://www.examenbladmbo.nl/examen/rekenen-3f/2015-2016.

Gillies, R. M. (2004). The effects of cooperative learning on junior high school students during small group learning. Learning and Instruction, 14, 197-213. doi: 10.1016/S0959-4752(03)00068-9

Jost, K., Bryck, R. L., Vogel, E. K., \& Mayr, U. (2010). Are old adults just like low working memory young adults? Filtering efficiency and age differences in visual working memory. Cerebral Cortex, 21, 1147-1154. doi:10.1093/cercor/bhq185 
Kalyuga, S., Chandler, P., Tuovinen, J., \& Sweller, J. (2001). When problem solving is superior to studying worked examples. Journal of Educational Psychology, 93, 579588. doi:10.1037/0022-0663,93,3,579

Kalyuga, S., \& Liu, T. C. (2015). Guest editorial: Managing cognitive load in technologybased learning environments. Educational Technology \& Society, 18(4), 1-8. Retrieved from

https://www.epc.ntnu.edu.tw/uploads/asset/data/5cc904741d41c8362f00001c/15 50_a76a3058.pdf

Kanselaar, G., De Jong, T., Andriessen, J., \& Goodyear, P. (2000). New technologies. In R. J. Simons, J. van der Linden, \& T. Duffy (Eds.), New learning (pp. 55-83). Dordrecht, The Netherlands: Kluwer Academic Publishers.

Knezek, G., \& Christensen, R. (2008). The importance of information technology attitudes and competences in primary and secondary education. In J. Voogt \& G. Knezek (Eds.), International handbook of information technology in primary and secondary education (pp. 321-331). New York, NY: Springer. doi:10.1007/978-0-387-733159

Kollar, I., Fischer, F., \& Slotta, J. D. (2007). Internal and external scripts in computersupported collaborative learning. Learning and Instruction, 17, 708-721. doi:10.1016/jlearninstruc.2007.09.021

Kollar, I., Ufer, S., Reichersdorfer, E., Vogel, F., Fischer, F., \& Reiss, K. (2014). Effects of collaboration scripts and heuristic worked examples on the acquisition of mathematical argumentation skills of teacher students with different levels of prior achievement. Learning and Instruction, 32, 22-36. doi:10.1016/jlearninstruc.2014.01.003

Lagendijk, R., Heebels, S., Telkamp, S., Bassa, H., Van Abswoude, J., Oomen, M., ..., Folkertsma, J. (2010). Startrekenen [Starting mathematics]. Amersfoort, The Netherlands: Deviant.

Lee, L. -T., \& Hung, J. C. (2015). Effects of blended e-learning: A case-study in higher education tax learning setting. Human-centric Computing and Information Sciences, 5, 1-15. doi:10.1186/s13673-015-0024-3

Mayer, R. E. (2001). Multimedia learning. New York, NY: Cambridge University Press. doi: $10.1017 /$ СBO9781139164603

McKenney, S. (2013). Designing and researching technology-enhanced learning for the zone of proximal implementation. Research in Learning Technology, 21, 1-9. doi: $10.3402 /$ rlt.v21i0.17374

Ministry of Education, Culture and Science (2015). Invoering referentieniveaus taal en rekenen [Implementation framework language and mathematics]. Retrieved from 
http://mboinbedrijf.nl/images/Stand_van_zaken_invoering_referentienive aus_taal_en_rekenen_2016.pdf.

Noroozi, O., Busstra, M. C., Mulder, M., Biemans, H. J. A., Tobi, H., Geelen, M. M. E. E.,... Chizari, M. (2012). Online discussion compensates for suboptimal timing of supportive information presentation in a digitally supported learning environment. Educational Technology Research and Development, 60, 193-221. doi: 10.1007/s11423-011-9217-2

Noroozi, O., Kirschner, P., Biemans, H. J. A., \& Mulder, M. (2018). Promoting argumentation competence: Extending from first- to second-order scaffolding through adaptive fading. Educational Psychology Review, 30, 153-176. doi: 10.1007/s10648-017-9400-z

Noroozi, O., Weinberger, A., Biemans, H. J. A., Mulder, M., \& Chizari, M. (2012). Argumentation-based computer supported collaborative learning ( $A B C S C L$ ). A systematic review and synthesis of fifteen years of research. Educational Research Review, 7, 79-106. doi:10.1016/j.edurev.2011.11.006

Payne, A. M., Stephenson, J. E., Morris, W. B., Tempest, H. G., Mileham, A., \& Griffin, D. K. (2009). The use of an e-learning constructivist solution in workplace learning. International Journal of Industrial Ergonomics, 39, 548-553. doi: $10.1016 /$ j.ergon.2008.10.019

Peng, P., Namkung, J., Barnes, M., \& Sun, C. (2016). A meta-analysis of mathematics and working memory: Moderating effects of working memory domain, type of mathematics skill, and sample characteristics. Journal of Educational Psychology, 4, 455-473. doi:10.1037/edu0000079

Sweller, J. (2010). Element interactivity and intrinsic, extraneous and germane cognitive load. Educational Psychology Review, 22, 123-138. doi:10.1007/s10648-010-91285

Van Merriënboer, J. J. G., \& Kirschner, P. A. (2007). Ten steps to complex learning. Mahwah, NJ: Lawrence Erlbaum Associates.

Wei, W., Yuan H., Chen, C., \& Zhou, X. (2012). Cognitive correlates of performance in advanced mathematics. British Journal of Educational Psychology, 82, 157-181. doi:10.1111/j.2044-8279.2011.02049.x 


\section{Chapter 3}

\section{Effects of Digital Learning Materials on Nursing Students' Mathematics Learning, Self-Efficacy, and Task Value in Vocational Education}

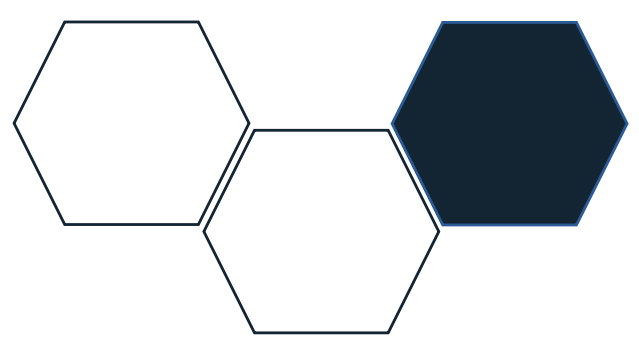

This chapter is published as: Zwart, D. P., Noroozi, O., Van Luit, J. E. H., \& Goei, S. L (2020). Effects of Digital Learning Materials on nursing students' mathematics learning, self-efficacy, and task value in vocational education. Nurse education in practice, 44: 102755. doi:10.1016/j.nepr.2020.102755

Authors contributions: J.E.H.V.L., O.N., S.L.G. and D.P.Z. conceptualized the research. D.P.Z. collected and analyzed the data; D.P.Z. wrote the original draft, visualized the results, and edited the paper; J.E.H.V.L., O.N., and S.L.G. critically reviewed the paper. 


\section{Abstract}

The use of digital environments in nursing education offers new opportunities for nursing students' medical mathematics learning. The aim of this study was to investigate the effects of Digital Learning Materials (DLMs) on nursing students' mathematics learning, self-efficacy, and task value. A pre-test/post-test control group design was used. Students were assigned to the DLMs group (experimental condition) or the face-to-face group (control condition). Students in both conditions completed the same assignments and discussed these with their peers and the (online) teacher via the discussion board or in the classroom setting. The results showed that the mathematics learning of students undergoing DLMs training and of those undergoing face-to-face training improved from the pretest to the post-test, but no significant differences were found between the two conditions. A significant interaction effect between condition and self-efficacy was reported, producing a large reduction in the self-efficacy of students in the DLMs condition and a small reduction in the self-efficacy of students in the face-to-face condition. No significant differences were found for students' task value. The study offers new insights for the future design of mathematics training with DLMs, focusing on students' appreciation of DLMs features, considering students with low and high learning abilities separately. 


\section{Introduction}

Nurses are expected to have an accurate knowledge of how to administer medication, especially the mathematical knowledge needed for the safe calculation of medication dosages (Weeks et al., 2013; Weeks, Lyne \& Torrance, 2000). Many training schemes and solutions have been invented to minimize errors in medication dosages; these include wearing a special 'do not disturb' smock while administering medication, or the mandatory 'check-double check' action (Actiz Health Organization, 2012). Although errors can occur at any stage from prescribing, dispensing, and administering to recording and reporting, it is recognized that nurses are the final line of defence (Adhikari, Tocher, Smith, Corcoran, \& MacArthur, 2014). Nurses' competencies in dose calculation are therefore of vital importance. These competencies are gained not only from the teaching of medical mathematics in the context of real-life situations, but also from the teaching of ordinary computational skills, such as the addition, subtraction, multiplication and division of whole numbers, decimals and fractions, and conversions between decimals and fractions (Stelzer, Richard's, Andrés, Vernucci, \& Introzzi, 2019; Weeks et al., 2000). Not every student is aware of the procedural knowledge that contains the items of declarative knowledge needed when solving problems step-by-step (Anderson \& Schunn, 2000; Ashcraft \& Krause, 2007; Daubert \& Ramani, 2019). In the long run, this procedural knowledge needs to be automatic so that it hardly needs any attention in future practice. So that nursing students do not lose track of the interconnections between regular computational and domain-specific medical mathematics skills, the teaching of these skills can be combined (Van Merriënboer \& Kirschner, 2007). One approach to this is via Digital Learning Materials (DLMs). DLMs offer possibilities for teaching mathematics that cannot be achieved by faceto-face delivery, such as place- and time-independent learning. Furthermore, DLMs offer more flexible and meaningful teaching by combining the teaching of regular and domainspecific medical mathematics with the support of instructional procedural and domainspecific clips, collaboration tools, and online guidance (Zwart, Van Luit, Noroozi, \& Goei, 2017). Students can benefit from this support, because DLMs are retrievable at any time and wherever students are located. This also allows students to solve medical mathematics problems during traineeships. The instructional procedural clips clarify pieces of declarative knowledge, such as facts about ordinary computational skills, and connect these with domain-specific clips that demonstrate mathematical assignments with medical contexts. The literature suggests that the use of DLMs has positive effects on various aspects of students' learning, motivation, etc. (e.g., De Mooij, Kirkham, Raijmakers, Van der Maas, \& Dumontheil, 2020; Mayer, 2014; Moreno, 2006; Passey, Goodison, Machell, \& McHugh, 2004). However, DLMs have not yet been used for nursing students' mathematics learning, or, in particular, for the teaching of both regular and medical mathematics skills in vocational education. This study, therefore, investigates the effectiveness of mathematics 
training with DLMs on nursing students' mathematics learning, task value and self-efficacy, comparing DLMs training with a traditional face-to-face method. Furthermore, students' appreciation of the various features of DLMs are investigated.

\section{Domain-specific knowledge and working memory load}

Nursing students in senior secondary vocational education need to understand the clinical source of, and the relationship between, the elements of dosage and rate formulae and equations when solving calculation problems (Weeks et al., 2013, p. e26). For this reason, the mathematical procedures must be identifiable: the students should learn cognitive and appropriate rules for developing the competencies necessary in complex care situations within their future jobs. Stelzer et al. (2019) refer to general and maths-specific conditions that foster mathematical conceptual knowledge. The domain-specific mathematical knowledge, defined by Alexander and Judy (1988) as declarative, procedural, and conditional knowledge, is the knowledge that nursing students must possess. To possess this knowledge, students need to memorize relevant information that can lead to action permitting the completion of specified tasks over indefinite periods of time (Tricot \& Sweller, 2014. p. 266). As numbers become larger and more complex, the use of automatic or memorized knowledge decreases, thus increasing the load on the working memory (Ashcraft \& Krause, 2007; Sweller, 2010). Working memory is important for mathematical performance (Alloway, Bible, \& Lau, 2013; Daubert \& Ramani, 2019; Wei, Yuan, Chen, \& Zhou, 2012). It is the capacity to store information over short periods (Baddeley, 1986). Peng, Namkung, Barnes and Sun (2016, p. 466) acknowledge that: "When students are knowledgeable in a particular domain, they can encode and retrieve information specific to it more efficiently than when they are less knowledgeable". As such, working memory integrates domain-specific skills, knowledge, and procedures to meet the particular demands of learning tasks within a specific domain. This implies that different mathematical skills may have different degrees of cognitive load.

\section{Cognitive load and students' learning abilities}

According to Sweller (2010), cognitive load in working memory comprises intrinsic, extraneous, and germane cognitive load. Intrinsic cognitive load cannot be altered because it has to do with the expertise of the learner. Extraneous cognitive load refers to the extra load of irrelevant and mostly useless activities during learning, while germane cognitive load refers to the relevant and useful activities engaged in by a learner while interacting with learning materials (Kollar et al., 2014; Sweller, 2010). Variations in students' learning, however, require teachers to adapt education to the needs of their students (Corno, 2008). This also applies to DLMs, which can tailor students' learning experiences (De Mooij et al., 2020). A task within the reach of students with average achievement levels may be impossible for students with lower achievement levels while, on the other hand, students 
with high achievement levels will already have mastered the task. Therefore, instructional approaches with DLMs should consider the variations in students' learning and decrease the extraneous load and increase the germane load for carrying out difficult tasks like mathematical calculations or solving complex problems (Noroozi, Busstra et al., 2012). To increase the germane load, instructional procedural knowledge clips and domain-specific knowledge clips with procedures, text and pictures from real life contexts can be used to teach mathematics. The instructional design with DLMs should align these instructional procedural knowledge clips to the domain-specific clips, making it possible to lower the extraneous cognitive load and increase the germane cognitive load (Kollar et al., 2014).

\section{Instructional design with DLMs}

DLMs offer educational opportunities that cannot be obtained through regular face-to-face forms of learning and instruction (Kalyuga \& Liu, 2015). DLMs can increase the effectiveness of instruction and offer a more diversified learning experience without the constraints of time and space (Chen, 2011; Lee \& Hung, 2015; Noroozi, Biemans, Weinberger, Mulder, \& Chizari, 2013). Despite this advantage, Zwart et al. (2017) acknowledge that the role of teachers is not to be underestimated. Teachers encounter technology related problems when supporting students' participation and collaboration online (Compton, 2009). These problems relate to the teachers' abilities to use software and hardware, and their communication skills for motivating students online and forging a group identity in the online community (Gray, 2004). DLMs with an online teacher can enhance the positive effects on perceived learning, but students and teachers are not always motivated to use DLMs for instructional practice (Wu, Tennyson, \& Hsia, 2010). This is a striking point since motivation is an important condition for engaging in learning processes in any educational context. Motivation is the internal state that initiates, maintains and energizes the learner's effort to engage in a learning process (Mayer, 2014, p. 171). Therefore, as with face-to-face learning, both teachers and students need to be motivated to generate a positive learning atmosphere within the DLMs context. One aspect that needs to be taken into account from motivational view when using DLMs is the selfefficacy of students (Huang, 2012).

\section{Self-efficacy}

Self-efficacy refers to the confidence of a learner when completing a task successfully (Bandura, 1986). Self-efficacy is correlated with academic achievement: Students feel more competent when they do well and value their tasks highly (Denissen, Zarrett, \& Eccles, 2007; Reichwein Zientek, Fong, \& Phelps, 2019). Self-efficacy can be enhanced by creating a learning environment that allows for collaboration and autonomy (Pekrun, 2006). In this context, care should be taken to ensure that the learning environment does not make too many demands on learners, as this might give rise to negative emotions. Wu 
et al. (2010) designate self-efficacy in e-learning environments as "computer self-efficacy" (p. 157). They state that computer self-efficacy influences performance expectations, which may, in turn, influence behaviour. This implies that students will be more motivated to learn and will benefit and learn more with DLMs when they become more confident and capable of learning with DLMs and more accustomed to doing so. Passey et al. (2004) found that DLMs had a motivational impact on engagement, but little research has been conducted on the motivational aspects of learning and DLMs: this has largely been neglected (Leutner, 2014; Mayer, 2014). Apart from self-efficacy in DLMs, appreciation of a task, or task value, also influences learning behaviour and academic results (Joo, Lim, \& Kim, 2013; Wigfield \& Eccles, 2000).

\section{Task value}

Task value is a concept that indicates the importance, usefulness or interest a student ascribes to a certain task (Wigfield \& Eccles, 2000). Motivational effort depends on the importance the student ascribes to completing the task. Andrews and Aikens (2019) report that students who gave a high utility task value to mathematics in the context of biology were more interested in using mathematics to understand biology. Van der Veen and Peetsma (2009) show that students ascribing a high task value to a task were more motivated than students giving it a low task value. Joo et al. (2013) state that task value is a predictor of student satisfaction with the task. Denissen et al. (2007) found that task value is positively related to perceived competence. There is no empirical scientific literature on how DLMs will impact task value and self-efficacy. Affective aspects, such as motivation and emotion, have largely been neglected in research on online environments such as DLMs (Leutner, 2014; Mayer, 2014). Therefore, this study aims to explore the effects of DLMs on learning outcomes, self-efficacy, and task value in nursing mathematics in secondary vocational education.

\section{The objectives and research questions}

This study aims to investigate the effects on learning outcomes, self-efficacy, and task value of solving medical mathematics problems with DLMs training. A pre-test/post-test control group design was used. Students were assigned to the DLMs training group (experimental condition) or the face-to-face training group (control condition). Furthermore, this study explores the differences between students with high and low learning abilities, and what they appreciate about the DLMs features. The following research questions are formulated to address these issues:

1. What are the differences between DLMs training and face-to-face training in relation to the mathematics learning of nursing students in vocational education?

2. What are the differences between DLMs training and face-to-face training in relation to nursing students' self-efficacy in vocational education? 
3. What are the differences between DLMs training and face-to-face training in relation to nursing students' task value in vocational education?

4. What are the differences between students with high learning abilities (highest $25 \%$ ) and students with low learning abilities (lowest 25\%) in relation to their appreciation of the features of DLMs?

\section{Method}

Context and participants

This study took place at a regional senior secondary vocational education school in the Netherlands. Senior secondary vocational education comprises programmes on four qualification levels, ranging from level 1 to level 4 of the European Qualification Framework (Baartman \& De Bruijn, 2011, p. 126). Students obtain a qualification by learning in school and in the workplace. Students with a level 4 qualification can enter Bachelor's programmes in higher professional education. In this study, the focus is on the learning of level 4 students. The participants were first-year nursing students $(\mathrm{N}=39$ ). Nursing students are challenged to achieve an adequate level in two separate courses: mathematics and specific medical mathematics. These two complementary subjects are required to accomplish the learning task in this study successfully. The students were divided into two groups: the experimental group (DLMs condition) and the control group (face-to-face condition). The DLMs condition consisted of 28 students who attended Monday mathematics lessons. The face-to-face condition consisted of 11 students who attended Wednesday mathematics lessons. Only these classes were available because of central timetabling, which explains the discrepancy in the numbers of students. All the participants were female. The mean age was $18.8(\mathrm{SD}=2.93)$ for the students in the DLMs condition and 18.5 (SD = 3.59) for the students in the face-to-face condition. Although the students in the face-to-face condition ( $M=50.70, S D=3.58)$ generally scored higher than the students in the DLMs condition $(M=48.00, S D=4.16)$ in terms of their learning abilities, this difference was not significant: $t(37)=-1.91, p=.05$. The teacher was the same for both conditions: he was male, aged 37, with a Master's in mathematics for senior secondary vocational education and five years of professional experience in this education sector.

Materials and learning tasks

The mathematics topic was measurement and geometry. Measurement relates to the control of real things, finding answers to questions like how big or heavy something is or how long something lasts. Geometry involves problem-solving and reasoning about shape, size, the relative position of figures, and the properties of space (see Peng et al., 2016, p. 458). Students in both the DLMs condition and the face-to-face condition were offered the same learning activities and mathematics assignments. 
Digital learning materials (DLMs)

DLMs were designed and used in this study on a web-enabled platform (Wikispaces) and consisted of the following features: structured content, goals, assignments, procedural knowledge clips, instructional domain-specific clips, and a discussion board. The focus of the learning content with DLMs was structured for each week. Instructional procedural knowledge clips and domain-specific clips were present, so that there could be a focus on the relationships between the mathematical elements (see Fig. 1). There was a discussion board for students to work together and ask questions about the mathematics assignments prescribed by the teacher. For more detail, see Zwart et al. (2017).

\section{Procedure and measurements}

Overall, the experimental session consisted of four main phases (see Table 1). During (1) the introduction and personal data phase, which took $45 \mathrm{~min}$, students read the introduction letter about the ethical aspects of research study for $5 \mathrm{~min}$. Then the teacher explained the procedure, materials, and the purpose of the research study for about 30 min. They were then asked to complete a questionnaire on their personal data (10 $\mathrm{min}$ ). During (2) the individual pre-test measurements phase (in total $95 \mathrm{~min}$ ), students first received an introductory explanation of how to answer different questions of various surveys on self-efficacy, task-value, domain-specific mathematical knowledge, and the non-verbal abilities test ( $5 \mathrm{~min}$ ). Students were then given $15 \mathrm{~min}$ to fill in the surveys on self-efficacy and task-value. After a 10-min break, they were tested on their domainspecific mathematical knowledge (30 $\mathrm{min}$ ) followed by the non-verbal abilities test which took $45 \mathrm{~min}$. Then (3) the learning phase began. This phase for both conditions took about $60 \mathrm{~min}$ for six consecutive weeks. The method of delivery was the only difference between the two conditions. During (4) the post-tests and debriefing phase (60 min), students were first tested on their domain-specific mathematical knowledge (30 min) followed by a 15 min assessment on their self-efficacy and task-value measurements. As an extra activity, students in the DLMs condition were also asked to fill in a survey on their satisfaction with the use of DLMs and their learning experiences and outcomes (10 min). Finally, students received a short debriefing for about $5 \mathrm{~min}$.

Method of delivery via face-to-face classes

Students in the face-to-face condition were taught face-to-face mathematics lessons as usual in the classroom for $1 \mathrm{~h}$ a week for six consecutive weeks. The teacher was present in all sessions and students could ask questions in a regular manner when solving mathematical problems. Teacher delivered instruction as usual when needed and students had the opportunity to interact with their fellow students and the teacher. 


\section{Method of delivery via DLMs}

Students in the DLMs condition were taught with DLMs for one hour a week for six consecutive weeks. In this condition, students carried out assignments, watched instructional clips, and collaborated online with other students and their online teacher when solving mathematical problems. In this condition, an online teacher was available to answer any question related to the mathematical problems or the functionalities of the DLMs.

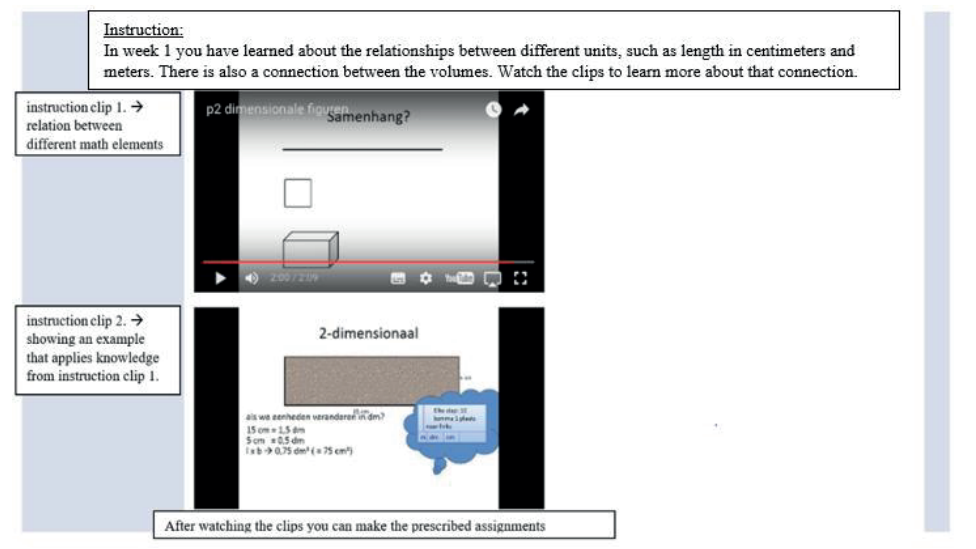

Figure 1. Instructional clips that demonstrate the relationship between mathematical elements.

Measurement of students' learning outcomes

The students took a standardized mathematics test (Startrekenen, Lagendijk et al., 2013). The test consisted of tasks with text and pictures about domain-specific knowledge of geometry. Students could score a maximum of 37 points on the test. The test is validated and used as a school-based formative assessment.

Measurement of students' learning abilities

The Raven test was used to measure students' level of general nonverbal intelligence; this test takes into account both innate factors and acquired skills (Alloway and Alloway, 2010; Raven, Court, \& Raven, 1992). Lovett and Forbus (2017) state that the Raven test is the best predictor of fluid intelligence and a good predictor of mathematical ability. The test consists of 60 items divided into five sets of 12 items each, ranging from easy to complex (subtests: A, B, C, D, and E). Each item consists of a figure with a missing piece. Below the figure, there are six or eight answers that might be the missing piece. Only one answer is correct. The reliability score of the test in this study was average (Cronbach's $a=.60$ ). The test was handed out on paper. There was no time limit on the test; completing the test in this study took between 45 and $60 \mathrm{~min}$. 
Measurement of students' self-efficacy and task value

The students' self-efficacy and task value were measured using the Global Math Motivation Questionnaire for Children (Prast, Van de Weijer, Miocevic, Kroesbergen, \& Van Luit, 2018). The questionnaire was adjusted for secondary vocational education students. Cronbach's alpha for the 15 items of this questionnaire was .78. Although this can be considered adequate, a closer examination of the total statistics for the questionnaire items indicated that the alpha would increase to .84 if item 2 were removed. This item asked students to rate the following sentence: "I make many mistakes in mathematics". Consequently, this item was removed from the questionnaire, and all subsequent analyses were based on the remaining 14 items. Finally, the Cronbach's alphas (with item 2 deleted) were .88 for selfefficacy and .78 for task value. The answers were given on a four-point Likert scale. High scores meant that working with DLMs fostered students' self-efficacy and that students appreciated the task with DLMs (task value).

Measurement of students' appreciation of the features of DLMs

We set up a questionnaire for students in the experimental condition with items reflecting their appreciation of the features of DLMs: the structure of the website (e.g., general expectations), the goals, the procedural knowledge clips, the domain-specific clips, the assignments, and the discussion board. This questionnaire consisted of 45 items with a five-point Likert scale ranging from fully disagree to fully agree. The reliability measurement for this questionnaire was high (Cronbach's $a=.96$ ).

Analyses

A mixed ANOVA for repeated measurement was conducted to determine the changes from pre-test to post-test and to see if there were any differences between the scores of the nursing students in the DLMs and face-to-face conditions in terms of learning mathematics and self-efficacy. An ANOVA was conducted to compare the mean differences between students in the two conditions in terms of task value. Furthermore, for students in the DLMs condition, we divided the students' learning abilities $(M=48.00, S D=4.16$, Min $=$ $39.00, \operatorname{Max}=55.00)$ into the lowest $25 \%$ of scores $(M=43.10, S D=2.47)$ and the highest $25 \%$ of scores $(M=52.50, S D=1.60)$, and conducted an ANOVA to test whether the appreciation of the DLMs features was different for these groups.

\section{Ethics}

The Faculty Ethics Review Committee (FETC) of the Faculty of Social Sciences of Utrecht University reviewed and approved this research study with respect to ethical implications which was registered under the number 19-230. The FETC promotes, monitors, and tests ethical conduct in scientific research. This committee assumes that research at the Faculty of Social Sciences of Utrecht University is carried out in an ethically responsible manner, 
following the applicable codes of conduct and professional codes and (European, national, and international) legislation and regulations. To comply with the ethical aspects, two weeks before the intervention, students received a letter in which they were informed that the results of this study will be used for research purposes. With this letter, students were given the opportunity to decline to participate in this research study. No student declined to participate in the research study. Students were assured that identifying information was not available to anyone, except for researchers. Results were de-identified by numbering the students and their test results both in the pre-tests and in the post-tests. This implies that student's data and results were treated confidentially meaning that no one could link the results to any individual student.

\section{Results}

Results for students' mathematics learning outcomes

The average scores for the nursing students' mathematics learning outcomes improved significantly in both the DLMs condition (M T1 $=19.12$, SD T1 $=8.82 ; \mathrm{M} \mathrm{T2}=26.15, \mathrm{SD}$ $\mathrm{T} 2=7.99)$ and the face-to-face condition $(\mathrm{M} \mathrm{T} 1=17.70, \mathrm{SD} T 1=7.12 ; \mathrm{M} \mathrm{T} 2=27.80$, $\mathrm{SD} \mathrm{T2}=7.61)$ from pre-test to post-test, $F(1,34)=42.83, \mathrm{p}<.001, \eta 2=.56$. No significant difference was found between the two conditions, $F(1,34)=33.85, p=.25$.

Results for students' self-efficacy outcomes

A significant main effect was obtained regarding the students' self-efficacy scores $F(1,36)$ $=16.56, \mathrm{p}<.001, \mathrm{\eta} 2=.32$. The average scores of the nursing students' self-efficacy decreased from the pre-test $(M=12.03, S D=2.97)$ to the post-test $(M=13.42, S D=$ 2.34). There was no significant difference between the two conditions, $F(1,36)=3.56, p$ $=.07$. However, a significant interaction between condition and self-efficacy was reported, $F(1,36)=7.35, p<.05, \eta 2=.17$. Examination of the means indicated that the intervention produced a large reduction in the self-efficacy of nursing students in the DLMs condition from pre-test $(M=13.15, S D=2.54)$ to post-test $(M=11.33, S D=3.09)$, and a small reduction in the self-efficacy of nursing students in the face-to-face condition from pre-test $(M=14.09, S D=1.70)$ to post-test $(M=13.73, S D=1.85)$.

Results for students' task value outcomes

No significant main effect was obtained for the results for task value, $F(1,36)=1.15, p<$ .29. The results for task value were almost equal in the pre-test $(M=20.45, S D=3.78)$ and the post-test $(M=20.03, S D=3.66)$. No significant differences were found between the two conditions, $F(1,36)=.36, \mathrm{p}=.74$.

Differences in appreciation of DLMs between students with high and low learning abilities 
Students in the low and high learning ability groups differed in their appreciation of the DLMs features (see Table 1). The DLMs feature 'domain-specific clips' obtained a statistically significant result: students with high learning abilities appreciated the domainspecific instructional clips significantly more than students with lower learning abilities: $\mathrm{F}(1,15)=6.44, \mathrm{p}=.02, \mathrm{\eta} 2=.30$. For the remainder of the DLMs features, no significant differences were found: structure $F(1,15)=.67, p=.43, \eta 2=.04$; goals $F(1,15)=.64$, $\mathrm{p}=.44, \mathrm{\eta} 2=.04$; procedural knowledge clips $\mathrm{F}(1,15)=3.59, \mathrm{p}=.08, \mathrm{\eta} 2=.19$; assignments $F(1,15)=1.24, p=.28, \eta 2=.08$; and discussion board $F(1,15)=.97, p$ $=.34, \mathrm{\eta} 2=.06$.

Table 1

Nursing Students' Raven Scores, Mathematics test Scores and Scores for Appreciation of DLMs Features

\begin{tabular}{|c|c|c|c|c|c|c|c|c|c|c|c|c|}
\hline \multirow[t]{2}{*}{ Measure } & \multicolumn{4}{|c|}{$\begin{array}{l}\text { Total experimental } \\
\text { group }\end{array}$} & \multicolumn{4}{|c|}{$\begin{array}{c}\text { Group Low } \\
\qquad N=9\end{array}$} & \multicolumn{4}{|c|}{$\begin{array}{c}\text { Group High } \\
\qquad N=8\end{array}$} \\
\hline & M & SD & Min & $\operatorname{Max}$ & M & SD & Min & $\operatorname{Max}$ & M & SD & Min & Max \\
\hline $\begin{array}{l}\text { Cognitive } \\
\text { abilities }\end{array}$ & 48.0 & 4.2 & 39.0 & 55.0 & 43.1 & 2.5 & 39.0 & 46.0 & 52.5 & 1.6 & 51.0 & 55.0 \\
\hline Pretest & 18.8 & 8.8 & 3.0 & 36.0 & 17.8 & 9.6 & 3.0 & 29.0 & 20.9 & 7.0 & 11.0 & 34.0 \\
\hline Posttest & 25.8 & 8.0 & 13.0 & 38.0 & 26.4 & 9.3 & 13.0 & 38.0 & 27.1 & 7.6 & 15.0 & 38.0 \\
\hline Structure & 33.3 & 9.8 & 15.0 & 49.0 & 32.4 & 9.6 & 15.0 & 46.0 & 36.0 & 8.1 & 25.0 & 49.0 \\
\hline Goals & 12.3 & 3.1 & 4.0 & 17.0 & 11.9 & 3.6 & 4.0 & 16.0 & 13.0 & 1.6 & 11.0 & 15.0 \\
\hline Clips Pre-req & 18.1 & 4.8 & 8.0 & 27.0 & 15.6 & 4.1 & 8.0 & 20.0 & 19.3 & 3.9 & 14.0 & 26.0 \\
\hline Clips Domain & 23.6 & 6.9 & 8.0 & 35.0 & 20.2 & 6.3 & 10.0 & $31.0 *$ & 26.9 & 4.1 & 23.0 & $35.0 *$ \\
\hline Assignments & 27.5 & 4.7 & 15.0 & 36.0 & 25.9 & 4.5 & 15.0 & 30.0 & 28.4 & 4.7 & 22.0 & 36.0 \\
\hline Discussionboard & 17.6 & 4.5 & 10.0 & 25.0 & 16.9 & 4.7 & 10.0 & 24.0 & 19.1 & 4.7 & 11.0 & 25.0 \\
\hline
\end{tabular}

\section{Discussion}

The present study investigated the effects of DLMs teaching on mathematics learning outcomes, self-efficacy, and task value for first-year nursing students in vocational education, with a pre-test/post-test control group design. Students were assigned to the DLMs training group (experimental condition) or the face-to-face training group (control condition). The appreciation of DLMs features by students with low and high learning abilities was compared as well. With regard to the first research question, we can conclude that both the DLMs training and the face-to-face training conditions enhanced nursing students' mathematics learning. Nursing students' understanding of the relationship between the different mathematical elements necessary for doing calculations in medical situations was especially emphasized in the DLMs training via the instructional clips; the procedural knowledge clips clarified facts from ordinary computational skills and connected them with the assignments in the instructional domain-specific clips. Since these 
instructional clips were retrievable at any time and in any location, nursing students were able to watch these demonstrations on how to apply procedures to mathematical problems over and over again. As a result, it was expected that nursing students from the DLMs training would be more capable of making connections between ordinary computational and domain-specific skills, and thus would be more likely to improve their mathematics learning, than nursing students from the face-to-face training who received their instruction only once a week in a classroom setting (Chen, 2011; Lee \& Hung, 2015; Noroozi et al., 2013; Zwart et al., 2017). In contrast to these expectations, no significant difference was found between the two conditions. However, we should bear in mind that students in the face-to-face condition $(M=50.7, S D=3.58)$ tended to have higher scores for their learning abilities than students in the DLMs condition $(M=48.0, S D=4.16$ ). Concerning research question two, we found that students' self-efficacy decreased after the intervention. Pekrun (2006) states that learning environments that allow for collaboration and autonomy enhance self-efficacy. That might be the case in classroom settings, but in this study the online DLMs training showed the opposite effect. According to social cognitive theory (Wu et al., 2010, p. 157): Individuals form their perceptions of self-efficacy towards a task based on cue they receive from four information sources: (1) by past experience and familiarity with similar activities, (2) through vicarious learning, (3) with social support and encouragement, and (4) through attitude toward the task. One plausible explanation for the decrease in students' self-efficacy is that the learning environment with DLMs demanded too much from these nursing students, since it was their first online education experience, and they were not familiar with the instructional activities in the DLMs training. Online education requires self-directed learning from the individual student and also online interaction with other peers and the online teacher. This shared regulation of interaction and collaboration needs task conditions such as quality criteria or criteria for the completion of tasks (Hadwin, Järvelä, \& Miller, 2011). These conditions were not clearly communicated beforehand. Perhaps the DLMs features demanded too much from the nursing students and thus gave rise to negative emotions (Pekrun, 2006). With regard to the third research question, in contrast to several previous studies (e.g., Andrews \& Aikens, 2019; Denissen et al., 2007; Joo et al., 2013; Van der Veen \& Peetsma, 2009; Wigfield \& Eccles, 2000), the students' task value scores showed no significant difference between the DLMs training group and the face-to-face training group. Again, it should be noted that this was the first attempt by these students to work with DLMs in a real educational setting. Students will be more motivated to learn, and will benefit more and learn more, when they become more confident and capable of learning with DLMs and more accustomed to doing so (Wu et al., 2010). For this reason, teachers' online communication skills to motivate students for mathematics tasks with DLMs should not be underestimated (Gray, 2004; Zwart et al., 2017). With regard to the fourth research 
question, the results showed that the students with higher learning abilities, based on the Raven test, appreciated the instructional domain-specific clips DLMs feature more than students with lower learning abilities. Moreover, we discovered that 19 per cent of all the variability in the differences in the appreciation of DLMs features by students with high and low learning abilities was explained by the DLMs feature of instructional procedural knowledge clips. It seems that students with low learning abilities find it more difficult to engage when they are interacting with learning materials, which increases their extraneous load and thus their working memory load (Kollar et al., 2014; Sweller, 2010). In educational classroom settings, students rely heavily on their teacher's affirmations, and consequently do not build their own starting points for evaluation (Baldwin, 1967). Since these affirmations are related to the teacher, his proximity and attention is, in itself, confirmatory for students. Students' dependence can lead to fear if the teacher is absent. As a consequence, students find it difficult to break through their own learning and studying patterns in relation to their expectations of both their teacher and the other students.

\section{Conclusion}

Overall, this study showed that nursing students became less confident during a period of learning with DLMs, although their confidence did not affect their mathematics learning. If we want to create more flexible learning activities with DLMs that engage nursing students and encourage them to participate actively in DLMs training for present and future (lifelong) learning, certain aspects should be taken into account. First, starting points should be provided to students that enable them to support their own online evaluation. Secondly, there should be task conditions that are discussed beforehand and that describe the quality criteria for assignments or criteria for completion of tasks. Thirdly, the teacher and the students should not only discuss the assignments but should also share rules and come to an agreement on online collaboration and online interaction. Finally, the teacher's online role should not only encourage feedback for finishing assignments but also support students socially for their sense of efficacy. Another point that can enhance computer selfefficacy is to move DLMs forward to a more virtual-based learning environment. According to Xinhao and Fengfeng (2016) virtual-based learning can foster affective, behavioural and cognitive engagement. Many problem-solving scenarios can be designed that enable active interactions with the content and enhance knowledge acquisition and transfer.

\section{Limitations}

This study had a small sample of participants, especially in the control group. This might limit the generalizability of the findings of the study and might lead to strong claims that are based only on coincidence. This would imply that the findings of this study should be treated cautiously. We did not control for the various nursing students' needs or the communication skills of the teacher in motivating the students online. Furthermore, we did 
not count for the actual level of engagement especially for the students in the DLMs condition. For example, we did not collect information on the extent to which students used various features of the DLMs, and the number of clicks on these features. Replication of this study with more nursing students and measuring their levels of engagement by checking their activities in the DLMs would be needed to confirm the results of this study. Therefore, a future study should also target second- and third-year nursing students to see to what extent similar or different results are obtained.

\section{References}

Adhikari, R., Tocher, J., Smith, P., Corcoran, J., \& MacArthur, J. (2014). A multi-disciplinary approach to medication safety and the implication for nursing education and practice. Nurse Education Today, 34, 185-190. doi:10.1016/j.nedt.2013.10.008

Actiz Health Organization. (2012). Veilige principes in de medicatieketen [Safety principles in chain of medication]. Retrieved from

https://www.zorgvoorbeter.nl/docs/PVZ/vindplaats/medicatieveiligheid/veiligeprincipes-in-de-medicatieketen.pdf

Alexander, P. A., \& Judy, J. E. (1988). The interaction of domain-specific and strategic knowledge in academic performance. Review of Educational Research, 58, 375-404.

Alloway, T. P., \& Alloway, R. G. (2010). Investigating the predictive roles of working memory and IQ in academic attainment. Journal of Experimental and Child Psychology, 106, 20-29. doi:10.1016/j.jecp.2009.11.003

Alloway, T. P., Bibile, V., \& Lau, G. (2013). Computerized working memory training: Can it lead to gains in cognitive skills in students? Computers in Human Behavior, 29, 632-638. doi:10.1016/j.chb.2012.10.023

Anderson, J. R., \& Schunn, C. D. (2000). Implications of the ACT-R learning theory: No magic bullets. In R. Glaser (Ed.), Advances in instructional psychology, Educational design and cognitive science (Vol. 5, pp. 1-33). Mahwah, NJ: Lawrence Erlbaum.

Ashcraft, M. H., \& Krause, J. A. (2007). Working memory, math performance, and math anxiety. Psychonomic Bulletin \& Review, 14, 243-248. doi:10.3758/BF03194059

Baartman, L. K. J., \& De Bruijn, E. (2011). Integrating knowledge, skills, and attitudes: Conceptualizing learning processes towards vocational competence. Educational Research Review, 6, 125-134. doi:10.1016/j.edurev.2011.03.001

Baddeley, A. D. (1986). Working memory. New York, NY: Oxford University Press.

Baldwin, A. L. (1967). Theories of child development. New York, NY: John Wiley and Sons. Bandura, A. (1986). Social foundations of thought and action: A social cognitive theory. 
Englewood, NJ: Prentice-Hall.

Chen, J.-L. (2011). The effects of education compatibility and technological expectancy on e-learning acceptance. Computers \& Education, 57, 1501-1511. doi: 10.1016/j.compedu.2011.02.009

Compton, L. K. L. (2009). Preparing language teachers to teach language online: A look at skills, roles, and responsibilities. Computer Assisted Language Learning, 22, 73-99. doi: 10.1080/09588220802613831

Corno, L. (2008). On teaching adaptively. Educational Psychologist, 43, 161-173. doi: $10.1080 / 00461520802178466$

De Mooij, S. M. M., Kirkham, N. Z., Raijmakers, M. E. J., Van der Maas, H. L. J., \& Dumontheil, I. (2020). Should online math learning environments be tailored to individuals' cognitive profiles? Journal of Experimental Child Psychology, 19:104730. doi:10.1016/j.jecp.2019.104730

Denissen, J. J. A., Zarrett, N. R., \& Eccles, J. S. (2007). I like to do it, I'm able, and I know I am: Longitudinal couplings between domain-specific achievement, self-concept, and interest. Child Development, 78, 430-437. doi:10.1111/j.14678624.2007.01007.x

Gray, B. (2004). Informal learning in an online community of practice. Journal of Distance Education, 19, 20-35.

Hadwin, A. F., Järvelä, S., \& Miller, M. (2011). Self-regulated, co-regulated, and socially shared regulation of learning. In B. J. Zimmerman \& D. H. Schunk (Eds.), Handbook of self-regulation of learning and performance (pp. 65-84). New York, NY: Routledge.

Huang, C. (2012). Discriminant and incremental validity of self-concept and academic selfefficacy: A meta-analysis. Educational Psychology, 32, 777-805. doi: $10.1080 / 01443410.2012 .732386$

Joo, Y. J., Lim, K. Y., \& Kim, J. (2013). Locus of control, self-efficacy, and task value as predictors of learning outcome in an online university context. Computers \& Education, 62, 149-158. doi:10.1016/j.compedu.2012.10.027

Kalyuga, S., \& Liu, T. C. (2015). Guest editorial: Managing cognitive load in technologybased learning environments. Educational Technology \& Society, 18, 1-8. http://www.jstor.org/stable/jeductechsoci.18.4.1

Kollar, I., Ufer, S., Reichersdorfer, E., Vogel, F., Fischer, F., \& Reiss, K. (2014). Effects of collaboration scripts and heuristic worked examples on the acquisition of mathematical argumentation skills of teacher students with different levels of prior 
achievement. Learning and Instruction, 32, 22-36.

doi:10.1016/j.learninstruc.2014.01.003.

Lagendijk, R., Schaap, K., De Wit, P., Kramer, M., Lugten, I., Wolters, S., ... Wynia, R. (2016). Startrekenen [Starting mathematics]. Amersfoort, The Netherlands: Deviant.

Lee, L.-T., \& Hung, J. C. (2015). Effects of blended e-learning: A case-study in higher education tax learning setting. Human-centric Computing and Information Sciences, 5, 1-15. doi:10.1186/s13673-015-0024-3

Leutner, D. (2014). Motivation and emotion as mediators in multimedia learning. Learning and Instruction, 29, 174-175. doi:10.1016/j.learninstruc.2013.05.004

Lovett, A., \& Forbus, K. (2017). Modeling visual problem solving as analogical reasoning. Psychological Review, 124, 60-90. doi:10.1037/rev0000039

Mayer, R. E. (2014). Incorporating motivational learning into multimedia learning. Learning and Instruction, 29, 171-173. doi:10.1016/j.learninstruc.2013.04.003

Moreno, R. (2006). Does the modality principle hold for different media? A test of the method-affects-learning hypothesis. Journal of Computer Assisted Learning, 22, e149-e158. doi:10.1111/j.1365-2729.2006.00170.x

Noroozi, O., Biemans, H. J. A., Weinberger, A., Mulder, M., \& Chizari, M. (2013). Scripting for construction of a transactive memory system in multidisciplinary CSCL environments. Learning and Instruction, 25, 1-12. doi:10.1016/j.learninstruc.2012.10.002

Noroozi, O., Busstra, M. C., Mulder, M., Biemans, H. J. A., Tobi, H., Geelen, M. M. E. E., ..., Chizari, M. (2012). Online discussion compensates for suboptimal timing of supportive information presentation in a digitally supported learning environment. Educational Technology Research and Development, 60, 193-221. doi: $10.1007 /$ s11423-011-9217-2

Passey, D., Goodison, R., Machell, J., \& McHugh, G. (2004). The motivational effect of ICT on pupils. Lancaster University, Department of Educational Research. Retrieved from

http://downloads01.smarttech.com/media/research/international_research/uk/lan caster_report.pdf

Pekrun, R. (2006). The control-value theory of achievement emotions: assumptions, corollaries, and implications for educational research and practice. Educational Psychology Review, 18, 315-341. doi:10.1007/s10648-006

Peng P., Namkung, J., Barnes, M., \& Sun, C. (2016). A meta-analysis of mathematics and 
working memory: Moderating effects of working memory domain, type of mathematics skill, and sample characteristics. Journal of Educational Psychology, 108, 455-473. doi:10.1037/edu0000079

Prast, E. J., van de Weijer, E., Miocevic, M., Kroesbergen, E. H., \& Van Luit, J. E. H. (2018). Relations between mathematics achievement and motivation in students of diverse achievement levels. Contemporary Educational Psychology, 55, 84-96. doi:10.1016/j.cedpsych.2018.08.002

Raven, J. C., Court, J. H., Raven, J. (1992). Standard Progressive Matrices (1992 Edition). Oxford, UK: Oxford Psychologists Pres.

Reichwein Zientek, L., Fong, C. J., \& Phelps, J. M. (2019). Sources of self-efficacy of community college students enrolled in developmental mathematics. Journal of Further and Higher Education, 43, 183-200. doi:10.1080/0309877X.2017.1357071

Stelzer, F., Richard's, M. M., Andrés, M. L., Vernucci, S., \& Introzzi, I. (2019). Cognitive and maths-specific predictors of fraction conceptual knowledge. Educational Psychology, 41(2), 172-190. doi:10.1080/01443410.2019.1693508

Sweller, J. (2010). Element interactivity and intrinsic, extraneous, and germane cognitive load. Educational Psychology Review, 22, 123-138. doi:10.1007/s10648-010-91285

Tricot, A., \& Sweller, J. (2014). Domain-specific knowledge and why teaching generic skills does not work. Educational Psychology Review, 26, 265-283. doi:10.1007/s10648013-9243-1

Van der Veen, I., \& Peetsma, T. (2009). The development in self-regulated learning behavior of first- year students in the lowest level of secondary school in the Netherlands. Learning and Individual Differences, 19, 34-46. doi:10.1016/j.lindif.2008.03.001

Van Merriënboer, J. J. G., \& Kirschner, P. A. (2007). Ten steps to complex learning. New York, NY: Routledge.

Weeks, K. W., Hutton, B. M., Young, S., Coben, D., Clochesy, J. M., \& Pontin, D. (2013). Safety in numbers 2: Competency modelling and diagnostic error assessment in medication dosage calculation problem-solving. Nurse Education in Practice, 13, e23-e32. doi:10.1016/j.nepr.2012.10.013

Weeks, K. W., Hutton, B. M., Young, S., Coben, D., Clochesy, J. M., \& Pontin, D. (2013b). Safety in numbers 3: Authenticity, Building knowledge \& skills and Competency development \& assessment: the $A B C$ of safe medication dosage calculation 
problem-solving pedagogy. Nurse Education in Practice, 13, e23-e26. doi: $10.1016 /$ j.nepr.2012.10.013

Weeks, K. W., Lyne, P., \& Torrance, C. (2000). Written drug dosage errors made by students: The threat to clinical effectiveness and the need for a new approach. Clinical Effectiveness in Nursing, 4, e20-e29. doi:10.1054/cein.2000.0101

Wei, W., Yuan, H., Chen, C., \& Zhou, X. (2012). Cognitive correlates of performance in advanced mathematics. British Journal of Educational Psychology 82, 157-181. doi:10.1111/j.2044-8279.2011.02049.x

Wigfield, A., \& Eccles, J. S. (2000). Expectancy-value theory of achievement motivation. Contemporary Educational Psychology, 25, 68-81. doi:10.1006/ceps.1999.1015

Wu, J.-H., Tennyson, R. D., \& Hsia, T-L. (2010). A study of student satisfaction in a blended e-learning system environment. Computers \& Education, 55, 155-164. doi: 10.1016/j.compedu.2009.12.012

Xinhao, X., \& Fengfeng, K. (2016). Designing a virtual-reality-based, gamelike math learning environment. American Journal of Distance Education, 30, 27-38. doi: $10.1080 / 08923647.2016 .1119621$

Zwart, D. P., Van Luit, J. E. H., Noroozi, O., \& Goei, S. L. (2017). The effects of digital learning material on students' mathematics learning in vocational education. Cogent Education, 4: 1313581. doi:10.1080/2331186X.2017.1313581 


\section{Chapter 4}

\section{The Effects of Computer-Based Virtual Learning Environments on Nursing Students' Mathematical Learning in Medication Processes}

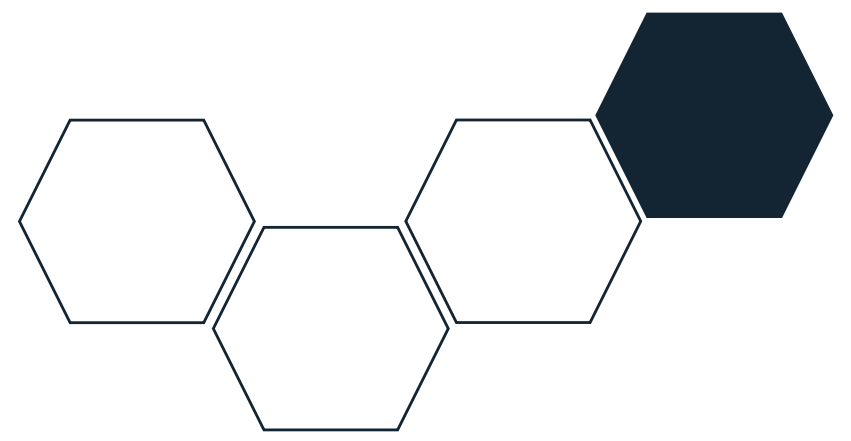

This chapter is published as: Zwart, D. P., Goei, S. L., Noroozi, O., \& Van Luit, J. E. H. (2021). Effects of Computer-Based Virtual Learning Environments on Nursing Students' Mathematical Learning in Medication Processes. Research and Practice in Technology Enhanced Learning, 16: 4. doi:10.1186/s41039-021-00147-x

Authors contributions: J.E.H.V.L., O.N., S.L.G. and D.P.Z. conceptualized the research. D.P.Z. collected and analyzed the data; D.P.Z. wrote the original draft, visualized the results, and edited the paper; J.E.H.V.L., O.N., and S.L.G. critically reviewed the paper. 


\section{Abstract}

Computer-based virtual learning environments (CBVLEs) are potentially useful teaching tools for training nursing students in professional duties such as the mathematical tasks associated with medication processes. In this study, a CBVLE was designed with wellstructured instructional activities such as interleaved practice and feedback. Mathematical medication scenarios and basic arithmetic exercises were integrated into the CBVLE. Four training conditions were used in the CBVLE to facilitate extra support for mathematical medication learning: (1) learning without worked examples, (2) learning with worked examples involving domain-specific knowledge, (3) learning with worked examples involving regular thinking strategies, and (4) learning with combined worked examples. This study was conducted with 118 nursing students enrolled in post-secondary nursing education and Bachelor's nursing programs. Students were pre-tested and post-tested on their mathematical medication learning. Training in the CBVLE improved mathematical medication learning for all students from pre-test to the post-test stages, but no differences were found among the four different conditions. Nursing students' prior knowledge, nonverbal intelligence, and number of correct tasks predicted mathematical medication learning outcomes. When controlling for non-verbal intelligence, students in the condition 1 benefited more than students in condition 3 in terms of their mathematical medication learning outcomes. The same accounted for the support of the low-achieving students in the CBVLE. The support conditions for the high-achieving group appeared to be unimportant for mathematical medication learning. It seems that technology is taken over some of the capacity of working memory, which accounts for the benefits to the lowachieving learners. 


\section{Introduction}

Nursing students are trained in mathematical medication skills for future high-risk professional care situations in which they will need to check, prepare, distribute, administer, and evaluate medication for patients. These are important skills, and even a simple mistake could create serious complications for the patient (Prins, Zwart, Voogt, \& Hettinga, 2019). The medication process is complex and involves the application of theoretical knowledge of medicines, administration of medications, communication, hygiene, and calculation of dosages. The latter requires a conceptual understanding, since it involves knowledge about the underlying unifying principles (Canobi, 2009). To train for this complexity and the challenges of conceptual understanding, nursing students' skills in terms of these high-risk professional practices can be trained using a lifelike computerbased virtual learning environment (CBVLE). This is a simulated environment specifically designed to contain a variety of mathematical medication scenarios and basic computational arithmetic exercises that visualise the underlying unifying mathematical principles that students need to apply when solving complex mathematical medication tasks (Wang, Kirschner, Spector, \& Ge, 2018).

In a CBVLE, numerous of different kinds of mathematical medication problems can be offered, so that students can train for interleaved practice (Dunlosky, Rawson, Marsh, Nathan, \& Willingham, 2013; Rohrer, Dedrick, \& Burgress, 2014; Rohrer, Dedrick, \& Stershic, 2015). In interleaved practice, students are trained on different types of problems over time. This requires students to make connections between the various problems, and thus provides a broader knowledge base that allows them to grasp the procedure for solving different domain-specific types of maths problems. When students make mistakes while solving problems, feedback is provided by giving the correct answer accompanied by domain-specific mathematical rules (Dunlosky et al., 2013; Hattie \& Timperly, 2007). This should, however, be combined with feedback at the process level, so that students also pay close attention to adequate strategies and domain-specific rules for an appropriate conception of the task (Hattie \& Timperly, 2007; Nicol \& Macfarlane-Dick, 2006).

Although the instructional activities of interleaved practice and feedback are relevant, they may not facilitate learning via a CBVLE for all students. Support for cognitive approaches plays an important role in helping students persist and to overcome challenges and setbacks (Wang et al., 2018). One way of providing students with cognitive approaches is the use of worked examples (Kirschner, Sweller, Kirschner, \& Zambrano, 2018; Sweller, 2010; Van Gog, Kester, \& Paas, 2011). These are effective instructional procedures that can be embedded in the CBVLE to show students how to solve specific mathematical problems (Chen, Kalyuga, \& Sweller, 2016; Kirschner et al., 2018; Van Gog et al., 2011). Worked examples can be combined in various ways, such as elaborate mathematical 
medication examples that illustrate how to apply procedures to specific cases (Chen et al., 2016; Kirschner et al., 2018; Van Gog et al., 2011), or can be combined with regular problem-solving steps to emphasise thinking strategies that increase transfer to other problem issues (Ben-David \& Zohar, 2009; Hattie \& Timperly, 2007). Though, worked examples can enhance the acquisition of domain-specific and domain-general knowledge, their use may lead to overloading of students' working memory (Kirschner et al., 2018). The main purpose of this study is to investigate how training in a CBVLE with or without worked examples can facilitate mathematical medication learning by nursing students.

\section{Computer-Based Virtual Learning Environments}

CBVLEs are simulated environments that can be programmed with scenarios involving professional learning tasks, with a focus on making tacit aspects of learning tasks and related knowledge visible and accessible to students (Wang et al., 2018). CBVLEs enable students to interact with their future professional world and allow them to be trained on and understand complex tasks. Using CBVLEs, students can interact with their peers via a keyboard, mouse, joystick, or touch screen (Lee \& Wong, 2014; Lee, Wong, \& Fung, 2010; Noroozi, Biemans, Weinberger, Mulder, \& Chizari, 2013), and during this process, they are immersed in computer-based environments (Shute, Ventura, Bauer, \& Zapata-Rivera, 2009).

The design of a CBVLE includes features such as interactive stories and requires practical and clear objectives to ensure that students have immersive experiences in a virtual world and to create a 'state of flow' in which students can succeed only through effort (Csikszentmihalyi, 1990; Shute et al., 2009). A CBVLE can illuminate learning experiences and make situations more authentic by including learning tasks with essential aspects that students need to master for their future profession. A CBVLE makes it possible to concretise abstract ideas and concepts by reorganising integrated facts, procedures, and ideas so that they are retrievable and easy to practice (Pollock, Chandler, \& Sweller, 2002; Xinhao \& Fengfeng, 2016).

When various scenarios, involving students' professional learning tasks are embedded, CBVLEs offer potential situated learning possibilities, allowing students to train for future professional knowledge and skills. Nevertheless, as in traditional classroom settings, the instructional activities within CBVLEs such as interleaved practice and feedback need to be considered.

\section{Instructional Activities in a CBVLE}

Interleaved Practice

Interleaved practice refers to practicing different types of problems over time (Dunlosky, 2013). Interleaved mathematics distribute problems of the same kind, across different 
assignments (Rohrer et al., 2014). It is a learning technique that allows students to study conceptual and technical features and the relationships between them and has a positive effect on future retention (Roediger \& Karpicke, 2006; Weeks et al., 2013). 'Students practice several instances of one type of math problem (e.g., addition) before practicing the next type (e.g., subtraction). Interleaving would involve one mathematical problem from each type before solving a new mathematical problem from each type' (Dunlosky, 2013, p. 16). Interleaved practice provides students with a broader knowledge base (Dunlosky et al., 2013; Rohrer et al., 2015). According to Rohrer et al. (2014), interleaved practice has two important characteristics: Firstly, problems of different kinds are interleaved that allow students to learn a strategy. Secondly, problems of the same kind are distributed that enhance students' retention. Practicing many different domain-specific types of mathematical problems permits the student to grasp the procedures and to make connections between various subjects. This improves students' achievements in the domain of mathematical problem solving (Dunlosky, 2013). To make the learning process in a CBVLE explicit, the structure of the learning environment can be programmed with feedback at the task and process levels (Hattie \& Timperly, 2007; Nicol \& Macfarlane-Dick, 2006).

\section{Feedback}

Feedback is defined as the information provided by a teacher, peer or computer on a student's performance or understanding to promote learning (Hattie \& Gan, 2011; Hattie \& Timperly, 2007). Feedback should be informative and include corrective advice that can help students move towards their learning goals (Dunlosky et al., 2013; Nicol \& MacfarlaneDick, 2006). Sadler (2010, p. 536) states that 'feedback on complex learning may incorporate a variety of elements', and these include a description of the global quality of the work; praise, encouragement or other affective comments; and suggestions on how to attend to specific deficiencies and strengthen the work as a whole. This should be combined with feedback at the process level, since right strategies and domain-specific rules are key issues that deserve students' special attention for an appropriate understanding of the task (Hattie \& Timperly, 2007; Nicol \& Macfarlane-Dick, 2006). Feedback at the process level, as a reflection on learning, can be given after each round of play (Nicol \& Macfarlane-Dick, 2006). Reflection on learning is necessary for students to become aware of their own thinking processes (Schön, 1983), as it closes the gap between what students learn and what they know. However, interleaved practice and feedback in a CBVLE may not facilitate learning for all students. Support for cognitive approaches plays an important role in helping students persist in the face of challenges and setbacks (Wang et al., 2018). One method of providing students with cognitive approaches and place emphasis on appropriate cognitive rules is the use of worked examples (Kirschner et al., 2018; Sweller, 2010; Van Gog et al., 2011). 


\section{Worked Examples}

Worked examples are effective instructional procedures (Kirschner et al., 2018; Sweller, 2010; Van Gog et al., 2011) that can support students in solving problems and help in connecting prior knowledge to new knowledge (Ausubel, 1968; Tynjäla, 2013). They may take the form of domain-specific scaffolds for problem solving (Sweller, 2010). Whereas an unguided problem does not indicate which elements should be attended to, a worked example does; this reduces the number of elements that must be processed in working memory (Chen et al., 2016; Eiriksdottir \& Catrambone, 2011; Margulieux \& Catrambone, 2016). Worked examples can support low-achieving students to acquire the domainspecific knowledge (Kalyuga et al., 2001a; Kalyuga et al., 2001b; Tricot \& Sweller, 2014; Van Gog et al., 2011). However, they can also have adverse effects: once levels of expertise have increased, they become redundant, particularly for high-achieving students.

Worked examples promote conceptual understanding and transfer and demonstrate how to apply procedures to specific cases (Eiriksdottir \& Catrambone, 2011; Margulieux \& Catrambone, 2016). This also represents a drawback of worked examples, since they are bound to a specific context (Margulieux \& Catrambone, 2016). Worked examples can also be combined with problem-solving steps to emphasise regular thinking strategies, and this approach can increase transfer to other learning situations (Ben-David \& Zohar, 2009). These regular thinking strategies provoke students' active thinking and foster deep learning (Zohar \& David, 2008). Thus, the use of worked examples can serve to support both regular thinking strategies and the organisation of the mathematical domain-specific knowledge needed to solve complex mathematical medication problems.

Mathematical Medication and Domain-Specific Knowledge

Mathematical medication requires not only a theoretical knowledge of medicines and their administration, but also a mathematical domain-specific knowledge of medication (Prins et al., 2019). Mathematical medication demands basic computational skills such as addition, subtraction, multiplication, and division of whole numbers, units of measurement, decimals, fractions, and conversion between them (Weeks et al., 2013). This knowledge is often invisible; it is the underlying unifying knowledge that is featured in mathematical medication problems. Canobi (2009) describes these principles as the structure underlying the problem domain of mathematical medication, which calls for a conceptual understanding by students. It includes both an implicit and an explicit understanding of the principles that govern a domain and of the interrelations between units of knowledge in a domain (Krathwohl, 2002; Rittle-Johnson, Siegler, \& Alibali, 2001).

Although conceptual knowledge is flexible, and is not tied to specific problem types, competence in a particular domain requires not only a knowledge of concepts, but also procedural knowledge (Rittle-Johnson et al., 2001). Procedural knowledge is tied to specific 
problem types and involves the ability to execute action sequences to solve mathematical problems (Krathwohl, 2002). It requires domain-specific knowledge, since this is the best predictor of the performance of a task (Tricot \& Sweller, 2014). The acquisition of domainspecific knowledge also plays an important role when solving problems (Polya, 1973; Tricot \& Sweller, 2014). Ben-David and Zohar (2009) find that an emphasis on thinking strategies can increase transfer to other issues, while Rittle-Johnson et al. (2001) emphasise the importance of examining both conceptual and procedural knowledge together; however, according to Kirschner et al. (2006) and Wang et al. (2018), presenting domain-specific knowledge with the relevant underlying domain-specific principles makes it easier to retrieve and apply the knowledge needed to solve problems.

Table 1 shows domain-specific mathematical knowledge from the field of mathematical medication, which is categorised in this study into the three domains of liquid medication, infusion fluids, and solid medication. Procedural knowledge tied to these specific areas and the domain-specific principles underlying mathematical medication are mentioned in columns 3 and 4 of the table, respectively, while the last two columns give examples of mathematical medication scenarios across domains and examples of exercises for practicing the underlying domain-specific principles in the CBVLE. 
Table 1

Aspects of Domain-specific Mathematical Knowledge Related to 'Liquid Medication',

'Infusion Fluid' and 'Solid Medication' in a CBVLE

\begin{tabular}{|c|c|c|c|c|c|}
\hline $\begin{array}{l}\text { Medication } \\
\text { domains }\end{array}$ & $\begin{array}{l}\text { Domain- } \\
\text { specific } \\
\text { knowledge }\end{array}$ & $\begin{array}{l}\text { Domain-specific } \\
\text { rules for feedback }\end{array}$ & $\begin{array}{l}\text { Underlying } \\
\text { domain-specific } \\
\text { principles for all } \\
\text { domains }\end{array}$ & $\begin{array}{l}\text { Learning } \\
\text { tasks }\end{array}$ & $\begin{array}{l}\text { Basic } \\
\text { computatio } \\
\text { nal skills }\end{array}$ \\
\hline $\begin{array}{l}\text { Liquid } \\
\text { medication } \\
\text { (incl. } \\
\text { dilution) }\end{array}$ & $\begin{array}{l}\text { Ratio of the } \\
\text { dissolved } \\
\text { substance and } \\
\text { diluent }\end{array}$ & $\begin{array}{l}\begin{array}{l}\text { mass/volume } \\
(\mathrm{m} / \mathrm{v})\end{array} \\
1 \%=1 \text {-gram } \\
\text { dissolved } \\
\text { substance/100 ml } \\
1 \% \text { o }=1 \text {-gram } \\
\text { dissolved } \\
\text { substance/1000 ml } \\
(1 \text { litre) } \\
\text { volume/volume } \\
\text { (v/v) } \\
1 \%=1 \mathrm{ml} \\
\text { liquid/100 ml } \\
1 \%=1 \mathrm{ml} \\
\text { liquid/1000 ml (1 } \\
\text { litre) }\end{array}$ & $\begin{array}{l}\text { Quantities, } \\
\text { units, } \\
\text { conversions of } \\
\text { ratios: } \\
\text { a. fractions } \\
\text { b. decimals } \\
\text { c. numbers } \\
\text { d. percentage } \\
\text { relations between } \\
\text { a,b,c,d, } \\
\text { divide, } \\
\text { multiplication, } \\
\text { hours, minutes, } \\
\text { seconds (time } \\
\text { ratio), } \\
\text { elements of the } \\
\text { prescription } \\
\text { dispensed, } \\
\text { extract numerical } \\
\text { information, } \\
\text { apply calculations } \\
\text { correctly and } \\
\text { accurately }\end{array}$ & $\begin{array}{l}\text { P. suffers } \\
\text { severe pain. He } \\
\text { is prescribed } 15 \\
\text { mg morphine } \\
\text { every four } \\
\text { hours. Stocked: } \\
1 \mathrm{ml} \text { morphine } \\
\text { ampoules of } 15 \\
\text { mg/ml. How } \\
\text { many ml do you } \\
\text { inject every } \\
\text { four hours? } \\
\text { How many ml is } \\
\text { this per day? }\end{array}$ & $\begin{array}{l}16 \times 8= \\
12 \times 9= \\
1 / 4+3 / 4= \\
3 / 3+5 / 3= \\
3 / 4-2 / 8= \\
14 / 5-9 / 5= \\
3 / 4 \times 4 / 5= \\
5 / 10 \times 4 / 8= \\
4 / 5: 2 / 5= \\
3 / 5: 1 / 3= \\
1 / 4=0.25 \\
1 / 20=0.05 \\
0.09=\ldots \% \\
0.50=\ldots \% \\
75 \%=0.75 \\
30 \%=0.30 \\
\text { How much is: }\end{array}$ \\
\hline $\begin{array}{l}\text { Infusion of } \\
\text { fluids }\end{array}$ & Drip rating & $\begin{array}{l}20 \text { drops per } \\
\text { millilitre } \\
\text { 1. Calculate the total } \\
\text { number of drips } \\
\text { 2. Calculate the } \\
\text { drips per hour } \\
\text { 3. Calculate the } \\
\text { drips per minute }\end{array}$ & & $\begin{array}{l}\text { G. is } \\
\text { administered a } \\
\text { drip of } 500 \mathrm{ml} \\
0.9 \% \mathrm{NaCl} \text { in } \\
\text { three hours. } \\
\text { How many drips } \\
\text { are } \\
\text { administered to } \\
\text { G. per minute? }\end{array}$ & $\begin{array}{l}5 \% \text { of } \\
1000 \mathrm{ml} ? \\
4 \% \text { of } \\
250 \mathrm{ml} ? \\
1 \mathrm{~L}=\ldots \mathrm{ML} \\
1 \mathrm{ML}=\ldots \mathrm{CC}\end{array}$ \\
\hline $\begin{array}{l}\text { Solid } \\
\text { medication }\end{array}$ & $\begin{array}{l}\text { Dosage } \\
\text { calculation for } \\
\text { tablets }\end{array}$ & $\begin{array}{l}\text { Count, divide, } \\
\text { multiply, work with } \\
\text { fractions, } \\
\text { reference } \\
\text { measurements: } \\
24 \text { hours in a day } \\
60 \text { minutes in an } \\
\text { hour } \\
50 \%=1 / 2 \\
1 / 4=25 \% \\
\text { etc. }\end{array}$ & & $\begin{array}{l}\text { F. suffers from } \\
\text { cystitis. She } \\
\text { receives } \\
\text { treatment with } \\
\text { antibiotics for } \\
\text { six days: } 750 \\
\text { mg Amoxicillin } \\
\text { every } 12 \text { hours. } \\
\text { Stocked: } \\
\text { Flemoxin with } \\
375 \text { mg } \\
\text { Amoxicillin per } \\
\text { tablet. How } \\
\text { many tablets } \\
\text { should F. } \\
\text { swallow during } \\
\text { treatment? }\end{array}$ & \\
\hline
\end{tabular}




\section{Programming Instructional Activities and Simulations in the CBVLE}

Simulations can support learning by providing virtual activities and procedures that reflect or replicate those required in the real world, frequently using visually compelling environments (Boyle et al., 2016). In our CBVLE, interleaving practice involves learning tasks that are programmed as mathematical medication scenarios. The underlying domainspecific principles are introduced in the CBVLE in the form of short exercises, which are necessary to develop a high level of automaticity and require students to make connections between the various subjects in order to grasp the procedures for solving different domainspecific types of mathematical medication problems (Dunlosky et al., 2013; Rohrer et al., 2015). In addition, feedback is programmed in the CBVLE as the information from the procedures column that the computer provides on each student's performance after solving a mathematical medication problem (Dunlosky et al., 2013; Hattie \& Timperly, 2007; Nicol \& Macfarlane-Dick, 2006). At the end of each practice round, which involves solving six mathematical medication problems and two sets of five short exercises involving the underlying domain-specific principles, nursing students are given feedback at the process level to reflect their learning (Hattie \& Timperly, 2007; Nicol \& Macfarlane-Dick, 2006).

It is currently unclear how learning via a CBVLE, involving a structured learning environment based on the instructional design aspects of interleaved practice and feedback, can facilitate mathematical medication learning by nursing students. Furthermore, there has been little empirical research into the assumption that the embedding of worked examples into a CBVLE, in order to support regular thinking strategies or the organisation of mathematical domain-specific knowledge, has a positive effect on the domain-specific mathematical medication knowledge of nursing students. The following research questions were formulated to address these issues.

1. Which predictors affect the mathematical medication learning of nursing students in a CBVLE?

2. To what extent can a CBVLE foster mathematical medication learning by nursing students without worked examples (condition 1), with worked examples involving domain-specific knowledge (condition 2), with worked examples involving regular thinking strategies (condition 3 ), and with a combination of both types of worked example (condition 4)?

In the first place, we expect that the use of worked examples with domain-specific knowledge (condition 2) will enhance mathematical medication learning to the greatest extent. Secondly, high-achieving students are expected to score more highly in mathematical medication learning under condition 1 , since worked examples are 
detrimental to the acquisition of skills when levels of expertise are sufficiently high (Kalyuga, Chandler, \& Sweller, 2001a; Kalyuga, Chandler, Tuovinen, \& Sweller, 2001b; Tricot \& Sweller, 2014). Finally, we expect low-achieving students to score higher in mathematical learning under condition 2 (with worked examples supported by domainspecific knowledge), since this condition demonstrates how to apply procedures to specific cases and thus reduces the number of elements that must be processed in working memory (Chen et al., 2016; Eiriksdottir \& Catrambone, 2011; Margulieux \& Catrambone, 2016).

\section{Method}

\section{Context and Participants}

The study was conducted in the Netherlands. Participants were drawn from five postsecondary vocational nursing schools and from seven universities of applied sciences, at which a bachelor's nursing program was offered. Although the educational levels are different for these two groups of students, the mathematical medication training and its content is the same in both educational programs. The total sample involved 118 students, 10 men and 108 women, aged between 17 and $31(M=19.6, S D=2.4)$. Of this sample, 44 students were following a post-secondary vocational nursing course and 74 were bachelor's nursing students. Students worked on a bring your own device (BYOD) basis in this study, except for two schools in which students used PCs. Students had basic computer skills (Mpre $=3.7, S D=0.7 ;$ Min $=1.0, \operatorname{Max}=5.0$ ), but working with a CBVLE was new to them. Each student was compensated with 15 euros for their contribution and gave active informed consent to take part in the study.

The students were randomly assigned to one of four conditions in the same CBVLE, which provided a structured learning environment based on the instructional design aspects of interleaved practice and feedback: mathematical medication learning without worked examples (condition 1), mathematical medication learning with worked examples involving domain-specific knowledge (condition 2), mathematical medication learning with worked examples involving regular thinking strategies (condition 3), and mathematical medication learning with a combination of both types of worked example (condition 4).

Computer-Based Virtual Learning Environment

The Second Life ${ }^{1}$ platform was used to design a CBVLE to train nursing students in mathematical medication learning (Figure 1). Students were assigned to avatars and logged into the CBVLE. It was a simulated world in the form of a field hospital comprising 10 tents and was based on a television series from the 1970s called MASH (Mobile Army Surgical Hospital). In this field hospital, there were four medical doctors who each tended

\footnotetext{
${ }^{1}$ Second Life is a free 3D online virtual world where users can create, connect and interact with others across the globe using voice and chat (secondlife.com).
} 
to patients in these tents. The name of the patients was matched to the names mentioned in the mathematical medication problems in the CBVLE. The mathematical medication problems were presented in the screen with four answers when students clicked on the patient map (see Figure 1). Students used the worked examples as a support to solve the mathematical medication problems. After solving the mathematical medication problem, the patient showed that it was the right answer (Thank you nurse, I feel much better) or the wrong answer (Help nurse, I do not feel good). Then, the doctor gave the right answer and the mathematical medication rule. In a tent called 'The Lab', the underlying domainspecific mathematical principles could be practiced via two sets of five short exercises. The primary goals of the training were to:

- Help the nursing students learn to recognise the various problem states to which each mathematical theorem applies;

- Enhance the mathematical medication competences of the nursing students with a solid base of mathematical facts and procedures;

- Motivate nursing students to learn mathematics by integrating a CBVLE with 'real life' situations; and

- Bridge transfer problems using a CBVLE involving 'real life' situations.

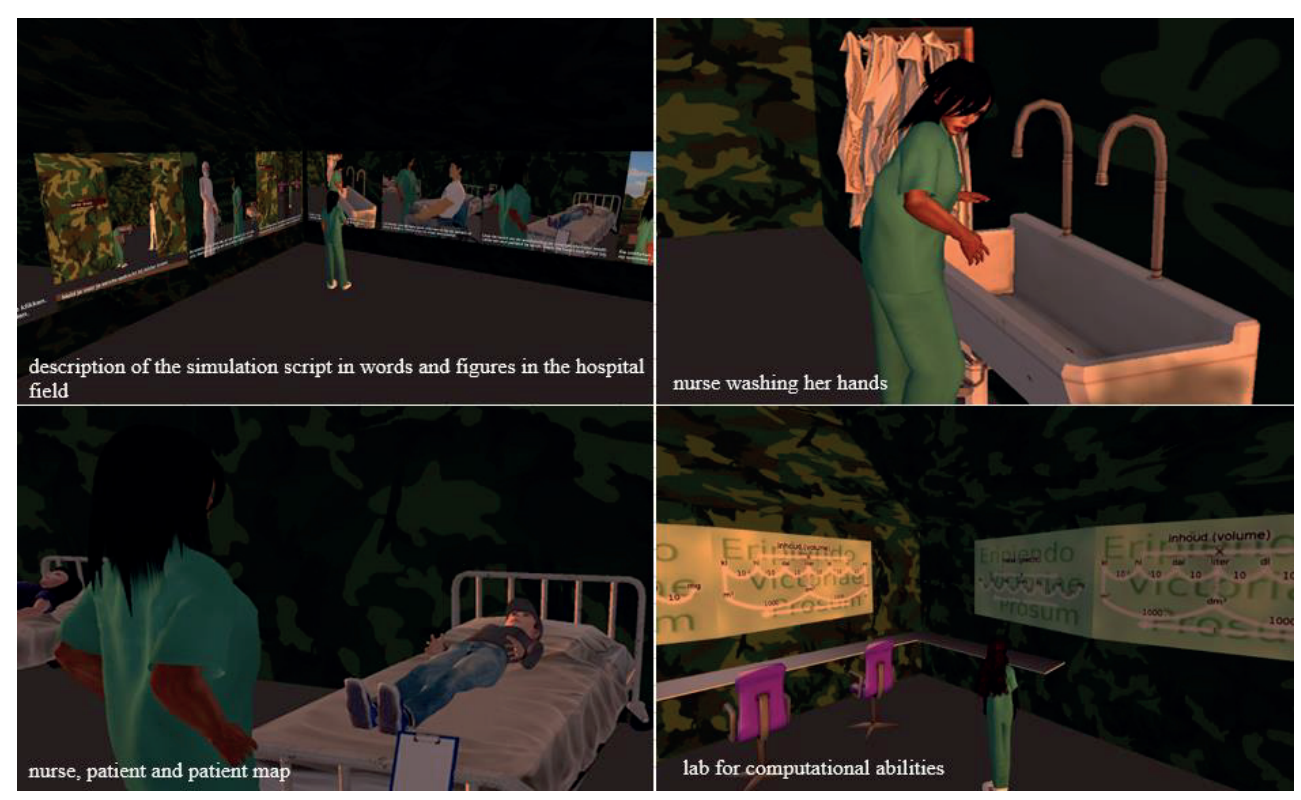

Figure 1. Screenshots of the MASH learning environment. 


\section{Learning Materials}

The subject to be learned was the concept of mathematical medication, and specifically the three domains of liquid medication, infusion fluids, and solid medication. We therefore conducted a procedural cognitive analysis with six mathematical subject matter experts (SMEs) to discuss the mathematical concepts, principles and rules, and procedures of five different mathematical medication problems. Each step of the analysis included three questions (Morrison, Ross, Kalman, \& Kemp, 2011, p. 85): (i) What does the learner do? (ii) What does the learner need to know? and (iii) What cues inform the learner that there is a problem, the step is complete, or a different step is needed? For the knowledge audit, the SMEs also discussed and described the contextual knowledge necessary to solve the mathematical medication problem, the reasons why this assignment might be difficult, and the errors students might make. This information was used to create 90 medication scenarios, 100 short exercises on the underlying domain-specific principles, and a worked example involving domain-specific procedural knowledge with an example description, for each domain (Table 1). The student's task was to complete at least one round per training session, consisting six mathematical medication problems and two sets of five short exercises. Each mathematical medication problem formed part of the administration medication process, which was clarified by conducting a task analysis to identify its components and describe them in the form of steps (Morrison et al., 2011). These steps then formed the sequence of actions required in the CBVLE: (i) receive the assignment from a doctor; (ii) wash hands; (iii) communicate with patient; (iv) prepare medication by solving a mathematical medication problem; ( $v$ ) administer medication; and (vi) update the patient's file and return to the doctor. The doctor may also tell the nurse to go to 'The Lab' to carry out the short exercises.

\section{Procedure}

Mathematical medication teachers from higher and vocational education schools, drawn from the first author's network, were contacted by phone by the first author. When the teachers and their managers had expressed interest in participating in the study and had given consent, they contacted the first author and gave their approval to conduct the study in their schools. The teachers gave fact sheets to the nursing students to inform them about the study and its goals, and flyers were also posted on the schools' online platforms with links to allow students to confirm their participation. An initial introduction session was arranged, in which students were informed about the study and filled in consent forms.

Through a pilot study lasting four weeks and involving 11 students, we ensured that the learning materials used in the CBVLE were comprehensible, the technical aspects of the CBVLE were functional, and the tests appropriate. As a result of this pilot study, we changed the introduction section to a single shorter meeting, designed a paper-based 
manual and introduced technical instruction, using photos in the CBVLE to guide students through the practice rounds in the CBVLE (see Figure 1).

The experimental session consisted of three main phases (see Table 2). During the first of these, an introduction and personal data phase that took 70 minutes, students were introduced to the CBVLE training via a personal introduction session. In each session, which lasted 30 minutes, the student was informed about the structure of the upcoming lessons and what was expected from them. Students were then assigned to avatars and logged into the CBVLE. These avatars (students) were randomly allocated one of four conditions. Students practiced on one round in the CBVLE, and it was made clear that they were expected to work individually during the game, without help from the researcher or their peers, while paying attention to the information on the screen (30 min). After this first introduction session, students were asked to complete a questionnaire on their personal data, such as their name, gender, age, and computer skills (10 min).

During the second stage, which was the individual pre-test measurement phase (which lasted a total of $125 \mathrm{~min}$ ), students first received an introductory explanation of how to answer different questions in various surveys on basic computational skills, a non-verbal intelligence test, and domain-specific mathematical knowledge (5 min). Students were then given 15 minutes for a test of their basic computational skills, and the Standard Progressive Matrices (SPM) non-verbal intelligence test was applied (Raven et al., 1992), which took 45 minutes. After a 10 min break, students were tested on their domain-specific mathematical knowledge (60 $\mathrm{min})$.

Week 2 to 5 formed the third stage, which was the learning phase. This phase took 90 minutes per week (45 minutes per training session), for four consecutive weeks. In the fourth stage, involving post-tests and debriefing (90 $\mathrm{min}$ ), students were first tested on their domain-specific mathematical knowledge (60 min) followed by a short debriefing (10 min). After this, the students' activity logs were uploaded to a disk belonging to the researcher. 
Table 2

Procedure for the CBVLE Study

\begin{tabular}{ll}
\hline Procedure for mathematical medication training in the CBVLE & Duration \\
\hline Week 1: Introduction and personal data & $70 \mathrm{~min}$ \\
Introductory explanations of the procedure, materials, and the purpose & $30 \mathrm{~min}$ \\
of the research study & $30 \mathrm{~min}$ \\
Students were given avatars, logged in and played a round & $10 \mathrm{~min}$ \\
Personal data questionnaire & $85 \mathrm{~min}$ \\
Individual pre-test measurements & $5 \mathrm{~min}$ \\
Introductory remarks & $20 \mathrm{~min}$ \\
Assessment of self-efficacy (se) and intrinsic motivation (im) & $60 \mathrm{~min}$ \\
(questionnaire) & $90 \mathrm{~min}$ per week \\
Pre-test assessment of domain-specific mathematical knowledge & $100 \mathrm{~min}$ \\
Weeks 2-5: Learning phase: CBVLE training & $60 \mathrm{~min}$ \\
Week 6: Post-tests and debriefing & $30 \mathrm{~min}$ \\
Post-test assessment of domain-specific mathematical knowledge & $10 \mathrm{~min}$ \\
Assessment of se, im, and design components (questionnaires) & Debriefing
\end{tabular}

Measurements and Instruments

Measurement of Nursing Students' Non-Verbal Intelligence

As children get older, the measurement of cognitive abilities requires particular attention to both predisposition factors and acquired skills (Alloway \& Alloway, 2010). This is possible with the SPM test (Raven, Court, \& Raven, 1992), which measures students' non-verbal intelligence. The test consists of 60 problems divided into five sets of 12 problems, ranging from easy to complex (A, B, C, D, E). The reliability score for this test in our study was at an average level (Cronbach's $a=.62$ ). The test was given in a paper-based format, and each item consisted of a figure with a missing piece. Below the figure, six or eight possible answers were given to complete the missing piece, only one of which was correct. There was no time limit on the test, but it generally took about 45 minutes.

Measurement of Nursing Students' Degree of Automation of Basic Computational Abilities To ascertain the degree of automation of basic computational abilities, a mathematical speed test was completed. This was a validated test in Dutch that measured students' computational skills in terms of addition, subtraction, multiplication, and division (De Vos, 1992). The four types of arithmetic computations were distributed over five columns, with one column for each type of computation and one containing all types in a random order. There were 40 arithmetic assignments per column, and these were presented in ascending order of difficulty. The students had one minute per column to solve as many of these arithmetic problems as possible. The more arithmetic assignments a student solved correctly, the higher their score for fundamental computational abilities. Students could obtain scores of between zero and a maximum of 40 per column, and an overall maximum of 200 for the test. The reliability score for this study was high (Cronbach's $a=.90$ ). 
Measurement of Nursing Students' Mathematical Medication Knowledge

Domain-specific mathematical medication knowledge was assessed with a test composed by Cito (the Dutch national organisation for test development; see Lampe, Straetmans, \& Eggen, 2011), which was used to measure domain-specific mathematical medication knowledge both before and after intervention with the CBVLE. Two parallel versions were therefore developed by Cito. The original domain-specific mathematical medication knowledge test consisted of 50 multiple choice questions, with 20 questions on domainspecific mathematical medication knowledge for infusion fluids, 19 questions on liquid medication, and 11 questions on solid medication (tablets). After an item response analysis, four items with poor discriminatory power were eliminated from the test. Students could obtain a maximum score of 46 for both tests. Cronbach's a $=.80$. The post-test reliability was also good (Cronbach's $a=.83$ ).

Measurement of Nursing Students' Mathematical Medication Activities in CBVLE

The students' activities (in the form of solved mathematical medication problems) were logged in the CBVLE, and these logs were used as a control variable for the total numbers of mathematical medication problems solved by nursing students during their sessions. Some computers did not save these logs on students' computers, for safety reasons or due to the amount of space available on disk. We were able to retrieve logs for 60 students, which showed that they completed a mean of 56 activities, a median of 57 , a minimum of 23 and a maximum of 109 .

Data Analyses

A total of 118 students participated in the study. However, due to the spread over eight training sessions and internship commitments, 17 students dropped out of the study $(14 \%)$. The results for performance are based on analyses of data from 101 students who completed all the sessions and tests. First, the comparability of the conditions was tested with a one-way analysis of variance (ANOVA). A hierarchical multiple analysis (MRA) was then employed to determine which variables accounted for mathematical medication learning after CBVLE training. A paired sample t-test was conducted to find significant differences between mathematical medication results before (pre-test) and after (posttest) the CBVLE training, and more specifically domain-specific knowledge of infusion, fluid medication, and solid medication. A repeated measures ANOVA was used to compare the differences in mathematical medication learning between the conditions. A one-way analysis of covariance (ANCOVA) was also set up to insert the conditions and to indicate whether there were significant differences in nursing students' mathematical medication learning after the CBVLE training, controlling for prior knowledge (pre-test scores), nonverbal intelligence scores (RAVEN) and basic computational abilities. We finished the analysis by combining the non-verbal intelligence scores into three groups of high- 
achieving, mid-level achieving, and low-achieving students. T-tests were conducted to calculate the differences in mathematical medication learning. An ANOVA was used to investigate the differences and an ANCOVA to indicate differences to their assigned conditions. The differences between the groups and their conditions were tested using a multivariate analysis of variance (MANOVA).

Ethics

When students were informed by their teacher about the study, they were given the opportunity to choose to participate in the research. After giving their agreement and after an introductory verbal explanation from the researcher and the teacher of the aims of the CBVLE training research, students could still decline to take part in the research. Students were assured that identifying information was not available to anyone except the researchers. Results were de-identified by numbering both the students and their tests, and files were located in different places under different names. The Faculty Ethics Review Committee (FETC) of the Faculty of Social Sciences of Utrecht University reviewed and approved the research study under case number 19-230.

\section{Results}

The results for each condition were compared with respect to the basic computational skills, non-verbal intelligence, and prior knowledge of nursing students. No significant differences were found in the degree of automation of basic computational abilities (TTRtot) $(F(3,114)$ $=2.19, p=.09)$, non-verbal intelligence outcomes $(F(3,108)=1.48, p=.23)$ or pre-test scores (prior knowledge) $(F(3,114)=2.35, p=.08)$. More specifically, we found no significant differences in domain-specific knowledge for infusion $(F(3,114)=2.59, p=.06)$ or solid medication $(F(3,114)=.83, p=.48)$. However, a significant difference was observed for domain-specific knowledge for liquid medication $(F(3,114)=3.62, p<.05$, $\eta 2=.87)$. A further Tukey HSD analysis revealed no differences between the four conditions $(p=0.70)$, showing that these conditions are comparable with respect to the basic computational skills, non-verbal intelligence outcomes, and prior knowledge of nursing students. Table 3 gives descriptive statistics for the nursing students' test scores and their performance for each condition in the CBVLE. 
Table 3

Summary of Nursing Students' Scores for Each Condition

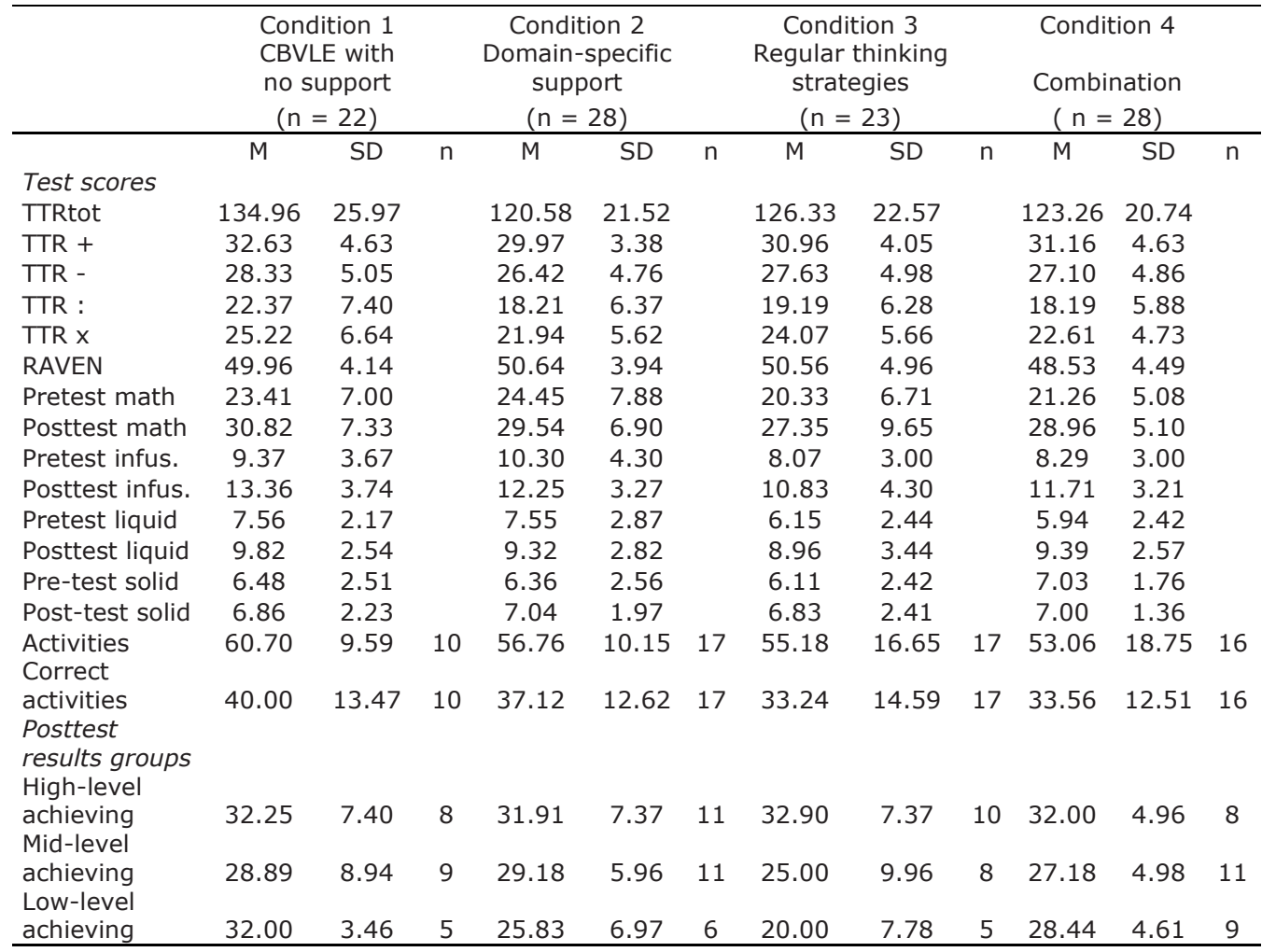

Predictors for Mathematical Medication Learning by Nursing Students in CBVLE Training

To identify which predictors accounted for mathematical medication learning by nursing students after CBVLE training (post-test performance), an MRA was conducted using the number of activities in the CBVLE (based on logs), support (worked examples), basic computational skills (TTRtot), non-verbal intelligence outcomes and prior knowledge (pretest performance). Several assumptions were tested, and checks were performed. Stem and leaf plots and boxplots indicated three univariate outliers, which were deleted (two students with exceptionally low scores, and one with an extremely high score). A test to determine whether the data met the assumption of collinearity indicated that multicollinearity was not a concern (support tolerance $=.895$, VIF $=1.12$; pre-test tolerance $=.656$, VIF $=1.52$; basic computational skills tolerance $=.762$, VIF $=1.31$; non-verbal intelligence tolerance $=.755, \mathrm{VIF}=1.32$; CBVLE activities tolerance $=.839$, VIF $=1.19 ;$ number of correct CBVLE activities tolerance $=.270$, VIF $=3.70$ ). The Mahalanobis distance did not exceed the critical value of $x^{2}$ of 22.46 for $\mathrm{df}=6$ for any cases in the data file, indicating that multivariate outliers were not of concern. In step 1 of the hierarchical MRA, support, prior knowledge, basic computational skills, non-verbal 
intelligence and CBVLE activities accounted for $60 \%$ of the variance in mathematical medication learning after training with $\operatorname{CBVLE}\left(R^{2}=.60, F(5,51)=15.42, p<.001\right)$, a significant proportion. Since the CBVLE activities did not show significant results, the number of correctly solved CBVLE activities was added to the regression equation in step 2 , and this accounted for a significant additional $3 \%$ of the variance in compliance $\left(\Delta R^{2}=\right.$ $.03, \Delta F(1,50)=4.45, p<.05)$. When combined, the predictor variables explained $63 \%$ of the mathematical medication learning by nursing students after training with CBVLE $\left(R^{2}=\right.$ .63 , adjusted $\left.R^{2}=.59, F(6,50)=14.46, p<.001\right)$. Table 4 gives unstandardised and standardised regression coefficients and squared semi-partial correlations for each predictor at each step of the hierarchical MRA.

Table 4

Regression Coefficients and Semi-partial Correlations $\left(s r^{2}\right)$ for Each Predictor Variable

\begin{tabular}{lllcc}
\hline \multicolumn{1}{c}{ Variable } & $B[95 \% \mathrm{CI}]$ & $\beta$ & $\mathrm{sr}^{2}$ \\
\hline Step 1 & & & \\
& & & & \\
& Support & $0.90[-0.24,2.04]$ & 0.15 & .02 \\
& Prior knowledge & $0.44[0.25,0.64]^{* * *}$ & 0.49 & .16 \\
& Computational skills & $0.03[-0.02,0.09]$ & 0.12 & .01 \\
& Non-verbal intelligence & $0.40[0.13,0.67]^{*}$ & 0.31 & .07 \\
& CBVLE activities & $0.66[-0.04,0.67]$ & 0.12 & .01 \\
Step 2 & & & \\
& Support & $0.80[-0.31,1.91]$ & 0.13 & .01 \\
& Prior knowledge & $0.36[0.15,0.56]$ & 0.40 & .09 \\
& Computational skills & $0.03[-0.02,0.08]$ & 0.11 & .01 \\
& Non-verbal intelligence & $0.40[0.14,0.66]$ & 0.30 & .07 \\
& CBVLE activities & $-0.07[-0.22,0.10]$ & -0.12 & .00 \\
& Correct CBVLE activities & $0.18[0.01,0.36]^{*}$ & 0.35 & .03 \\
\hline
\end{tabular}

Note: $\mathrm{CI}=$ confidence interval.

$* p<.05 . * * * p<.001$

Effects of the CBVLE Training

A paired sample t-test across all participants indicated a significant difference between the pre-test and post-test scores $(t(100)=10.68, p<.001, \eta 2=.89)$, in favour of the posttest. More specifically, the domains for infusion $(t(100)=8.33, p<.001, \eta 2=.76)$, and liquid medication $(t(100)=8.08, p<.001, \eta 2=.90)$ also showed a significant difference. For solid medication, no significant result was found $(t(100)=1.07, p=.29)$. This shows that all the mathematical medication learning was improved by training with CBVLE. A oneway ANOVA was used to compare the mathematical medication learning outcomes under 
the four different support conditions in the CBVLE training. No significant differences were found $(F(3,97)=.883, p=.45)$ between the different conditions in terms of the learning outcomes. A covariate was included to partial out the effects of prior knowledge (pre-test). The effect of the support conditions after controlling for prior knowledge was statistically non-significant $(F(3,96)=.678, p=.57)$, and a non-significant result was also found for the support conditions after controlling for basic computational skills $(F(3,93)=.010, p=$ .99). Controlling for non-verbal intelligence scores revealed a significant result $(F(3,93)=$ 3.33, $p=.02, \eta 2=.10$ ), meaning that after controlling for these scores, the post-test results are significantly related to the support conditions. Post-hoc testing revealed that students with no support from worked examples (condition 1) reported significantly higher learning scores after training with the CBVLE than students with support from regular thinking strategies (condition 3 ) (Mdifference $=5.04, S D=1.98, p=.01$ ). The remaining pairwise comparisons were not significant.

Effects of CBVLE Training on High-, Mid-level -, and Low-Achieving Students

Effects of CBVLE Training in the high-, mid-level -, and low-achieving groups

The non-verbal intelligence outcomes were divided into three groups $(M=49.9, S D=4.4$, Min = 37.0, Max = 59.0) of high-, mid-level-, and low-achieving students. T-tests revealed significant differences in low achieving students' learning, $(\mathrm{t}(24)=7.65, p<.001, d=$ 1.13), mid-level achieving students' learning, $(\mathrm{t}(38)=5.58, p<.001, d=0.84)$, and high achieving students' learning $(\mathrm{t}(36)=6.36, p<.001, d=0.94)$. Further analysis found no significant differences between the support conditions in the high-achieving group $(F(3,33)$ $=.041, p=.99)$ and the mid-level achieving group $(F(3,35)=.591, p=.63)$, although in the low achieving group, significant differences between the support conditions were found $(F(3,21)=3.95, p=.02, \eta 2=.03)$. A Tukey HSD revealed significant differences between students with no support from worked examples (condition 1 ) and students with support from regular thinking strategies (condition 3 ), (Mdiff $=12.0, S D=3.66, p=0.17$ ) (see Figure 2).

Effects of CBVLE training between the high-, mid-level-, and low-achieving groups A significant difference in mathematical medication learning was found between the groups $(F(2,98)=5.98, p=<.001, \eta 2=.11)$. A Tukey HSD test showed a difference between the low-achieving and high-achieving group (Mdiff $=-5.43, S D=1.8$ ) and the mid-level achieving and high-achieving group ( $M$ diff $=-4.58, S D=1.6$ ). Identifying the differences between the high-achieving, mid-level achieving, and low-achieving nursing students groups based on the support conditions used in the CBVLE, a significant univariate main effect was found for the post-test scores $(F(2,89)=6.37, p<.001, \eta 2=.13)$, and particularly for the mathematical medication domains of infusion $(F(2,89)=5.49, p<.001$, $\eta 2=.11)$ and liquid medication $(F(2,89)=6.25, p<.001, \eta 2=.12)$. For solid medication, 
no univariate main effect was found $(F(2,89)=1.47, p=.24)$. Further analysis with a Tukey HSD test revealed that these differences related to the groups under condition 1 (with no support from worked examples; $M=13.4, S D=.76$ ) and condition 3 (worked examples with regular thinking strategies; $M=10.3, S D=.75$ ). Figure 2 shows the differences in post-test mathematical medication training for the groups of nursing students (high-achieving/mid-level achieving/low-achieving) and the conditions in which they experienced the CBVLE training (marked with dotted lines).

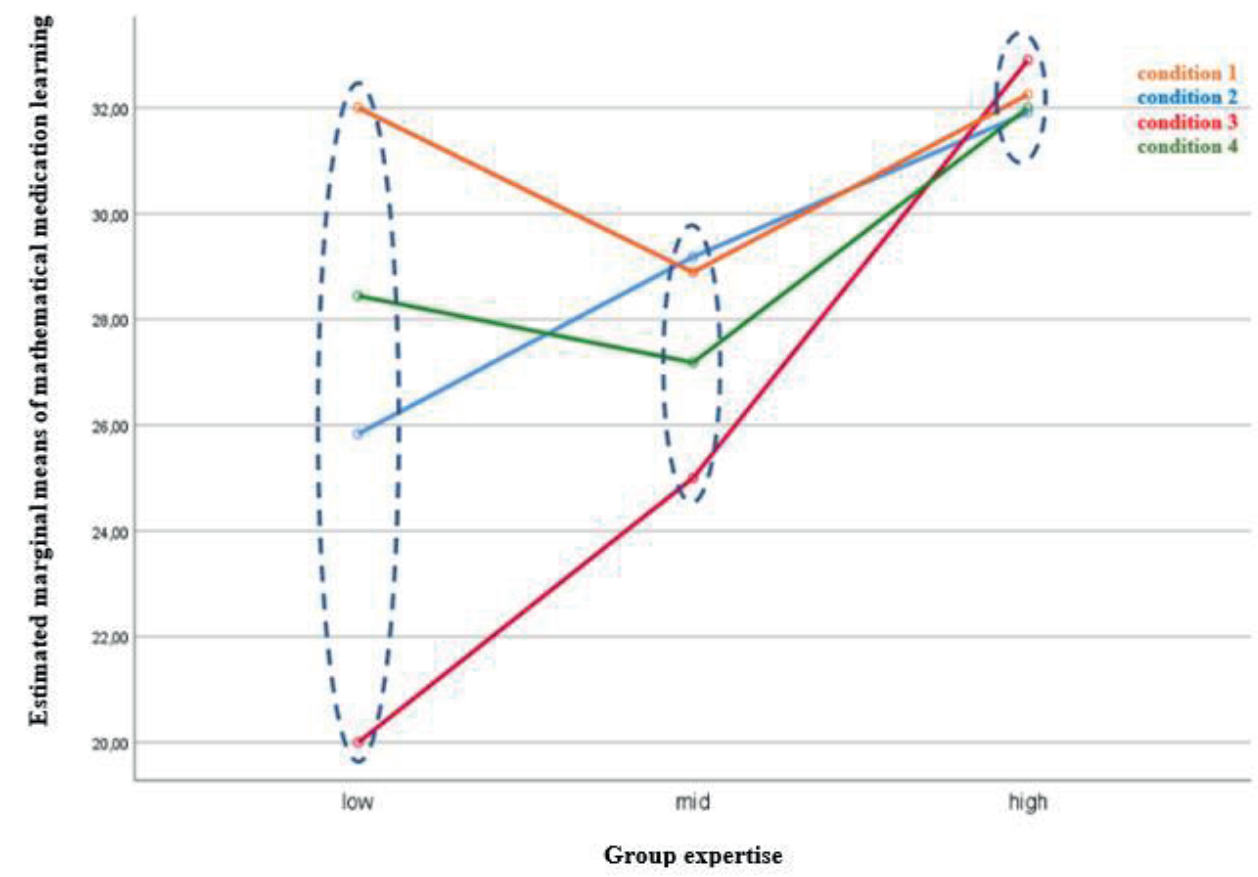

Figure 2. Differences in mathematical medication learning between the achieving groups and their support conditions.

\section{Discussions}

The overall results of this study confirm our expectations that learning via a CBVLE considering instructional activities as interleaved practice and feedback fosters nursing students' mathematical medication learning. Based on these instructional activities in the CBVLE, nursing students were able to solve different mathematical medication problems within a relatively short time. This correspondents with the findings of Tynjälä (2013), who reports that exposing students to numerous mathematical medication problems trains them in extracting the relevant mathematical information from complex problems. A further detail of Tynjälä's results that is pertinent to this study is that this extraction of 
information does not relate to the number of exercises but the number of correct exercises in terms of its effect on mathematical medication learning. In addition, nursing students' prior mathematical medication knowledge and their non-verbal intelligence accounted as predictors for mathematical medication learning via the CBVLE. However, when the mathematical learning outcomes were compared under the four different support conditions, controlling for prior knowledge did not reveal any effect between the support conditions and mathematical medication learning outcomes; only controlling for nursing students' non-verbal intelligence accounted for significant results. More specifically, when non-verbal intelligence scores were considered, students in condition 1 (without worked examples) scored significantly higher learning outcomes than students in condition 3 (worked examples with the support from regular thinking strategies). This may be attributable to the characteristics of the instructional material of the worked example with regular thinking strategies. To trigger the learner to conduct active thinking, regular thinking strategies should be 'formulated as statements that may be individually and socially negotiated' (Zohar \& David, 2008, p. 60). The worked examples in the CBVLE did not include this linguistic component. Zohar and David (2008) stress the importance of a strong verbal component of thinking strategies. In this CBVLE, thinking strategies were presented only on paper, and this might be the reason that they could not trigger students to carry out active thinking. Moreover, the structure of the learning environment in the CBVLE outlined a domain-specific learning task and had control over many of the information elements and their interactions, which were pre-programmed for the learners. Worked examples may therefore have been redundant. This applied not only to highachieving students (see Anderson, Fincham, \& Douglas, 1997; Kalyuga et al., 2001a; Kalyuga et al., 2001b; Kirschner et al., 2018; Van Merriënboer \& Sweller, 2010), but also to the low-achieving nursing students. From a cognitive load theory (CLT) perspective, this means that technology has taken over some of the capacity of working memory, which accounts for the benefits to low-achieving learners. Thereby, interleaved practice ensures a broader knowledge base for all nursing students (Dunlosky et al., 2013; Rohrer et al., 2015). Different mathematical medication problems with the same mathematical medication rules distributed in the CBVLE enhance nursing students' retention. Students learn to choose the right strategies next to focus on executing strategies (Rohrer et al., 2014). Students constantly focus on retrieving different solutions, which strengthens memory associations (Rohrer et al., 2015).

Our findings are different from those of Anderson et al. (1997), who state that worked examples can be effective for skill acquisition in well-structured domains such as mathematics. It seems that the amount of information forwarded by the instructional activities in the CBVLE supported nursing students sufficiently in mathematical medication learning. In addition, Gick and Holyoak (1987) state that transfer tasks cue the retrieval 
of appropriate prior knowledge. In the CBVLE, these transfer tasks took the form of short exercises that encouraged nursing students to retrieve and apply the appropriate underlying knowledge necessary to solve the mathematical medication problems. The similarity of processing may have generated the transfer of knowledge necessary for mathematical medication learning. This is in line with Warner et al. (2020) who state that online instruction should be adapted to students' prior knowledge to improve learning. Another important factor for transfer, according to Gick and Holyoak (1987), is the students' background knowledge of the subject. The CBVLE supports the mathematical medication learning of nursing students in the context of their future professional tasks. This was underlined by the high percentage of nursing students who reported that the CBVLE made them more aware of their skills in medication administration: $90 \%$ (fully) agreed. Consequently, the hypothesis tested in this study that students would benefit from the worked examples supported by domain-specific knowledge (condition 2) was not supported.

In this study, the mathematical medication learning of low-achieving nursing students improved most. More interesting is the fact that the low-achieving nursing students in condition 1, with no support from worked examples, gained the highest mathematical medication learning results. Worked examples with regular thinking strategies were also detrimental to learning in the low-achievement group. This result is subject to the restrictions on regular thinking strategies mentioned above, but the importance of knowledge should not be underestimated. For some learning tasks, regular thinking strategies may be counterproductive, since knowledge matters (Hirsch, 2016; Tricot \& Sweller, 2014). Sweller (2010) places considerable emphasis on devising techniques that support students' domain-specific knowledge learning, rather than regular skills (Pollock et al., 2002). On the other hand, worked examples with domain-specific knowledge may have imposed an excessive load (see Sweller, 2010), which might be a reason that the hypothesis of the low-achieving students was not supported in this study. The lowachieving students did not show higher mathematical learning outcomes under condition 2 (with worked examples supported by domain-specific knowledge).

The structure of the learning environment in the CBVLE burdens the short-term memory of low-achieving nursing students by focusing on a variety of mathematical medication problems and retrieving different solutions from short-term memory that foster good longterm recall (Roediger \& Karpicke, 2006; Rohrer et al., 2015). This is clearly visible in Figure 2 , where it can be seen that there are big differences in mathematical medication learning in the low-achievement group in terms of the various support conditions in the CBVLE, while the level of support conditions in the CBVLE appears to be unimportant for the experienced students in the high-achieving group. The latter is in line with Mayer (2001) who states that experienced students need less guidance than inexperienced students. 
Experienced students have more developed schemas that enable to process information automatically and reduce the burden on working memory (Clarke, Ayres, \& Sweller, 2005). This enables students to engage in activities that are more complex. Hence, worked examples are detrimental to the acquisition of skills when levels of expertise are sufficiently high (Kalyuga et al., 2001a; Kalyuga et al., 2001b; Tricot \& Sweller, 2014). Nevertheless, the second hypothesis tested in this study, regarding the expectations that high-achieving students were expected to score more highly in mathematical medication learning under condition 1 (no support of worked examples), was not supported. The support conditions in the CBVLE for the high-achieving group appeared to be unimportant for mathematical medication learning.

\section{Conclusions, Limitations and Suggestions for Future Research}

To conclude, we designed the CBVLE with numerous mathematical medication scenarios to create an environment in which nursing students could study the concept of mathematical medication that would be essential in their future profession. Although this study focused on mathematical medication learning, the importance of nursing students' learning in terms of the future task of medication administration should not be underestimated. Our results seem to indicate that the CBVLE can engage nursing students in training on difficult, unclear situations that they are likely to come across in professional practice (Prins et al., 2019).

This study was an initial attempt to train nursing students in mathematical medication via a CBVLE. This is a form of learning that enables students to engage in transformative and innovative, rather than reproductive, learning (Tynjälä, 2013). Learning can also be facilitated by taking into account the emotional process during learning in the CBVLE (Pekrun, 2011), and it would be interesting to find out whether this is the case in relation to CBVLE training and its effects on learning. We therefore suggest that future research should focus on how the features of a CBVLE can facilitate the emotional process and thus learning, especially for nursing students in mid-level achieving and low-achieving groups. This study used a small sample of participants, especially in the low-, mid-level-, and highachieving groups, since we were able to only download the activity logs of 60 students. This may limit the generalisability of the findings of the study and may prevent strong claims being made that are not based on coincidence. The findings of this study should therefore be treated cautiously. For instance, although worked examples that can serve the organisation of the knowledge needed to solve complex mathematical medication problems take time to complete, we established a limited time per lesson (45 minutes); hence, the nursing students who were given worked examples based on domain-specific procedural knowledge were unable to solve as many mathematical medication problems as the other groups. In future studies, this needs to be considered. 


\section{References}

Alloway, T. P., \& Alloway, R. G. (2010). Investigating the predictive roles of working memory and IQ in academic attainment. Journal of Experimental and Child Psychology, 106, 20-29. doi:10.1016/j.jecp.2009.11.003

Anderson, J. R., Fincham, J. M., \& Douglas, S. (1997). The role of examples and rules in the acquisition of a cognitive skill. Journal of Experimental Psychology, 23, 932945.

Ausubel, D. P. (1968). Educational psychology: A cognitive view. New York, NY: Holt, Rinehart and Winston.

Ben-David, A., \& Zohar, A. (2009). Contribution of meta-strategic knowledge to scientific inquiry learning. International Journal of Science Education, 31, 1657-1682. doi: $10.1080 / 09500690802162762$

Boyle, E., Hainey, T., Connolly, M., Gray, G., Earp, J., Ott, M., ... Riberio, C. (2016). An update to the systematic literature review of empirical evidence of the impacts and outcomes of computer games and serious games. Computers and Education, 94, 178-192. doi:10.1016/j.compedu.2015.11.003

Canobi, K. H. (2009). Concept-procedure interactions in children's addition and subtraction. Journal of Experimental Child Psychology, 102, 131-149. doi:10.1016/j.jecp.2008.07.008

Chen, O., Kalyuga, S., \& Sweller, J. (2016). Relations between the worked example and generation effects on immediate and delayed tests. Learning and Instruction, 45, 20-30. doi:10.1016/j.learninstruc.2016.06.007

Clarke, T., Ayres, P., \& Sweller, J. (2005). The impact of sequencing and prior knowledge on learning mathematics through spreadsheet applications. Educational Technology Research and Development, 53, 15-24. doi:10.1007/BF02504794

Csikszentmihalyi, M. (1990). Flow: The psychology of optimal experience. New York, NY: Harper Collins Publishers.

De Vos, T. (1992). Tempo Toets Rekenen [Tempo Test Mathematics]. Nijmegen, The Netherlands: Berkhout.

Dunlosky, J. (2013). Strengthening the student toolbox. Student strategies to boost learning. American Educator, Fall 2013. Retrieved from https://www.aft.org/sites/default/files/periodicals/dunlosky.pdf

Dunlosky, J., Rawson, K. A., Marsh, E. J., Nathan, M. J., \& Willingham, D. T. (2013). Improving students' learning with effective learning techniques: Promising directions from cognitive and educational psychology. Psychological Science in the Public Interest, 14, 4-58.

Eiriksdottir, E., \& Catrambone, R. (2011). Procedural instructions, principles, and examples: How to structure instructions for procedural tasks to enhance 
performance, learning, and transfer. Human Factors, 53, 749-770. doi: $10.1177 / 0018720811419154$

Gick, M. L., \& Holyoak, K. J. (1987). The cognitive basis of knowledge transfer. In S. M. Cormier \& J. D. Hagman (Eds.), Transfer of learning: Contemporary research and applications (pp. 9-46). San Diego, CA: Academic Press.

Hattie, J., \& Gan, M. J. (2011). Instruction based on feedback. In R. E. Mayer \& P. A. Alexander (Eds.), Handbook of research on learning and instruction (pp. 249-271). New York, NY: Routledge.

Hattie, J., \& Timperly, H. (2007). The power of feedback. Review of Educational Research, 77, 81-112. doi:10.3102/003465430298487

Hirsch, E. D. Jr. (2016). Why knowledge matters. Rescuing our children from failed educational theories. Cambridge, MA: Harvard Education Press.

Kalyuga, S., Chandler, P., \& Sweller, J. (2001a). Learner experience and efficiency of instructional guidance. Educational Psychology, 21, 5-23. doi:10.1080/01443410124681

Kalyuga, S., Chandler, P., Tuovinen, J., \& Sweller, J. (2001b). When problem solving is superior to studying worked examples. Journal of Educational Psychology, 93, 579588. doi:10.1037/0022-0663.93.3.579

Kirschner, P. A., Sweller, J., \& Clark, R. E. (2006). Why minimal guidance during instruction does not work: An analysis of the failure of constructivist, discovery, problembased, experiential, and inquiry-based teaching. Educational Psychologist, 41, 7586. doi:10.1207/s15326985ep4102_1

Kirschner, P. A., Sweller, J., Kirschner, F., \& Zambrano, R. J. (2018). From cognitive load theory to collaborative load theory. International Journal of Computer-Supported Collaborative Learning, 13, 213-233. doi:10.1007/s11412-018-9277-y

Krathwohl, D. R. (2002). A revision of Bloom's taxonomy: An overview. Theory into Practice, 41, 212-218.

Lampe, T., Straetmans, G., \& Eggen, T. (2011). De rekenvaardigheid van de Nederlandse verpleegkundige [Nurses' mathematical skills in the Netherlands]. Onderwijs en Gezondheidszorg, 35(3), 3-9. doi:10.1007/s12477-011-0030-y

Lee E. A.-L., \& Wong, K. W. (2014). Learning with desktop virtual reality: Low spatial ability learners are more positively affected. Computers \& Education, 79, 49-58. doi: $10.1016 /$ j.compedu.2014.07.010

Lee, E. A.-L., Wong, K. W., \& Fung, C. C. (2010). How does desktop virtual reality enhance learning outcomes? A structural equation modeling approach. Computers \& Education, 55, 1424-1442. doi:10.1016/j.compedu.2010.06.006 
Margulieux, L., \& Catrambone, R. (2016). Improving problem solving with subgoal labels in expository text and worked examples. Learning and Instruction, 42, 58-71. doi:10.1016/j.learninstruc.2015.12.002

Mayer, R. M. (2001). Multimedia learning. New York, NY: Cambridge University Press.

Morrison, G. R., Ross, S. M., Kalman, H. K., \& Kemp, J. E. (2011). Designing effective instruction. Hoboken, $\mathrm{NJ}$ : John Wiley.

Nicol, D. J., \& Macfarlane-Dick, D. (2006). Formative assessment and self-regulated learning: A model and seven principles of good feedback practice. Studies in Higher Education, 31, 199-218. doi:10.1080/03075070600572090

Noroozi, O., Biemans, H. J. A., Weinberger, A., Mulder, M., \& Chizari, M. (2013). Scripting for construction of a transactive memory system in multidisciplinary CSCL environments. Learning and Instruction, 25, 1-12. doi:10.1016/j.learninstruc.2012.10.002

Pekrun, R. (2011). Emotions as drivers of learning and cognitive development. In R. A. Calvo \& S. K. D'Mello (Eds.), New perspectives on affect and learning technologies: $\mathrm{Vol}$ 3. Exploration in the learning sciences, instructional systems and performance technologies (pp. 23-39). New York, NY: Springer.

Pollock, E., Chandler, P., \& Sweller, J. (2002). Assimilating complex information. Learning and Instruction, 12, 61-86. doi:10.1016/S0959-4752(01)00016-0

Polya, G. (1973). How to solve it: A new aspect of mathematical method. Princeton, NJ: Princeton University Press.

Prins, H., Zwart, D. P., Voogt, J., \& Hettinga, M. (2019). Which professional contexts can enrich the training of medication skills of nurses through virtual reality? Retrieved from

http://healthbytech.com/wp-content/uploads/Abstract-bookSupportingHealth-5.pdf.

Raven, J. C., Court, J. H., Raven, J. (1992). Standard progressive matrices (SPM) (1992 Edition). Oxford, UK: Oxford Psychologists Press.

Rittle-Johnson, B., Siegler, R. S., \& Alibali, M. W. (2001). Developing conceptual understanding and procedural skill in mathematics: An iterative process. Journal of Educational Psychology, 93, 346-362. doi:10.1037/0022-0663.93.2.346

Roediger, H. L., \& Karpicke, J. D. (2006). The power of testing memory: Basic research and implications for educational practice. Perspectives on Psychological Science, 1, 181-210.

Rohrer, D., Dedrick, R. F., \& Burgress, K. (2014). The benefit of interleaved mathematics practice is not limited to superficially similar kinds of problems. Psychonomic Bulletin \& Review, 21, 1323-1330. doi:10.3758/s13423-014-0588-3 
Rohrer, D., Dedrick, R. F., \& Stershic, S. (2015). Interleaved practice improves mathematics learning. Journal of Educational Psychology, 107, 900-908. doi:10.1037/edu0000001

Sadler, D. R. (2010). Beyond feedback: Developing student capability in complex appraisal. Assessment \& Evaluation in Higher Education, 35, 535-550. doi:10.1080/02602930903541015

Schön, D. A. (1983). The reflective practitioner. London, UK: Basic Books.

Shute, V., Ventura, M., Bauer, M., \& Zapata-Rivera, D. (2009). Melding the power of serious games and embedded assessment to monitor and foster learning. In $U$. Ritterfeld, M. Cody, \& P. Vorderer (Eds.), Serious games: Mechanisms and effects (pp. 295-321). New York, NY: Routledge.

Sweller, J. (2010). Element interactivity and intrinsic, extraneous, and germane cognitive load. Educational Psychology Review, 22, 123-138. doi:10.1007/s10648-01091285

Tricot, A., \& Sweller, J. (2014). Domain-specific knowledge and why teaching generic skills does not work. Educational Psychology Review, 26, 265-283. doi:10.1007/s10648013-9243-1

Tynjälä, P. (2013). Toward a 3-P model of workplace learning: A literature review. Vocations and Learning, 6, 11-36. doi:10.1007/s12186-012-9091-z

Van Gog, T., Kester, L., \& Paas, F. (2011). Effects of worked examples, example-problem, and problem-example pairs on novices' learning. Contemporary Educational Psychology, 36, 212-218. doi:10.1016/j.cedpsych.2010.10.004

Van Merriënboer, J. J., \& Sweller, J. (2010). Cognitive load theory in health professional education: Design principles and strategies. Medical Education, 44, 85-93. doi:10.1111/j.1365-2923.2009.03498.x

Wang, M., Kirschner, P. A., Spector, J. M., \& Ge, X. (2018). Computer-based learning environments for deeper learning in problem-solving contexts. Computers in Human Behavior, 87, 403-405. doi:10.1016/j.chb.2018.06.026

Warner, D. O., Nolan, M., Garcia-Marcinkiewicz, A., Schultz, C., Warner, M. A., Schroeder, R., \& Cook, D. A. (2020). Adaptive instruction and learner interactivity in online learning: A randomized trial. Advances in Health Sciences Education, 25, 95-109. doi: 10.1007/s10459-019-09907-3

Weeks, K. W., Hutton, B. M., Young, S., Coben, D., Clochesy, J. M., \& Pontin, D. (2013). Competency modelling and diagnostic error assessment in medication dosage calculation problem-solving. Nurse Education in Practice, 13, 23-32. doi: $10.1016 /$ j.nepr.2012.10.013

Xinhao, X., \& Fengfeng, K. (2016). Designing a virtual reality based, gamelike math learning environment. American Journal of Distance Education, 30, 27-38. 
doi:10.1080/08923647.2016.1119621

Zohar, A., \& David, A. B. (2008). Explicit teaching of meta-strategic knowledge in authentic classroom situations. Metacognition and Learning, 3, 59-82. doi:10.1007/s11409007-9019-4 


\section{Chapter 5}

\section{The Effects of a Computer-Based Virtual Learning Environment on Nursing Students' Mathematical Learning, Self-Efficacy, and Intrinsic Motivation*}

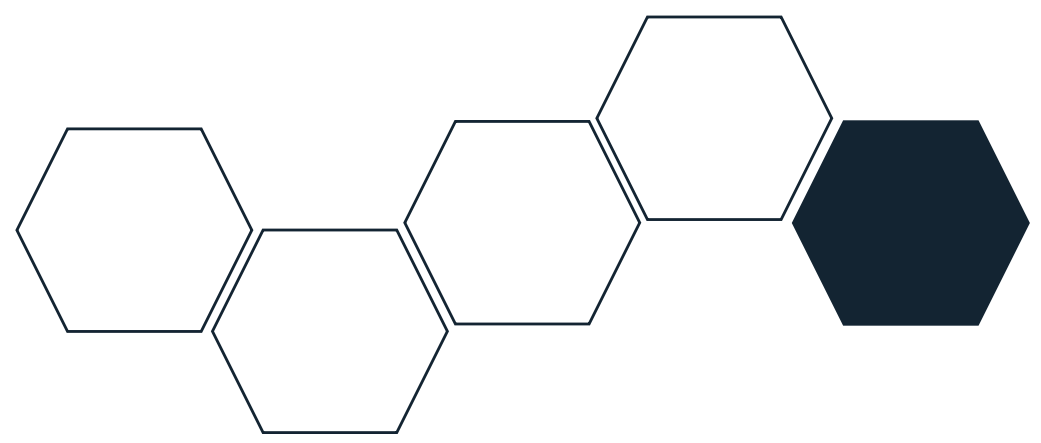

*Parts of this chapter are published as: Zwart, D. P., Goei, S. L., Noroozi, O., \& Van Luit, J. E. H. (2021). Effects of Computer-Based Virtual Learning Environments on Nursing Students' Mathematical Learning in Medication Processes. Research and Practice in Technology Enhanced Learning, 16: 4. doi:10.1186/s41039-021-00147-x

This chapter is submitted in October 2020 for publication. Zwart, D. P., Noroozi, O., Van Luit, J. E. H., \& Goei, S. L. The Effects of a Computer-Based Virtual Learning Environment on Nursing Students' Mathematical Learning, Self-Efficacy, and Intrinsic Motivation. Authors contributions: J.E.H.V.L., O.N., S.L.G. and D.P.Z. conceptualized the research. D.P.Z. collected and analyzed the data; D.P.Z. wrote the original draft, visualized the results, and edited the paper; J.E.H.V.L., O.N., and S.L.G. critically reviewed the paper. 


\begin{abstract}
Computer-based virtual learning environments (CBVLEs) can contribute to mathematical medication learning. This study investigates how training using a CBVLE with standardised conditions, informative feedback, and corrective advice, affects nursing students' mathematical medication learning, self-efficacy, and intrinsic motivation. Four training conditions were used in the CBVLE to facilitate extra support for mathematical medication learning: learning without worked examples, learning with worked examples involving domain-specific knowledge, learning with worked examples involving regular thinking strategies, and learning with combined worked examples. In this study, 118 nursing students were randomly assigned to four conditions, and trained with mathematical medication learning tasks in the CBVLE for four consecutive weeks. Students were pretested and post-tested on their mathematical medication learning, self-efficacy, and intrinsic motivation. The results showed that nursing students' mathematical medication learning, self-efficacy, and intrinsic motivation was enhanced over time. Differences were found between the training conditions of combined worked examples and worked examples involving domain-specific knowledge on self-efficacy outcomes, and on mathematical medication learning when partialling out nursing students' non-verbal intelligence outcomes. This study indicates that mathematical medication learning using the CBVLE with the extra support of worked examples helps nursing students with their selfconfidence and ability to successfully complete mathematical medication learning tasks.
\end{abstract}




\section{Introduction}

Mathematical medication learning requires students' mastery of procedural skills, domainspecific knowledge, and the rules underlying basic computational skills, as well as effective communication, teamwork, expert knowledge, and decision-making in medicine (Duffy, Lajoie, Pekrun, \& Lachapelle, 2018). Computer-based virtual learning environments (CBVLEs) can account for that: they have the potential to be effective learning tools for mathematical medication learning (Zwart, Noroozi, Van Luit, Goei, \& Nieuwenhuis, 2020), especially when forms of instruction are based on cognitive load theory principles (Chen, Woolcott, \& Sweller, 2017). On top of that, CBVLEs are learning environments for students to train mathematical medication tasks and procedural skills, as they combine a lot of scenarios with different mathematical medication problems that students can practice without risking patients' safety (Makransky et al., 2019). What is unclear however, is how mathematical medication learning using a CBVLE affects fundamental motivational aspects, such as self-efficacy and intrinsic motivation (for example, Bandura, 1988; Deci \& Ryan, 1985; Denissen, Zarrett, \& Eccles, 2007; Lee \& Seo, 2021; Pekrun, 2006). Such a stimulating learning environment can enhance students' self-efficacy (Bandura, 1988), but students' level of self-efficacy depends on the context and is enhanced when students appreciate the task they have fulfilled and perform well (Denissen et al., 2007; Schunk \& DiBenedetto, 2016). Self-efficacy is positively associated with motivation, which in turn enhances the learning outcomes of students (Schunk \& DiBenedetto, 2016; Schunk \& Pajares, 2009). In the CBVLE, the learning tasks can be adapted to students' future professions. This might enhance students' interest, which is a typical intrinsic motive (Liu, Hau, \& Zheng, 2019). Intrinsic motivation is the motive derived from the activity itself, rather than from other factors (Deci \& Ryan, 1985). Standardised conditions in the CBVLE, displayed as corrective advice and informative feedback, can support students in learning (Nicol \& Macfarlane-Dick, 2006). For mathematical medication learning in a CBVLE, extra conditions for complex learning tasks might be needed (Wang, Kirschner, Spector, \& Ge, 2018), especially for students struggling with mathematics. For that reason, worked examples can be embedded in a CBVLE. Worked examples show students how to solve specific mathematical problems (Chen, Kalyuga, \& Sweller, 2016; Kirschner, Sweller, Kirschner, \& Zambrano, 2018; Van Gog, Kester, \& Paas, 2011). To determine which training condition in the CBVLE fosters mathematical medication learning, self-efficacy, and intrinsic motivation, this study investigates the effects of four different training conditions, in addition to the existing standardised conditions in the CBVLE, on nursing students' mathematical medication learning, self-efficacy, and intrinsic motivation. 


\section{Computer-Based Virtual Learning Environments (CBVLEs)}

CBVLEs offer potential situated learning possibilities, especially when instructional activities are based on Cognitive Load Theory (CLT) principles, such as interleaved practice and feedback (Chen et al., 2017). Such CBVLEs are designed with features that represent students' future professional tasks, resulting in a high degree of realism (Lee, Wong, \& Fung, 2010). The future professional tasks are meaningful for vocational education students since they are interested in school subjects that cover their future profession. Moreover, when students have opportunities to learn tasks based on their interests, it positively emphasises their perception of capabilities (Lent, Brown, \& Hackett, 2002). In a virtual learning environment, students are provided opportunities to safely train in realistic scenarios making the right decisions that are not possible in real life situations (Makransky, Borre-Gude, \& Mayer, 2019). Structured learner-centred activities in CBVLEs promote students' awareness of the expectations of learning tasks and the available means that fulfil these expectations (Alfassi, 2003). Because of this, the level of students' confidence could increase while successfully accomplishing the learning tasks. When students have a strong sense of confidence, their interest and attention for the task improves (Bandura, 1997; Pajares, 2003; Schunk, 2012). CBVLEs enable students to work on their future professional tasks, such as everyday mathematical medication-related tasks for nursing students, including mathematical medication problems, procedural skills, and developing basic computational skills.

\section{Mathematical medication}

Mathematical medication is about the clinical source of - and the relationships between the elements of dosage and rate formulae and equations when administering medication (Weeks et al., 2013). Besides theoretical knowledge of medicines, mathematical medication learning also requires mathematical domain-specific knowledge of medication (Prins, Zwart, Voogt, \& Hettinga, 2019). In addition, basic computational skills, such as addition, subtraction, multiplication, and division of whole numbers, units of measurement, decimals, fractions, and conversion between them, are important knowledge units that nursing students must possess (Weeks et al., 2013; Zwart et al., 2020). This is the underlying unifying knowledge that is not always visible and requires both implicit and explicit understanding of the principles that govern the interrelations between the units of knowledge in the mathematical medication domain (Canobi, 2009; Rittle-Johnson, Siegler, \& Alibali, 2001). Also, the importance of procedural knowledge for administration of medication should not be underestimated. Procedural knowledge is tied to specific problem types, which in turn requires domain-specific knowledge (Rittle-Johnson et al., 2001). Domain-specific knowledge enables students to successfully complete their learning tasks, 
and thus affects students' self-efficacy positively (Denissen et al., 2007; Schunk \& DiBenedetto, 2016).

\section{Self-efficacy}

Self-efficacy refers to students' belief or expectation in successfully completing learning tasks (Bandura, 1988; Pajares \& Schunk, 2001). Self-efficacy influences the choices that students make. Pintrich (1988) states that students with high levels of self-efficacy will set their sights higher than those who do not believe that they can be successful. In addition, Pintrich mentions that students' efforts to learn can also be driven by the relevance of the learning tasks. The complexity of the learning tasks, however, can also affect students' confidence (Keller, 2010, p. 9): 'Tasks that either are too difficult or are perceived by the learner to be excessively challenging can reduce confidence which can lead to levels of performance that are lower than the actual capabilities of a learner'. Zwart et al. (2020) found that self-directed learning, namely connecting prior knowledge to new knowledge with digital learning materials (DLMs), appeared to be much more difficult than previously thought: supporting students to learn with DLMs needs task conditions that are either clearly communicated or, as in CBVLEs, clearly programmed. Their study found that working with DLMs decreased nursing students' self-efficacy outcomes, which according to self-efficacy theorists cause motivational problems. Accordingly, when students consider their self-regulatory skills positively, students' beliefs in their academic capabilities are enhanced (Bandura \& Schunk, 1981). These beliefs boost students' inner motivation that conversely steer students' task-directed learning (Liu et al., 2019).

\section{Intrinsic motivation}

Intrinsic motivation is the consequent satisfaction associated with the performance of the learning tasks (Ryan \& Deci, 2000). It is students' urge to constantly respond to challenges, to extend their capacities, to examine and study, and to learn. Intrinsic value of activities means that no matter the produced relevant outcomes, students still appreciate the activity in contrast to extrinsic value, where the outcomes produced are a jumping-off place (Pekrun \& Stephens, 2010). Intrinsic value and enjoyment are important affective factors for the process of learning and for students' expectancy of success in classroom instruction (Lee \& Seo, 2021; Pekrun, 2006), and the same applies for computer-based instruction, of course. Enjoyment refers to activities that are controllable and valued positively. This contributes positively to completing learning tasks, which gives rise to students' efficacy expectations (Bandura, 1988). Many students who are struggling, have no belief in their ability to succeed and quit easily when solving problems becomes too difficult. They constantly fail in efforts to achieve the learning goals, so for them, there is no reason to engage in a learning activity. Whereas high-achieving students show goal-directed behaviour and engage in activity for its own sake (Liu et al., 2019), struggling students 
might get motivated by presenting a learning task that identifies them with the process or product (Csikszentmihalyi, 1990). Moreover, the support provided by worked examples can motivate students in solving mathematical problems, since worked examples contribute to completing tasks and achieving goals.

\section{Worked examples}

Worked examples are instructional activities that can show students how to apply procedures to specific mathematical problems (Chen et al., 2016; Kirschner et al., 2018; Van Gog et al., 2011). Worked examples can also be combined with regular problemsolving steps to emphasise thinking strategies that increase transfer to other problems and issues (Ben-David \& Zohar, 2009). Worked examples can enhance the acquisition of domain-specific and domain-general knowledge, but their use may lead to overloading of students' working memory (Kirschner et al., 2018), which can cause motivational problems. Development of fundamental motivational aspects, such as self-efficacy and intrinsic motivation in CBVLEs, is under-researched (Merchant et al., 2012).

In this study, we will compare the effect of four different training conditions in a CBVLE on nursing students' mathematical medication learning, self-efficacy, and intrinsic motivation. The students were randomly assigned to one of four conditions in the CBVLE: mathematical medication learning without worked examples (condition 1), mathematical medication learning with worked examples involving domain-specific knowledge (condition 2), mathematical medication learning with worked examples involving regular thinking strategies (condition 3), and mathematical medication learning with a combination of both types of worked example (condition 4). Since struggling students might have lower general learning capacities and lower self-efficacy for mathematical medication learning, we also investigate how differences in nursing students' general learning capacities, as demonstrated in their non-verbal intelligence outcomes, are considered to be important for individual differences in mathematical medication learning, self-efficacy, and intrinsic motivation for multimedia learning (e.g., Kalyuga, Ayres, Chandler, \& Sweller, 2003; Liu \& Koirala, 2009; Zwart et al., 2020). Specifically, the following research questions are addressed:

1. What are the effects of the four different instructional approaches in the CBVLEs on nursing students' mathematical medication learning, self-efficacy, and intrinsic motivation?

2. What are the effects of the four different instructional approaches in the CBVLEs on nursing students' mathematical medication learning, self-efficacy, and intrinsic motivation when controlling for nursing students' expertise level? 


\section{Method}

\section{Context and Participants}

The study is part of a larger study (see also Zwart, Goei, Noroozi, \& Van Luit, 2021) and took place in the Netherlands. The participants were 118 students from five post-secondary vocational nursing schools $(\mathrm{N}=44)$ and from seven universities of applied sciences $(\mathrm{N}=74)$, at which a bachelor's nursing programme was offered. Although the educational levels are different for these two groups of students, the mathematical medication training and its content is the same in both educational programmes. The mean age of the participants was 19.6 years $(S D=2.4) ; 92 \%$ were female and $8 \%$ were male. Students worked on a bring-your-own-device (BYOD) basis in this study, except for two schools in which students used PCs. Students had basic computer skills (Mpre = 3.7, SD =0.7; Min $=1.0, \operatorname{Max}=5.0$ ), but working with a CBVLE was new to them. Each student was compensated with a $€ 15$ voucher for their contribution and gave active informed consent to take part in the study.

The students were randomly assigned to one of four conditions in the CBVLE: mathematical medication learning without worked examples (condition 1), mathematical medication learning with worked examples involving domain-specific knowledge (condition 2), mathematical medication learning with worked examples involving regular thinking strategies (condition 3), and mathematical medication learning with a combination of both types of worked example (condition 4).

\section{The Computer-Based Virtual Learning Environment}

The CBVLE is defined as an interactive digital learning environment via desktop VR that uses a 3-D image on a computer screen (Lee \& Wong, 2014). The CBVLE was designed with standardised conditions supporting students' self-regulated learning, corrective advice, and informative feedback in the form of domain-specific mathematical rules (see Table 1). The CBVLE was designed in Second Life $^{2}$ platform as a field hospital with six medical doctors who each tended to patients in these tents. The names of the patients were matched to the names mentioned in the mathematical medication problems in the CBVLE. Basic computational skills were practised using exercises in a tent called 'the Lab'. For this study, the four different training conditions, demonstrated as worked examples, were embedded in the CBVLE.

\footnotetext{
${ }^{2}$ Second Life is a free 3D online virtual world where users can create, connect, and interact with others in the world using voice and chat (secondlife.com).
} 


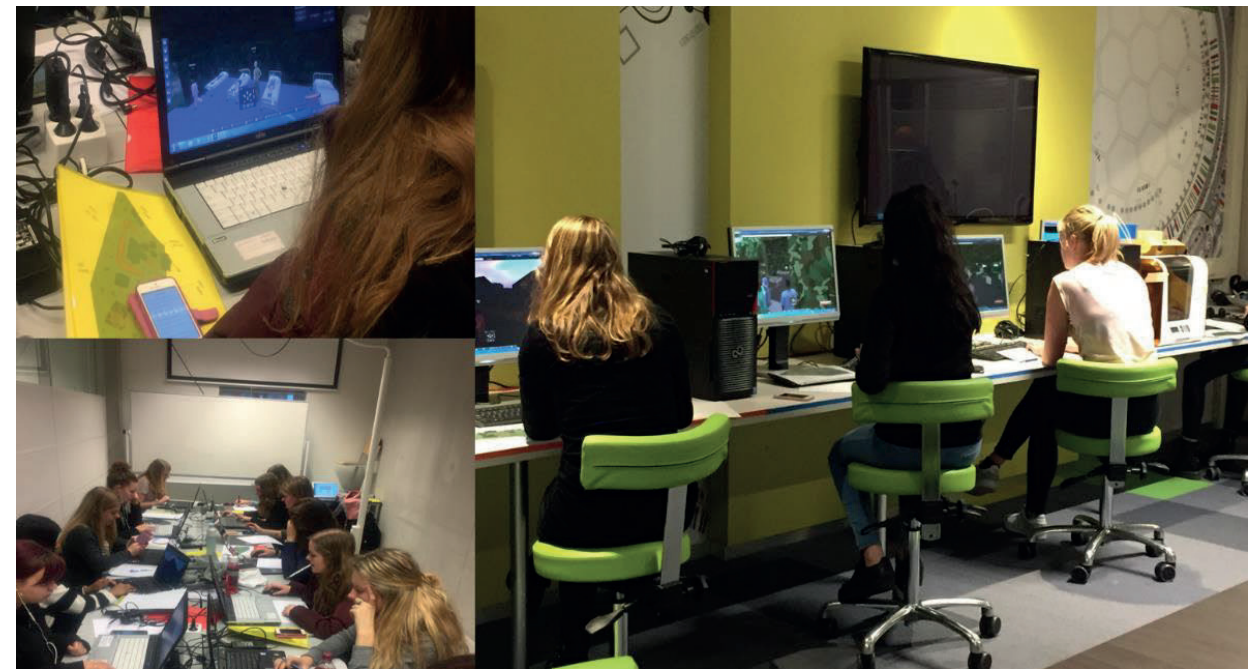

Figure 1. Nursing students training their mathematical medication learning with the CBVLE.

\section{Learning Materials}

The subject to be learned was the concept of mathematical medication, and specifically the three domains of liquid medication, infusion fluids, and solid medication (see Table 1). The actions to be taken by the nursing students (as avatars), required in the CBVLE: (i) receiving the assignment from a doctor; (ii) washing hands; (iii) communicating with the patient; (iv) preparing the medication by solving a mathematical medication problem; ( $v$ ) administering medication; and (vi) updating the patient's file and returning it to the doctor. The doctor could also tell the nurse to go to 'The Lab' to carry out shorter mathematical exercises. 
Table 1

Overview of the Aspects of Domain-specific Mathematical Knowledge Related to 'Liquid

Medication', 'Infusion Fluid', and 'Solid Medication' in a CBVLE

\begin{tabular}{|c|c|c|c|c|c|}
\hline $\begin{array}{l}\text { Medication } \\
\text { domains }\end{array}$ & $\begin{array}{l}\text { Domain- } \\
\text { specific } \\
\text { knowledge }\end{array}$ & $\begin{array}{l}\text { Domain-specific } \\
\text { rules for feedback }\end{array}$ & $\begin{array}{l}\text { Underlying } \\
\text { domain-specific } \\
\text { principles for all } \\
\text { domains }\end{array}$ & $\begin{array}{l}\text { Learning } \\
\text { tasks }\end{array}$ & $\begin{array}{l}\text { Basic } \\
\text { computatio } \\
\text { nal skills }\end{array}$ \\
\hline $\begin{array}{l}\text { Liquid } \\
\text { medication } \\
\text { (incl. } \\
\text { dilution) }\end{array}$ & $\begin{array}{l}\text { Ratio of the } \\
\text { dissolved } \\
\text { substance and } \\
\text { diluent }\end{array}$ & $\begin{array}{l}\begin{array}{l}\text { mass/volume } \\
(\mathrm{m} / \mathrm{v})\end{array} \\
1 \%=1 \text {-gram } \\
\text { dissolved } \\
\text { substance } / 100 \mathrm{ml} \\
1 \% \text { o }=1 \text {-gram } \\
\text { dissolved } \\
\text { substance } / 1000 \mathrm{ml} \\
(1 \text { litre) } \\
\text { volume/volume } \\
(\mathrm{v} / \mathrm{v}) \\
1 \%=1 \mathrm{ml} \\
\text { liquid/100 ml } \\
1 \%=1 \mathrm{ml} \\
\text { liquid/1000 } \mathrm{ml}(1 \\
\text { litre })\end{array}$ & $\begin{array}{l}\text { Quantities, } \\
\text { units, } \\
\text { conversions of } \\
\text { ratios: } \\
\text { a. fractions } \\
\text { b. decimals } \\
\text { c. numbers } \\
\text { d. percentage } \\
\text { relations between } \\
\text { a,b,c,d, } \\
\text { divide, } \\
\text { multiplication, } \\
\text { hours, minutes, } \\
\text { seconds (time } \\
\text { ratio), } \\
\text { elements of the } \\
\text { prescription } \\
\text { dispensed, } \\
\text { extract numerical } \\
\text { information, } \\
\text { apply calculations } \\
\text { correctly and } \\
\text { accurately }\end{array}$ & $\begin{array}{l}\text { P. suffers } \\
\text { severe pain. He } \\
\text { is prescribed } 15 \\
\text { mg morphine } \\
\text { every four } \\
\text { hours. Stocked: } \\
1 \mathrm{ml} \text { morphine } \\
\text { ampoules of } 15 \\
\mathrm{mg} / \mathrm{ml} \text {. How } \\
\text { many ml do you } \\
\text { inject every } \\
\text { four hours? } \\
\text { How many } \mathrm{ml} \text { is } \\
\text { this per day? }\end{array}$ & $\begin{array}{l}16 \times 8= \\
12 \times 9= \\
1 / 4+3 / 4= \\
3 / 3+5 / 3= \\
3 / 4-2 / 8= \\
14 / 5-9 / 5= \\
3 / 4 \times 4 / 5= \\
5 / 10 \times 4 / 8= \\
4 / 5: 2 / 5= \\
3 / 5: 1 / 3= \\
1 / 4=0.25 \\
1 / 20=0.05 \\
0.09=\ldots . . \% \\
0.50=\ldots \% \\
75 \%=0.75 \\
30 \%=0.30 \\
\text { How much is: }\end{array}$ \\
\hline $\begin{array}{l}\text { Infusion of } \\
\text { fluids }\end{array}$ & Drip rating & $\begin{array}{l}20 \text { drops per } \\
\text { millilitre } \\
\text { 1. Calculate the total } \\
\text { number of drips } \\
\text { 2. Calculate the } \\
\text { drips per hour } \\
\text { 3. Calculate the } \\
\text { drips per minute }\end{array}$ & & $\begin{array}{l}\text { G. is } \\
\text { administered a } \\
\text { drip of } 500 \mathrm{ml} \\
0.9 \% \mathrm{NaCl} \text { in } \\
\text { three hours. } \\
\text { How many drips } \\
\text { are } \\
\text { administered to } \\
\text { G. per minute? }\end{array}$ & $\begin{array}{l}5 \% \text { of } \\
1000 \mathrm{ml} ? \\
4 \% \text { of } \\
250 \mathrm{ml} \text { ? } \\
1 \mathrm{~L}=\ldots \mathrm{ML} \\
1 \mathrm{ML}=\ldots \mathrm{CC}\end{array}$ \\
\hline $\begin{array}{l}\text { Solid } \\
\text { medication }\end{array}$ & $\begin{array}{l}\text { Dosage } \\
\text { calculation for } \\
\text { tablets }\end{array}$ & $\begin{array}{l}\text { Count, divide, } \\
\text { multiply, work with } \\
\text { fractions, } \\
\text { reference } \\
\text { measurements: } \\
24 \text { hours in a day } \\
60 \text { minutes in an } \\
\text { hour } \\
50 \%=1 / 2 \\
1 / 4=25 \% \\
\text { etc. }\end{array}$ & & $\begin{array}{l}\text { F. suffers from } \\
\text { cystitis. She } \\
\text { receives } \\
\text { treatment with } \\
\text { antibiotics for } \\
\text { six days: } 750 \\
\text { mg Amoxicillin } \\
\text { every } 12 \text { hours. } \\
\text { Stocked: } \\
\text { Flemoxin with } \\
375 \mathrm{mg} \\
\text { Amoxicillin per } \\
\text { tablet. How } \\
\text { many tablets } \\
\text { should F. } \\
\text { swallow during } \\
\text { treatment? }\end{array}$ & \\
\hline
\end{tabular}




\section{Procedure}

Before carrying out the experimental study, 11 students participated in a pilot test to determine the feasibility of the study with respect to the introduction setting, learning tasks, materials, instruments, feedback, and the platform. This pilot resulted in a slight modification of the introduction section - a paper-based manual - and we introduced an instruction in the CBVLE, using photos to guide the student in their first activities.

The experimental session consisted of four main phases (see Table 2). During the (1) introduction and personal data phase, which took 70 minutes, students received introductory explanations about the CBVLE training. Students were then assigned to avatars and logged into the CBVLE. These avatars (students) were randomly allocated one of four conditions. Students practiced on one round in the CBVLE, and it was made clear that they were expected to work individually during the game, without help from the researcher or their peers, while paying attention to the information on the screen (30 minutes). Then students were asked to complete a questionnaire on their personal data, such as their name, gender, age, and computer skills (10 minutes). During the (2) individual phase, students first received an introductory explanation of how to complete the questionnaire, the non-verbal intelligence test, and the domain-specific mathematical knowledge test ( 5 minutes). Then they were asked to complete the questionnaire (20 minutes) on intrinsic motivation and self-efficacy. The Standard Progressive Matrices (SPM) non-verbal intelligence test was applied (Raven et al., 1992), which took 45 minutes. After a 10-minute break, students were tested on their domain-specific mathematical knowledge by the CITO test ( 60 minutes). Week 2 to 5 formed the (3) the learning phase. This phase took 90 minutes per week, for four consecutive weeks. During the (4) post-test and debriefing phase (100 minutes), students first completed their domain-specific mathematical knowledge test (60 minutes). Then students were given the questionnaires on self-efficacy and intrinsic motivation on training using a CBVLE. Finally, the participants got a short debriefing for about 10 minutes. After this, the students' activity logs were uploaded to a disk belonging to the researcher. 
Table 2

Procedure Used for the CBVLE Study

\begin{tabular}{ll}
\hline Procedure for mathematical medication training in the CBVLE & Duration \\
\hline Week 1: Introduction and personal data & $70 \mathrm{~min}$ \\
Introductory explanations of the procedure, materials, and the purpose & $30 \mathrm{~min}$ \\
of the research study & $30 \mathrm{~min}$ \\
Students were given avatars, logged in and played a round & $10 \mathrm{~min}$ \\
Personal data questionnaire & $85 \mathrm{~min}$ \\
Individual pre-test measurements & $5 \mathrm{~min}$ \\
Introductory remarks & $20 \mathrm{~min}$ \\
Assessment of self-efficacy (se) and intrinsic motivation (im) & $60 \mathrm{~min}$ \\
(questionnaire) & $90 \mathrm{~min}$ per week \\
Pre-test assessment of domain-specific mathematical knowledge & $100 \mathrm{~min}$ \\
Weeks 2-5: Learning phase: CBVLE training & $60 \mathrm{~min}$ \\
Week 6: Post-tests and debriefing & $30 \mathrm{~min}$ \\
Post-test assessment of domain-specific mathematical knowledge & $10 \mathrm{~min}$ \\
Assessment of se, im, and design components (questionnaires) & Debriefing
\end{tabular}

Measurements and Instruments

Measurement of Nursing Students' Non-Verbal Intelligence

Nursing students' non-verbal intelligence was tested using a paper-based format of the SPM test (Raven et al., 1992). The test consisted of 60 problems divided into five sets of 12 items, ranging from easy to complex $(A, B, C, D, E)$. Each item consisted of a figure with a missing piece. Below the figure, six or eight possible answers were given to complete the missing piece, only one of which was correct. There was no time limit on the test, but it generally took about 45 minutes. The reliability score for this test in our study was at an average level (Cronbach's $a=.62$ ).

Measurement of Nursing Students' Mathematical Medication Knowledge

Domain-specific mathematical medication knowledge was assessed with a test composed by Cito (the Dutch national organisation for test development; see Lampe, Straetmans, \& Eggen, 2011), which was used to measure domain-specific mathematical medication knowledge both before and after intervention with the CBVLE. Two parallel versions were therefore developed by Cito. The original domain-specific mathematical medication knowledge test consisted of 50 multiple choice questions, with 20 questions on domainspecific mathematical medication knowledge for infusion fluids, 19 questions on liquid medication, and 11 questions on solid medication (tablets). After an item response analysis, four items with poor discriminatory power were eliminated from the pretest, after which Cronbach's $a=.80$. The post-test reliability was also good (Cronbach's $a=.83$ ). 
Measurement of Nursing Students' Self-Efficacy and Intrinsic Motivation

Self-efficacy and intrinsic motivation were assessed using a questionnaire with 12 items on a five-point Likert scale ranging from 'fully disagree' to 'fully agree'. The questionnaire was designed by Oprins et al. (2015) and adjusted for this study. Seven items asked students to ascertain the extent to which they believed in their ability to successfully complete learning tasks (self-efficacy). For example, they were asked to rate their own expertise in mathematical medication and to qualify themselves against other students. The reliability coefficients were high; in the pre-assessment $a=.81$, and $a=.86$ in the post-assessment. Five items of this questionnaire were aimed at ascertaining students' intrinsic motivation towards mathematical medication. For example, they were asked to rate whether the mathematical medication lessons held interest for them and their level of pleasure during mathematical medication lessons. The reliability coefficient was sufficiently high; in the pre-assessment it was $a=.78$ and it was also high in the post-assessment, $a$ $=.84$.

\section{Ethics}

Students were free to engage in the study. After giving their consent and after a verbal introduction on the goals of the CBVLE training, students could still choose not to participate. Students were assured that identifying information was not available to anyone except the researchers. Results were de-identified by numbering both the students and their tests, and files were located in different places under different names. The Faculty Ethics Review Committee (FETC) of the Faculty of Social Sciences of Utrecht University reviewed and approved the research study under case 19-230.

Data Analyses

A total of 118 students participated in the study. For several reasons, 17 students (14\%) dropped out of the study. The results for performance are based on analyses of data from 101 students who completed all the sessions and tests.

To answer the first research question, repeated measurement ANOVAs were applied to corroborate the individual acquisition of nursing students' mathematical medication learning, nursing students' self-efficacy, and nursing students' intrinsic motivation across the four training conditions. Thereafter, post hoc tests were conducted to determine the significant differences between the four training conditions. For research question 2 we included nursing students' non-verbal intelligence as a covariate, after controlling for assumptions. 


\section{Results}

Firstly, for research question one, we found that nursing students' mathematical medication outcomes showed significant differences from pre-test to post-test, $F(1,97)=$ $119.80, p<.001, \eta 2=.55$. No significant results were found between the training conditions in the CBVLE on mathematical medication learning, $F(3,97)=1.36, p=.26$.

Secondly, we found that nursing students' outcomes on self-efficacy showed significant differences from pre-test to post-test, $F(1,88)=17.64, p<.001, \eta 2=.17$. The training conditions in the CBVLE, obtained no significant differences in nursing students' selfefficacy, $F(3,88)=2.31, p=.08$. However, further analysis showed that training condition 4 showed significantly higher outcomes than the training conditions one, (Mdiff $=2.85$, SDdiff $=1.30, p<.05)$, and training condition two $($ Mdiff $=3.28$, SDdiff $=1.35, p<.05)$.

Thirdly, with respect to intrinsic motivation, significant results were obtained from pre-test to post-test, $F(1,85)=33.69, p<.001, \eta 2=.28$. No differences were found between the training conditions in the CBVLE on intrinsic motivation outcomes, $F(3,85)=.25, p=$ .86. Table 3 shows the means and standard deviations of nursing students' mathematical medication learning, self-efficacy, and intrinsic motivation in the four training conditions in the CBVLE.

For research question 2, the assumptions of the covariate model of the regression slopes and homogeneity of variance results have not been violated. When we partial out the effects of nursing students' non-verbal intelligence on nursing students' mathematical medication learning related to the training conditions in the CBVLE, no significant outcomes were found on mathematical medication learning: $F(3,97)=2.18, p=.10$. However, further analysis by pairwise comparisons showed that training condition 1 showed a significant larger mean difference on mathematical medication learning then training condition 2 (Mdiff $=3.16$, SDdiff $=1.52, p<.05$ ). In addition, training condition 4 showed a significant larger mean difference on mathematical medication learning than training condition 2 (Mdiff $=3.74$, SDdiff $=1.62, p<.05$ ).

After partialling out nursing students' non-verbal intelligence scores to determine the results of nursing students' self-efficacy related to the training conditions in the CBVLE, no significant differences were found, $F(3,88)=2.56, p=.06$. In addition, pairwise comparison showed significant results for training condition 4 against training condition 1 (Mdiff $=3.03$, SDdiff $=1.31, p<.05)$, and training condition 2 (Mdiff $=3.41$, SDdiff $=$ $1.35, p<.05)$ when not controlling for non-verbal intelligence outcomes.

No significant results were found after controlling for nursing students' non-verbal intelligence outcomes on nursing students' intrinsic motivation for mathematical learning via the four different training conditions in the $\operatorname{CBVLE}, F(3,84)=.27, p=.85$. Table 3 
shows the means and standard deviations of nursing students' non-verbal intelligence scores in the four instructional support conditions.

Table 3

Summary of Nursing Students' Results

\begin{tabular}{|c|c|c|c|c|c|c|c|c|c|c|c|c|}
\hline & \multicolumn{2}{|c|}{$\begin{array}{l}\text { Condition } 1 \\
\text { CBVLE with no } \\
\text { support }\end{array}$} & & \multicolumn{2}{|c|}{$\begin{array}{c}\text { Condition } 2 \\
\text { Domain- } \\
\text { specific } \\
\text { support } \\
\end{array}$} & & \multicolumn{3}{|c|}{$\begin{array}{c}\text { Condition } 3 \\
\text { Regular } \\
\text { thinking } \\
\text { strategies } \\
\end{array}$} & \multicolumn{3}{|c|}{$\begin{array}{l}\text { Condition } 4 \\
\text { Combination }\end{array}$} \\
\hline & M & SD & $\mathrm{n}$ & M & SD & $\mathrm{n}$ & M & SD & $\mathrm{n}$ & M & SD & $\mathrm{n}$ \\
\hline \multicolumn{13}{|l|}{ Test scores } \\
\hline Non-verbal ability & 49.96 & 4.14 & 24 & 50.64 & 3.94 & 33 & 50.56 & 4.96 & 25 & 48.53 & 4.49 & 30 \\
\hline Pre-test maths & 23.41 & 7.00 & 27 & 24.45 & 7.88 & 33 & 20.33 & 6.71 & 27 & 21.26 & 5.08 & 31 \\
\hline Post-test maths & $30.82 * * *$ & 7.33 & 22 & 29.54 & 6.90 & 28 & 27.35 & 9.65 & 28 & 28.96 & 5.10 & 28 \\
\hline Pre-test self-efficacy & 18.73 & 5.67 & 30 & 18.00 & 5.41 & 26 & 19.14 & 4.13 & 28 & 21.14 & 5.02 & 22 \\
\hline Post-test self-efficacy & $20.07 * * *$ & 5.45 & 28 & 20.21 & 4.62 & 24 & 21.88 & 4.53 & 26 & 22.18 & 4.37 & 22 \\
\hline $\begin{array}{l}\text { Pre-test intrinsic } \\
\text { motivation }\end{array}$ & 15.58 & 3.26 & 31 & 16.31 & 3.62 & 26 & 16.50 & 3.12 & 28 & 16.83 & 3.32 & 24 \\
\hline $\begin{array}{l}\text { Post-test intrinsic } \\
\text { motivation }\end{array}$ & $18.89 * * *$ & 2.41 & 28 & 19.00 & 2.51 & 24 & 18.26 & 3.62 & 26 & 18.52 & 3.16 & 22 \\
\hline
\end{tabular}

$* * * p<.001$

\section{Discussion}

The results of this study confirm the expectations that learning using the computer-based virtual Learning environment (CBVLE) facilitates nursing students' mathematical medication learning, their self-efficacy outcomes for mathematical medication learning, and also encourages their intrinsic motivation for mathematical medication learning using the CBVLE. This study also found that the four training conditions in the CBVLE did not discriminate between nursing students' mathematical medication outcomes and their intrinsic motivation for mathematical medication learning using the CBVLE. For self-efficacy outcomes, training condition 4 (extra support of worked examples involving domainspecific knowledge and regular thinking strategies) found significant higher self-efficacy outcomes than training condition 1 (without the extra support of worked examples) and training condition 2 (extra support of worked examples involving domain-specific knowledge). This indicates that nursing students' self-efficacy in successfully completing mathematical medication learning tasks using the CBVLE might be positively influenced by the extra support of worked examples involving both domain-specific knowledge and 
regular thinking strategies. Accordingly, the same accounted for the training conditions on mathematical medication learning when partialling out the effect of nursing students' nonverbal intelligence: nursing students' mathematical medication learning was positively influenced by the extra support of worked examples involving domain-specific knowledge and regular thinking skills. What is interesting however is that nursing students in training condition 1 (no worked example support) also showed higher mathematical medication learning outcomes than nursing students in training condition 2 when removing the effect of non-verbal intelligence outcomes. This might indicate that the CBVLE is well-designed for mathematical medication learning, but for complex learning tasks and for nursing students who approach mathematical medication learning using the CBVLE as a huge challenge, the extra support of worked examples involving domain-specific knowledge and regular thinking skills might give added impetus to mathematical medication learning using the CBVLE.

Nursing students' enhanced self-efficacy in mathematical medication learning using the CBVLE might be driven by the relevance of the learning tasks that display nursing students' future professional medication tasks (Bandura \& Schunk, 1981; Csikszentmihalyi, 1990; Pekrun \& Stephens, 2010). When students designate the learning task as useful and important for their future, students' motivation for learning strengthens (Deci \& Ryan, 2000). This explains the increasing intrinsic motivation for mathematical medication learning using the CBVLE. The learning tasks in the CBVLE were contextualised in a way so that nursing students were able to recognise their importance: the learning tasks were subject to the medical procedure laid down in the medication description for nursing students (Actiz Health Organization, 2012). Mathematical medication learning using the CBVLE encouraged students, as avatars, to enhance their mathematical medication knowledge and basic computational skills, without being afraid to fail, given results that showed that nursing students' self-efficacy was rising. It appears that, compared with mathematical medication learning with DLMs, where nursing students' self-efficacy outcomes decreased (see Zwart et al., 2020), mathematical medication learning using the CBVLE enhanced nursing students' self-efficacy by creating a learning environment that allowed for autonomy and collaboration (Pekrun, 2006). Though nursing students were not able to collaborate but worked on the learning tasks in the CBVLE individually, the importance of seeing, being, and meeting together in the virtual world, cannot be underestimated. This might compensate for the teacher's absence, as opposed to mathematical medication learning with DLMs. The concept of teaching with a teacher implies the existence of a teacher in favour of the student (Hattie \& Timperly, 2007), but students can feel the exact opposite: when teachers do not recognise students' mathematical learning outcomes as stable, students fail faster (Woodcock \& Vialle, 2011). This implies that the teacher's presence might not be an exceptionally good factor for every 
nursing students' mathematical learning. This - as well as the lack of time for teachers to give adequate feedback to all their students during mathematical medication lessons might create students' learned helplessness (Seligman, 1972; Seligman \& Campbell, 1965) in traditional learning or learning with DLMs. By contrast, a CBVLE enables the design of the procedure of the mathematical medication learning tasks that provokes goal-directed learning: nursing students solve mathematical medication problems playfully; and the standardised conditions in the CBVLE support nursing students with corrective advice and informative feedback. Nursing students appreciated the activity in the CBVLE. The intrinsic motivation outcomes were highly significant which is an important factor for the process of learning and for students' expectancy of being successful (Lee \& Seo, 2021; Pekrun, 2006). This is in line with the outcomes of this study and recent studies (e.g., Huang, Johnson, \& Han, 2013; Lee et al., 2010; Makransky \& Peterson, 2019; Xinhao \& Fengfeng, 2016), who also found that learning with virtual reality led to higher motivation and selfefficacy. That is to say, nursing students who are confident in their mathematical performance, show better mathematics achievement (Liu \& Koirala, 2009).

\section{Conclusions, Limitations, and Suggestions for Future Research}

In conclusion, this study found that a computer-based virtual learning environment in which nursing students can practise professional mathematical medication learning tasks consisting of standardised conditions with corrective advice and informative feedback enhances nursing students' mathematical medication learning, self-efficacy, and intrinsic motivation. The results indicate that a CBVLE with the extra support of worked examples involving domain-specific knowledge and general thinking skills can also train nursing students for complex situations that they are likely to come across in professional medication practice (Prins et al., 2019), and helps them with their belief that they can successfully complete mathematical medication learning tasks (Bandura, 1988; Pajares \& Schunk, 2001).

This study was an initial attempt to train nursing students in mathematical medication procedures with a CBVLE and investigate the effects on mathematical medication learning, self-efficacy, and intrinsic motivation. It should be noted the standardized conditions in the CBVLE, such as feedback and the other design features in the CBVLE are not included in this study. Since research on design features in virtual learning environments is quite piecemeal (Boyle et al., 2016, p. 22), we suggest that future research should focus on how the design features of a CBVLE facilitate mathematical medication learning, self-efficacy, and intrinsic motivation. Moreover, CBVLEs can be used as game-based assessments that capture real-time, and (in-game) activities as evidence for monitoring nursing students' mathematical medication learning (Kim, Almond, \& Shute, 2016). Then, the CBVLE can become a balanced form of learning that enables students to engage in transformative and 
innovative - rather than reproductive - learning (Tynjälä, 2013). The CBVLE can be used as a technology-enhanced educational assessment system that nursing students can use to train and assess for their mathematical medication learning, for example on a quarterly or half year basis. This form of formative assessment, or assessment for learning, supports teaching and learning (Shute \& Rahimi, 2017).

This study used a small sample of participants. This may limit the generalisability of the findings of the study and may prevent strong claims being made that are not based on coincidence. The findings of this study should therefore be treated cautiously.

\section{References}

Actiz Health Organization. (2012). Veilige principes in de medicatieketen [Safety principles in chain of medication].

https://www.zorgvoorbeter.nl/docs/PVZ/vindplaats/medicatieveiligheid/veiligeprincipes-in-de-medicatieketen.pdf

Alfassi, M. (2003). Promoting the will and skill of students at academic risk: An evaluation of an instructional design geared to foster achievement, self-efficacy and motivation. Journal of Instructional Psychology, 30(3): 2840. https://psycnet.apa.org/record/2003-03343-005

Bandura, A. (1988). Self-efficacy conception of anxiety, Anxiety Research, 1, 77-98. doi: $10.1080 / 10615808808248222$

Bandura, A. (1997). Self-efficacy: The exercise of control. New York, NY: Freeman. https://psycnet.apa.org/record/1997-08589-000

Bandura, A., \& Schunk, D. H. (1981). Cultivating competence, self-efficacy, and intrinsic interest through proximal self-motivation. Journal of Personality and Social Psychology, 41, 586-598. doi:10.1037/0022-3514.41.3.586

Ben-David, A., \& Zohar, A. (2009). Contribution of meta-strategic knowledge to scientific inquiry learning. International Journal of Science Education, 31, 1657-1682. doi: $10.1080 / 09500690802162762$

Boyle, E. A., Hainey, T., Connolly, T. M., Gray, G., Earp, J., Ott, M., Lim, T., Ninaus, M., Riberio, C., \& Pereira, J. (2016). An update to the systematic literature review of empirical evidence of the impacts and outcomes of computer games and serious games. Computers \& Education, 94, 178-192. doi:10.1016/j.compedu.2015.11.003

Canobi, K. H. (2009). Concept-procedure interactions in children's addition and subtraction. Journal of Experimental Child Psychology, 102, 131-149. doi:10.1016/j.jecp.2008.07.008 
Chen, O., Kalyuga, S., \& Sweller, J. (2016). Relations between the worked example and generation effects on immediate and delayed tests. Learning and Instruction, 45, 20-30. doi:10.1016/j.learninstruc.2016.06.007

Chen, O., Woolcott, G., \& Sweller, J. (2017). Using cognitive load theory to structure computer-based learning including MOOCs. Journal of Computer Assisted Learning, 33, 293-305. doi: 10.1111/jcal.12188

Csikszentmihalyi, M. (1990). Flow: The psychology of optimal experience. Harper-Collins. https://mktgsensei.com/AMAE/Consumer\%20Behavior/flow_the_psychology_of_o ptimal_experience.pdf

Deci, E. L., \& Ryan, R. M. (1985). Intrinsic motivation and self-determination in human behavior. New York, NY: Plenum. doi:10.1007/978-1-4899-2271-7

Denissen, J. J. A., Zarrett, N. R., \& Eccles, J. S. (2007). I like to do it, I'm able, and I know I am: Longitudinal couplings between domain-specific achievement, self-concept, and interest. Child Development, 78, 430-437. doi:10.1111/j.14678624.2007.01007.x

Duffy, M. C., Lajoie, S. P., Pekrun, R., \& Lachapelle, K. (2018). Emotions in medical education: Examining the validity of the Medical Emotion Scale (MES) across authentic medical learning environments. Learning and Instruction, 70: 101150. doi:10.1016/j.learninstruc.2018.07.001

Hattie, J., \& Timperly, H. (2007). The power of feedback. Review of Educational Research, 77, 81-112. doi:10.3102/003465430298487

Huang, W. D., Johnson, T. E., \& Han, S-H. C. (2013). Impact of online instructional game features on college students perceived motivational support and cognitive investment: A structural equation modeling study. Internet and Higher Education, 17, 58-68. doi:10.1016/j.iheduc. 2012011.004

Kalyuga, S., Ayres, P., Chandler, P., \& Sweller, J. (2003). The expertise reversal effect. Educational Psychologist, 38(1), 23-31. doi:10.1207/S15326985EP3801_4

Keller, J. M. (2010, September 28-31). Challenges in learner motivation: A holistic integrative model for research and design on learner motivation. Paper presented at the $11^{\text {th }}$ International Conference on Education Research New Educational Paradigm for Learning and Instruction, Amsterdam, The Netherlands. https://www.viethmms.com/ aect/docs/ICER4.pdf

Kim, Y. J., Almond, R. G., \& Shute, V. J. (2016). Applying evidence-centered design for the development of game-based assessments in physics playground. International Journal of Testing, 16, 142-163. doi:10.1080/15305058.2015.1108322 
Kirschner, P. A., Sweller, J., Kirschner, F., \& Zambrano, R. J. (2018). From cognitive load theory to collaborative load theory. International Journal of Computer-Supported Collaborative Learning, 13, 213-233. doi:10.1007/s11412-018-9277-y

Lampe, T., Straetmans, G., \& Eggen, T. (2011). De rekenvaardigheid van de Nederlandse verpleegkundige [Nurses' mathematical skills in the Netherlands]. Onderwijs en Gezondheidszorg, 35(3), 3-9. doi:10.1007/s12477-011-0030-y

Lee, Y., \& Seo, E. (2021). Longitudinal relations between South Korean adolescents' academic self-efficacy and values in mathematics and English. British Journal of Educational Psychology, 91, 217-236. doi:10.1111/bjep.12357.

Lee, E., A-L., \& Wong, K. W. (2014). Learning with desktop virtual reality: Low spatial ability learners are more positively affected. Computers \& Education, 79, 49-58. doi: $10.1016 /$ j.compedu.2014.07.010

Lee, E., A-L., Wong, K. W., \& Fung, C. C. (2010). How does desktop virtual reality enhance learning outcomes? A structural equation modeling approach. Computers \& Education, 55, 1424-1442. doi:10.1016/j.compedu.2010.06.006

Lent, R. W., Brown, S. D., \& Hackett, G. (2002). Social cognitive career theory. In J. Greenhaus, \& G. Callanan (Eds.), Encyclopedia of career development (pp. 750754). Thousand Oaks, CA: Sage.

https://www.researchgate.net/publication/303257953_Social_cognitive_career_th eory

Liu, X., \& Koirala, H. (2009, October, 21-23). The effect of mathematics self-efficacy on mathematics achievement of high school students [Paper presentation]. 40 ${ }^{\text {th }}$ Annual NERA Conference, Rocky Hill, CT, United States. https://opencommons.uconn.edu/nera_2009

Liu, Y., Hau, K-T., \& Zheng, X. (2019). Do both intrinsic and identified motivations have long-term effects? The Journal of Psychology, 153, 288-306. doi: 10.1080/00223980.2018.1516611

Makransky, G., Borre-Gude, S., \& Mayer, R. E. (2019). Motivational and cognitive benefits of training in immersive virtual reality based on multiple assessments. Journal of Computers Assisted Learning, 35, 691-707. doi:10.1111/jcal.12375

Makransky, G., \& Petersen, G. B. (2019). Investigating the process of learning with desktop virtual reality: A structural equation modeling approach. Computers \& Education, 134, 15-30. doi:10.1016/j.compedu.2019.02.002

Merchant, Z., Goetz, E. T., Keeney-Kennicutt, W., Oi-man K., Cifuentes, L., \& Davis, T. J. (2012). The learner characteristics features of desktop 3D virtual reality 
environments, and college chemistry instruction: A structural equation modeling analysis. Computers \& Education, 59, 551-568. doi: $10.1016 /$ j.compedu.2012.02.004

Nicol, D. J., \& Macfarlane-Dick, D. (2006). Formative assessment and self-regulated learning: A model and seven principles of good feedback practice. Studies in Higher Education, 31, 199-218. https://doi.org/10.1080/03075070600572090

Oprins, E., Visschedijk, G., Bakhuys Roozeboom, M., Dankbaar, M., Trooster, \& Schuit, S. C. E. (2016). The game-based learning evaluation model (GEM): measuring the effectiveness of serious games using a standardised method. International Journal of Technology Enhanced Learning, 7, 326-345. doi:10.1504/IJTEL.2015.074189

Pajares, F. (2003). Self-efficacy beliefs, motivation, and achievement in writing: A review of the literature. Reading and Writing Quarterly, 19, 139-158. doi: $10.1080 / 10573560390143085$

Pajares, F., \& Schunk, D. H. (2001). Self-beliefs and school success: Self-efficacy, selfconcept, and school achievement. In R. Riding \& S. Rayner (Eds), Perception (pp. 239-266). London, UK: Ablex Publishing. https://www.uky.edu/ eushe2/Pajares/PajaresSchunk2001.html

Pekrun, R. (2006). The control-value theory of achievement emotions: Assumptions, corollaries, and implications for educational research and practice. Educational Psychology Review, 18, 315-341. doi:10.1007/s10648-006-9029-9

Pekrun, R., \& Stephens, S. J. (2010). Achievement emotions in higher education. In J. C. Smart (Ed.), Higher education: Handbook of theory and research ( $p p$ 257-306). Springer. https://link.springer.com/content/pdf/10.1007\%2F978-94-6300-6361.pdf

Pintrich, P. R. (1988). A process-oriented view of student motivation and cognition. In J. S. Stark, \& L. Mets (Eds.), Improving teaching and learning through research. New directions for institutional research ( $\mathrm{pp}$ 55-70). Hoboken, NJ: Jossey-Bass. https://onlinelibrary.wiley.com/doi/10.1002/ir.37019885707

Prins, H., Zwart, D. P., Voogt, J., \& Hettinga, M. (2019). Which professional contexts can enrich the training of medication skills of nurses through virtual reality? http://healthbytech.com/wp-content/uploads/Abstract-book-SupportingHealth5.pdf.

Raven, J. C., Court, J. H., \& Raven, J. (1992). Standard progressive matrices (SPM) (1992 Edition). Oxford, UK: Oxford Psychologists Press. https://link.springer.com/chapter/10.1007/978-1-4615-0153-4_11 
Rittle-Johnson, B., Siegler, R. S., \& Alibali, M. W. (2001). Developing conceptual understanding and procedural skill in mathematics: An iterative process. Journal of Educational Psychology, 93, 346-362. doi:10.1037/0022-0663.93.2.346

Ryan, R. M., \& Deci, E. L. (2000). Self-determination theory and the facilitation of intrinsic motivation, social development, and well-being. American Psychologist, 55(1), 6878. doi:10.1037/0003-066X.55.1.68

Schunk, D. H. (2012). Learning theories. An educational perspective (6 $6^{\text {th }}$ ed.). Pearson Education. https://www.pearson.com/us/higher-education/product/SchunkLearning-Theories-An-Educational-Perspective-6th-Edition/9780137071951.html

Schunk, D. H., \& DiBenedetto, M. K. (2016). Self-efficacy theory in education. In K. R. Wentzel, \& D. B. Miele (Eds.), Handbook of motivation at school 2 (pp. 34-54). Routledge. doi: $10.4324 / 9781315773384 . c h 3$

Schunk D. H., \& Pajares, F. (2009). Self-efficacy theory. In K. R. Wentzel \& A. Wigfield (Eds.), Handbook of motivation at school (pp. 35-53). New York, NY: Routledge. https://psycnet.apa.org/record/2009-24219-003

Seligman, M. E. P. (1972). Learned helplessness. Annual Review of Medicine, 23, 407-412. doi:10.1146/annurev.me.23.020172.002203

Seligman, M. E. P., \& Campbell, B. A. (1965). Effect of intensity and duration of punishment on extinction of an avoidance response. Comparative and Physiological Psychology, 59, 295-297. doi:10.1037/h0021845

Shute, V. J., \& Rahimi, S. (2017). Review of computer-based assessment for learning in elementary and secondary education. Journal of Computer Assisted Learning, 33, 1-19. doi:10.1111/jcal.12172

Tynjälä, P. (2013). Toward a 3-P model of workplace learning: A literature review. Vocations and Learning, 6(1), 11-36. doi:10.1007/s12186-012-9091-z

Van Gog, T., Kester, L., \& Paas, F. (2011). Effects of worked examples, example-problem, and problem-example pairs on novices' learning. Contemporary Educational Psychology, 36, 212-218. doi:10.1016/j.cedpsych.2010.10.004

Wang, M., Kirschner, P. A., Spector, J. M., \& Ge, X. (2018). Computer-based learning environments for deeper learning in problem-solving contexts. Computers in Human Behavior, 87, 403-405. doi:10.1016/j.chb.2018.06.026

Weeks, K. W., Hutton, B. M., Young, S., Coben, D., Clochesy, J. M., \& Pontin, D. (2013). Competency modelling and diagnostic error assessment in medication dosage calculation problem-solving. Nurse Education in Practice, 13, 23-32. doi:10.1016/j.nepr.2012.10.013 
Woodcock, S., \& Vialle, W. J. (2011). Are we exacerbating students' learning disabilities? An investigation of preservice teachers' attributions of the educational outcomes of students with learning disabilities. Annals of Dyslexia, 61, 223-241. doi:10.1007/s11881-011-0058-9

Xinhao, X., \& Fengfeng, K. (2016). Designing a virtual reality based, gamelike math learning environment. American Journal of Distance Education, 30, 27-38. doi: $10.1080 / 08923647.2016 .1119621$

Zwart, D. P., Goei, S. L., Noroozi, O., \& Van Luit, J. E. H. (2021). The effects of computerbased virtual learning environments on nursing students' mathematical learning in medication processes. Research and Practice in Technology Enhanced Learning, 16: 4. doi:10.1186/s41039-021000147-x

Zwart, D. P., Noroozi, O., Van Luit, J. E. H., Goei, S. L., \& Nieuwenhuis, A. (2020). The effects of Digital Learning Materials on nursing students' mathematics learning, selfefficacy, and task-value in vocational education. Nurse Education in Practice, 44: 102755. doi:10.1016/j.nepr.2020.102755 


\section{Chapter 6}

\section{Nursing Students' Satisfaction with the Instructional Design of a Computer-Based Virtual Learning Environment for Mathematical Medication Learning*}

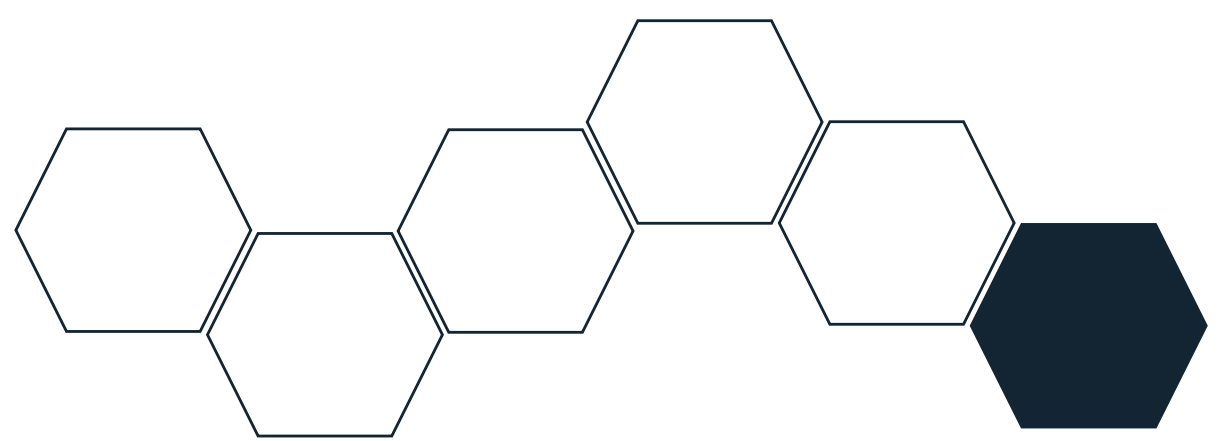

* Parts of this chapter are published as: Zwart, D. P., Goei, S. L., Noroozi, O., \& Van Luit, J. E. H. (2021). Effects of Computer-Based Virtual Learning Environments on Nursing Students' Mathematical Learning in Medication Processes. Research and Practice in Technology Enhanced Learning, 16: 4. doi:10.1186/s41039-021-00147-x

This chapter is submitted in December 2020 for publication. Zwart, D. P., Goei, S. L., Van Luit, J. E. H., \& Noroozi, O. Nursing students' satisfaction with the instructional design of a Computer-Based Virtual Learning Environment for mathematical medication learning. Authors contributions: J.E.H.V.L., O.N., S.L.G. and D.P.Z. conceptualized the research. D.P.Z. collected and analyzed the data; D.P.Z. wrote the original draft, visualized the results, and edited the paper; J.E.H.V.L., O.N., and S.L.G. critically reviewed the paper. 


\section{Abstract}

Computer-based virtual learning environments (CBVLEs) have attracted attention as a learning innovation that can foster students' self-efficacy and intrinsic motivation. Research on the instructional design regarding these aspects of learning in a virtual learning environment is rather piecemeal. This study investigates the instructional design of a CBVLE for mathematical medication learning by nursing students in vocational education. This CBVLE enabled the in-depth teaching of mathematics related to medication skills for nursing students. The instructional design was based on a holistic approach, and students' future learning tasks formed the backbone. We examine the extent to which the CBVLE fostered the nursing students' mathematical learning, self-efficacy, and intrinsic motivation, and the ways in which the design components of the CBVLE met nursing students' satisfaction. In total, 118 nursing students were trained via the CBVLE on mathematical medication learning tasks, over four consecutive weeks. Students were preand post-tested on their mathematical medication learning, self-efficacy, and intrinsic motivation. Students also rated their satisfaction with the instructional design in terms of five design components: learning tasks, supportive information, procedural information, part-task practice, and cognitive feedback. Results showed that the CBVLE fostered nursing students' mathematical medication learning, self-efficacy, and intrinsic motivation. Student satisfaction was above average in regard to the design components of learning tasks, supportive information, part-task practice and procedural information, although the cognitive feedback needed to be more closely customised to the nursing students' own efforts in the CBVLE. Overall, the design components predicted nursing students' mathematical medication learning, self-efficacy, and intrinsic motivation. 


\section{Introduction}

Now more than ever, digital learning materials (DLMs) are important in today's educational and online practices. The instructional design and methodology of DLMs is different from traditional on-site learning environments (Van Merriënboer \& Kirschner, 2018), and this also has an impact on the ways in which students learn and teachers instruct (Zwart, Noroozi, Van Luit, Goei, \& Nieuwenhuis, 2020; Zwart, Van Luit, Noroozi, \& Goei, 2017). A DLM such as a computer-based virtual learning environment (CBVLE) enables students to act in a game in a similar way to real life. CBVLEs are particularly interesting for the teaching of academic concepts (Buchanan, 2003), and can enable self-directed learning by students, enhance their self-efficacy, and boost their intrinsic motivation (e.g., Huang, Johnson, \& Han, 2013; Makransky \& Petersen, 2019; Xinhao \& Fengfeng, 2016). Selfefficacy is positively associated with motivation, which in turn enhances the learning outcomes of students (Schunk \& DiBenedetto, 2016; Schunk \& Pajares, 2009).

In this study, we focus on the instructional design of a CBVLE for mathematical medication learning by nursing students. In current educational programs, this domain is distinguished from the future professional competence of nursing students, in which they learn to solve problems in care situations based on the medication process. Mathematics forms part of this medication process, and cannot be applied without an in-depth knowledge of the structure of this domain. The mathematical medication process is complex and requires a conceptual understanding, since it involves a knowledge of the underlying unifying mathematical principles (Canobi, 2009). A CBVLE can be used to teach an in-depth knowledge of mathematics in relation to the medication skills of nursing students. Progress has been made in terms of design principles that foster learning via CBVLEs, but research in this area is rather piecemeal (Boyle et al., 2016, and the ways in which these design principles facilitate students' learning, self-efficacy, and intrinsic motivation remain unclear. We are also interested in the extent to which the instructional design generates student satisfaction in terms of mathematical medication learning via the CBVLE. This study therefore investigates the satisfaction of nursing students with the instructional design of a CBVLE, and the ways in which the instructional design facilitates these students' mathematical medication learning, self-efficacy, and intrinsic motivation for learning mathematical medication learning via the CBVLE.

\section{Computer-based virtual learning environments}

CBVLEs are digital environments based on desktop virtual reality (VR) that allow the user to dynamically interact with learning materials via 3D images on a computer screen (Lee, Wong, \& Fung, 2010; Merchant et al., 2012). CBVLEs can be defined as simulated learning environments containing various problem-solving scenarios (Wang, Kirschner, Spector, \& $\mathrm{Ge}, 2018$ ). Students use a keyboard or mouse to navigate through the CBVLE. CBVLEs are 
designed with VR features; according to Merchant et al. (2012), the two main VR features are "representational fidelity" and "learners' interaction" (see Dalgarno \& Lee, 2010). Since Merchant et al. (2012) took advantage of the same innovative 3D technology in Second Life ${ }^{\circledR}$ as used in this study, we use the same definitions in our work. "Representational fidelity refers to the realistic display of the virtual environment that can be attained by physical characteristics of the environment such as rich graphics, smooth temporal changes, and consistent object behaviour. Learners' interaction is the ability of users to influence the occurrences of events in the virtual environment by their actions" (Merchant et al., 2012, p. 552). These VR features offer opportunities to display interactive stories representing the students' future professional tasks. In the context of this study, "interaction" means that nursing students practice their mathematical medication knowledge and skills in a virtual environment involving doctors and patients. The graphical design of the CBVLE allows for a realistic representation, since a high degree of realism can cognitively engage students and motivate them to learn (Csikszentmihalyi, 1990, 2000; Lee, Wong, \& Fung, 2010; Shute, Ventura, Bauer, \& Zapata-Rivera, 2009).

\section{Instructional design of the computer-based virtual learning environment}

Designing instruction for VR involves developing and adapting instructional strategies to new technology. Since the students' learning tasks represent those that will be undertaken in future employment, these tasks can serve as encouragement for learning (Merchant, Goetz, Cifuentes, Keeney-Kennicutt, \& Davis, 2014), and are therefore essential for instructional design via technology. Van Merriënboer and Kirschner (2018) developed a task-centred design approach that bases the design of the instruction on real-life tasks. Their four-component instructional design for complex learning (4C/ID) is based on the advantage of using a holistic approach to design learning environments. The four basic components are (i) learning tasks, (ii) supportive information, (iii) procedural information, and (iv) part-task practice. It overcomes the problems of compartmentalisation and fragmentation of traditional instructional design models, and hence is a particularly interesting design model for teaching academic concepts via CBVLE.

\section{The learning tasks design component of a CBVLE}

Learning tasks form the backbone of the CBVLE learning program. "The learning task confronts the learner with all or almost all of the constituent skills important for real-life task performance, together with their associated knowledge and attitudes. The learning tasks are meaningful, authentic, and representative for the tasks that a professional might encounter in the real world" (Van Merriënboer \& Kirschner, 2007, p. 7). Learning tasks encourage students to learn; when the motive for learning arises from the activity itself, the activity of learning helps students to successfully complete learning tasks (Merchant et al., 2014; Pajares \& Schunk, 2001). Practicing many different activities, such as domain- 
specific types of problems, permits students to grasp learning procedures and make connections (Dunlosky, Rawson, Marsh, Nathan, \& Willingham, 2013; Rohrer, Dedrick, \& Stershic, 2015). Although CBVLEs should be challenging, it is easy to place excessive demands on students with activities that cause cognitive overload (Sweller, 2010). This may also result in negative emotions (Pekrun, 2006). One way to support students is to add information to the CBVLE.

\section{The supportive information design component of a CBVLE}

According to Van Merriënboer and Kirschner (2018), supportive information explains to students how a learning domain is organised and how to approach problems in that domain. It is information that is needed by students to develop cognitive models and strategies for completing learning tasks (Frerejean et al., 2019). A CBVLE enables the user to specify the relevant elements in a domain, as well as the relationships between these elements. Setting clear goals enhances performance and directs the attention of students towards the activity of learning rather than towards outcomes (Anderson \& Krathwohl, 2001; Csikszentmihalyi, 2000). For example, the future medication tasks of nursing students involve a range of nursing activities including verifying, preparing, checking, administering, registering, monitoring, and evaluating medication. Calculations are necessary for all these tasks. Seen in terms of the instructional design model of Van Merriënboer and Kirschner (2018), the first two components of 4C/ID, learning tasks and supportive information, can help students to build cognitive schemas through the acquisition of new knowledge that contributes to their existing knowledge. The other two components, procedural information and part-task practice stimulate the automation of schemas and the development of automatic, task-specific procedures that can be applied without undue demand on cognitive processing resources (Frerejean et al., 2019, p. 516).

\section{The procedural information design component of a CBVLE}

Procedural information specifies how to perform the recurrent aspects of the learning tasks (Van Merriënboer \& Kirschner, 2018), and involves corrective feedback, demonstrations of rules, procedures, and prerequisite knowledge. It should be displayed 'just in time'. Instructional activities that can show students how to apply procedures to specific problems include worked examples (Chen, Kalyuga, \& Sweller, 2016; Kirschner et al., 2018; Van Gog et al., 2011). Students can open a worked example and be provided with step-to-step digital instruction in the CBVLE, while solving the problem. When the answers are not correct, students receive corrective verification feedback (Maier, Wolf, \& Randler, 2016). This feedback can support reflection and improvement and is crucial for learning and achievement (Yuan et al., 2020). When students cannot master certain aspects of a learning task, part-task practice can be virtually embedded. 


\section{The part-task practice design component of a CBVLE}

The use of part-task practice to train one or more selected recurrent aspects of learning tasks is an instructional strategy for recurrent constituent skills that are critical to safety (Van Merrienboer \& Kirschner, 2018). Mathematical mistakes in the medication process can have serious consequences, meaning that the inclusion of exercises in the CBVLE that develop an in-depth knowledge of the underlying domain-specific mathematical knowledge is necessary if a high level of automation is desired. In this way, students can make connections between the underlying knowledge and the problems to be solved (Tynjäla, 2013). It can be treated as a feedback facilitator for students' understanding and performance (Yuan et al., 2020). The monitoring of students' learning processes also involves their reflections on learning. Van Merrienboer and Kirschner (2018) place this under the category of cognitive feedback; however, reflection on learning is not simply feedback on the quality of students' learning. In a CBVLE, reflection on learning is a tool for students' self-assessment regarding their learning as an experience, over the whole learning task. We therefore describe this step separately as a design component of the CBVLE.

\section{Cognitive feedback as a reflection on learning}

Reflection on learning stimulates students to identify their strengths and weaknesses in terms of the actions taken for learning in the CBVLE. Computer-based feedback on learning provides information drawn from the analysis of learning logs, and is based on each student's performance. Ideally, feedback contains both cognitive and affective features (Nelson \& Schunn, 2009): cognitive features influence performance and understanding, allowing students to know what to improve, and affective features effect students' agreement with feedback. It has to take students in the CBVLE from an initial state of mind to a desired state of mind (Mor, Ferguson, \& Wasson, 2015). Table 1 gives an overview of the implementation of the design components of the instructional design of the CBVLE in this study. 
Table 1

Design Components of the Instructional Design Implemented in the CBVLE

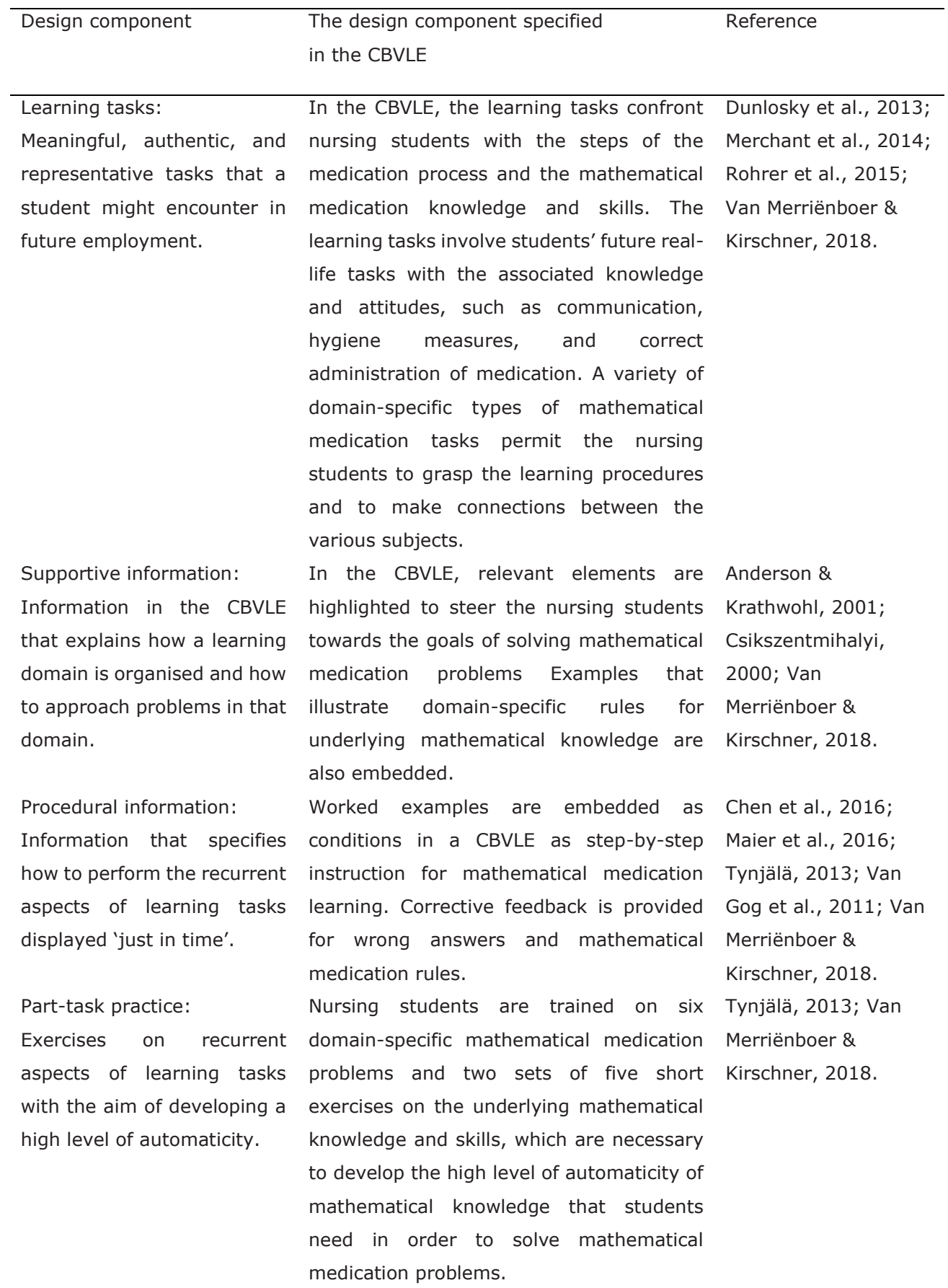




\begin{tabular}{|c|c|c|}
\hline $\begin{array}{l}\text { Cognitive feedback as } \\
\text { reflection on learning: }\end{array}$ & $\begin{array}{l}\text { After practicing six domain-specific } \\
\text { mathematical medication problems and } \\
\text { two sets of five short exercises, nursing } \\
\text { students navigated through the CBVLE } \\
\text { towards a doctor, who gave a feedback } \\
\text { message as a reflection on learning. This } \\
\text { message was related to the points that } \\
\text { nursing students were awarded during the } \\
\text { play round for the right actions and } \\
\text { solutions to problems. }\end{array}$ & $\begin{array}{l}\text { Mor et al., 2015; Var } \\
\text { Merriënboer \& } \\
\text { Kirschner, 2018; } \\
\text { Yuang et al., 2020; }\end{array}$ \\
\hline
\end{tabular}

Since the CBVLE is a structured system involving activities, exercises and support as an integral part of the virtual environment, it can increase nursing students' intrinsic motivation and enhance their self-efficacy (Merchant et al., 2014; Pekrun, 2006).

\section{Self-efficacy and intrinsic motivation in a CVBLE}

Self-efficacy refers to the student's judgements of their own level of competence in dealing with prospective situations (Bandura, 1982). Successful completion of learning tasks contributes to students' self-efficacy (Pajares \& Schunk, 2001). Self-efficacy is also enhanced when students value the task that they are undertaking (Schunk \& DiBenedetto, 2016), and is positively associated with motivation, which in turn enhances the learning outcomes of students (Schunk \& DiBenedetto, 2016; Schunk \& Pajares, 2009). When students are intrinsically motivated to learn, their satisfaction is associated with the performance of learning tasks (Ryan \& Deci, 2000). In fact, it has been shown that the relevant outcomes are of less importance than the activities themselves (Pekrun \& Stephens, 2010). Interactions in CBVLEs can enable students' self-directed learning and can stimulate their intrinsic motivation and self-efficacy (e.g., Huang et al., 2013; Lee et al., 2010; Makransky \& Petersen, 2019; Xinhao \& Fengfeng, 2016), but this depends on whether or not they are satisfied with the instructional design of the CBVLE. Hence, with respect to the issues of mathematical medication learning, self-efficacy, and intrinsic motivation, the research questions addressed in this study are as follows:

1. What are the effects of the instructional design in a CBVLE in terms of facilitating nursing students' mathematical medication learning, self-efficacy, and intrinsic motivation for learning via the CBVLE?

2. To what extent are nursing students satisfied with the instructional design, and how do combinations of design components account for nursing students' mathematical medication learning, self-efficacy, and intrinsic motivation? 


\section{Method}

Context and participants

The study is part of a larger study (see also Zwart, Goei, Noroozi, \& Van Luit, 2021) and took place at five post-secondary vocational nursing schools $(\mathrm{N}=44)$ and at seven universities of applied sciences $(\mathrm{N}=74)$ in the Netherlands. The participants, who were compensated with a $€ 15$ voucher for their contribution, were 118 students enrolled in these schools. The educational levels of the participants were different, but the mathematical medication training and its content is the same in both educational programmes. The mean age of the participants was $19.6(S D=2.4)$, and $92 \%$ were female. Students worked on a bring your own device (BYOD) basis in this study, except for two schools in which students used PCs. Although students had basic computer skills (Mpre $=3.7, S D=0.7$; $\operatorname{Min}=1.0$, Max $=5.0$ ), working with a CBVLE was new to them.

The students were randomly assigned to one of four groups, who undertook mathematical medication learning under different conditions: without worked examples (group 1); with worked examples involving domain-specific knowledge (group 2); with worked examples involving regular thinking strategies (group 3); and with a combination of both types of worked example (group 4).

Learning materials

The subject matter to be learned was the concept of mathematical medication, which involved three mathematical domains: liquid medication, infusion of fluids, and solid medication. The different mathematical domains involve different mathematical rules, and students need to master these. The details of the learning tasks and the principles of the underlying design and mathematical content are summarised in Table 2. 
Table 2

Learning Tasks Involving Domain-specific Mathematical Medication Knowledge Related to

Liquid Medication, Infusion of Fluids, and Solid Medication in a CBVLE

\begin{tabular}{llll}
\hline $\begin{array}{l}\text { Medication } \\
\text { domains }\end{array}$ & $\begin{array}{l}\text { Domain- } \\
\text { specific } \\
\text { knowledge }\end{array}$ & $\begin{array}{l}\text { Domain-specific } \\
\text { rules for feedback }\end{array}$ & $\begin{array}{l}\text { Underlying } \\
\text { domain-specific } \\
\text { principles for all } \\
\text { domains }\end{array}$ \\
\hline
\end{tabular}

\begin{tabular}{ll}
\hline Liquid & Ratio of the \\
medication & dissolved \\
(incl. & substance and \\
dilution) & diluent
\end{tabular}

mass/volume $(\mathrm{m} / \mathrm{v})$

$1 \%=1$-gram dissolved substance/100 ml $1 \%$ o 1 -gram dissolved substance/1000 ml (1 litre)

volume/volume (v/v)

$1 \%=1 \mathrm{ml}$ liquid/100 ml $1 \%$ o $1 \mathrm{ml}$ liquid/1000 ml (1 litre)

Quantities,
units,
conversions of
ratios:
a. fractions
b. decimals
c. numbers
d. percentage
relations between
a,b,c,d,
divide,
multiplication,
hours, minutes,
seconds (time
ratio),
elements of the
prescription
dispensed,
extract numerical
information,
apply calculations
correctly and
accurately

\section{Infusion of Drip rating fluids}

20 drops per millilitre

1. Calculate the total number of drips

2. Calculate the drips per hour

3. Calculate the drips per minute

\section{Solid medication}

\section{Count, divide,} multiply, work with fractions, reference measurements: 24 hours in a day 60 minutes in an hour $50 \%=1 / 2$ $1 / 4=25 \%$ etc.

\section{Learning \\ tasks}

P. suffers severe pain. He is prescribed 15 mg morphine every four hours. Stocked: $1 \mathrm{ml}$ morphine ampoules of 15 $\mathrm{mg} / \mathrm{ml}$. How many $\mathrm{ml}$ do you inject every four hours? How many $\mathrm{ml}$ is this per day?

\section{Basic computatio nal skills}

$16 \times 8=$

$12 \times 9=$

$1 / 4+3 / 4=$

$3 / 3+5 / 3=$

$3 / 4-2 / 8=$

$14 / 5-9 / 5=$

$3 / 4 \times 4 / 5=$

$5 / 10 \times 4 / 8=$

$4 / 5: 2 / 5=$

$3 / 5: 1 / 3=$

$1 / 4=0.25$
$1 / 20=0.05$

$0.09=\ldots \%$

$0.50=\ldots \%$

$75 \%=0.75$

$30 \%=0.30$

How much is:

G. is

administered a

drip of $500 \mathrm{ml}$

$0.9 \% \mathrm{NaCl}$ in

three hours.

How many drips

are

administered to

$5 \%$ of

$1000 \mathrm{ml}$ ?

$4 \%$ of

$250 \mathrm{ml}$ ?

$1 \mathrm{~L}=\ldots \mathrm{ML}$

$1 \mathrm{ML}=\ldots \mathrm{CC}$
F. suffers from cystitis. She receives treatment with antibiotics for six days: 750 mg Amoxicillin every 12 hours. Stocked:

Flemoxin with $375 \mathrm{mg}$ Amoxicillin per tablet. How many tablets should $F$. swallow during treatment? 
About 30 scenarios were developed for each domain, at three levels (easy, difficult, and very difficult), so that students could practice each type of problem at different levels and multiple times. Almost all the constituent skills that are important for the future performance of nursing students in mathematical medication tasks were included. In this way, the skills important for real-life task performance could be trained, together with their associated knowledge and attitudes (Van Merriënboer \& Kirschner, 2018). Figure 1 illustrates the procedure of mathematical medication learning via the CBVLE.

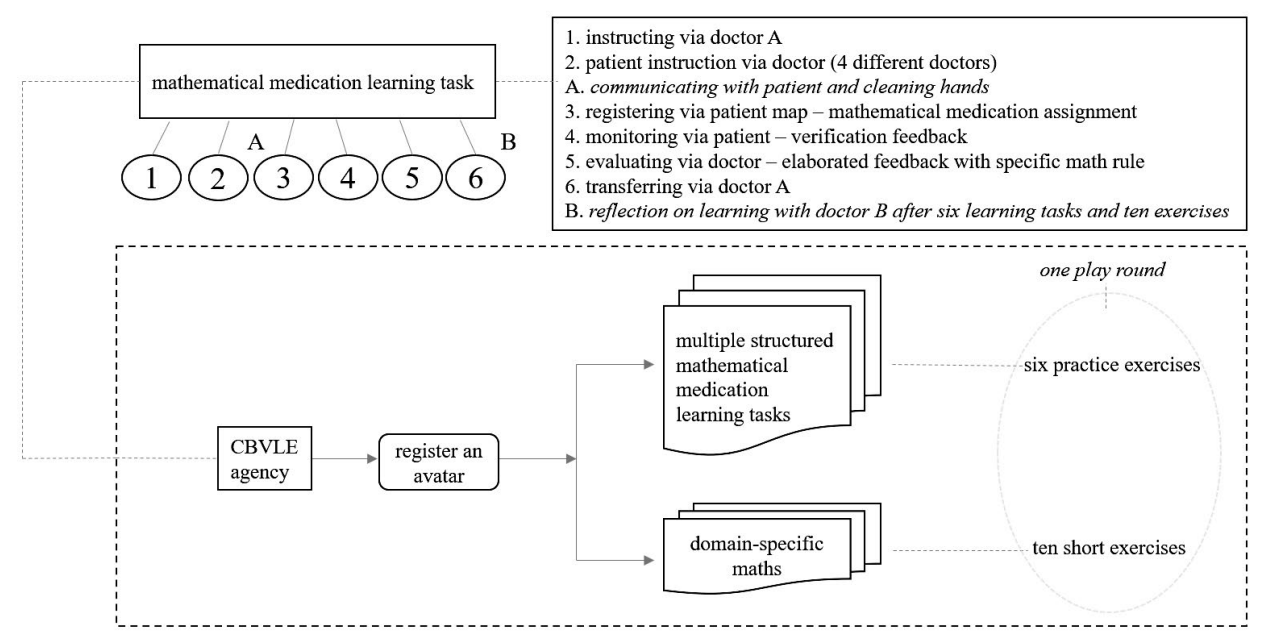

Figure 1. Structure of mathematical medication learning in the CBVLE.

Procedure

A pilot test was conducted with 11 students to determine the feasibility of the study with respect to the introduction, learning tasks, materials, instruments, feedback, and platform. This pilot study resulted in a slight modification to the introduction section to include an extra short meeting, and a paper-based manual that was provided before and during the exercises. We also introduced an instruction in the CBVLE, using photos to guide students in their initial activities.

The experimental session consisted of four main phases (see Table 3). During the introduction and personal data phase (1), which took 70 minutes, students received introductory explanations about the CBVLE training. Students were then assigned to avatars and logged into the CBVLE. These avatars (students) were randomly allocated to one of the four groups. 
Students carried out one practice round in the CBVLE, and it was made clear that they were expected to work individually during the game, without help from the researcher or their peers, while paying attention to the information on the screen (30 $\mathrm{min}$ ). Students were then asked to complete a questionnaire on their personal data, including their name, gender, age, and computer skills (10 $\mathrm{min})$.

During the individual phase (2), students first received an introductory explanation of how to fill in the questionnaire and a description of the domain-specific mathematical knowledge test (5 min). Next, they were then asked to fill in a questionnaire (20 minutes) on intrinsic motivation and self-efficacy, and then to complete the domain-specific mathematical knowledge test (60 $\mathrm{min})$.

From the second week onwards, the learning phase (3) took 90 minutes per week, over four consecutive weeks. Students completed the domain-specific mathematical knowledge test (60 min) during the post-test phase (4) in the sixth week and were then given two questionnaires: the first measured self-efficacy and intrinsic motivation, and the second measured their satisfaction with the components of the instructional design of the CBVLE (30 min). Finally, the participants received a short debriefing for about 10 minutes.

\section{Table 3}

\section{Procedure Used for the CBVLE Study}

\begin{tabular}{ll}
\hline Procedure for mathematical medication training in the CBVLE & Duration \\
\hline Week 1: Introduction and personal data & $70 \mathrm{~min}$ \\
Introductory explanations of the procedure, materials, and the purpose & $30 \mathrm{~min}$ \\
of the research study & $30 \mathrm{~min}$ \\
Students were given avatars, logged in and played a round & $10 \mathrm{~min}$ \\
Personal data questionnaire & $85 \mathrm{~min}$ \\
Individual pre-test measurements & $5 \mathrm{~min}$ \\
Introductory remarks & $20 \mathrm{~min}$ \\
Assessment of self-efficacy (se) and intrinsic motivation (im) & $60 \mathrm{~min}$ \\
(questionnaire) & $90 \mathrm{~min}$ per week \\
Pre-test assessment of domain-specific mathematical knowledge & $100 \mathrm{~min}$ \\
Weeks 2-5: Learning phase: CBVLE training & $60 \mathrm{~min}$ \\
Week 6: Post-tests and debriefing & $30 \mathrm{~min}$ \\
Post-test assessment of domain-specific mathematical knowledge & $10 \mathrm{~min}$ \\
Assessment of se, im, and design components (questionnaires) & Debriefing
\end{tabular}

Measurements and instruments

Measurement of nursing students' mathematical medication knowledge

Domain-specific mathematical medication knowledge was assessed via a test provided by Cito (the Dutch national organisation for test development; see Lampe, Straetmans, \& Eggen, 2011). This test measured the domain-specific mathematical medication knowledge 
of the nursing students. Cito offered two parallel versions, both before and after intervention with the CBVLE. The original domain-specific mathematical medication knowledge test consisted of 50 multiple choice questions, with 20 questions on domainspecific mathematical medication knowledge for infusion of fluids, 19 on liquid medication, and 11 on solid medication (tablets). An item response analysis showed that four items had poor discriminatory power, and these were eliminated from the pre-test (Cronbach's $a=.80)$. The post-test reliability was good (Cronbach's $a=.83$ ).

Measurement of nursing students' self-efficacy and intrinsic motivation

Self-efficacy and intrinsic motivation were assessed using a questionnaire with 12 items on a five-point Likert scale ranging from "fully disagree" to "fully agree". The questionnaire was designed by Oprins, Visschedijk, Bakhuys-Roozeboom, Dankbaar, and Trooster (2015) and adjusted for this experiment. Seven items of this questionnaire asked students to ascertain the extent to which they believed in successfully completing learning tasks (selfefficacy); for example, they were asked to rate their own expertise in mathematical medication and to assess themselves against the other students. The reliability coefficients were high in both the pre-assessment $(a=.81)$ and in the post-assessment $(a=.86)$. Five items of this questionnaire aimed to ascertain students' intrinsic motivation towards mathematical medication; for example, they were asked to rate whether mathematical medication lessons held any excitement for them and their level of pleasure during these lessons. The reliability coefficient was satisfactory at the pre-assessment stage $(a=.78)$ and high at the post-assessment stage $(a=.84)$.

Measurement of nursing students' satisfaction with the instructional design

Using the questionnaire from Oprins et al. (2015), students were asked to score their satisfaction with the components of the instructional design of the CBVLE after training. On a five-point Likert scale ranging from "fully disagree" to "fully agree", students rated their satisfaction with the instructional design. These items can be related to the design components of the 4C/ID model (Van Merriënboer \& Kirschner, 2018); for example, students were asked whether they could relate to a particular character, and whether what they learned could be transferred to different situations. The reliability coefficient of the questionnaire was high $(a=.79)$.

\section{Ethics}

Students were free to participate in this study. After giving active informed consent and receiving an introductory verbal explanation about the aims of the study, students could still decline to take part. Students were assured that identifying information would not be accessible by anyone except the researchers. Results were de-identified by numbering both the students and their tests, and files were held in different places under different names. 
The Faculty Ethics Review Committee (FETC) of the Faculty of Social Sciences of Utrecht University in the Netherlands reviewed and approved this research study, under case number 19-230.

Data analysis

A total of 118 students participated in the study. Due to external circumstances (scheduling, internships, illness), 17 students (14\%) dropped out of the study. The results were based on analyses of data from the 101 students who completed all the sessions and tests. Repeated measurement ANOVAs were applied in order to answer the first research question, regarding the individual acquisition of mathematical medication learning, the self-efficacy and the intrinsic motivation of the nursing students in each of the four training groups. Post-hoc tests were conducted to determine the significant differences between the four training conditions. For the second research question, the questionnaire items were tested with an ANOVA to check whether there were differences between the satisfaction levels of the nursing students in the different groups. Multiple regression analyses were also applied to determine whether each combination of design components accounted for the mathematical medication learning, self-efficacy, and intrinsic motivation of the nursing students.

\section{Results}

For the first research question, we found significant differences between the pre-test and post-test stages in the mathematical medication learning of the nursing students, $F(1,97)$ $=119.80, p<.001, \eta 2=.55$. We found no significant differences in mathematical medication learning between the different training groups, $F(3,97)=1.36, p=.26$.

The students' outcomes in terms of self-efficacy showed significant differences between the pre-test and post-test stages, $F(1,88)=17.64, p<.001, \eta 2=.17$. The different training conditions in the CBVLE did not gave rise to any significant differences in the selfefficacy of the nursing students, $F(3,88)=2.31, p=.08$. However, further analysis with a post-hoc test showed that training group 4 achieved significantly higher outcomes than training group 1 , (Mdiff $=2.85$, SDdiff $=1.30, p<.05)$ and training group 2 (Mdiff $=3.28$, SDdiff $=1.35, p<.05)$.

With respect to the students' intrinsic motivation, significant differences were found between the pre-test and post-test stages, $F(1,85)=33.69, p<.001, \eta 2=.28$. No differences were observed between the training groups in the CBVLE in terms of the intrinsic motivation outcomes, $F(3,85)=.25, p=.86$. Table 4 shows the values for the mean and standard deviation for the mathematical medication learning, self-efficacy, and intrinsic motivation of nursing students in the four training groups. 
Table 4

Summary of Outcomes

\begin{tabular}{|c|c|c|c|c|c|c|c|c|c|c|c|c|}
\hline & \multicolumn{3}{|c|}{$\begin{array}{l}\text { Group } 1 \\
\text { CBVLE with } \\
\text { no support }\end{array}$} & \multicolumn{3}{|c|}{$\begin{array}{l}\text { Group } 2 \\
\text { Domain- } \\
\text { specific } \\
\text { support }\end{array}$} & \multicolumn{3}{|c|}{$\begin{array}{l}\text { Group } 3 \\
\text { Regular } \\
\text { thinking } \\
\text { strategies } \\
\end{array}$} & \multicolumn{3}{|c|}{$\begin{array}{l}\text { Group } 4 \\
\text { Combination }\end{array}$} \\
\hline & M & SD & $\mathrm{n}$ & M & SD & $\mathrm{n}$ & M & SD & $\mathrm{n}$ & M & SD & $\mathrm{n}$ \\
\hline \multicolumn{13}{|l|}{ Test scores } \\
\hline Pre-test maths & 23.41 & 7.00 & 27 & 24.45 & 7.88 & 33 & 20.33 & 6.71 & 27 & 21.26 & 5.08 & 31 \\
\hline Post-test maths & 30.82 & 7.33 & 22 & 29.54 & 6.90 & 28 & 27.35 & 9.65 & 28 & 28.96 & 5.10 & 28 \\
\hline Pre-test self-efficacy & 18.73 & 5.67 & 30 & 18.00 & 5.41 & 26 & 19.14 & 4.13 & 28 & 21.14 & 5.02 & 22 \\
\hline Post-test self-efficacy & 20.07 & 5.45 & 28 & 20.21 & 4.62 & 24 & 21.88 & 4.53 & 26 & 22.18 & 4.37 & 22 \\
\hline Pre-test intrinsic motivation & 15.58 & 3.26 & 31 & 16.31 & 3.62 & 26 & 16.50 & 3.12 & 28 & 16.83 & 3.32 & 24 \\
\hline Post-test intrinsic motivation & 18.89 & 2.41 & 28 & 19.00 & 2.51 & 24 & 18.26 & 3.62 & 26 & 18.52 & 3.16 & 22 \\
\hline
\end{tabular}

For the second research question, we found that the satisfaction of the students with the components of the design were above average (see Table 5 for mean scores per design component), but no differences were found between the four groups, $F(3,93)=0.37, p=$ .08 .

Table 5

Outcomes from Nursing Students' Satisfaction with the Instructional Design Components

\begin{tabular}{lccccc}
\hline & $N$ & Min. & Max. & $M$ & $S D$ \\
\hline Learning tasks & 102 & 2.00 & 5.00 & 3.65 & .64 \\
Supportive information & 103 & 1.50 & 5.00 & 3.67 & .66 \\
Procedural information & 104 & 1.00 & 5.00 & 3.41 & .80 \\
Part-task practice & 104 & 1.00 & 5.00 & 3.56 & .82 \\
Cognitive feedback & 102 & 1.33 & 5.00 & 3.13 & .71 \\
\hline
\end{tabular}

In combination, the students' satisfaction with the components of the instructional design did significantly account for their mathematical medication learning, $R^{2}=.21, F(5,87)=$ $4.48, p<.001$. Significant results were also obtained for satisfaction with the components of the instructional design and self-efficacy, $R^{2}=.38, F(5,88)=10.72, p<.001$, and intrinsic motivation, $R^{2}=.47, F(5,84)=15.11, p<.001$. 


\section{Conclusion and Discussion}

This study investigated the instructional design of a CBVLE for mathematical medication learning by nursing students in (higher) vocational education. The outcomes of the study showed that training via the CBVLE did enhance the mathematical medication learning, self-efficacy, and intrinsic motivation of these students; however, no differences were found between the four groups who learned under different conditions. We also accounted for the students' satisfaction with the instructional design: they were satisfied with the separate design components to an above average level, but no differences were found between the four different groups. In combination, the nursing students' satisfaction with the design components had a medium effect on their mathematical medication learning, and a large effect on their self-efficacy and intrinsic motivation.

This study was conducted in order to show that mathematical medication learning in secondary and higher vocational nursing education can be taught via a CBVLE with a holistic approach to design, rather than a focus on one particular domain of mathematics learning (Van Merriënboer \& Kirschner, 2018). In current vocational education programmes for nursing students, mathematics is distinguished from future professional competences in medication administration. Furthermore, mathematical medication learning is broken into isolated parts, and little attention is paid to structure of the domain (Zwart, Van Luit, Noroozi, \& Goei, 2017). It is therefore worth noting that in the Netherlands, mathematics is assessed only once in the educational programme, and that nursing students are then presumed to be familiar with the mathematical medication content. We designed a CBVLE specifically so that nursing students could practice mathematics in a meaningful medication context, and could also maintain their knowledge and skills in this domain by periodic training via the CBVLE. When nursing students practice their mathematical medication knowledge and skills in this way, the emphasis may shift from the outcomes produced to training on the activities necessary for future mathematical medication tasks (Pekrun \& Stephens, 2010). In terms of learning outcomes, the instructional design of the CBVLE stimulated students' attention to the activity of mathematical medication learning (Anderson \& Krathwohl, 2001; Csikszentmihalyi, 2000).

The outcomes of this study not only demonstrate that the mathematical medication learning of these students was enhanced; they also confirm reports in the research literature that virtual learning environments support students' self-efficacy and boost their intrinsic motivation (e.g., Huang et al., 2013; Lee et al., 2010; Makransky \& Petersen, 2019; Xinhao \& Fengfeng, 2016). The CBVLE allowed nursing students to navigate their own self-directed learning, and produced cognitive engagement (Csikszentmihalyi, 2000). Again, when the content was structured using a holistic approach to design, positive 
emotions were found for nursing students regarding mathematical medication learning via the CBVLE.

With regard to the design component of learning tasks, the positive emotions can be attributed to nursing students' future professional mathematical medication tasks, which they believe are important and thus influence their learning behaviour (Csikszentmihalyi, 1990; Wigfield \& Eccles, 2000). Most of the nursing students (80\%) confirmed that they were able to relate to the character of the nurse avatar, and that the virtual learning environment was sufficiently realistic for their learning goals. These results reflect Csikszentmihalyi's (2000) 'presence', defined as a realistic and attractive learning environment that engages students and motivates them to learn. It should be noted that we chose not to make the environment realistic, it was nothing but a virtual encampment. However, we did analyse a real professional learning task, and used strategies to structure this learning task in the CBVLE. The efforts made by the students in terms of mathematical medication learning might therefore have been driven by the relevance of these learning tasks. This corresponds to the findings of Grigg, Perera, McIlveen, and Svetleff (2018), who state that students who have an interest in the learning tasks enjoy learning, which leads to task competence.

The CBVLE was pre-programmed and structured for this study. In terms of the design component of supportive information, the learning domain was organised in such a way that it enabled the students to understand how the mathematical medication domain was organised and how they should complete the learning tasks (Frerejean et al., 2019; Van Merriënboer \& Kirschner, 2018). Self-directed learning was therefore programmed by navigating students towards the activities for learning involving the learning goals, and students were unable to control the virtual environment. In contrast to the findings of Bandura (1993), who stated that students' self-efficacy was influenced by their ability to control the environment, our study showed that controlling the environment seemed less important for nursing students. This was also illustrated by the students' satisfaction with the design component of supportive information, since $77 \%$ of the nursing students were satisfied to an above average level with the choices made for this design component.

For the design component of procedural information, we included worked examples that enabled nursing students to apply procedures to specific mathematical medication problems (Chen et al., 2016; Kirschner et al., 2018; Van Gog et al., 2011). Although these worked examples were embedded to support students, this did not lead to different outcomes for the different groups. The demonstrations of rules and procedures in the worked examples, that were displayed 'just in time', showed only one standard example per domain-specific mathematical medication problem. This may have challenged the students in terms of finding out how the rules and procedures fitted their own mathematical 
medication problems that they needed to solve. Hence, the worked examples could have caused cognitive overload (Kalyuga et al., 2001; Sweller, 2010), due to the presence of the feedback elements in the CBVLE that already supported nursing students to solve the mathematical medication problems. For example, students obtained corrective feedback after providing the wrong answers and feedback on the rules of mathematical medication. An analysis of Merchant et al. (2014) found that different learning tasks require different types of feedback: when learning tasks are declarative in nature, elaborate explanations seem to be more effective as feedback, while for procedural learning tasks, providing the correct response is sufficient for learning. This corroborates the results of a study by Maier et al. (2016) on elaborated feedback, including explanatory information and verification feedback, in response to students' right or wrong answers to a question. The findings revealed that verification feedback was more effective, and the authors concluded that the text used for feedback was too long and detailed. The feedback in this CBVLE study was provided in manageable units (e.g., Shute, 2009), and the outcomes showed that this did enhance the nursing students' feeling of competency in relation to mathematical medication learning via the CBVLE. Providing students with more cognitive approaches via the use of worked examples was unnecessary.

The short exercises on the underlying domain-specific mathematical knowledge were embedded in the CBVLE as part-task practice, to stimulate higher automaticity in terms of the schemas and procedures necessary to solve mathematical medication problems. However, Dunlosky et al. (2013) and Makransky, Terkildsen, and Mayer (2019) state that these practices can also be designated as a function of feedback. In addition, the exercises in this CBVLE study enabled the nursing students to make connections between their prior mathematical knowledge and new knowledge related to mathematical medication learning tasks (Tynjäla, 2013).

We structured the CBVLE environment using a holistic design model, and a variety of cognitive and affective feedback elements were incorporated that could strengthen the nursing students' learning as a whole (Nelson \& Schunn, 2009; Sadler, 2010). The cognitive feedback component of reflection on learning, after six practice problems on mathematical medication and 10 exercises, was considered to be crucial for learning and achievement (Yuang et al., 2020); it was intended to take the students from an initial state of mind to a desired state of mind after training on mathematical medication learning via the CBVLE (Mor et al., 2015). However, the nursing students were not very satisfied with this component, and only $47 \%$ of them were satisfied to an above average level with this design principle. This was as expected, since the cognitive feedback for reflection on learning in this pilot was based on a continuum of points for four levels, which in general means a collection of all values. In order for the nursing students to reach the desired level of skill after training on mathematical medication learning via the CBVLE, this cognitive 
feedback should be customised more specifically to the students' own mathematical medication knowledge.

\section{Suggestions for Future Research and Limitations}

This study investigated the instructional design of a CBVLE for mathematical medication learning in the context of nursing. The CBVLE was based on a structured environment involving 4C/ID design components, and the learning tasks were related to students' future professional tasks, which enhanced their mathematical medication learning. It also boosted their levels of self-efficacy and intrinsic motivation for mathematical medication learning via the CBVLE. This study was a first attempt to concretise (i) the conceptual model of mathematical medication learning by classifying the objects, events and activities of the mathematical medication domain; (ii) the structural model, in order to outline how the objects, events, and activities are related to each other in order to reach specific goals; and (iii) the causal model, in order to address the effects that objects, events and activities have on each other (Van Merriënboer \& Kirschner, 2007). The design of the CBVLE shifts from an instructional design for learning to a learning design tailored to the nursing students' future mathematical medication tasks.

This study represents a first step towards influencing the science of assessment of mathematical medication learning in (higher) vocational education. It aims to contribute to a more dynamic understanding of the integration of assessment with technology. Assessment with a CBVLE refers to a specific use of a learning environment that captures activities as evidence of nursing students' levels of mathematical medication learning (Kim, Almond, \& Shute, 2016). Nevertheless, the results in this study should be interpreted with some caution. The study was conducted in a context that was not part of the standard curriculum, and the results may also have been affected by the reward received by students. The sample of participants was also small, which might limit the generalisability of the findings and the making of strong claims that are not based on coincidence. A repeat of this study with more nursing students and more controlled conditions would be required to confirm the results.

\section{References}

Anderson, L. W., \& Krathwohl, D. R. (2001). A taxonomy for learning, teaching, and assessing: A revision of Bloom's taxonomy of educational objectives. New York, NY: Longman.

Bandura, A. (1982). Self-efficacy mechanism in human agency. American Psychologist, 37, 122-147. doi:10.1037/0003-066X.37.2.122

Bandura, A. (1993). Percieved self-efficacy in cognitive development and functioning. Educational Psychologist, 28, 117-148. doi:10.1207/s15326985ep2802_3 
Boyle, E. A., Hainey, T., Connolly, T. M., Gray, G., Earp, J., Ott, M., ... Pereira, J. (2016). An update to the systematic literature review of empirical evidence of the impacts and outcomes of computer games and serious games. Computers \& Education, 94, 178-192. doi:10.1016/j.compedu.2015.11.003

Buchanan, K. (2003). Opportunity knocking: Co-opting and games. Association for Learning Technology- $N$, 43, 10-11. Retrieved from

https://www.alt.ac.uk/sites/default/files/assets_editor_uploads/documents/ALT43 weg.pdf.

Chen, O., Kalyuga, S., \& Sweller, J. (2016). Relations between the worked example and generation effects on immediate and delayed tests. Learning and Instruction, 45, 20-30. doi:10.1016/j.learninstruc.2016.06.007

Csikszentmihalyi, M. (1990). Flow: The psychology of optimal experience. New York, NY: Harper-Collins.

Csikszentmihalyi, M. (2000). Beyond boredom and anxiety. San Francisco, CA: JosseyBass.

Dalgarno, B., \& Lee, M. J. W. (2010). What are the learning affordances of 3-D virtual environments? British Journal of Educational Technology, 41, 10-32. doi:10.1111/j.1467-8535.2009.01038.x

Dunlosky, J., Rawson, K. A., Marsh, E. J., Nathan, M. J., \& Willingham, D. T. (2013). Improving students' learning with effective learning techniques: Promising directions from cognitive and educational psychology. Psychological Science in the Public Interest, 14, 4-58. doi:10.1177/1529100612453266

Frerejean, J., Van Merriënboer, J. J. G., Kirschner, P. A., Roex, A., Aertgeerts, B., \& Marcellis, M. (2019). Designing instruction for complex learning: 4C/ID in higher education. European Journal of Education, 54, 513-524. doi:10.1111/ejed.12363

Grigg, S., Perera, H. N., McIlveen, P., \& Svetleff, Z. (2018). Relations among math selfefficacy, interest, intentions, and achievement: A social cognitive perspective. Contemporary Educational Psychology, 53-86. doi: $10.1016 /$ j.cedpsych.2018.01.007

Huang, W. D., Johnson, T. E., \& Han, S-H. C. (2013). Impact of online instructional game features on college students perceived motivational support and cognitive investment: A structural equation modeling study. Internet and Higher Education, 17, 58-68. doi:10.1016/j.iheduc.2012011.004 
Kim, Y. J., Almond, R. G., \& Shute, V. J. (2016). Applying evidence-centered design for the development of game-based assessments in physics playground. International Journal of Testing, 16, 142-163. doi:10.1080/15305058.2015.1108322

Lampe, T., Straetmans, G., \& Eggen, T. (2011). De rekenvaardigheid van de Nederlandse verpleegkundige [Nurses' mathematical skills in the Netherlands]. Onderwijs en gezondheidszorg, 35(3), 3-9. doi:10.1007/s12477-011-0030-y

Lee, E., A-L., Wong, K. W., \& Fung, C. C. (2010). How does desktop virtual reality enhance learning outcomes? A structural equation modeling approach. Computers \& Education, 55, 1424-1442. doi:10.1016/j.compedu.2010.06.006

Maier, U., Wolf, N., \& Randler, C. (2016). Effects of a computer-assisted formative assessment intervention based on multiple-tier diagnostic items and different feedback types. Computers \& Education, 95, 85-98. doi: $10.1016 / j . c o m p e d u .2015 .12 .002$

Makransky, G., \& Petersen, G. B. (2019). Investigating the process of learning with desktop virtual reality: A structural equation modeling approach. Computers \& Education, 134, 15-30. doi:10.1016/j.compedu.2019.02.002

Makransky, G., Terkildsen, S., \& Mayer, R. E. (2019). Adding immersive virtual reality to a science lab simulation causes more presence but less learning. Learning and Instruction, 60, 225-236. doi:10.1016/j.learninstruc.2017.12.007

Merchant, Z., Goetz, E. T., Cifuentes, L., Keeney-Kennicutt, W., \& Davis, T. J. (2014). Effectiveness of virtual reality-based instruction on students' learning outcomes in K-12 and higher education: A meta-analysis. Computers \& Education, 70, 29-40. doi: $10.1016 /$ j. compedu.2013.07.033

Merchant, Z., Goetz, E. T., Keeney-Kennicutt, W., Oi-man K., Cifuentes, L., \& Davis, T. J. (2012). The learner characteristics features of desktop 3D virtual reality environments, and college chemistry instruction: A structural equation modeling analysis. Computers \& Education, 59, 551-568. doi: $10.1016 /$ j.compedu.2012.02.004

Mor, Y., Ferguson, R., \& Wasson, B. (2015). Learning design, teacher inquiry into student learning, and learning analytics: A call for action. British Journal of Educational Technology, 46, 221-229. doi:10.1111/bjet.12273

Nelson, M. M., \& Schunn, C. D. (2009). The nature of feedback: How different types of peer feedback affect writing performance. Instructional Science, 37, 375-401. doi: $10.1007 /$ s11251-008-9053-x

Oprins, E., Visschedijk, G., Bakhuys-Roozeboom, M., Dankbaar, M., \& Trooster, W. (2015) 
'The Game-based learning Evaluation Model (GEM): measuring the effectiveness of serious games using a standardized method'. International Journal of Technology Enhanced Learning, 7, 326-345. doi:10.1504/IJTEL.2015.074189

Pajares, F., \& Schunk, D. H. (2001). Self-beliefs and school success: self-efficacy, selfconcept, and school achievement. In R. Riding \& S. Rayner (Eds.), Perception (pp. 239-266). London, UK: Ablex Publishing.

Pekrun, R. (2006). The control-value theory of achievement emotions: Assumptions, corollaries, and implications for educational research and practice. Educational Psychology Review, 18, 315-341. doi:10.1007/s10648-006-9029-9

Pekrun, R., \& Stephens, S. J. (2010). Achievement emotions in higher education. In J. C. Smart (Ed.), Higher education: Handbook of theory and research (Vol. 25, pp. 257306). New York: Springer. doi:10.1007/978-90-481-8598-6_7

Rohrer, D., Dedrick, R. F., \& Stershic, S. (2015). Interleaved practice improves mathematics learning. Journal of Educational Psychology, 107, 900-908. doi:10.1037/edu0000001

Ryan, R. M., \& Deci, E. L. (2000). Self-determination theory and the facilitation of intrinsic motivation, social development, and well-being. American Psychologist, 55, 68-78. Retrieved from https://selfdeterminationtheory.org/SDT/documents/2000_RyanDeci_SDT.pdf

Sadler, D. R. (2010). Beyond feedback: Developing student capability in complex appraisal. Assessment \& Evaluation in Higher Education, 35, 535-550. doi: $10.1080 / 02602930903541015$

Schunk, D. H., \& DiBenedetto, M. K. (2016). Self-efficacy theory in education. In K. R. Wentzel, \& D. B. Miele (Eds.), Handbook of motivation at school (2nd ed., pp. 3454). London, UK: Routledge. doi:10.4324/9781315773384.ch3

Schunk D. H., \& Pajares, F. (2009). Self-efficacy theory. In K. R. Wentzel \& A. Wigfield (Eds.), Handbook of motivation at school (pp. 35-53). London, UK: Routledge. https://psycnet.apa.org/record/2009-24219-003

Shute, V., Ventura, M., Bauer, M., \& Zapata-Rivera, D. (2009). Melding the power of serious games and embedded assessment to monitor and foster learning. In $U$. Ritterfeld, M. Cody, \& P. Vorderer (Eds.), Serious games: Mechanisms and effects (pp. 295-321). New York, NY: Routledge.

Sweller, J. (2010). Element interactivity and intrinsic, extraneous, and germane cognitive load. Educational Psychology Review, 22, 123-138. doi:10.1007/s10648-01091285 
Tynjälä, P. (2013). Toward a 3-P model of workplace learning: A literature review. Vocations and Learning, 6, 11-36. doi:10.1007/s12186-012-9091-z

Van Merriënboer, J. J. G., \& Kirschner, P. A. (2007). Ten steps to complex learning. A systematic approach to four-component instructional design. Mahwah, $\mathrm{NJ}$ : Lawrence Erlbaum Associates.

Van Merriënboer, J. J. G., \& Kirschner, P. A. (2018). Ten steps to complex learning (3rd ed.). New York, NY: Taylor \& Francis.

Wang, M., Kirschner, P. A., Spector, J. M., \& Ge, X. (2018). Computer-based learning environments for deeper learning in problem-solving contexts. Computers in Human Behavior, 87, 403-405. doi:10.1016/j.chb.2018.06.026

Wigfield, A., \& Eccles, J. S. (2000). Expectancy-value theory of achievement motivation. Contemporary Educational Psychology, 25, 68-81. doi:10.1006/ceps.1999.1015.

Xinhao, X., \& Fengfeng, K. (2016). Designing a virtual reality based, gamelike math learning environment. American Journal of Distance Education, 30, 27-38. doi: $10.1080 / 08923647.2016 .1119621$

Yuan, B. Wang, M., Van Merriënboer, J., Tao, X., Kushniruk, A., \& Peng, J. (2020). Investigating the role of cognitive feedback in practice-oriented learning for clinical diagnostics. Vocations and Learning, 13, 159-177. doi:10.1007/s12186-01909234-z

Zwart, D. P., Goei, S. L., Noroozi, O., \& Van Luit, J. E. H. (2021). The effects of computerbased virtual learning environments on nursing students' mathematical learning in medication processes. Research and Practice in Technology Enhanced Learning, 16: 4. doi:10.1186/s41039-021000147-x

Zwart, D. P., Noroozi, O., Van Luit, J. E. H., Goei, S. L., \& Nieuwenhuis, A. (2020). The effects of Digital Learning Materials on nursing students' mathematics learning, selfefficacy, and task-value in vocational education. Nurse Education in Practice, 44 : 102755. doi: $10.1016 /$ j.nepr.2020.102755

Zwart, D. P., Van Luit, J. E. H., Noroozi, O., \& Goei, S. L. (2017). The effects of Digital Learning Material on students' mathematics learning in vocational education. Cogent Education, 4: 1313581. doi:10.1080/2331186X.2017.1313581. 


\section{Chapter 7}

General Summary and Conclusion

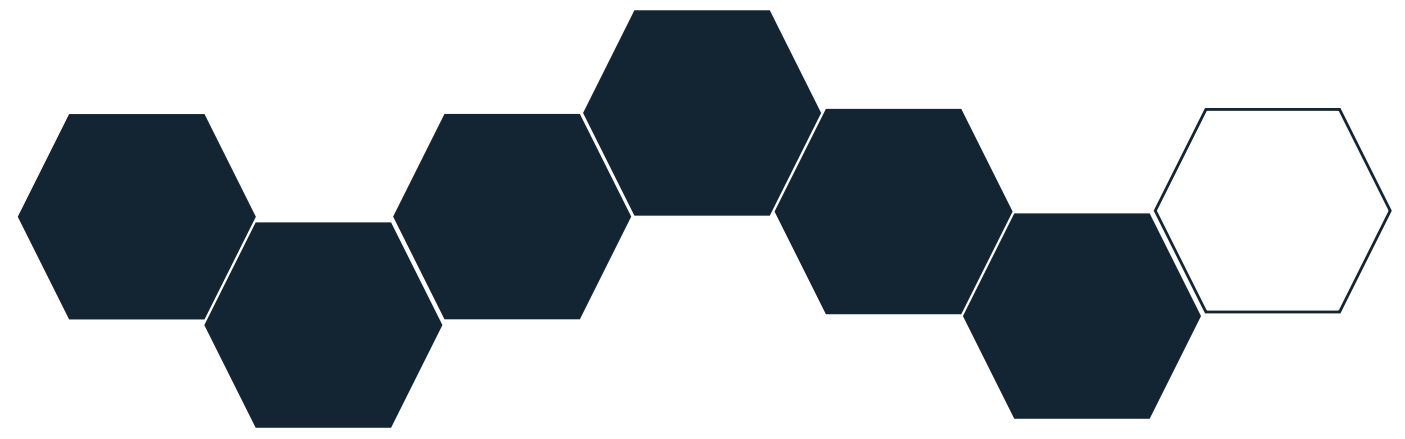




\section{Introduction}

This final chapter summarizes and combines the outcomes of the studies described in previous chapters. As mentioned in Chapter 1 , the research in this dissertation was twofold. The first aim was to study teaching the concept of mathematics with digital learning materials (DLMs) in the context of students' future profession, and the second aim was to study students' mathematics in a self-supportive and motivated DLMs learning environment as exercises for maintaining their mathematical knowledge and skills during their vocational education program. These two aims were addressed in five research articles for the further development of training the concept of mathematics in vocational education with DLMs involving students' future learning task. In this chapter the main findings will be discussed in a meta-perspective involving the literature methodology, future research directions, practical implications, and an ethical reflection on learning with technology. To do so, the first section summarizes the main findings and recapitulates how the studies answered the research questions. Additionally, the research findings are described in an integrated perspective and discussed in a broader sense. In the next section, the strengths and the weaknesses of the studies are discussed, and suggestions are made for future research. Finally, this chapter ends with implications for educational practice as well as an ethical reflection on DLMs and the emphasis on technology against the common values in educational programs in general.

\section{Main findings of the empirical studies}

The study of mathematics is an essential objective in vocational education, especially for healthcare professionals, such as nurses. These individuals are expected to have an accurate knowledge of how to administer medication, especially the mathematical knowledge needed for the safe calculation of medication dosage. Although errors can occur at any stage, from prescribing, dispensing, and administering to recording and reporting, it is recognized that nurses are the final line of defence regarding safety and patients' health (Adhikari, Tocher, Smith, Corcoran, \& MacArthur, 2014). Nurses' competence in dose calculation is of vital importance, and therefore emphasis on mathematics in vocational education is needed. Using DLMs can support students to improve their mathematics scores, especially when mathematics is linked to students' future professional learning tasks. Therefore, I have explored how the instructional design for mathematical learning, especially mathematical medication learning with DLMs, affects mathematics learning of students, especially nursing students, in vocational education.

Chapter 2 dealt with the research question What are the effects of DLMs on students' mathematics learning in vocational education? with two studies designed to determine the effect of DLMs, including instructional clips, online guidance, structuring of content, and a collaboration tool, on the mathematics learning outcomes of apprenticeship students in 
vocational education. Furthermore, the relationship between working memory (WM) scores and mathematics results was investigated. The general conclusion was drawn that a DLMs environment, including instructional clips, online guidance, structuring of content, and a collaboration tool, can foster positive learning outcomes and knowledge construction. Differences in mathematics results could not be accounted for by WM scores, but students in the healthcare sector demonstrated significantly higher learning gains that students from other sectors. The students were involved in the assignments and collaborated as a group, and if they found technical and organizational problems the teacher was immediately notified. The nursing students showed deep involvement, in contrast to the students from the other sectors, who showed no interested in the DLMs environment. At this point, teachers' expertise in giving students guidance on technology use might have been overestimated in previous research (Knezek \& Christensen, 2008). The teachers' role in closing the gap between the innovation of the environment and classroom curricula did not sufficiently emerge during and after sessions. Key system factors that could not have been manipulated by the innovation were ignored. In a productive DLMs environment, to construct knowledge, students need to work together, but this collaborative learning needs to be structured and guided appropriately (e.g., Gillies, 2004; Kollar, Fischer, \& Slotta, 2007); otherwise, students often engage in low-level learning processes. A central role for the online teacher was envisaged here. For this to occur successfully, the central role of the teacher in giving impetus to scaffolds between DLMs and students should be enabled by having teachers gain and update their qualifications and skills for DLMs environments.

Since only the effects of DLMs on nursing students' mathematics learning were investigated, the next step was to involve the effects of DLMs on students' self-efficacy and determine whether the students appreciated the mathematics tasks in the DLMs environment. To grasp the concept of mathematics learning with DLMs and align the instructional clips and mathematics content to students' future professional skills, the focus of the research became nursing education. Emphasis on maintenance of mathematical medication learning in vocational education is needed, since nurses are the professionals who provide medication (Adhikari et al., 2014). Nursing students' understanding of the relationship between the different mathematical elements necessary for doing calculations in medical situations was especially emphasized in the DLMs training via the instructional clips; the procedural knowledge clips clarified facts from ordinary computational skills and connected them with the assignments in the instructional domain-specific clips. Since these instructional clips were linked with nursing students' future profession, retrievable at any time and in any location, nursing students were able to watch these demonstrations on how to apply procedures to mathematical problems repeatedly.

In Chapter 3 the effects of DLMs teaching on mathematics learning outcomes, self-efficacy, and task value for nursing students in vocational education were examined. Results showed 
that both DLMs training and face-to-face training conditions enhanced nursing students' mathematics learning, but no significant difference was found between the two conditions. Again, regarding nursing students' task value scores, no significant differences were found in and between the groups. However, nursing students' self-efficacy regarding the study with the DLMs training showed an effect opposite from our expectations: nursing students' self-efficacy decreased after the intervention. One plausible explanation for the decrease in students' self-efficacy is that the DLMs environment demanded too much from these nursing students and thus gave rise to negative emotions (Pekrun, 2006).

Online education requires self-directed learning from the individual student and online interaction with other peers and the online teacher. This shared regulation of interaction and collaboration needs task conditions such as quality criteria or criteria for the completion of tasks (Hadwin, Järvelä, \& Miller, 2011). These conditions were not clearly communicated beforehand. Again, teachers' online communication skills to motivate students for mathematics tasks with DLMs during training should not be overestimated (Gray, 2004; Zwart, Van Luit, Noroozi, \& Goei, 2017). In educational classroom settings, students rely heavily on their teacher's affirmations, and consequently do not build their own starting points for evaluation (Baldwin, 1967). Since these affirmations are related to the teacher, his or her proximity and attention is confirmatory for students. Students' dependence can lead to fear if the teacher is absent. Consequently, students find it difficult to break through their own learning and studying patterns in relation to their expectations of both their teacher and the other students. This applies in particular for students with lower learning abilities. Results revealed that students with higher learning abilities appreciated the instructional domain-specific DLMs feature more than students with lower learning abilities. It seems that students with low learning abilities find it more difficult to engage when they are interacting with learning materials, which increases their extraneous load and thus their working memory load (Kollar et al., 2014; Sweller, 2010).

According to the literature (e.g., Merchant, Goetz, Cifuentes, Keeney-Kennicutt, \& Davis, 2014; Merchant et al., 2012; Makransky \& Petersen, 2019; Xinhao \& Fengfeng, 2016), virtual-based learning can foster affective, behavioural, and cognitive engagement. Many problem-solving scenarios can be designed that enable active interactions with the content and enhance knowledge acquisition and transfer. Structured learner-centred activities in a virtual-based learning environment promote students' awareness of the expectations of learning tasks and the available means that fulfil these expectations (Alfassi, 2003). Because of this, the level of students' confidence could increase while successfully accomplishing the learning tasks, which, according to Pekrun (2006), fosters self-efficacy. Therefore, a computer-based virtual learning environment (CBVLE) with worked examples was developed, to test the effect on mathematical medication learning, self-efficacy, and intrinsic motivation. 
Chapter 4 therefore dealt with the research question: What are the effects of the CBVLE on nursing students' mathematical learning in medication processes? Students were randomly assigned to four conditions in the CBVLE, which trained them in extracting the relevant mathematical information from (complex) medication problems. The four conditions facilitated students with extra support for mathematical medication learning in the CBVLE: (1) learning without worked examples, (2) learning with worked examples involving domain-specific knowledge, (3) learning with worked examples involving regular thinking strategies, and (4) learning with combined worked examples. Students were pretested and post-tested on their mathematical medication learning. Results showed no differences among the four conditions. Nursing students' prior knowledge, non-verbal intelligence, and number of correct tasks predicted mathematical medication learning outcomes. When controlling for non-verbal intelligence, students in condition 1 benefited more than students in condition 3 in terms of their mathematical medication learning outcomes. This might have been attributable to the characteristics of the regular thinking strategies. Zohar and David (2008) stress the importance of a strong verbal component of thinking strategies. In this CBVLE, thinking strategies were presented only on paper, and thus could not trigger students to carry out active thinking. Moreover, the structure of the learning environment in the CBVLE already outlined a domain-specific task and had control over many of the information elements and their interactions, which were pre-programmed for the learners. Worked examples may therefore have been redundant.

The redundancy of worked examples applied not only to high-achieving students (see Anderson, Fincham, \& Douglas, 1997; Kalyuga, Chandler, \& Sweller, 2001; Kalyuga, Chandler, Tuovinen, \& Sweller, 2001; Kirschner, Sweller, Kirschner, \& Zambrano, 2018; Van Merriënboer \& Sweller, 2010), but also to low-achieving learners. It was striking that the mathematical medication learning of low-achieving nursing students improved most. More interesting was the fact that low-achieving nursing students gained the highest learning results in the first group, with no support from worked examples. It seems that technology has taken over some of the capacity of working memory, which accounted for the benefits to the low-achieving learners in the CBVLE.

Sweller (2010) places considerable emphasis on devising techniques that support students' domain-specific knowledge learning, rather than regular skills (Pollock, Chandler, \& Sweller, 2002). On the other hand, worked examples with domain-specific knowledge might have imposed an excessive load (see Sweller, 2010). This chapter focused on mathematical medication learning and left us with the question of whether mathematical medication learning via the CBVLE could enhance nursing students' self-efficacy and intrinsic motivation for learning via the CBVLE. 
Therefore, Chapter 5 dealt with the research question: What are the effects of a CBVLE on nursing students' mathematical medication learning, self-efficacy, and intrinsic motivation? The study confirmed the expectations that the CBVLE facilitates nursing students' mathematical medication learning, their self-efficacy, and intrinsic motivation outcomes for mathematical medication learning. Outcomes showed that the four training conditions in the CBVLE did not discriminate between nursing students' mathematical medication outcomes and their intrinsic motivation for mathematical medication learning using the CBVLE. For self-efficacy outcomes, training condition 4 (extra support of worked examples involving domain-specific knowledge and regular thinking strategies) showed significantly higher self-efficacy outcomes than training condition 1 (without the extra support of worked examples) and training condition 2 (extra support of worked examples involving domain-specific knowledge). This indicated that nursing students' self-efficacy in successfully completing mathematical medication learning tasks using the CBVLE might have been positively influenced by the extra support of worked examples involving both domain-specific knowledge and regular thinking strategies. What was interesting was that nursing students in training condition 1 (no worked example support) also showed higher mathematical medication learning outcomes than nursing students in training condition 2 when removing the effect of non-verbal intelligence outcomes. This indicated that the CBVLE was well-designed for mathematical medication learning, but for complex learning tasks and for nursing students who approached mathematical medication learning using the CBVLE as a huge challenge, the extra support of worked examples involving domainspecific knowledge and regular thinking skills gave added impetus to mathematical medication learning using the CBVLE.

Nursing students' enhanced self-efficacy in mathematical medication learning using the CBVLE might have been driven by the relevance of the learning tasks that display nursing students' future professional medication tasks (Bandura \& Schunk, 1981; Csikszentmihalyi, 1990; Pekrun \& Stephens, 2010). When students designate the learning task as useful and important for their future, their motivation for learning strengthens (Deci \& Ryan, 1985). This explained the increasing intrinsic motivation for mathematical medication learning using the CBVLE. The learning tasks in the CBVLE were contextualized in a way so that nursing students were able to recognize their importance: the learning tasks were subject to the medical procedure laid down in the medication description for nursing students. The CBVLE enabled the design of the procedure of the mathematical medication learning tasks that provoked goal-directed learning: nursing students solved mathematical medication problems playfully, and the standardized conditions in the CBVLE supported their mathematical medication learning. Nursing students' intrinsic motivation was highly significant, which was an important factor for the process of learning and for students' expectation of being successful (Lee \& Seo, 2021; Pekrun, 2006). 
To investigate more specifically what components of the instructional design in the CBVLE dealt with students' positive outcomes, Chapter 6 dealt with the research question: What design components of the instructional design in the CBVLE satisfied nursing students and related to students' mathematical medication learning, self-efficacy, and intrinsic motivation? The instructional design of virtual learning environments needed careful consideration to foster nursing students' mathematical medication learning, self-efficacy, and intrinsic motivation for learning with CBVLEs. Five design components were defined and described, according to the whole-task design (4C/ID) model (Van Merriënboer \& Kirschner, 2018): (i) learning tasks, (ii) supportive information, (iii) procedural information, (iv) part-task practice, and (v) cognitive feedback as reflection on learning.

The outcomes of the instructional design of this study showed that training via the CBVLE enhanced nursing students' mathematical medication learning, self-efficacy, and intrinsic motivation. However, no differences were found among the different conditions. This also accounted for nursing students' appreciation of the instructional design; the nursing students exhibited above-average satisfaction towards the separate design components, but no differences were found among the four conditions. In combination, nursing students' appreciation of the design components accounted for a medium effect on their mathematical medication learning, and for a large effect on their self-efficacy and intrinsic motivation. Concerning the design component learning tasks, the positive emotions could be attributed to nursing students' future professional mathematical medication tasks, which students labelled as important, thus influencing their learning behaviour (Csikszentmihalyi, 1990; Wigfield \& Eccles, 2000). Most of the nursing students (80\%) confirmed that they were able to relate to the character of the nurse avatar, and that the virtual learning environment was sufficiently realistic for their learning goals. These results reflect Csikszentmihalyi's (1990) 'presence', defined as a realistic and attractive learning environment that engages students and motivates them to learn. It should be noted that we chose not to make the environment realistic; it was nothing but a virtual encampment. However, we analysed a real professional learning task and used strategies to structure this learning task in the CBVLE. The efforts made by the students in terms of mathematical medication learning might therefore have been driven by the relevance of these learning tasks. This corresponded to the results of Grigg, Perera, McIlveen, and Svetleff (2018), who state that students with interest in learning tasks enjoy learning, which leads to task competence. The design component supportive information was developed in the CBVLE in such a way that it enabled the nursing students to understand how the mathematical medication domain was organized and how nursing students had to complete the learning tasks (Frerejean et al., 2019; Van Merriënboer \& Kirschner, 2018). This led to nursing students' self-directed learning navigated by the learning goals towards the programmed 
activities for learning. Of the nursing students, $77 \%$ expressed above-average satisfaction with the choices made in the design component supportive information.

For the design component procedural information, worked examples were included that enabled nursing students to apply procedures to specific mathematical medication problems (Chen, Kalyuga, \& Sweller, 2016; Kirschner et al., 2018; Van Gog, Kester, \& Paas, 2011). Though the worked examples were embedded to support students, in this study this did not lead to different outcomes. The demonstrations of rules and procedures, which were displayed just in time, showed one standard example per domain-specific mathematical medication problem. This might have challenged the students in terms of determining how the rules and procedures fitted their own mathematical medication problems that they needed to solve. Hence, the worked examples could have caused cognitive overload (Kalyuga et al., 2001; Sweller, 2010), due to the presence of the feedback elements in the CBVLE that already supported nursing students to move towards their learning goals. Nursing students gained corrective feedback through providing the right answers and mathematical medication rules. The feedback in this CBVLE study was provided in manageable units (e.g., Shute, Ventura, Bauer, \& Zapata-Rivera, 2009), which, according to the outcomes, enhanced nursing students' feeling of competency for mathematical medication learning via the CBVLE. The method of providing students with more cognitive approaches with the use of worked examples was not necessary. We structured the CBVLE using a holistic design model. The cognitive feedback component as a reflection on learning, after six mathematical medication problems and ten exercises, was crucial for learning and achievement (Yuang et al., 2020); it was intended to bring the students from an initial state of mind to a desired state of mind after training mathematical medication learning via the CBVLE (Mor, Ferguson, \& Wasson, 2015). However, the nursing students were not very satisfied with this component, and only $47 \%$ of them were satisfied to an above-average level with this design principle. This was as expected, since the cognitive feedback for reflection on learning in this pilot was based on a continuum of points, which in general means a collection of all values. For nursing students to reach the desired state of mind after training on mathematical medication learning via the CBVLE, this cognitive feedback should be customized more specifically to the nursing students' own mathematical medication knowledge.

\section{Research findings in an integrated perspective}

The research reported in this thesis was conducted to show that mathematical medication learning in (higher) vocational education can be taught via digital learning materials with a holistic approach design, and not as a focus on one domain of mathematics learning (Van Merriënboer \& Kirschner, 2018). In current (higher) vocational education programs, mathematics is distinguished from nursing students' future professional competences for 
medication administration. Furthermore, mathematical medication learning in secondary and higher education is broken into isolated parts, and little attention is paid to the structure of the domain. Thereby, it is worth noting that mathematics is assessed only once in the educational program and that nursing students are presumed to stay familiar with the complex mathematical medication content. This is striking, since nurses' competences in dose calculation are of vital importance for all of us. Although errors can occur at any stage in the medication process, from prescribing, dispensing, and administering to recording and reporting, it is recognized that nurses are the last participants in this chain, who provide medication to their patients (Adhikari et al., 2014). Therefore, emphasis on the maintenance of mathematical medication learning in vocational education is needed during the whole educational program. The studies in this thesis showed that DLMs enabled nursing students' mathematical medication learning in a meaningful context for maintaining their mathematical medication knowledge and skills. In addition, not only did the outcomes with the CBVLE demonstrate that nursing students' mathematical medication learning was enhanced, but they also endorsed earlier research finding that students' self-efficacy and intrinsic motivation could be enhanced through virtual learning (e.g., Huang, Johnson, \& Han, 2013; Lee, Wong, \& Fung, 2010; Makransky \& Petersen, 2019; Xinhao \& Fengfeng, 2016). When students can train their mathematical medication knowledge and skills in their educational program, playfully and periodically via a CBVLE, the emphasis might shift from produced outcomes to training relevant activities necessary for future mathematical medication learning tasks (Pekrun \& Stephens, 2010).

It appeared that the success of mathematical medication learning with DLMs still depended on the online guidance by the teacher and nursing students' self-directed learning. This became evident in the second study, where nursing students' self-efficacy outcomes decreased. The success of the mathematical medication training via the CBVLE, which enhanced nursing students' self-efficacy, could be attributed to a virtual learning environment that pre-programmed nursing students' self-directed learning and needed no guidance from a teacher. Though nursing students were not able to collaborate but worked on the learning tasks in the CBVLE individually, the importance of seeing, being, and meeting together in the virtual world should not be underestimated. The concept of learning with a teacher implies the existence of a teacher who is in favour of the student (Hattie \& Timperly, 2007), but students can feel the exact opposite: when teachers do not recognize students' mathematical learning outcomes as stable, students fail faster (Woodcock \& Vialle, 2011). This implies that the teacher's presence might not be an exceptionally helpful factor for mathematical learning for every nursing student. This-as well as the lack of time for teachers to give adequate feedback to all their students during mathematical medication lessons-might create students' learned helplessness (Seligman, 1972; Seligman \& Campbell, 1965) in traditional learning, or in learning with DLMs where 
the success of learning still depends on the guidance of the teacher. If one wants to create more flexible learning activities with DLMs that engage nursing students and encourage them to participate actively in training for present and future (lifelong) learning, certain aspects should be considered. Firstly, starting points should be provided to students that enable them to support their own online evaluation. Secondly, there should be task conditions that are discussed beforehand and that describe the quality criteria for assignments or criteria for completion of tasks. Thirdly, the teacher and the students should not only discuss the assignments but should also share rules and come to an agreement on online collaboration and online interaction. Finally, the teacher's online role should not only encourage feedback for finishing assignments but also support students socially for their sense of efficacy.

In contrast to Bandura (1993), who states that students' self-efficacy is influenced by their ability to control the environment, the studies in this thesis showed the opposite. Creating a CBVLE with future professional learning tasks with which students could identify fostered nursing students' self-efficacy for mathematical medication learning, even though their self-directed learning was pre-programmed. It can thus be inferred that controlling the virtual environment for learning mathematical medication seemed less important for the nursing students. This might have been a result of the feedback that supported the students in the CBVLE. The verification feedback, which consisted of the correct answers, and the elaborative feedback, which consisted of short domain-specific mathematical rules, mediated the strong relationship between mathematical medication learning and selfefficacy. Mathematical medication learning directly predicted nursing students' self-efficacy outcomes via CBVLE learning (66\%). Moreover, this effect was mediated by the feedback in the CBVLE (34\%). Thereby, the short exercises to train the underlying domain-specific mathematical knowledge that were embedded in the CBVLE can also be regarded as a function of feedback (Dunlosky, Rawson, Marsh, Nathan, \& Willingham, 2013; Makransky, Terkildsen, \& Mayer, 2019).

The holistic design model (4C/ID model) from Van Merriënboer and Kirschner (2018) allocates short exercises to the part-task practice design component. In the CBVLE training, these exercises enabled students to make connections between prior mathematical knowledge and new knowledge that the students needed to solve the mathematical medication learning tasks (Tynjäla, 2013). These exercises were designed as transfer tasks to cue the retrieval of appropriate prior knowledge (Gick \& Holyoak, 1987). The transfer tasks took the form of short exercises that encouraged nursing students to retrieve and apply the appropriate underlying knowledge necessary to solve complex mathematical medication problems. The similarity of processing might have generated the transfer of knowledge necessary for mathematical medication learning. The CBVLE supported the mathematical medication learning of nursing students in the context of their future 
professional tasks. This was underlined by the high proportion of nursing students $(90 \%)$ who reported that the mathematical medication training via the CBVLE made them more aware of their skills in medication administration.

\section{Strengths, weaknesses, and suggestions for future research}

This thesis is a compilation of studies in educational settings to contribute to the advancement of the use of DLMs to facilitate mathematics learning in vocational education. In this regard, strengths and weaknesses will be discussed, which lead to interesting directions for future research.

The pre-test-post-test design of the exploratory study presented in Chapter 2 was a first effort to explore the educational concept of mathematical learning with DLMs in Dutch vocational education. The results led to a clear view of students' mathematics learning and outcomes in a digital learning environment in a real vocational education setting. The use of a small sample in the exploratory study might have affected the outcomes. Furthermore, outcomes could have been influenced by student characteristics, such as age and educational background. Findings of this study should therefore be validated by further research in which students' backgrounds and characteristics are considered in more controlled conditions and in a larger group.

Chapter 3 presented a study with a pre-test-post-test control group design. In this study, students had the same backgrounds and characteristics, and this led to insights in teaching and learning with DLMs. However, the study had a small sample of participants, especially in the control group. This might have limited the generalizability of the findings and might lead to strong claims that are based only on coincidence. For example, no controls were established for various nursing students' needs or the communication and support skills of the teacher in motivating the students online. Furthermore, the actual level of engagement was not accounted for, especially for the students in the DLMs condition. Future research should thus collect information on the communication and support skills of the teacher and information on the extent to which students used various features of the DLMs by counting the number of clicks on these features. Replication of this study with more nursing students and measuring their levels of engagement by checking their activities in the DLMs would be needed to confirm the results. Thereby, teachers' skills as a nexus for teaching and learning with DLMs should be considered more explicitly to see to what extent similar or different results could be obtained. Consequently, it would be insightful to conduct research studies for mathematical medication learning that enables students to engage in more transformative and innovative learning, facilitating learning environments that stimulate self-directed learning.

Therefore, the studies presented in Chapters 4, 5, and 6 were conducted under more stringent conditions. The studies led to a more comprehensive picture of the effects of the 
different components of the instructional design on nursing students' learning and affective processes, and outcomes in a CBVLE. This experiment with four conditions, including a controlled condition with no support, provided us with the opportunity to take individual students' characteristics (non-verbal intelligence, prior domain-specific knowledge, selfefficacy, et cetera) into account. These measurements guaranteed that the observed differences between learners in the conditions were due to the intervention and not to biased or false distribution of learners over the conditions in terms of their characteristics. Furthermore, for this experiment the students were assigned to a condition at random, and the students were chosen from secondary and higher vocational nursing education all over the Netherlands. The learning task was identical and authentic for all students. It should also be mentioned that no differences were found between nursing students from secondary and higher vocational education. It is therefore assumed that comparable results would be achieved in curricular educational settings with a high ecological validity. For that, however, the choice of virtual learning for the maintenance of mathematics in vocational nursing education could have consequences for choices in the conversion of nursing curricula. Therefore, further research with more direct practical relevance with the CBVLE is needed to test the extent to which the results of this empirical study can be generalized in real educational settings.

In the studies in this PhD thesis, only short-term measurements for various types of individual performances were administered, such as domain-specific knowledge, selfefficacy, and intrinsic motivation. These variables were measured immediately after the intervention. This may have resulted in a misleading boost in short-term individual learning performance measures without keeping long-term retention in mind (Noroozi, 2013). The surveys consisted of self-reported data that might not have always been reliable. Furthermore, students could lose their interest over time, and thus it could also have been interesting to measure intrinsic motivation and self-efficacy in the middle of the intervention, to relate these outcomes to the number of practices and exercises performed in the CBVLE. Therefore, follow-up research needs to answer this question. This could have implications for the design components of the instructional design in the CBVLE, and consequently also for nursing students' learning.

The studies in this thesis were a first step towards influencing the science of assessment for mathematical medication learning in secondary and higher vocational education. The project aimed to contribute to a more dynamic understanding of the integration of assessment with technology. Assessment with a CBVLE refers to a specific use of learning environments that capture activities as evidence for nursing students' level of mathematical medication learning (Kim, Almond, \& Shute, 2016). A CBVLE allows nursing students to train their mathematical knowledge and skills for (future) medication processes. Then, the CBVLE can become a balanced form of learning that enables students 
to engage in transformative and innovative-rather than reproductive-learning (Tynjälä, 2013). The CBVLE can be used as a technology-enhanced educational assessment system that nursing students can use to train and assess their mathematical medication learning, for example on a quarterly or semi-annual basis. This form of formative assessment, or assessment for learning, supports teaching and learning (Shute \& Rahimi, 2017). In this thesis, we were only able to download the activity logs of 60 students. The extent to which the results of these measurements are consistent with students' achievements in the educational settings is under-investigated. Further research and analysis aim to answer this question.

\section{Implications for educational practice}

Finally, this PhD thesis had important implications for the instructional design of DLMs and CBVLEs in secondary and higher nursing education. Instructional design for virtual learning is an interesting new challenge for many instructional designers. The novelty factor should not overshadow effective and meaningful learning. The studies in this thesis were a first attempt to concretize design functions that make (i) the conceptual model of mathematical medication learning more tangible by classifying the objects and activities of the mathematical medication domain and (ii) the structural model of nursing students' future medication learning tasks more visible by outlining the phases of the learning task in the CBVLE that show how the objects and activities are related to each other for reaching goals (Van Merriënboer \& Kirschner, 2007). In addition, the causal model (iii) addressed the effect that objects, and activities have on each other. To conclude, the studies obviously show that DLMs themselves made it impossible to clearly identify the mathematical medication concept and reconcile the different aspects of mathematical medication learning. The learning environment with DLMs was still broken into isolated parts, and selfdirected learning and paying attention to the structure of the domain still depended on the teacher-the nexus of learning environments with DLMs. By contrast, the CBVLE, involving the whole-task design approach, made it possible to structure the phases of nursing students' future mathematical medication learning tasks and relate these to the mathematical transfer tasks in the virtual learning environment. The CBVLE supported selfdirected learning and enhanced nursing students' mathematical medication learning, their level of self-efficacy, and intrinsic motivation for mathematical medication learning.

The results of the various chapters of this thesis have several important implications for mathematics education in vocational education that are in line with the current transfer in educational practices. The transfer of educational practices in vocational education comprises changes of knowledge and skills in future professional practices and the possibilities that technology offers. In addition, demographic changes, such as ageing, smaller student cohorts, and jobs destined to disappear raise the question of how to 
associate educational practices in vocational education sufficiently to the future labour market. Given the situation that education will increasingly come closer to the labour market, the time is near that knowledge in vocational education should not be passively excluded and assessed, especially mathematical knowledge in vocational education. This should not be misunderstood, as if knowledge is not necessary in vocational education programs. On the contrary, knowledge does matter, especially when solving complex and critical problems, such as mathematical medication problems. Well-designed digital educational settings have the potential to provide students with the necessary professional knowledge and skills base for future professions.

This PhD thesis is in line with the innovation and latest developments in the field of educational technology. Education is changing rapidly from essentially transferring knowledge to actively applying knowledge and developing skills for the $21^{\text {st }}$ century, with the effect that students can manage the world as we encounter it. Where instructional design mainly focused on methodological support, instructional design for the $21^{\text {st }}$ century should focus much more on learning processes and experiences that match students' future authentic learning tasks. Using technology offers opportunities, since this study shows that clicking buttons with a mouse gives students the experience of really performing certain skills and mentalizing them. Further development of the virtual learning environment, including integration of assessment for the maintenance of nursing students' mathematical medication learning during their educational career, can be recorded with edubadges. Edubadges are digital certificates in Dutch education that give students or employees a proof of acquired knowledge and skills (Surf, nd). This also corresponds to the strategic direction of many educational institutions, including that of Windesheim University of Applied Sciences, where flexible and challenging learning environments are part of the development agendas. It is therefore suggested that the CBVLE should be used as a technology-enhanced educational assessment system that nursing students can use to train and assess their mathematical medication learning.

\section{Ethical reflection of the author}

This thesis argues that technology offers possibilities for teaching and learning. However, it is important to also mention the downside of using technology in education. Using DLMs constitutes a significant change for the teacher as a professional: more and more the teacher takes the role of a coach who collects and interprets data. Several times during the research for this thesis I had dialogues with professionals in the field about their role and, perhaps more relevant, about their autonomy. Technological developments constitute an influence on educational values: freedom, equity, privacy, and autonomy (Rathenau Institute, 2020). Educational technology is really shifting the educational environment, where it now seems as if the teacher has become more subservient to the system. I have 
tried to make clear with this thesis that technology can also expose current educational practices where the system is leading. Values such as the quality and efficiency of education should also be discussed, and if technology carries those values, it might be a solution. Therefore, I must say that technology is never neutral, and since technology development is a human product, human values are playing a role also.

My intentions are honourable, and thus students themselves are involved in fine-tuning the development of the virtual learning environment. In that way, students can increase their influence on their own learning process and strengthen their autonomy. The teacher remains in control of how and when the virtual learning environment can be used.

\section{References}

Adhikari, R., Tocher, J., Smith, P., Corcoran, J., \& MacArthur, J. (2014). A multi-disciplinary approach to medication safety and the implication for nursing education and practice. Nurse Education Today, 34, 185-190. doi:10.1016/j.nedt.2013.10.008

Alfassi, M. (2003). Promoting the will and skill of students at academic risk: An evaluation of an instructional design geared to foster achievement, self-efficacy and motivation. Journal of Instructional Psychology, 30, 28-40. https://psycnet.apa.org/record/2003-03343-005

Anderson, J. R., Fincham, J. M., \& Douglas, S. (1997). The role of examples and rules in the acquisition of a cognitive skill. Journal of Experimental Psychology, 23, 932945. doi: $10.1037 / 0278-7393.23 .4 .932$

Baldwin, A.L. (1967). Theories of child development. New York, NY: John Wiley and Sons.

Bandura, A. (1993). Percieved self-efficacy in cognitive development and functioning. Educational Psychologist, 28, 117-148. doi:10.1207/s15326985ep2802_3

Bandura, A., \& Schunk, D. H. (1981). Cultivating competence, self-efficacy, and intrinsic interest through proximal self-motivation. Journal of Personality and Social Psychology, 41, 586-598. https://psycnet.apa.org/record/1982-07527-001

Chen, O., Kalyuga, S., \& Sweller, J. (2016). Relations between the worked example and generation effects on immediate and delayed tests. Learning and Instruction, 45, 20-30. doi:10.1016/j.learninstruc.2016.06.007

Csikszentmihalyi, M. (1990). Flow: The psychology of optimal experience. New York, NY: Harper-Collins. https://mktgsensei.com/AMAE/Consumer\%20Behavior/flow_the_psychology_of_o ptimal_experience.pdf

Deci, E. L., \& Ryan, R. M. (1985). Intrinsic motivation and self-determination in human behavior. Boston, MA: Springer. doi:10.1007/978-1-4899-2271-7 
Dunlosky, J., Rawson, K. A., Marsh, E. J., Nathan, M. J., \& Willingham, D. T. (2013). Improving students' learning with effective learning techniques: Promising directions from cognitive and educational psychology. Psychological Science in the Public Interest, 14, 4-58. doi:10.1177/1529100612453266

Frerejean, J., Van Merriënboer, J. J. G., Kirschner, P. A., Roex, A., Aertgeerts, B., \& Marcellis, M. (2019). Designing instruction for complex learning: 4C/ID in higher education. European Journal of Education, 54, 1-12. doi:10.1111/ejed.12363

Gick, M. L., \& Holyoak, K. J. (1987). The cognitive basis of knowledge transfer. In S. M. Cormier \& J. D. Hagman (Eds.), Transfer of learning: Contemporary research and applications (pp. 9-46). San Diego, CA: Academic Press.

Gillies, R. M. (2004). The effects of cooperative learning on junior high school students during small group learning. Learning and Instruction, 14, 197-213. doi: 10.1016/S0959-4752(03)00068-9

Gray, B. (2004). Informal learning in an online community of practice. Journal of Distance Education, 20-35. 19, Retrieved from https://files.eric.ed.gov/fulltext/EJ807836.pdf

Grigg, S., Perera, H. N., McIlveen, P., \& Svetleff, Z. (2018). Relations among math selfefficacy, interest, intentions, and achievement: A social cognitive perspective. $\begin{array}{llll}\text { Contemporary Esychology, 53-86. } & \text { 53, }\end{array}$ doi:10.1016/j.cedpsych.2018.01.007

Hadwin, A. F., Järvelä, S., \& Miller, M. (2011). Self-regulated, co-regulated, and socially shared regulation of learning. In B. J. Zimmerman \& D. H. Schunk (Eds.), Handbook of self-regulation of learning and performance (pp. 65-84). New York, NY: Routledge.

Hattie, J., \& Timperly, H. (2007). The power of feedback. Review of Educational Research, 77, 81-112. doi:10.3102/003465430298487

Huang, W. D., Johnson, T. E., \& Han, S-H. C. (2013). Impact of online instructional game features on college students perceived motivational support and cognitive investment: A structural equation modeling study. Internet and Higher Education, 17, 58-68. doi:10.1016/j.iheduc.2012011.004

Kalyuga, S., Chandler, P., \& Sweller, J. (2001). Learner experience and efficiency of instructional guidance. Educational Psychology, 21, 5-23. doi: $10.1080 / 01443410124681$ 
Kalyuga, S., Chandler, P., Tuovinen, J., \& Sweller, J. (2001). When problem solving is superior to studying worked examples. Journal of Educational Psychology, 93, 579588. doi:10.1037/0022-0663.93.3.579

Kim, Y. J., Almond, R. G., \& Shute, V. J. (2016). Applying evidence-centered design for the development of game-based assessments in physics playground. International Journal of Testing, 16, 142-163. doi:10.1080/15305058.2015.1108322

Kirschner, P. A., Sweller, J., Kirschner, F., \& Zambrano, R. J. (2018). From cognitive load theory to collaborative load theory. International Journal of Computer-Supported Collaborative Learning, 13, 213-233. doi:10.1007/s11412-018-9277-y

Knezek, G., \& Christensen, R. (2008). The importance of information technology attitudes and competences in primary and secondary education. In J. Voogt \& G. Knezek (Eds.), International handbook of information technology in primary and secondary education (pp. 321-331). New York, NY: Springer. doi:10.1007/978-0-387-733159

Kollar, I., Fischer, F., \& Slotta, J. D. (2007). Internal and external scripts in computersupported collaborative inquiry learning. Learning and Instruction, 17, 708-721. doi:10.1016/j.learninstruc.2007.09.021

Kollar, I., Ufer, S., Reichersdorfer, E., Vogel, F., Fischer, F., \& Reiss, K. (2014). Effects of collaboration scripts and heuristic worked examples on the acquisition of mathematical argumentation skills of teacher students with different levels of prior achievement. Learning and Instruction, 32, 22-36. doi:10.1016/j.learninstruc.2014.01.003

Lee, E. A.-L., Wong, K. W., \& Fung, C. C. (2010). How does desktop virtual reality enhance learning outcomes? A structural equation modeling approach. Computers \& Education, 55, 1424-1442. doi:10.1016/j.compedu.2010.06.006

Lee, Y., \& Seo, E. (2021). Longitudinal relations between South Korean adolescents' academic self-efficacy and values in mathematics and English. British Journal of Educational Psychology, 91, 217-236.. doi:10.1111/bjep.12357

Makransky, G., \& Petersen, G. B. (2019). Investigating the process of learning with desktop virtual reality: A structural equation modeling approach. Computers \& Education, 134, 15-30. doi:10.1016/j.compedu.2019.02.002

Makransky, G., Terkildsen, S., \& Mayer, R. E. (2019). Adding immersive virtual reality to a science lab simulation causes more presence but less learning. Learning and Instruction, 60, 225-236. doi:10.1016/j.learninstruc.2017.12.007 
Merchant, Z., Goetz, E. T., Cifuentes, L., Keeney-Kennicutt, W., \& Davis, T. J. (2014). Effectiveness of virtual reality-based instruction on students' learning outcomes in K-12 and higher education: A meta-analysis. Computers \& Education, 70, 29-40. doi:10.1016/j. compedu.2013.07.033

Merchant, Z., Goetz, E. T., Keeney-Kennicutt, W., Oi-man K., Cifuentes, L., \& Davis, T. J. (2012). The learner characteristics features of desktop 3D virtual reality environments, and college chemistry instruction: A structural equation modeling analysis. Computers \& Education, 59, 551-568. doi: $10.1016 / j$.compedu.2012.02.004

Mor, Y., Ferguson, R., \& Wasson, B. (2015). Learning design, teacher inquiry into student learning, and learning analytics: A call for action. British Journal of Educational Technology, 46, 221-229. doi:10.1111/bjet.12273

Pekrun, R. (2006). The control-value theory of achievement emotions: assumptions, corollaries, and implications for educational research and practice. Educational Psychology Review, 18, 315-341. doi:10.1007/s10648-006

Pekrun, R., \& Stephens, S. J. (2010). Achievement emotions in higher education. In J. C. Smart (Ed.), Higher education: Handbook of theory and research (pp. 257-306). New York, NY: Springer. doi:10.1007/978-90-481-8598-6_7

Pollock, E., Chandler, P., \& Sweller, J. (2002). Assimilating complex information. Learning and Instruction, 12, 61-86. doi:10.1016/S0959-4752(01)00016-0

Rathenau Institute. (2020). Leren digitaliseren (2): Ethiek als motor van digitale onderwijsinnovatie [Learning to digitalize (2): Ethics as a motor of digital educational innovation]. Retrieved from https://www.rathenau.nl/nl/digitalesamenleving/leren-digitaliseren-2-ethiek-als-motor-van-digitaleonderwijsinnovatie

Seligman, M. E. P. (1972). Learned helplessness. Annual Review of Medicine, 23, 407-412. doi:10.1146/annurev.me.23.020172.002203

Seligman, M. E. P., \& Campbell, B. A. (1965). Effect of intensity and duration of punishment on extinction of an avoidance response. Comparative and Physiological Psychology, 59, 295-297. doi: 10.1037/h0021845

Shute, V. J., \& Rahimi, S. (2017). Review of computer-based assessment for learning in elementary and secondary education. Journal of Computer Assisted Learning, 33, 1-19. doi:10.1111/jcal.12172

Shute, V., Ventura, M., Bauer, M., \& Zapata-Rivera, D. (2009). Melding the power of serious games and embedded assessment to monitor and foster learning. In $U$. 
Ritterfeld, M. Cody, \& P. Vorderer (Eds.), Serious games: Mechanisms and effects (pp. 295-321). New York, NY: Routledge.

Surf. (nd). Edubadges: digitale certificaten uitreiken aan studenten [Edubadges: digital certificates for students]. Retrieved from https://www.surf.nl/edubadges-digitalecertificaten-uitreiken-aan-studenten

Sweller, J. (2010). Element interactivity and intrinsic, extraneous, and germane cognitive load. Educational Psychology Review, 22, 123-138. doi:10.1007/s10648-010-91285

Tynjälä, P. (2013). Toward a 3-P model of workplace learning: A literature review. Vocations and Learning, 6, 11-36. doi:10.1007/s12186-012-9091-z

Van Gog, T., Kester, L., \& Paas, F. (2011). Effects of worked examples, example-problem, and problem-example pairs on novices' learning. Contemporary Educational Psychology, 36, 212-218. doi:10.1016/j.cedpsych.2010.10.004

Van Merriënboer, J. J. G., \& Kirschner, P. A. (2007). Ten steps to complex learning. New York, NY: Routledge.

Van Merriënboer, J. J. G., \& Kirschner, P. A. (2018). Ten steps to complex learning (3rd ed.). New York, NY: Taylor \& Francis.

Van Merriënboer, J. J., \& Sweller, J. (2010). Cognitive load theory in health professional education: Design principles and strategies. Medical Education, 44, 85-93. doi:10.1111/j.1365-2923.2009.03498.x

Wigfield, A., \& Eccles, J. S. (2000). Expectancy-value theory of achievement motivation. Contemporary Educational Psychology, 25, 68-81. doi:10.1006/ceps.1999.1015

Woodcock, S., \& Vialle, W. J. (2011). Are we exacerbating students' learning disabilities? An investigation of preservice teachers' attributions of the educational outcomes of students with learning disabilities. Annals of Dyslexia, 61, 223-241. doi: 10.1007/s11881-011-0058-9

Xinhao, X., \& Fengfeng, K. (2016). Designing a virtual-reality-based, gamelike math learning environment. American Journal of Distance Education, 30, 27-38. doi:10.1080/08923647.2016.1119621

Yuan, B. Wang, M., Van Merriënboer, J., Tao, X., Kushniruk, A., \& Peng, J. (2020). Investigating the role of cognitive feedback in practice-oriented learning for clinical diagnostics. Vocations and Learning, 13, 159-177. doi:10.1007/s12186-01909234-z

Zohar, A., \& David, A. B. (2008). Explicit teaching of meta-strategic knowledge in authentic 
classroom situations. Metacognition and Learning, 3, 59-82. doi:10.1007/s11409007-9019-4

Zwart, D. P., Van Luit, J. E. H., Noroozi, O., \& Goei, S. L. (2017). The effects of digital learning material on students' mathematics learning in vocational education. Cogent Education, 4: 1313581. doi:10.1080/2331186X.2017.1313581 


\section{Samenvatting (Dutch summary)}

Het middelbaar beroepsonderwijs bereidt studenten voor op een beroepspraktijk of hoger beroepsonderwijs. Rekenen is een verplicht onderdeel van elke opleiding in het mbo en alle studenten moeten een rekenexamen maken. Het resultaat telt vanaf studiejaar 20222023 mee voor het diploma. De resultaten van de jaarlijkse rekenexamens vallen tegen. Dit kan deels worden toegeschreven aan de wijze waarop de rekenkundige inhoud in het beroepsonderwijs wordt onderwezen: de verschillende domein-specifieke rekendomeinen worden namelijk per periode aangereikt, zonder veel herhaling en oefening van rekenonderdelen die reeds aan bod zijn geweest. Dit wordt problematisch wanneer studenten de onderliggende (en voorafgaande) rekenkundige kennis en vaardigheden uit het ene rekendomein niet goed begrijpen of geautomatiseerd hebben, maar toch naar het nieuwe rekendomein over (moeten) gaan. Als gevolg hiervan kunnen studenten geen informatie coderen en ophalen, die nodig is om de gevraagde rekenproblemen op te lossen. Studenten hebben meer tijd en instructie nodig om de concepten van de verschillende rekendomeinen te doorgronden om verbindingen te kunnen maken met de nieuw aangeboden domein-specifieke kennis in de opkomende periode. Een ander aspect is dat er te weinig aandacht wordt besteed aan het integreren, evalueren en combineren van kenniselementen om de rekenkennis en -vaardigheden toe te passen in de beroepscontext. Hierdoor verliezen studenten de onderlinge verbanden uit het oog. Daarenboven raken studenten het vertrouwen in eigen kunnen kwijt vanwege de slechte rekenprestaties. Studenten voelen zich minder competent, met als gevolg dat de motivatie voor het rekenen in het beroepsonderwijs daalt. Voldoende rekenkennis en -vaardigheid is voor de dagelijkse rekentaken van beroepsprofessionals van cruciaal belang, in het bijzonder voor de verpleegkundige.

Om een optimale medicatieveiligheid te garanderen, is het noodzakelijk dat verpleegkundigen over voldoende rekenkennis en -vaardigheden beschikken. Daarvoor is niet alleen reken- en medicatiekennis noodzakelijk, maar ook het bewustzijn dat rekenkundige kennis noodzakelijk is voor het verstrekken van medicatie. Hoewel er in de beroepsopleiding tot verpleegkundige veel aandacht is voor medicatieveiligheid, worden er in de verpleegkundige praktijk regelmatig fouten gemaakt. De veiligheid is veelal in het geding door menselijke fouten: zorgprofessionals lezen het etiket van het geneesmiddel niet of niet zorgvuldig genoeg, er is sprake van een misverstand met een collega of ze maken fouten in toediening van juiste hoeveelheden. Deze voorbeelden wijzen op het belang van het trainen en onderwijzen van rekenkennis gecombineerd met kennis over noodzakelijke handelingen ten behoeve van medicatieverstrekking, zoals het begrijpen van de medicatieopdracht en het communiceren met de patiënt. Verder moet het belang van de onderliggende (en voorafgaande) domein-specifieke rekenkennis en -vaardigheden ook niet worden onderschat. Zo blijkt uit rapporten van de overheid en overheidsinstanties dat 
de meeste studenten in het beroepsonderwijs vooral problemen ondervinden met breuken en omrekenen. Voor toekomstige verpleegkundigen is deze kennis van cruciaal belang: de studenten moeten de relatie begrijpen tussen de verschillende elementen van dosering, alsook de bijbehorende formules en vergelijkingen om de juiste hoeveelheden vaste en vloeibare medicatie toe te kunnen dienen. Als de verpleegkundige de rekenkennis en vaardigheden in het beroep niet op een juiste wijze inzet, dan kan dit de veiligheid van patiënten in gevaar brengen. Welbeschouwd zijn verpleegkundigen de hekkensluiters van het medicatieproces; zij dienen de patiënt de medicatie toe. Daarom is het aanhoudend onderwijzen van rekenvaardigheid als onderdeel van het medicatieproces voor verpleegkundestudenten essentieel. De verpleegkundige dient opgeleid te worden als een bewuste professional, die zich verantwoordelijk voelt voor de te nemen beslissingen leidend tot een juiste toepassing en gebruik van medicatie en geneesmiddelen. Verpleegkundestudenten moeten hiertoe actief worden opgeleid en niet slechts worden getoetst. Om studenten tenminste toe te kunnen rusten met voldoende rekenkennis en vaardigheden is naast aandacht voor 'directe' rekenkennis ook bewustwording van handelen nodig. Inzet van technologie biedt de mogelijkheid om deze te onderwijzen, te trainen en te oefenen in een digitale leeromgeving.

Technologie in de vorm van digitale leeromgevingen biedt een breed scala aan educatieve mogelijkheden, die niet kan worden bereikt met traditionele face-to-face vormen van leren en instructie. Goed ontworpen digitale leeromgevingen hebben het potentieel om studenten te voorzien van kennis en vaardigheden over het toekomstige beroep, zodat deze als professionals in de beroepscontext authentieke problemen kunnen analyseren, conceptualiseren, synthetiseren, maar ook kunnen omgaan met complexe problemen. Instructie in een digitale leeromgeving bestaat uit digitaal leermateriaal (DLM), zoals instructieclips, online begeleiding en een tool voor samenwerking. De instructie in een leeromgeving met DLM kan studenten ondersteunen bij het identificeren van informatie en bij het begrijpen van de verschillende relaties tussen de materialen en inhouden. Met DLM kan inhoudelijk worden afgestemd op de verschillende niveaus van voorkennis van de studenten. Studenten kunnen in de leeromgeving met DLM zelf keuzes maken in voorgeschreven instructies, zoals het kijken van een korte domein-specifieke instructieclip of een clip die de onderlinge relatie uitlegt tussen de verschillende elementen van een berekening, alsook de bijbehorende formules en vergelijkingen. Daarnaast kunnen studenten vragen stellen in de online samenwerkingstool, die antwoorden genereert van medestudenten en de online docent. Studenten kunnen de clips herhalend inzien, en de keuzes om dit te doen zijn geheel autonoom en onbegrensd in tijd en plaats.

Het doel van de studie in dit proefschrift is tweeledig. Het eerste doel is om het rekenen te onderwijzen met DLM gerelateerd aan de context van het beroep verpleegkunde. Het tweede doel is om verpleegkundestudenten in het beroepsonderwijs rekenhandelingen in 
een toekomstige leertaak te laten instuderen door middel van een zelfsturende en motiverende DLM-omgeving. Deze doelen komen aan de orde in vijf studies, die worden beschreven in hoofdstuk 2 tot en met hoofdstuk 6 .

Allereerst wordt in hoofdstuk 2 het effect onderzocht van een onderwijsleeromgeving met DLM inclusief instructieclips, online begeleiding, inhoudelijke structurering en samenwerkingsinstrumenten op het leren rekenen van studenten in het beroepsonderwijs. Het onderzoek is exploratief van aard en de studie richt zich op de vraag: Wat is het effect van het leren rekenen met digitaal leermateriaal op de rekenresultaten van studenten in het beroepsonderwijs? In dit hoofdstuk worden resultaten gerapporteerd van een pretestposttest design in twee interventies. Studenten van verschillende afdelingen in het beroepsonderwijs (economie/dienstverlening, techniek, verpleegkunde) participeerden in een 8 weken durende training met DLM voor domein-specifieke rekenkennis. De resultaten toonden dat studenten verpleegkunde de hoogste leerresultaten behaalden. De studenten waren betrokken bij de rekenopdrachten en ze werkten als groep samen, in tegenstelling tot de studenten van de andere afdelingen (economie/dienstverlening en techniek). De exploratie van de literatuur en de context, samen met de resultaten uit deze studie, gaven inzicht in het rekenen in het beroepsonderwijs met DLM. Eén van de uitkomsten was dat het rekenen in het teken moest staan van de dagelijkse rekentaken in het beroep. Daarnaast kwam er de vraag wat het leren met DLM doet met de competentiebeleving ook wel bekend onder de term 'self-efficacy' - van studenten inzake het rekenen.

Om het rekenonderwijs te verbinden aan die beroepspraktijk was het voor het vervolg van het onderzoek noodzakelijk om participanten te betrekken van een specifieke opleiding. Omdat de uitkomsten uit het eerste onderzoek goede resultaten toonden bij de studenten verpleegkunde en omdat het onderwijzen van rekenen voor deze studenten van groot belang is in het kader van juiste medicatieverstrekking, is gekozen voor de beroepspraktijk van de zorgprofessional, specifiek de student verpleegkunde. Het prototype leeromgeving met DLM uit de eerste studie werd herontworpen, zodat het rekenen inhoudelijk meer verbonden kon worden aan het toekomstige beroep van de studenten verpleegkunde.

De tweede studie, beschreven in hoofdstuk 3, gaat in op de effecten van het onderwijzen van rekenen met DLM om de volgende onderzoeksvraag te beantwoorden: Wat is het effect van het onderwijzen van rekenen met DLM op rekenresultaten, self-efficacy en taakwaardering van de verpleegkundestudent in het beroepsonderwijs? De instructieclips in dit onderzoek zijn gedeeltelijk aangepast aan opdrachten uit het toekomstig beroep van de studenten verpleegkunde. Ook in dit onderzoek kunnen de clips herhalend worden ingezien, en zijn de keuzes van de studenten om de clips herhalend op te roepen geheel autonoom en onbegrensd in tijd en plaats. De studenten verpleegkunde werden verdeeld in twee groepen: een experimentele groep die het rekenonderwijs via DLM aangeboden 
kreeg met een gestructureerde inhoud bestaande uit de instructieclips en een samenwerkingstool, en een controlegroep die het rekenonderwijs 'as usual' kreeg, te weten traditioneel en face-to-face. Het effect van de 6 weken durende training werd door middel van een pretest-posttest controlegroep design onderzocht op rekenresultaten, self-efficacy en taakwaardering van 39 verpleegkundestudenten. Daarnaast werd de waardering van studenten voor de verschillende kenmerken van DLM onderzocht. De resultaten toonden een verbetering in rekenen aan, maar er waren geen verschillen in rekenresultaten tussen beide groepen. De taakwaardering voor het rekenen was in beide groepen gelijk gebleven. Daarentegen bleek dat de self-efficacy van de verpleegkundestudenten voor rekenen in de DLM-groep was verminderd. Verder vonden verpleegkundestudenten met een laag leervermogen (gemeten met de Raven, non-verbale intelligentie test) het leren rekenen met DLM moeilijker vanwege de interactie met DLM: de wijze waarop DLM als instructieleeromgeving het leren van studenten beïnvloedt. Dit ondanks de gestructureerde inhoud van de leeromgeving met DLM. Een grote barrière was de online competentie van de leraar en de afhankelijkheid van de studenten ervan. De online rol van de leraar diende niet alleen het stimuleren van de inhoudelijke feedback voor rekenopdrachten te bevatten, maar ook de sociale- en emotionele ondersteuning van studenten om hun competentiebeleving te verbeteren. Daarbij vonden studenten het moeilijk om hun eigen leer- en studiepatronen te doorbreken. Ze hielden vast aan gewoontes en gedragingen passend bij de face-to-face bijeenkomsten: de leraar werd gemaild bij onvoldoende reactie in de online-omgeving of de leraar werd in de school opgezocht. Dit betekent voor de leeromgeving met DLM dat deze moet worden voorzien van zichtbare aanknopingspunten, die de studenten houvast biedt om de eigen of elkaars online handelingen te evalueren. Bovendien moeten er vooraf condities aan de uit te voeren online opdrachten worden gesteld en deze moeten worden besproken met de studenten aan de hand van criteria voor het voldoende afronden van de opdracht.

De uitkomsten uit de tweede studie noopten tot heroverwegingen in het onderzoek naar het leren rekenen met DLM. De online leraar blijft de verbindende schakel in het leren rekenen met DLM. Deze studie gaat echter niet over de rol van de leraar in DLM, maar over leren met digitaal leermateriaal. Daarom is na studie twee het prototype van DLM herontworpen naar digitaal leermateriaal dat het zelfsturend leren van verpleegkundestudenten ondersteunt: een computergestuurde virtuele leeromgeving (CBVLE).

Een CBVLE maakt het mogelijk de handelingen van studenten in de leeromgeving richting te geven. In de CBVLE zijn 'virtual agents' als doctoren en voorwerpen ingebouwd, die de interactie met de speler aangaan en de speler wijzen op de volgende stappen die gezet moeten worden in de leeromgeving. De speler is de verpleegkundestudent die inlogt in de CBVLE en als verpleegkundig avatar in de leeromgeving verschijnt. In die leeromgeving 
worden situaties op een realistische wijze nagebootst, zoals het expliceren van de verschillende fasen in het medicatieproces waar rekenen deel van uitmaakt. De verpleegkundestudenten navigeren in de virtuele leeromgeving als een verpleegkundig avatar en volgen de door de virtual agents en voorwerpen aangereikte acties. Die acties verhouden zich tot de verschillende onderdelen van het medicatieproces, zoals communicatie met patiënten, hygiëne maatregelen en kennis van het rekenkundig concept van het medicatieproces (zie Figuur 1). In het rekenkundig concept staan drie rekendomeinen centraal, te weten domein-specifieke kennis van vaste medicatie, vloeibare medicatie en infusie. Voor het concretiseren van dit rekenkundig concept is een cognitieve procedurele taakanalyse uitgevoerd.

Aan de procedurele cognitieve taakanalyse hebben zes reken-wiskunde experts meegedaan. Er zijn vijf verschillende rekenkundige medicatieproblemen ontworpen, teneinde de rekenkundige concepten, principes, regels en procedures te analyseren. Voor elke stap in het probleemoplossingsproces van het rekenkundig medicatieprobleem werden de reken-wiskunde experts gevraagd om drie vragen te beantwoorden, (i) Wat zal de lerende (vermoedelijk) doen? (ii) Wat moet de lerende weten - welke kennis heeft de lerende nodig? en (iii) Welke signalen informeren de lerende dat er een probleem is, dat de stap voltooid is of dat er een andere stap nodig is? Tijdens de audit bespraken en beschreven de experts ook de benodigde contextuele kennis om het rekenprobleem van de medicatieopdracht op te kunnen lossen, de redenen warom de specifieke medicatieopdracht moeilijk kan zijn en de fouten die studenten zouden kunnen maken. Op deze wijze is de inhoud van de CBVLE gevalideerd. Daarnaast is de informatie uit de audit gebruikt om 90 medicatiescenario's en 100 korte oefeningen over de onderliggende domein-specifieke rekenkennis en rekenprincipes te maken. Ook is er per domein een uitwerking gemaakt van een werkvoorbeeld met de domein-specifieke procedurele kennis. Dit werkvoorbeeld is een extra ondersteuning voor de studenten in de CBVLE. 


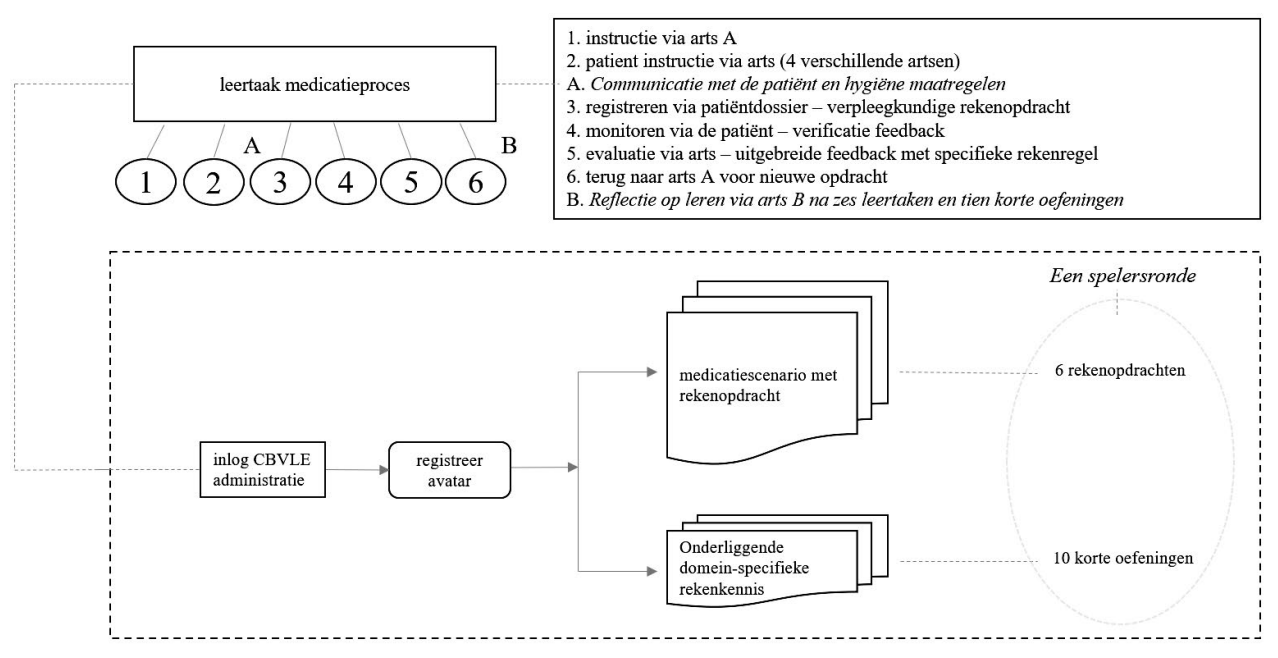

Figuur 1. Structuur van de computergestuurde virtuele leeromgeving.

Hoofdstuk 4 van dit proefschrift behandelt de volgende onderzoeksvraag: Wat zijn de effecten van de CBVLE-training op het verpleegkundig rekenen van de verpleegkundestudent? In deze studie is het effect van vier verschillende condities in de CBVLE op het rekenen in het medicatieproces van verpleegkunde studenten vergeleken. Omdat het rekenkundig concept en de verschillende fasen in het medicatieproces inhoudelijk gelijk zijn voor de studenten uit het middelbaar en het hoger beroepsonderwijs, zijn studenten uit beide groepen in de studie betrokken. In totaal zijn 118 studenten uit het middelbaar en hoger beroepsonderwijs uit diverse steden in Nederland aselect toegewezen aan een van de vier voorwaarden in de CBVLE: het leren rekenen zonder uitgewerkte voorbeelden (conditie 1), het leren rekenen met uitgewerkte voorbeelden met betrekking tot domein-specifieke kennis (conditie 2), het leren rekenen met uitgewerkte voorbeelden waarbij denkstrategieën worden getoond (conditie 3), en het leren rekenen met een combinatie van uitgewerkte voorbeelden met domein-specifieke kennis en denkstrategieën (conditie 4). Aangezien studenten met een lager dan gemiddeld leervermogen meer moeite toonden in het werken met DLM (studie 2), zijn ook in deze derde studie de algemene leercapaciteiten van de verpleegkunde studenten betrokken. De taak van de studenten was om gedurende vier weken twee trainingssessies van 45 minuten per week in de CBVLE uit te voeren. Studenten dienden per trainingssessie ten minste één ronde in de CBVLE te kunnen doorlopen, bestaande uit zes rekenkundige medicatieopdrachten en twee sets van vijf korte oefeningen over de onderliggende domeinspecifieke rekenkennis en rekenprincipes (zie Figuur 1). De student als een verpleegkundig avatar voert de volgende handelingen in de CBVLE uit: (i) de opdracht van arts A ontvangen; ii) de rekenkundige medicatieopdrachten van de arts van de patiënt ontvangen; iii) de handen wassen; iv) communiceren met de patiënt; (v) medicatie 
voorbereiden door het oplossen van de rekenkundige medicatieopdracht; vi) het toedienen van medicatie; (vii) het monitoren van de patiënt door verificatiefeedback op de rekenkundige medicatieopdracht; (viii) het dossier van de patiënt bijwerken; (ix) terug naar de arts van de patiënt die informatieve feedback met de rekenregel geeft bij een negatieve verificatie en de verpleegkundig avatar bedankt bij een positieve verificatie; $(x)$ terugkeren naar arts $A$ om af te melden en een nieuwe opdracht te ontvangen. Arts $A$ kan de verpleegkundige ook de opdracht geven om naar 'het lab' te gaan om daar korte oefeningen over de onderliggende domein-specifieke rekenkennis en rekenprincipes uit te voeren. De resultaten uit het onderzoek bevestigden de verwachting dat de rekenresultaten van verpleegkundestudenten aanzienlijk verbeterden, maar er werden geen verschillen gevonden tussen de vier condities in de CBVLE. Dat wil zeggen dat de extra ondersteuning met of zonder uitgewerkte voorbeelden in de CBVLE geen verschil in effect liet zien. Voor de verpleegkundestudenten met een hoger dan gemiddeld leervermogen was er geen verschil tussen de vier condities. De verpleegkundestudenten met een lager dan gemiddeld leervermogen (gemeten met de Raven, non-verbale intelligentie test) behaalden zonder extra ondersteuning van uitgewerkte voorbeelden in de CBVLE (conditie 1) aanzienlijk hogere leerresultaten dan de verpleegkundestudenten met een lager dan gemiddeld leervermogen met de extra ondersteuning van denkstrategieën (conditie 3). De CBVLE met de rekenkundige medicatieopdrachten en de korte oefeningen over de onderliggende domein-specifieke rekenkennis en rekenprincipes ondersteunde de studenten voldoende door de gestandaardiseerde verificatiefeedback en de informatieve feedback met rekenregel. De uitgewerkte voorbeelden leken dus overbodig. Vanuit een 'cognitief load theory' perspectief betekent dit dat de technologie een deel van de capaciteit van het werkgeheugen van studenten met een laag leervermogen lijkt te compenseren.

Hoofdstuk 5 van dit proefschrift betreft de vraag: Wat zijn de effecten van de CBVLEtraining op de rekenresultaten, self-efficacy en intrinsieke motivatie van de verpleegkundestudenten? In totaal zijn 118 studenten uit het middelbaar en hoger beroepsonderwijs uit diverse steden in Nederland willekeurig toegewezen aan één van de vier voorwaarden in de CBVLE: het leren rekenen zonder uitgewerkte voorbeelden (conditie 1 ), het leren rekenen met uitgewerkte voorbeelden met betrekking tot domein-specifieke kennis (conditie 2), het leren rekenen met uitgewerkte voorbeelden waarbij denkstrategieën worden getoond (conditie 3 ) en het leren rekenen met een combinatie van uitgewerkte voorbeelden met domein-specifieke kennis en denkstrategieën (conditie 4). De resultaten toonden aan dat de rekenresultaten, self-efficacy en intrinsieke motivatie van verpleegkundestudenten aanzienlijk verbeterden. Er zijn evenwel geen verschillen tussen de condities met of zonder uitgewerkte voorbeelden in de CBVLE op de rekenresultaten gevonden. Ook met betrekking tot de intrinsieke motivatie voor het leren 
rekenen via de CBVLE zijn geen verschillen tussen condities gevonden. De self-efficacy van de verpleegkundestudenten werd daarentegen positief beïnvloed door de extra ondersteuning van de combinatie van uitgewerkte voorbeelden met domein-specifieke kennis en denkstrategieën (conditie 4). Dat de self-efficacy en intrinsieke motivatie van de verpleegkundestudenten sterk is verbeterd, kan wellicht toegeschreven worden aan de zelfsturende leeromgeving, alsook aan de relevantie van de leertaken die de rekenkundige handelingen verbinden met de toekomstige leertaak van de verpleegkundestudenten, te weten de medicatieopdracht. Wanneer studenten de leertaak als bruikbaar en belangrijk identificeren, bevordert dit de motivatie voor leren. In deze studie zijn de toekomstige leertaken van de verpleegkundestudenten in de CBVLE gecontextualiseerd, zodat de studenten het belang van de rekenkundige handelingen onderkennen. De leraar was in de CBVLE niet aanwezig. Dit lijkt geen gemis te zijn geweest in het rekenen met de CBVLE. De aanwezigheid van een leraar hoeft niet altijd goed uit te pakken voor alle studenten in het rekenonderwijs; studenten kunnen ook het tegenovergestelde voelen bij de aanwezigheid van de leraar. Wanneer de leraar de rekenresultaten van de studenten niet als evenwichtig accepteert, falen studenten sneller. Dit, evenals het gebrek aan tijd voor leraren om voldoende feedback te genereren aan alle studenten in de Face-to-Face rekenlessen, kan aangeleerde hulpeloosheid van studenten veroorzaken. Een CBVLE maakt het mogelijk om de rekenkundige medicatietaak te construeren in een leeromgeving die doelgericht leren voor alle niveaus uitlokt: verpleegkunde studenten lossen rekenkundige medicatietaken op en de gestandaardiseerde voorwaarden in de CBVLE ondersteunen de verpleegkundestudenten door middel van verificatiefeedback en informatieve feedback.

Om specifieker te onderzoeken welke onderdelen van het instructieontwerp in de CBVLE betrekking hebben op de leerresultaten, self-efficacy en intrinsieke motivatie van de 118 verpleegkunde studenten, gaat de vijfde studie (hoofdstuk 6) over de volgende onderzoeksvraag: Hoe ervaren en evalueren studenten verpleegkunde de ontwerpcomponenten van het instructieontwerp in de CBVLE en wat is het effect van de ontwerpcomponenten op de leerresultaten, self-efficacy en intrinsieke motivatie van de verpleegkundestudenten? Het educatieve ontwerp van de virtuele leeromgeving is gebaseerd op een vijftal ontwerpcomponenten, gedefinieerd en beschreven volgens het holistisch benaderingsontwerp, het vier componenten instructie designmodel (4C/ID) model, te weten: i) leertaken, ii) ondersteunende informatie, (iii) procedurele informatie, (iv) deeltaak oefening, en ( $v$ ) cognitieve feedback als reflectie op leren. Deze studie gaat in op de resultaten betreffende de ervaringen en evaluatie van de verpleegkundestudenten op de verschillende ontwerpcomponenten van het educatieve ontwerp van de CBVLE en op de effecten hiervan op de leerresultaten, self-efficacy en intrinsieke motivatie. De resultaten toonden dat de verpleegkundestudenten bovengemiddeld tevreden waren met de ontwerpcomponenten leertaken, ondersteunende informatie, procedurele informatie en 
deeltaak oefening. Het ontwerpcomponent cognitieve feedback als reflectie op leren bleek evenwel te algemeen en diende meer specifiek te worden aangepast aan de eigen inspanningen van de verpleegkundestudenten in de CBVLE. De ervaringen en evaluatie van de studenten over het instructieontwerp (als gecombineerde ontwerpcomponenten) van de CBVLE toonden een gemiddeld positief effect op de leerresultaten, en een positief effect op de self-efficacy en intrinsieke motivatie van studenten verpleegkunde.

Hoofdstuk 7 vat de verschillende deelstudies samen en spiegelt de resultaten aan de doelen van het proefschrift. Het onderzoek in dit proefschrift is uitgevoerd om aan te tonen dat rekenkundige handelingen verbonden aan de toekomstige medicatie leertaak van verpleegkundestudenten, onderwezen via digitaal leermateriaal met een holistisch benaderingsontwerp, positief bijdraagt aan leerresultaten, self-efficacy en intrinsieke motivatie van de verpleegkundestudenten in het beroepsonderwijs. In het huidige beroepsonderwijs is rekenen van groot belang voor het beheersen van de dagelijkse rekentaken in het beroep, met name voor de verpleegkundestudent. Het rekenonderwijs is in het huidige onderwijsprogramma opgesplitst in geïsoleerde delen en er wordt weinig aandacht besteed aan de structuur van het domein. Daarbij is het vermeldenswaard dat de kennis van het rekenen in het gehele onderwijsprogramma slechts éénmalig wordt beoordeeld. Dit, terwijl studenten verpleegkunde worden geacht door de gehele opleiding heen vertrouwd te blijven met de complexe rekenkundige handelingen, die verbonden zijn aan de medicatieopdrachten. Het is dus opvallend dat dit niet wordt geëvalueerd. Dit is opmerkelijk omdat de competenties van verpleegkundigen bij het berekenen van medicatiedoses van vitaal belang zijn. Hoewel fouten kunnen optreden in elk stadium van het medicatieproces van het voorschrijven, uitdelen en toedienen tot registratie en rapportage, is de verpleegkundige een belangrijke schakel in de medicatieverstrekking. Daarom is het leren en onderhouden van rekenkundige handelingen in het medicatieproces in het beroepsonderwijs van groot belang. Dit betekent dat een voortdurende aandacht voor rekenen gedurende het hele onderwijsprogramma van de verpleegkunde student noodzakelijk is. De studies in dit proefschrift tonen aan dat digitaal leermateriaal, specifiek de computergestuurde virtuele leeromgeving, het mogelijk maakt om het leren van de rekenhandelingen in het medicatieproces van verpleegkundestudenten in een zinvolle context te onderwijzen, te trainen en te oefenen. Bovendien tonen de resultaten aan dat niet alleen de leerresultaten van de verpleegkundestudenten verbeteren, maar ook dat de resultaten uit eerder empirisch onderzoek worden onderschreven: de self-efficacy en intrinsieke motivatie van de verpleegkundestudenten verbeteren.

Dit proefschrift demonstreert een digitale draad van digitaal leermateriaal met gestructureerde inhoud, doelen, opdrachten, clips en discussietools naar een computergestuurde virtuele leeromgeving met professionele leertaken en instructieactiviteiten die het leren van cognitieve schema's, procedures en transfer van kennis 
ondersteunt. Het rekenen en het onderhouden van rekenen ten bate van dagelijkse rekentaken in de toekomstige beroepscontext kan adequaat onderwezen en geoefend worden in een computergestuurde virtuele leeromgeving. 
o
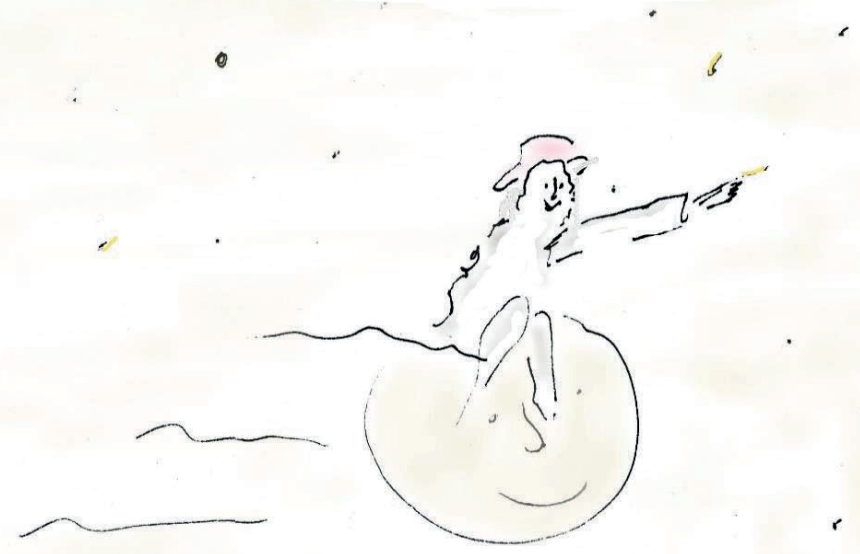

1 


\section{Dankwoord}

Het proefschrift is klaar. Ik ben een bevoorrecht mens dat ik dit pad heb mogen en kunnen bewandelen. De tocht als buitenpromovendus door het wetenschappelijke landschap was echter niet altijd zonder vallen en opstaan. Vijf jaar lang altijd nét te weinig tijd voor hoogtepunten, en altijd nét te weinig tijd voor dieptepunten. Het voltooien van dit proefschrift was dan ook alleen mogelijk dankzij de betrokkenheid van veel mensen om me heen. Soms waren ze dichtbij, soms waren ze ver weg, maar ze waren er altijd. Ik wil hier graag de ruimte en tijd nemen om hen te bedanken voor hun support, hulp, inspiratie en geduld.

Allereerst wil ik mijn promotor Hans van Luit en mijn copromotoren Sui Lin Goei en Omid Noroozi bedanken. Jullie hebben me aangemoedigd, geïnspireerd, onderwezen en gevormd. Bedankt voor het vertrouwen en de kansen die mij geboden zijn.

Hans ik ben je zeer dankbaar voor jouw geloof in mijn kunnen. Je was (zoals eerder geschreven) mijn benedictijns leider: je luisterde, je overzag het geheel en je stimuleerde me tot groei. Lekkere bakjes dubbelzwarte koffie, even een bezoekje in je kamer om me op te peppen wanneer ik weer met mijn ziel onder de arm door de bieb in de UU slenterde, me afvragende wat nou toch de bedoeling was. Je gaf geen antwoorden, maar je had wel altijd tijd om te luisteren. Het mogen zoeken naar antwoorden in de ruimte heb ik van jou geleerd. Ook de APA-regels zijn er dankzij jou ingestampt, al wist je altijd nog iets te vinden. Ik hoop je nog vaak te spreken, zodat we enthousiaste verhalen kunnen blijven delen over onze bezoeken aan de musea en filmtheaters. Je bent een oprecht en fijn mens.

Sui, ik ben je erg dankbaar voor de ruimte die gecreëerd is binnen jouw lectoraat op Windesheim. Je was een begeleider met veel expertise. Je feedback was scherp. Wat hebben we veel plezier en gezelligheid gekend tijdens onze tripjes richting conferenties, met als hoogtepunt de EARLI in Finland. Karaoke, dansen, en afsluitend een heerlijke borrel in de kroeg. Ik ging nu en dan veel te snel voor je, en stemde niet altijd goed af, maar ook daar gingen we als professionals over in gesprek. Je toonde je betrokken en ook buiten het promotietraject om konden we bij elkaar terecht. Ik vind het ongelooflijk knap hoeveel werk je verzet en hoe je de grote lijnen doorziet: niet alleen op het gebied van onderzoek, maar ook in je zorg om de collega's in je lectoraat. Je leerde me om af en toe een stapje terug te zetten om het grote geheel te overzien.

Dear Omid, thank you very much for being a teacher for me. I remember our moment in my car, driving from Amersfoort Central Station to Utrecht University. You were truly clear about this trajectory and your expectations towards me and my PhD. I also remember my trips to Wageningen University, sitting next to you while you taught me how to become a good writer. You have a very sharp analytical mind, and I will never forget your words 'be 
conscientious'. You taught me that a job done with conscientiousness is a job that endures. I wish you and your wife all the best, love, and health with your family expansion.

I am proud that you all were my guiding leaders, each with their own specialities, and I hope that Bart and I will be able to invite you all once again soon, for a dinner with Bart's delicious meatballs and a good glass of wine to say 'cheers'!

Mijn oprechte dank aan de leden van de leescommissie voor de tijd die jullie hebben besteed aan het lezen en beoordelen van mijn proefschrift en voor jullie bereidheid om te opponeren tijdens de verdediging: prof. dr. Jeroen van Merriënboer, prof. dr. Tamara van Gog, dr. Harm Biemans, prof. dr. Marieke van der Schaaf, en prof. dr. Evelyn Kroesbergen.

Verder wil ik een paar mensen bedanken die mij hebben begunstigd voorafgaand aan het promotietraject. Jo Hamers, bedankt dat je mij het zetje gaf richting een universitaire studie. Wat viel alles vanaf dat moment op z'n plek. Reinder Bos, jij bedankt voor het zetje richting deze onderwijskundige carrière. Hoewel ik de Dominicus Savio allang heb verlaten, kan ik zeggen dat daar mijn roots gelegd zijn voor onderzoek en onderwijs. Renate Wesselink, bedankt voor de ontmoeting op Wageningen, waar je me vervolgens aan Omid voorstelde. Reinder Blok, mijn eerste teamleider en reismaatje bij Windesheim. Een fantastische collega, en helaas ben je niet meer onder ons. Je relativeringsvermogen was enorm, en met een beetje humor viel alles weer op zijn plek. Wat hadden we mooie gesprekken tijdens de wandelingen met onze labradors Joris en Sam. Inmiddels heb je twee mooie kleinkinderen, om trots op te zijn. Zo jammer dat je er niet bij kunt zijn, maar zoals jij zou zeggen, 'it is as it is'.

Dan een grote dank aan mijn collega's bij Windesheim, in het bijzonder de collega's van de MEN en de MLI die hun betrokkenheid hebben getoond in mijn onderzoek. Ik wil enkele collega's bij naam noemen. Jan Doelman, Bert Meijer, en Harrie Frantzen, bedankt voor de facilitering. Harrie, bedankt voor de mooie gesprekken tijdens kleine lunchmomenten buiten Windesheim in de start van mijn PhD. Collega's van het kenniscentrum, en in het bijzonder mede-buitenpromovendi Jarise Kaskens, Monique Nelen, Tijmen Schipper en Jantien Gerdes. Jarise, wat ben je toch een geweldige professional en een mooi mens. Je werkt hard, maar gaat nooit voorbij aan de menselijke kant van het leven. Bedankt dat ik met jou kon sparren over de PhD struggles. Monique, dank voor de support in de laatste fase van mijn PhD. Wat fijn dat ik zo close met je heb mogen werken die laatste weken. Dank dat je zo eerlijk was en me mezelf liet afvragen wanneer ik weer eens aan mezelf ging denken. De humor overleeft Mo, altijd weer! Jantien, samen een cursus M-Plus met rollende ogen en zweet onder de oksels. Bedankt voor de toffe momenten met veel gelach. We zijn er! Wanneer kom je eens langs om je 
boek op te halen? Tijmen, fijne collega, bedankt voor de kleine sparringsmomenten over kennis en onze geweldige trip naar de EARLI in Finland. Wat hebben we ontzettend veel plezier gehad die week met Sui, Hans en Wouter van Joolingen. Wouter, jij ook veel dank voor de leermomenten tijdens onze kleine ontmoetingen. Zwanie, Greta, Bas, Ingrid, Frans, Erik, Edith, Diana en Catharina. Het is even geleden, maar wat hebben we een mooie MLI-tijd gehad. Inmiddels bijna allemaal uitgevlogen, maar jullie gaven me vleugels in de start van mijn PhD. Ik herinner me nog ons EAPRIL-moment, Zwanie en Greta. Na mijn presentatie over de VR omgeving zeiden jullie voor het eerst 'ah..nu begin ik het te begrijpen', terwijl ik er toch al ruim een jaar mee bezig was :-). Wanneer plannen we de port avond? Stefan Schraa ontzettend bedankt voor het intypen van een groot gedeelte van de data. Tecla Lampe van het Cito, bedankt voor je medewerking aan de verpleegkundig rekentoets voor het onderzoek. Wim Trooster en Arjen Breedveld, bedankt voor de samenwerking. Arjen, ik had de VR omgeving nooit zonder jou kunnen maken en testen. Dank voor je inzet, je kritische noten en je anders denken. Ik hoop dat Windesheim jouw expertise blijft inzetten en dat Rianne Hutten-Koggel de VR omgeving in de opleiding kan laten landen. Dank Rianne, je maakt het verschil! Ook dank aan Jasper Grimmius voor een klein beetje tijd, aandacht en ruimte in de opleiding. Marike Hettinga, bedankt dat je geloof had in mijn kunnen als onderzoeker, zodat ik naast mijn PhD aan de slag kon met mijn verdere ideeën over leren met VR. Je bood ruimte in je lectoraat en je koppelde me aan Hilco Prins. Hilco bedankt voor de gesprekken en leermomenten. Wat een toffe uitdaging was VR4MED naast mijn PhD. Ook wil ik alle studenten van de onderzoeksgroepen van de MEN \& MLI die ik de afgelopen jaren begeleid heb, bedanken voor hun support en interesse. Tijdens de begeleidingsbijeenkomsten toonden jullie je altijd nieuwsgierig naar mijn PhD. Ik heb ook veel van jullie geleerd, dank!

Verder wil ik de docenten en studenten van de opleidingen verpleegkunde van de hogescholen en mbo's bedanken. Zonder hen was dit onderzoek niet mogelijk geweest. Geen onderwijsontwikkeling zonder stem van studenten! Ondanks de volle onderwijsprogramma's werd er ruimte geboden om mijn onderzoek uit te kunnen zetten. In het bijzonder wil ik daarom de volgende mensen bedanken: Franco de Wolff en Evelien Warmelink (hogeschool VIAA), Hannie Coppoolse en Thóra Eymundsson (hogeschool Windesheim), Lieske de Wit (hogeschool Almere), Annemarie Borst (hogeschool Den Haag), Maartje van der Slikke (hogeschool Rotterdam), Annemiek Nijst (hogeschool Avans Den Bosch en Breda), Arjen Nieuwenhuis (Alfa-college Hoogeveen), Hiske Vaarwerk (ROC MN), Linda van Ballegooijen-Roland (Deltion Zwolle), en Marike Potgieter (Landstede Raalte). En dank aan eenieder die ik niet genoemd heb, maar met wie ik de afgelopen jaren wel leuke momenten heb beleefd. 
Ik wil mijn vriendinnen en tevens paranimfen Marjolein Schölvinck en Heidi de Vries bedanken voor hun motiverende woorden en relativeringsmomenten. Lieve Marjolein en Heidi, bedankt voor het stillen van de tijd, en voor het geduld en begrip op momenten dat ik het af liet weten omdat ik té weinig tijd had vanwege de zoveelste versie $x$. Wat fijn om met jullie te kunnen afschakelen, lachen en opladen. Bewonderenswaardig kijk ik naar jullie activiteiten in en buiten de school. Niet alleen vriendinnen, maar ook leerkrachten die ertoe doen. Lieve Marjolein, ga vooral door met kunst en cultuur op de school. Maak het verschil! Lieve Heidi, ik bewonder de wijze waarop je samen met Ron, Tom en Eva het leven oppakt na het overlijden van jullie mooie Daan. En Eva, dank voor de mooie boekomslag!

Het een-na-laatste dankwoord is voor mijn familie en schoonfamilie. Natuurlijk mijn broer en zus, Berry en Helma, ouders Wim en Fennie en schoonouders Truus en Pieter. Dank voor jullie betrokkenheid al die jaren. Lieve paps en mams, bedankt voor de ruimte die ik altijd gekregen heb om me te mogen ontwikkelen. Dank voor de bootmomentjes in de grote vakanties op de Friese meren, waarin ik me weer kon opladen. Wat een lol hebben we gehad. Dit jaar eindelijk een tochtje zonder computer! Bedankt dat jullie er altijd voor me zijn! Lieve Helma, grote zus, dank voor de relativerende gesprekken tijdens een bakje thee of een glas rosé.

Mijn laatste dankwoorden zijn voor mijn lieve man, mijn soulmate Bart en mijn lieve kinderen Daan en Lotte. Ik had dit traject nooit kunnen bewandelen zonder jullie onvoorwaardelijke steun, geduld en liefde. Lieve Bart, de combinatie van werk, studies, een verhuizing, verhuizingen van de kinderen, het was allemaal onmogelijk geweest zonder jou. Je was er altijd. Een PhD doe je niet alleen, die doe je samen. Vele weekenden zat ik achter mijn computer te werken aan mijn PhD. En nu en dan trok je me eruit: op naar musea, concerten, voorstellingen, filmtheater... op naar het leven. Leven in de tuin, leven in de natuur, leven voor elkaar, leven voor de liefde! Lieve Daan, kijk niet om, kijk vooruit. Ga voor je passie en maak de mensen blij in het leven. Muziek, meer is niet nodig! Lieve Lotte, omarm je bevlogenheid om verschil te durven maken. Duurzaam in de mode, psychologie in de mode, geen mode. Het geeft niet, je hebt geen haast. Ik wens jullie beiden veel tijd voor hoop. Tijd als hoop, voor het scheppen van ruimte voor nieuwe mogelijkheden. Ruimte om tot verandering, verbetering en vooral herinterpretatie van het reeds bestaande te kunnen komen (Joke Hermsen). Dat is noodzakelijk om de mensen in de wereld de liefde voor je vak te kunnen verklaren. Die ruimte en tijd kreeg ik van hogeschool Windesheim en de Nederlandse Organisatie voor Wetenschappelijk Onderzoek (NWO) door het toekennen van de Promotiebeurs voor Leraren. En daar ben ik zeer dankbaar voor. 


\section{About the author}

Diana Petra Zwart was born on April 15, 1970 in Harderwijk, the Netherlands. From primary to higher education, Diana always combined her education by spending many hours in the gym. Gymnastics was her passion in life up to the Dutch championships. After finishing her $\mathrm{P}$ at Windesheim, she started working at the Rabobank. She professionalized in mortgage, assurance, and investment advice. After ten years she decided to follow her heart; she quitted her job and started a teacher training program at KPZ in Zwolle. In 2006 she graduated from her bachelor and started working at the Dominicus Savio the Harderwijk as a teacher, internal coach, and deputy-director. In 2006 Diana started a teacher specialization for behavior and learning where she met Dr. Jo Hamers. He gave her the advice to start a Master program at the University for Educational Sciences. While still working in Harderwijk Diana started with a two-year pre-master program in Educational Sciences at Utrecht University in 2007, followed by a two-year master program. During the final year, in 2011, Diana was appointed as a teacher educator at the Master Educational Needs programs for mathematics of Windesheim University of Applied Sciences. In 2012 Diana obtained her Master of Science degree at Utrecht University. Next to the Master of Educational Needs, Diana also started as a teacher educator at the Master of Learning and Innovation. From that time on Diana has worked in a variety of roles. She has been involved in the research group of 'Teachers and Teacher Educators in Inclusive Learning Environments', led by Dr. Sui Lin Goei, who supported Diana to gain a doctoral grant for the idea to teach mathematics in vocational education with digital learning material. Diana discussed her ideas with Professor Dr. Hans van Luit from Utrecht University, who is an expert at mathematics and dyscalculia. And via Dr. Renate Wesselink from Wageningen University, Diana met Dr. Omid Noroozi, who has a lot of expertise in research into technology enhanced learning environments. In 2015 Diana received a doctoral grant from the Dutch Research Council NWO for her PhD proposal. Diana started her adventure at Utrecht University under the supervision of Professor Dr. Van Luit, Dr. Goei and Dr. Noroozi. In 2018 and 2019 Diana also gained two grants for her idea of training nursing professionals' mathematics with virtual reality in hospitals. From of the $1^{\text {st }}$ of July 2021, Diana will start with her new job at the University Medical Center Utrecht (UMCU) as assistant professor $(A)$ and senior advisor quality policies at the Center of Expertise. 


\section{Publications}

Zwart, D. P. (2013). Verborgen rekendocenten in het MBO. Nieuw Meesterschap, 3(1), 2126.

Zwart, D. P., Van Luit, J. E. H., \& Goei, S. L. (2016). Empowering vocational math teachers by using Digital Learning Material (DLM) with workplace assignments (pp. 81-97). In Y. Cai, S. L. Goei, \& W. Trooster (Eds.), Simulations and serious games for education. Singapore: Springer.

Zwart, D. P., Van Luit, J. E. H., Noroozi, O., \& Goei, S. L. (2017). The effects of digital learning material on students' mathematics learning in vocational education. Cogent Education, 4: 1313581. doi:10.1080/2331186X.2017.1313581

Zwart, D. P., Noroozi, O., Van Luit, J. E. H., \& Goei, S. L. (2020). Effects of digital learning materials on nursing students' mathematics learning, self-efficacy, and task-value in vocational education. Nursing In Practice, 44: 102755. doi:10.1016/j.nepr.2020.102755

Zwart, D. P., Goei, S. L., Noroozi, O., \& Van Luit, J. E. H. (2021). The effects of ComputerBased Virtual Learning Environments on nursing students' mathematical learning in medication processes. Research and Practice for Technology Enhanced Learning, 16: 4. doi: 10.1186/s41039-021-00147-x

\section{Publications under review}

Zwart, D. P., Noroozi, O., Van Luit, J. E. H., \& Goei, S. L. (2021). The effects of instructional support in a Computer-Based Virtual Learning Environment (CBVLE) on nursing students' mathematical medication learning, self-efficacy, and intrinsic motivation.

Zwart, D. P., Noroozi, O., Van Luit, J. E. H., \& Goei., S. L. (2021). Nursing Students' Satisfaction with the Instructional Design of a Computer-Based Virtual Learning Environment for Mathematical Medication Learning.

\section{Dutch publications}

De Munnik, H., \& Zwart, D. P. (2017). Interactief rekenen voor nieuwkomers [Interactive mathematics for new entrants]. Retrieved from https://plpo.nl/2017/03/27/interactief-rekenonderwijs-op-een-school-voornieuwkomers/

Zwart, D. P., \& Bosman, M. (2018). Makersonderwijs in het MBO: Dieper leren door zelf dingen te bedenken en te maken. [Maker education in vocational education: Deep learning by thinking and making]. Retrieved from https://www.canonberoepsonderwijs.nl/pedagogische-didactischeleerweg/makersonderwijs-in-het-MBO 
Van Dantzig, M. \& Zwart, D. P. (2018). Problem-based rekenen: Motivatie in de rekenlessen [Problem-based mathematics: Motivation in mathematics lessons in primary education].

https://plpo.nl/2018/10/23/problem-based-rekenen-motivatie-in-de-rekenlessen/

Zwart, D. P., \& Rouvoet, L. (2020). Er is kennis nodig om studenten de regie te laten nemen [We need knowledge to stimulate students' self-supported learning]. Vaktijdschrift Profiel, 1, 14-17.

\section{Award of grants}

This research was supported by the Netherlands Organization for Scientific Research (NWO) under grant number: 023.006.049. (2015)

Taskforce for Applied Research, SIA. (2018). Virtual Reality for Medication Safety. Collaboration between Windesheim University of Applied Sciences, Amphia Hospital, Medical Centre Leiden (LUMC) and CMG. Retrieved from file://C:/Users/Diana\%20Zwart/AppData/Local/Packages/Microsoft.MicrosoftEdge _8wekyb3d8bbwe/TempState/Downloads/Eindrapportage\%20KIEMLSH03016\%20 (1).pdf

Taskforce for Applied Research, SIA. (2020). Virtual Reality for Medication (VR4MED). Collaboration between Windesheim University of Applied Sciences, Amphia Hospital, Medical Centre Leiden (LUMC) and CMG.

\section{Conference Contributions}

Zwart, D. P., Van Luit, J. E. H., Noroozi, O., \& Goei, S. L. (2016). Het effect van digitale leermiddelen op rekenresultaten van studenten in het middelbaar beroepsonderwijs. [The effect of digital learning material on vocational education students' mathematical learning]. Conference, Rotterdam, The Netherlands.

Zwart, D. P., Van Luit, J. E. H., Goei, S. L., \& Noroozi, O. (2016). The effect of worked examples in a virtual learning environment on nurses' mathematics learning. Paper presented at the European Association for Practitioner Research on Improving Learning (EAPRIL). 2016. Conference, Porto, Portugal.

Zwart, D. P. Goei, S.L., Van Luit, J. E. H., \& Noroozi, O. (2017). A virtual learning environment to train mathematical learning in the context of nursing. Paper presented at the European Association for Research on Learning and Instruction (EARLI). Conference, Tampere, Finland.

Zwart, D. P. (2018). Trainen van rekenkennis en - vaardigheden in een virtuele leeromgeving. [Training mathematical medication learning in a virtual learning environment]. Paper presented at the HGZO Conference, Lunteren, The Netherlands. 
Zwart, D. P. (2018). A virtual learning environment for nursing students' mathematics. Paper presented at the Game Conference, Utrecht University, The Netherlands.

Zwart, D. P. (2018). Rekenen in het beroep. Een virtuele leeromgeving voor rekenkennis en - vaardigheden voor studenten verpleegkunde. [Mathematics in profession. A virtual learning environment for nursing students' mathematics]. Paper presented at the Vocational Education for Mathematics Conference, The Netherlands.

Zwart, D. P. (2018). Computergestuurde virtuele leeromgeving om rekenen in het beroepsonderwijs verpleegkunde te trainen. [Computer-Based Virtual Learning Environment to train nursing students' mathematics]. Paper presented at the Symposium Onderzoek naar rekenen/rekenproblemen en het belang voor de praktijk. Universiteit Utrecht, The Netherlands.

Zwart, D. P. Noroozi, O., Goei, S. L., \& Van Luit, J. E. H. (2018). Effects of virtual learning on nursing students' mathematics. Paper presented at the Special Interest Group (SIG 67), Instructional Design and Technology for 21st Century Learning, of the European Association for Research on Learning and Instruction (EARLI). Conference, Bonn, Germany. 



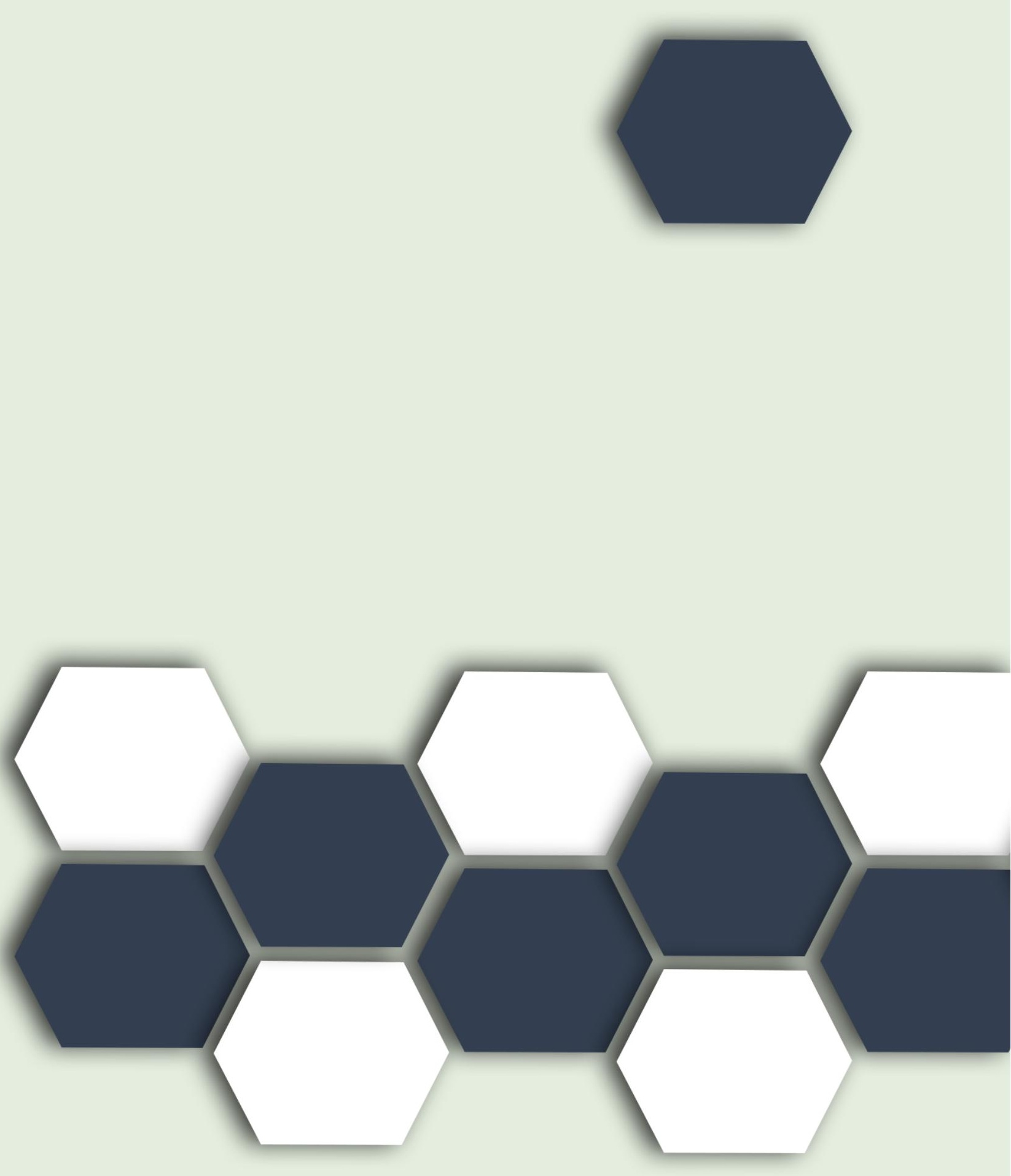